\title{
Hydrogeologic Data for the Big River-Mishnock River Stream-Aquifer System, Central Rhode Island
}

\author{
By Patrick A. Craft
}

\section{Abstract}

Hydrogeology, ground-water development alternatives, and water quality in the Big-Mishnock stream-aquifer system in central Rhode Island are being investigated as part of a long-term cooperative program between the Rhode Island Water Resources Board and the U.S. Geological Survey to evaluate the ground-water resources throughout Rhode Island. The study area includes the Big River drainage basin and that portion of the Mishnock River drainage basin upstream from the Mishnock River at State Route 3. This report presents geologic data and hydrologic and waterquality data for ground and surface water.

Ground-water data were collected from July 1996 through September 1998 from a network of observation wells consisting of existing wells and wells installed for this study, which provided a broad distribution of data-collection sites throughout the study area. Streambed piezometers were used to obtain differences in head data between surface-water levels and ground-water levels to help evaluate stream-aquifer interactions throughout the study area. The types of data presented include monthly ground-water levels, average daily ground-water withdrawals, drawdown data from aquifer tests, and water-quality data. Historical water-level data from other wells within the study area also are presented in this report.

Surface-water data were obtained from a network consisting of surface-water impoundments, such as ponds and reservoirs, existing and newly established partial-record stream-discharge sites, and synoptic surface-water-quality sites. Water levels were collected monthly from the surface-water impoundments. Stream-discharge measurements were made at partial-record sites to provide measurements of inflow, outflow, and internal flow throughout the study area. Specific conductance was measured monthly at partialrecord sites during the study, and also during the fall and spring of 1997 and 1998 at 41 synoptic sites throughout the study area.

General geologic data, such as estimates of depth to bedrock and depth to water table, as well as indications of underlying geologic structure, were obtained from geophysical surveys. Sitespecific geologic data were collected during the drilling of observation wells and test holes. These data include depth to bedrock or refusal, depth to water table, and lithologic information. 


\section{INTRODUCTION}

In 1995, the U.S. Geological Survey (USGS) in cooperation with the Rhode Island Water Resources Board (RIWRB) initiated a hydrogeologic investigation in the Big-Mishnock stream-aquifer system (fig. 1). This investigation was designed to assess the hydrogeologic setting and water resources within the study area. This report contains data collected as part of this study.

This report provides regulators, scientists, and managers with the data needed to understand and evaluate the hydrogeologic factors that affect ground-water development in the Big-Mishnock stream-aquifer system. This report presents data on ground-water and surface-water levels within the study area from July 1996 through September 1998. Descriptions of subsurface conditions, aquifer lithology from samples collected during drilling, stream-discharge measurements, and ground-water-quality data are also included.

The $32-\mathrm{mi}^{2}$ study area includes the Big River drainage basin and that portion of the Mishnock River drainage basin upstream from the Mishnock River at State Route 3. The Big River portion is about $29 \mathrm{mi}^{2}$, and the Mishnock River portion is about $3 \mathrm{mi}^{2}$. Both basins contain stratified-deposit aquifers overlying granite of the Scituate Igneous Suite (Hermes and others, 1994). The study area overlaps Coventry Center, Crompton, Hope Valley, and Slocum topographic quadrangles. The Big River portion is sparsely populated, with most of the population living along the upper reaches of the tributaries to the Big River. Most of the Big River area is woodlands and meadows. The Mishnock River portion is moderately to heavily populated and the predominant features are Mishnock Lake and Mishnock Swamp.

Both areas are sub-basins to the South Branch of the Pawtuxet River Basin. Additional data are in a hydrologic data report for the South Branch of the Pawtuxet River Basin (Gonthier, 1966).
Since the mid-1950s, the USGS has investigated the ground-water conditions and examined the bedrock and surficial geology of the study area shown on the four topographic quadrangles (Coventry Center, Crompton, Hope Valley, and Slocum topographic quadrangles). These studies were published as a series of ground-water maps, bedrock-geology maps, and surficial-geology maps. Ground-water maps have been published for all four quadrangles, bedrock-geology maps have been published for three quadrangles, and three quadrangles have surficial-geology maps (Allen and Johnson, 1959; Bierschenk and Hahn, 1959; Feininger, 1962; Hahn, 1959; Mason and Hahn, 1960; Moore, 1963; Power, 1959; Power, 1957; Quinn, 1963; and Smith, 1956).

In the 1960s, the State proposed to construct a reservoir in the study area to meet growing water needs. This proposal initiated a number of studies in the study area, including a preliminary geotechnical investigation and a feasibility study (Keyes and Associates and Metcalf and Eddy Inc., 1977; United States Army Corps of Engineers, 1979a, 1979b, 1979c, 1980a, 1980b, 1980c; Maguire and Goldberg, Zoino, and Associates, Inc., 1984; A.D. Little, Inc., 1989). The 1989 report by A.D. Little, Inc., states that "the central region is the area of the State with the most critical current water-supply deficit," which led to further studies of the Big-Mishnock stream-aquifer system.

On behalf of the Rhode Island Water Resources Board and the USGS, the author wishes to thank Scott Michaud, Jennifer Sandorf, Bill AbrahamsDematte, Dennis Orlowski, and Dr. Anne Veeger from the Department of Geosciences at the University of Rhode Island (URI), who volunteered many hours during the geophysical and water-quality-data collection efforts. Additionally, the author wishes to thank Mr. Timothy Brown, General Manager, Kent County Water Authority, for providing public-watersupply-well withdrawal and aquifer-test data associated with the Mishnock River portion of the study area. 


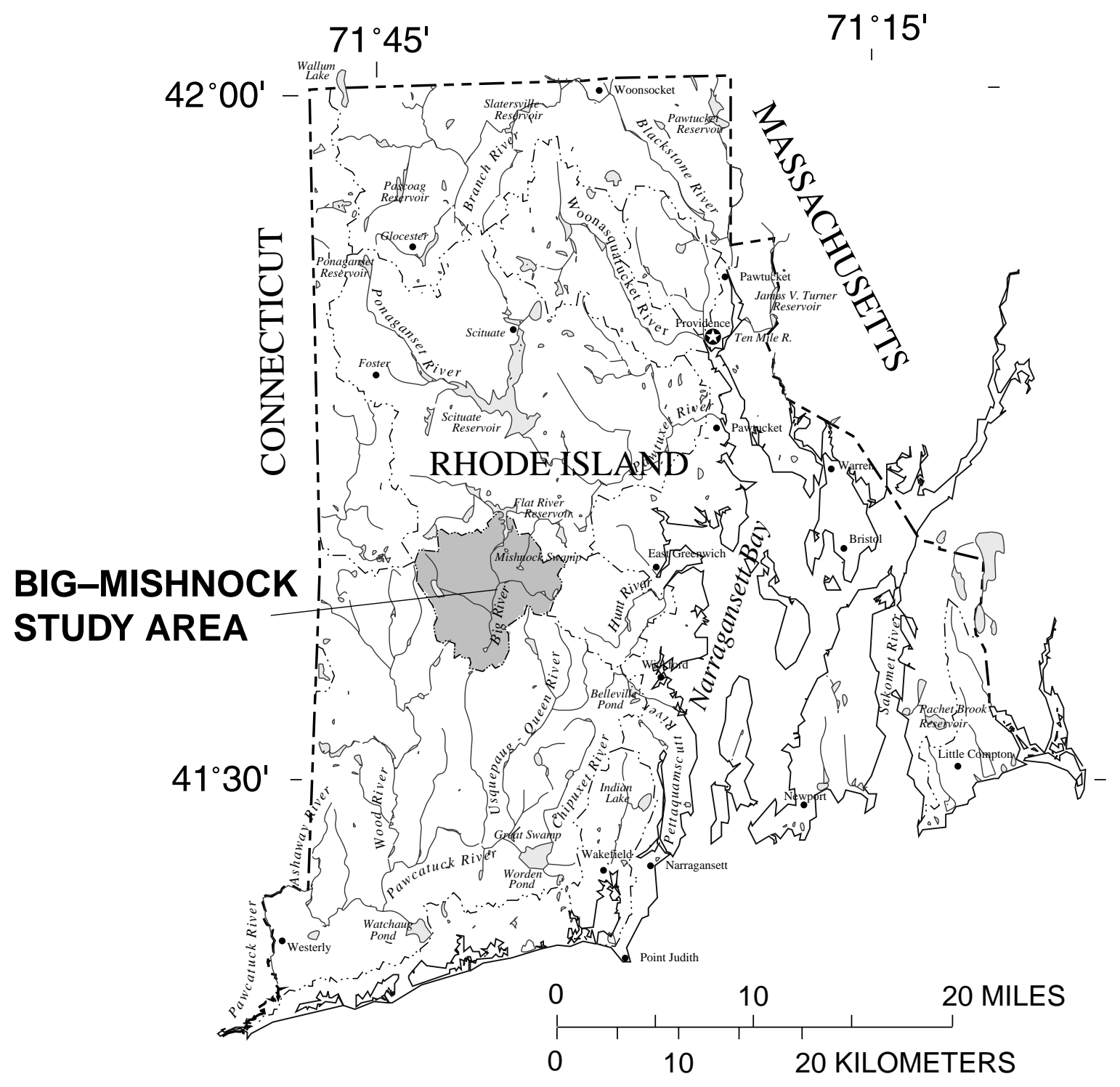

Figure 1. Location of the Big-Mishnock stream-aquifer system, central Rhode Island. 


\section{SITE-IDENTIFICATION NUMBERS}

All data-collection sites associated with this study, including wells, piezometers, ponds, reservoirs, and streams were assigned identification numbers (pl. 1). The USGS uses two methods to assign identification numbers to ground-water sites and surfacewater sites; both are based on location. The "latitudelongitude" system is used for ground-water sites, such as wells, springs, piezometers, and for pond and reservoir sites. In addition, each ground-water site is assigned a local well number from the "wellnumbering" system. Surface-water sites are assigned a number based on the "downstream-order" system.

The 15-digit identification numbers for groundwater, pond, or reservoir sites are assigned according to the latitude and longitude at the site. The first six digits denote the degrees, minutes, and seconds of latitude; the next seven digits denote degrees, minutes, and seconds of longitude; and the last two digits (assigned sequentially) distinguish between data-collection sites within a 1-second grid. Once assigned, this siteidentification number no longer has locational significance. If an error was made in the initial determination of latitude or longitude, the station will retain its original identification number, and the corrected site latitude and longitude will be listed within the tables in the report.

The USGS in Rhode Island assigns a local well number and a two-letter code that is based on the city or town in which the site is located to each groundwater site. The two-letter codes used in this investigation, CO (Coventry), EX (Exeter), and WG (West Greenwich), are followed by W, for well, and a sequential number.

Since October 1, 1950, USGS publications have listed surface-water sites in a downstream direction along the main stream. A site on a tributary entering upstream from a main stream site is listed before that site. A site on a tributary that enters between two main stream locations is listed between them. A similar order is followed in listing sites on first rank, second rank, and other ranks of tributaries. This downstream-order system of identification shows which sites are on tributaries between any two sites and the rank of the tributary on which each site is situated.
In assigning site-identification numbers to surface-water sites, no distinction is made between continuous-record sites and other types of sites such as partial-record sites; therefore, the site number for a continuous-record site indicates downstream-order position in a list made up of all types of sites. Gaps are left in the series of numbers to allow for new sites that may be established; hence, the numbers are not always consecutive. The first two digits indicate the Part number (formerly used in USGS Water-Supply Papers to designate major river systems) and the last six or more digits indicate the downstream order within the Part. For example, in the site number 01115630, "01" is the Part number for the "North Atlantic Slope Basins" and the "115630" is the downstream order number.

\section{HYDROLOGIC DATA}

The hydrologic data are divided into groundwater data and surface-water data. Within the streamaquifer system there is usually continual interaction between ground water and surface water, as in the relation between decreased streamflow and increased withdrawals of ground water from wells. USGS data networks were established for the collection of groundwater and surface-water data, including water-quality data. Sites where data had been collected prior to this investigation were evaluated when developing the study-area network. New sites were added to improve areal coverage and provide information in areas where there were little or no existing data.

\section{Ground Water}

Ground-water levels, ground-water withdrawals, and aquifer-test data were monitored, along with waterquality data, such as chemical analyses and physical properties of ground-water analyzed in the field and in the laboratory. Ground-water quality data were collected from 10 sites by the URI Department of Geosciences in 1997, from six aquifer-test sites by the USGS in 1998 and 1999, from eight exploratory test wells by the USGS between 1996 and 1998, and from 12 seasonal sampling sites by the USGS in May and November 1999. 


\section{Ground-Water Levels}

Ground-water level data were collected during the course of this study, and historic water-level data were compiled from over 375 ground-water sites throughout the study area (table 1 , at back of report). The initial data network established for this study in July 1996 consisted of 21 ground-water sites measured monthly from 2 existing wells and 19 wells installed for this study. The existing wells included one dug well (WGW 211) that was originally measured for the South Branch of the Pawtuxet River study (Gonthier, 1966) and one well (WGW 305) installed by the Rhode Island Department of Environmental Management as part of their Individual Sewage Disposal System well network. Between the summer of 1996 and summer of 1997, the data-collection network was expanded to a total of 62 sites with the addition of 3 more observation wells, 5 exploratory test wells drilled in remote areas, 18 aquifer-test observation wells, and 15 streambed piezometers. Six of the 60 wells installed for the BigMishnock study were 3 pairs of nested observation wells that included one shallow well screened just below the water table and a deep well screened near the bottom of the aquifer to check for possible vertical gradients.

Additional test holes were drilled and wells were installed between fall 1997 and spring 2000. These sites consisted of three 8-inch aquifer-test wells, three 10-inch aquifer-test wells, nine exploratory wells, and thirteen 2-inch polyvinyl chloride (PVC) aquifer-test observation wells. During the course of this study, 88 wells were installed from the 105 borings. All wells were pumped to develop the aquifer surrounding the well screens to assure a good hydrologic connection with the aquifer. Short duration withdrawal and recovery tests were made to insure that each well was responding to aquifer stresses.

Observation-well water-level measurements were made by USGS personnel with an electric tape or a chalked steel tape. The electric and steel tapes are marked with gradations in hundredths of a foot and are generally considered accurate to $0.01 \mathrm{ft}$. Water-level data were collected between October 1996 and October 1998 (table 2, at back of report).

To provide more data about the interaction between ground water and surface water, piezometers were installed at 15 stream and pond sites across the study area. The 15 piezometers consist of a screened drive point threaded to 1 -inch diameter steel pipe that was driven into the stream or pond bed with a slide hammer. Each piezometer was developed with a diaphragm pump and polyethylene tubing. Water-level measurements were taken inside of each of the piezometers and in the stream or pond immediately adjacent to the piezometer. The difference between these two water levels indicates the direction of water flow in the aquifer at the time of the measurement. If the water level inside the piezometer is above the water level outside the piezometer, then that area of the stream is receiving ground-water discharge, referred to as a gaining section of stream. If the water level inside the piezometer is lower than the outside water level, then water is moving into the aquifer from the stream channel, referred to as a losing section of stream. Water-level data were collected between May 1997 and August 1998 at these piezometers (table 3, at back of report).

Historical water-level data from wells inventoried between 1938 and 1996 (table 4, at back of report) include a long-term monitoring well, WGW 211, that was measured monthly from September 1954 until December 1963. Data collection was reestablished at well WGW 211 during this study.

\section{Ground-Water Withdrawals}

Data associated with withdrawal of ground water from wells in the stratified sand and gravel aquifer in the Mishnock portion of the study area were obtained from Kent County Water Authority (KCWA) for the period January 1995 through December 1999. Groundwater withdrawals were from two KCWA wells designated as Mishnock wells 1 and 2. Withdrawal data from these public-supply wells (table 5, at back of report) indicate the only known large hydraulic stresses to the ground-water-flow system in the study area.

\section{Aquifer Tests}

Aquifer tests were performed at six sites (pl. 1) to determine the hydraulic properties of the aquifer, such as vertical and horizontal hydraulic conductivity and transmissivity in the vicinity of each test well. All aquifer tests were performed on eight- or ten-inch test wells that were pumped continually for 48 hours at rates ranging from 325 to $900 \mathrm{gal} / \mathrm{min}$. Several 
observation wells were installed at different radial distances and developed at the six aquifer test sites to monitor ground-water responses to pumping. Drawdown data from these aquifer tests are given in tables 6-11 (at back of report).

\section{Water Quality}

Forty-eight ground-water-quality samples were collected from 31 wells during 3 sampling periods; 10 wells were sampled by the URI Department of Geosciences and the USGS in February and March 1997; 14 wells were sampled by the USGS and analyzed by the Rhode Island Department of Health (RIDOH) laboratory; and 12 wells were sampled by the USGS in May and November 1999, and analyzed at the USGS National Water Quality Laboratory. In all of the samplings, at least three well volumes were purged from each well. Standard field parameters, such as specific conductance, temperature, $\mathrm{pH}$, and dissolved oxygen, were measured and checked for stability prior to the collection of the samples (table 12, at back of report).

USGS protocols for ground-water sampling (Wood, 1976) were used when the ground-water samples were collected from the 12 network-observation wells during May and November of 1999 (table 12). Samples were filtered, treated, and packaged for shipment to the USGS National Water-Quality Laboratory (NWQL) per analysis requirements, where they were analyzed for major dissolved constituents. Duplicate samples were taken during each sample period and submitted for analysis to assure quality control.

A total of eight exploratory wells and six aquifer test wells were sampled by the USGS and analyzed by the RIDOH Laboratory, an EPA approved lab (table 12). Aquifer-test samples were collected after 48 hours of continuous pumping and were analyzed by the RIDOH for nitrate, nitrite, chloride, iron, and manganese, as well as coliform bacteria and radiological occurrences (gross alpha and beta).

In February and March 1997, personnel from the URI Department of Geosciences, in cooperation with the USGS and the RIWRB, sampled and analyzed water from 10 wells in the study area. The samples were extracted by using a submersible pump after three well volumes had been purged from the well. If specific conductance, $\mathrm{pH}$, and temperature, which were monitored during the purging process, were stable at the conclusion of three well volumes, then a sample was collected. Otherwise, pumping continued until the parameters stabilized. Duplicate and split samples also were taken for analysis. The samples were analyzed for major dissolved constituents (table 12).

\section{Surface Water}

Changes in water levels in lakes, ponds, or reservoirs, and changes in stream discharge in a river or brook were monitored. Water-quantity data were collected at 8 surface-water impoundment sites and 10 partial-record stream-discharge sites. Surface-waterquality data were collected at 51 river and brook sites.

Water levels were measured in eight ponds and reservoirs (table 13, at back of report). Staff gages were installed in six ponds. A wire-weight gage was installed on a bridge over the Flat River Reservoir and a slope gage was installed in one pond in an abandoned gravel pit. Measuring points at these gages were surveyed to mean sea level.

Stream-discharge measurements were made at 10 partial-record sites in the study area from July 1996 through October 1998 (table 14, at back of report). All measurements were made by USGS personnel who used standard procedures described in Rantz and others (1982). Additional surface-water data for the study area can be found in Gonthier (1966).

Specific-conductance data were collected monthly at each of the 10 partial-record sites during the stream-discharge measurement (table 14). Additionally, during April and October of 1997 and 1998, 4 synoptic studies were made to measure temperature and specific conductance at 41 miscellaneous sites across the study area (pl. 1). These synoptic runs were made during periods of expected base flow, when there was no precipitation for at least 5 consecutive days prior to the measurement (table 15, at back of report).

\section{GEOLOGIC DATA}

The geologic data acquired during this study are primarily the physical test-hole samples that were collected during drilling operations. These samples were examined, described, and logged to provide a better understanding of the subsurface geologic framework that can affect the flow of ground water. 
Geophysical methods were used to investigate aquifer geometries and structure. Seismic refraction, ground-penetrating radar (pl. 1), and borehole geophysical techniques were used to estimate depth to bedrock, depth to water table, and structure of the unconsolidated materials. The geophysical data were used to locate exploratory and aquifer-test wells.

Lithologic logs were compiled from information on cuttings gathered during the drilling (table 16, at back of report). Four well-drilling methods were used during the study: hollow-stem auger, drive and wash, cable tool, and air rotary. A total of 41 test holes were drilled with the hollow-stem auger method which resulted in the installation of forty 2 -inch diameter, PVC-cased and -screened observation wells. The drilling of one test hole reached refusal before reaching the water table and, therefore, could not be used as an observation well.

Of 30 test holes that were drilled with the driveand-wash method, 14 observation wells were installed. In the drive-and-wash method, steel casing is driven into the formation a given distance (usually 5-7 ft) and the material in the casing is washed out from the top of the casing. As the material flows from the casing top, it is caught, examined, bagged, and logged. These holes were drilled to locate possible aquifer-test well sites, to explore an area with limited information available, or to determine depth to bedrock in areas where the use of geophysical methods was limited.

Three 8-inch aquifer-test wells were installed by the use of the cable-tool drilling method. These wells were finished with an 8-inch-diameter steel casing and $20 \mathrm{ft}$ of stainless-steel screen. In cable-tool drilling, the casing is driven into the ground and the material is removed from inside the casing by a bailer or sand pump and is then logged. If the material is too compact or too large to fit inside the bailer, a large chisel bit is lowered into the casing at the end of the cable and the material is pulverized by drilling before removal with the bailer. Occasionally material in front of the casing must be drilled in order to advance the casing.

The air-rotary method was used to install three 10-inch aquifer-test wells and thirteen 2-inch PVC aquifer-test-observation wells. Each aquifer-test well was finished with a 10-inch-diameter steel-casing and $20 \mathrm{ft}$ of stainless-steel screen. In air-rotary drilling, the casing is advanced and the material is removed from inside the casing with high-pressure compressed air that is expelled from the bottom of the drill stem. The material is collected through a cyclonic decelerator, after which it is examined and logged. When the casing encounters compact material or rocks, an air hammer at the end of the drill stem is used to break up the formation.

\section{SELECTED REFERENCES}

A.D. Little, Inc., 1989, Water supply analysis for the State of Rhode Island, Task Series 400 supply and supply management-Report to the Rhode Island Water Resources Coordinating Council: Cambridge, Mass., $149 \mathrm{p}$.

Allen, W.B., and Johnson, K.E., 1959, Ground-water map of the Crompton quadrangle, Rhode Island: Rhode Island Water Resources Coordination Board Ground-Water Map 3, 1 sheet, scale 1:24,000.

Bierschenk, W.H., and Hahn, G.W., 1959, Ground-water map of the Hope Valley quadrangle, Rhode Island: Rhode Island Water Resources Coordination Board Ground-Water Map 6, 1 sheet, scale 1:24,000.

Feininger, T.G., 1962, Surficial geology of the Hope Valley quadrangle, Rhode Island: U.S. Geological Survey Quadrangle Map GQ-166, 1 sheet, scale 1:24,000.

Gonthier, J.B., 1966, Hydrologic data for the South Branch of the Pawtuxet River Basin, Rhode Island: Rhode Island Hydrologic Bulletin 6, 35 p.

Hahn, G.W., 1959, Ground-water map of the Slocum quadrangle, Rhode Island: Rhode Island Water Resources Coordination Board Ground-Water Map 2, 1 sheet, scale 1:24,000.

Hermes, O.D., Gromet, L.P., and Murray, D.P., 1994, Bedrock geologic map of Rhode Island: Rhode Island Map Series No. 1, 1 sheet, scale 1:100,000.

Keyes Associates and Metcalf and Eddy, Inc., 1977, Phase I report, Rhode Island Water Resources Board, Big River water supply project, preliminary geotechnical investigation, vol. 1 and 2: Providence, R.I., variously paged.

Maguire, C.E., and Goldberg, Zoino, and Associates, Inc., 1984, Phase II Geotechnical report, Rhode Island Water Resources Board, Big River water supply project, vol. 1 through 4: Providence, R.I., variously paged.

Mason, R.A., and Hahn, G.W., 1960, Ground-water map of the Coventry Center quadrangle, Rhode Island: Rhode Island Water Resources Coordination Board GroundWater Map 8, 1 sheet, scale 1:24,000.

Moore, G.E., Jr., 1963, Bedrock geology of the Coventry Center quadrangle, Rhode Island: U.S. Geological Survey Bulletin, 1158-A, 24 p. 
Power, W.R., 1957, Surficial geology of the Slocum quadrangle, Rhode Island: U.S. Geological Survey Quadrangle Map GQ-106, 1 sheet, scale 1:24,000.

Power, W.R., 1959, Bedrock geology of the Slocum quadrangle, Rhode Island: U.S. Geological Survey Quadrangle Map GQ-114, 1 sheet, scale 1:24,000.

Quinn, A.W., 1963, Bedrock geology of the Crompton quadrangle, Rhode Island: U.S. Geological Survey Bulletin, 1158-B, 17 p.

Rantz, S.E., and others, 1982, Measurement and computation of streamflow: U.S. Geological Survey Water-Supply Paper 2175, 631 p.

Smith, J.H., 1956, Surficial geology of the Crompton quadrangle, Rhode Island: U.S. Geological Survey Quadrangle Map GQ-94, 1 sheet, scale 1:24,000.

U.S. Army Corps of Engineers, 1979a, Pawcatuck River and Narragansett Bay drainage basins water related land resources study, Big River Reservoir project, Main Report, Preliminary Draft: Waltham, Mass., 94 p.

1979b, Pawcatuck River and Narragansett Bay drainage basins water related land resources study, Big River Reservoir project, Summary of Environmental Considerations, Preliminary Draft: Waltham, Mass., $22 \mathrm{p}$.

1979c, Pawcatuck River and Narragansett Bay drainage basins water related land resources study, Big River Reservoir project, Appendixes A,B,E,F,G,H (vol. I, II, III) and I, Preliminary Draft: Waltham, Mass., variously paged.

1980a, Pawcatuck River and Narragansett Bay drainage basins water related land resources study, Big River Reservoir project, Interim Report Big River Reservoir Project, Main Report, vol. I, Draft: Waltham, Mass., 71 p.

1980b, Pawcatuck River and Narragansett Bay drainage basins water related land resources study, Big River Reservoir project, Interim Report Big River Reservoir Project, Environmental Impact Statement, Draft: Waltham, Mass., 40 p.

1980c, Pawcatuck River and Narragansett Bay drainage basins water related land resources study, Big River Reservoir project, Interim Report Big River Reservoir Project, The Clean Water Act Section 404 Evaluation, Draft: Waltham, Mass., 40 p.

Wood, W.W., 1976, Guidelines for collection and field analysis of ground-water samples for selected unstable constituents: U.S. Geological Survey Techniques of Water-Resources Investigations, book 1, chap. D 2, $24 \mathrm{p}$.

\section{DEFINITION OF TERMS}

The following are definitions of selected technical terms as they are used in this report; they are not necessarily the only valid definitions for these terms.

Aquifer: A geologic formation, group of formations, or part of a formation that contains enough saturated permeable material to yield significant quantities of water to wells and springs.

Aquifer test: A controlled field experiment wherein the effect of pumping a well is measured in the pumped well and in the observation wells to determine hydraulic properties of an aquifer.

Bedrock: The solid rock, commonly called "ledge" that forms the Earth's crust.

Discharge: The volume of water that passes a given point within a given period of time.

Drawdown: The decline in water level in a well after pumping begins. It is the difference between the water level in a well after pumping begins and the water level as it would have been if the well had not been pumped.

Ground water: Water in the ground that is in the zone of saturation.

Hydraulic conductivity: The rate of flow of water through a unit area under a unit change in head per unit distance, at the prevailing temperature.

Lithologic log: Description of geologic material collected during drilling of wells or test holes.

pH: Symbol denoting the logarithm to base 10 of hydrogenion concentration in a solution. $\mathrm{pH}$ values range from 0 to 14 . The lower the value, the more hydrogen ions the sample contains and the more acidic the solution. A value of 7.0 is neutral; values greater than 7.0 indicate an alkaline solution; values less than 7.0 indicate an acidic solution.

Refusal: the inability to advance the drilling stem.

Specific conductance: A measure of the ability of water to conduct an electrical current, expressed in microsiemens per centimeter at $25^{\circ} \mathrm{Celsius}$. Specific conductance is related to the type and concentration of ions in solution and can be used for estimation of the dissolved-solids content of the water. Commonly, the concentration of dissolved solids (in milligrams per liter) is about 65 percent of the specific conductance (in microsiemens per centimeter at $25^{\circ}$ Celsius). This relationship varies depending on the composition of the dissolved solids.

Stratified deposit: Unconsolidated sediment that has been sorted by grain size by glacial meltwater and deposited in layers or strata.

Transmissivity: The product of the hydraulic conductivity and the saturated thickness. 
TABLES 1-16 
Table 1. Ground-water data-collection sites in the Big-Mishnock stream-aquifer system, central Rhode Island

[Site locations are shown on plate 1. Latitude and longitude are in degrees, minutes, and seconds. Well No.: COW, Coventry well; EXW, Exeter well; depth: Depths are in feet below land surface. Casing finish: G, gravel wall with commercial screen; O, open end; P, perforated or slotted; S, screened; Altitude is in feet above land surface. Site use: $\mathrm{O}$, observation; T, test; U, unused; W, water withdrawal. Water use: H, domestic; N, industrial; P, public SDGL, sand and gravel; SDST, sand and silt; SGVC, sand, gravel, and clay; STCL, silt and clay; TILL, till. Depth to bedrock: B, bedrock; R, refusal.

\begin{tabular}{|c|c|c|c|c|c|c|c|c|c|c|c|}
\hline \multirow{3}{*}{ Well No. } & \multirow{3}{*}{$\begin{array}{c}\text { Latitude } \\
\text { o, }\end{array}$} & \multirow{3}{*}{ 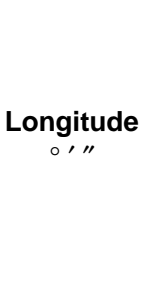 } & \multirow{3}{*}{$\begin{array}{c}\text { Site } \\
\text { identification }\end{array}$} & \multicolumn{8}{|c|}{ Construction } \\
\hline & & & & \multirow{2}{*}{ Year } & \multirow{2}{*}{ Method } & \multirow{2}{*}{$\begin{array}{c}\text { Hole } \\
\text { depth } \\
\text { (feet } \\
\text { below } \\
\text { land } \\
\text { surface) }\end{array}$} & \multirow{2}{*}{$\begin{array}{l}\text { Well } \\
\text { depth } \\
\text { (feet) }\end{array}$} & \multicolumn{2}{|c|}{ Casing } & \multicolumn{2}{|c|}{$\begin{array}{c}\text { Screened interval } \\
\text { (feet below land } \\
\text { surface) }\end{array}$} \\
\hline & & & & & & & & $\begin{array}{l}\text { Diameter } \\
\text { (inches) }\end{array}$ & Finish & Top & Bottom \\
\hline COW 34 & 414022 & 713814 & 414022071381401 & 1947 & $\mathrm{C}$ & -- & 80 & 6 & $\mathrm{X}$ & -- & -- \\
\hline COW 51 & 414002 & 713959 & 414002071395901 & -- & $\mathrm{D}$ & -- & 15.4 & 30 & -- & -- & -- \\
\hline COW 59 & 413955 & 713413 & 413955071341301 & -- & $\mathrm{C}$ & -- & 60 & 6 & $\mathrm{X}$ & -- & -- \\
\hline COW 61 & 414051 & 713522 & 414051071352201 & -- & $\mathrm{C}$ & -- & 180 & -- & $\mathrm{O}$ & -- & -- \\
\hline COW 64 & 414021 & 713634 & 414021071363401 & 1947 & $\mathrm{C}$ & -- & 45 & -- & $\mathrm{O}$ & -- & -- \\
\hline COW 65 & 414031 & 713646 & 414031071364601 & 1950 & $\mathrm{C}$ & -- & 80 & 6 & $\mathrm{O}$ & -- & -- \\
\hline COW 66 & 414038 & 713649 & 414038071364901 & 1948 & $\mathrm{C}$ & -- & 65 & -- & $\mathrm{X}$ & -- & -- \\
\hline COW 77 & 414004 & 713410 & 414004071341001 & 1945 & $\mathrm{C}$ & -- & 101 & 8 & $\mathrm{X}$ & -- & -- \\
\hline COW 93 & 413953 & 713606 & 413953071360601 & 1949 & $\mathrm{D}$ & -- & 12 & 30 & $\mathrm{O}$ & -- & -- \\
\hline COW 94 & 414008 & 713603 & 414008071360301 & -- & $\mathrm{V}$ & -- & 20 & 1.5 & $\mathrm{~T}$ & -- & -- \\
\hline COW 95 & 414002 & 713610 & 414002071361001 & -- & $\mathrm{D}$ & -- & 15 & 30 & $\mathrm{O}$ & -- & -- \\
\hline COW 96 & 413948 & 713610 & 413948071361001 & -- & $\mathrm{V}$ & -- & 12 & 1.25 & $\mathrm{~T}$ & -- & -- \\
\hline COW 98 & 413949 & 713724 & 413949071372401 & 1941 & $\mathrm{D}$ & -- & 15.4 & 30 & $\mathrm{O}$ & -- & -- \\
\hline COW 99 & 413955 & 713717 & 413955071371701 & -- & $\mathrm{D}$ & -- & 27 & 30 & -- & -- & -- \\
\hline COW 100 & 413957 & 713713 & 413957071371301 & -- & $\mathrm{D}$ & -- & 18 & -- & W & -- & -- \\
\hline COW 101 & 414003 & 713727 & 414003071372701 & -- & $\mathrm{D}$ & -- & 22 & 30 & -- & -- & -- \\
\hline COW 102 & 413959 & 713649 & 413959071364901 & -- & $\mathrm{D}$ & -- & 20 & 30 & $\mathrm{O}$ & -- & -- \\
\hline COW 104 & 414010 & 713608 & 414010071360801 & -- & $\mathrm{D}$ & -- & 30 & 30 & W & -- & -- \\
\hline COW 130 & 414024 & 713544 & 414024071354401 & -- & $\mathrm{D}$ & -- & 9.8 & 30 & $\mathrm{O}$ & -- & -- \\
\hline COW 136 & 414003 & 713657 & 414003071365701 & 1951 & $\mathrm{C}$ & -- & 130 & -- & $\mathrm{X}$ & -- & -- \\
\hline COW 154 & 414002 & 713416 & 414002071341601 & 1932 & $\mathrm{D}$ & -- & 15.5 & 30 & $\mathrm{O}$ & -- & -- \\
\hline COW 158 & 414000 & 713604 & 414000071360401 & 1950 & $\mathrm{C}$ & -- & 125 & 6 & $\mathrm{O}$ & -- & -- \\
\hline COW 205 & 414035 & 713908 & 414035071390801 & -- & $\mathrm{D}$ & -- & 17.9 & 30 & $\mathrm{O}$ & -- & -- \\
\hline COW 206 & 414033 & 713859 & 414033071385901 & 1950 & $\mathrm{C}$ & -- & 110 & 8 & $\mathrm{X}$ & -- & -- \\
\hline COW 207 & 414033 & 713851 & 414033071385101 & 1949 & $\mathrm{C}$ & -- & 225 & 6 & $\mathrm{X}$ & -- & -- \\
\hline COW 208 & 414035 & 713849 & 414035071384901 & 1949 & $\mathrm{C}$ & -- & 150 & 6 & $\mathrm{X}$ & -- & -- \\
\hline COW 209 & 414023 & 713821 & 414023071382101 & -- & $\mathrm{D}$ & -- & 24 & 18 & W & -- & -- \\
\hline COW 211 & 414007 & 713736 & 414007071373601 & 1948 & $\mathrm{C}$ & -- & 60 & 6 & $\mathrm{X}$ & -- & -- \\
\hline COW 212 & 414006 & 713737 & 414006071373701 & -- & $\mathrm{D}$ & -- & 13.6 & 30 & W & -- & -- \\
\hline COW 216 & 414037 & 714000 & 414037071400001 & -- & $\mathrm{D}$ & -- & 20.8 & 30 & W & -- & -- \\
\hline COW 217 & 414026 & 714001 & 414026071400101 & -- & $\mathrm{D}$ & -- & 13.9 & 30 & $\mathrm{O}$ & -- & -- \\
\hline COW 218 & 414011 & 714000 & 414011071400001 & -- & $\mathrm{D}$ & -- & 14.7 & 30 & W & -- & -- \\
\hline COW 219 & 413955 & 713741 & 413955071374101 & 1953 & $\mathrm{D}$ & -- & 23.2 & 30 & $\mathrm{O}$ & -- & -- \\
\hline COW 220 & 413948 & 713759 & 413948071375901 & 1950 & $\mathrm{D}$ & -- & 18.9 & 24 & W & -- & -- \\
\hline COW 221 & 413945 & 713747 & 413945071374701 & -- & $\mathrm{D}$ & -- & 9 & 30 & $\mathrm{O}$ & -- & -- \\
\hline
\end{tabular}


WGW, West Greenwich well. Method: A, air rotary; B, auger; C, cable tool; D, dug; J, jetted; P, air percussion; V, driven; W, drive and wash. Hole and well T, sandpoint; W, walled or shored; X, open hole. Screened interval: Bottom of open interval may not equal the finished well depth. Land surface altitude: supply; S, stock; U, unused. Aquifer lithology: Principal water-bearing material: CLAY, clay; GLCL, glacial (undifferentiated); GRVL, gravel; SAND, sand; Log: G, geologist log of lithology present in table 16. Water quality: Chemical analyses available in table 12. No., number; --, no data available]

\begin{tabular}{|c|c|c|c|c|c|c|c|c|c|c|}
\hline \multirow[b]{2}{*}{ Well No. } & \multirow{2}{*}{$\begin{array}{c}\text { Land surface } \\
\text { altitude } \\
\text { (feet above } \\
\text { mean sea } \\
\text { level) }\end{array}$} & \multirow[b]{2}{*}{$\begin{array}{l}\text { Site } \\
\text { use }\end{array}$} & \multirow[b]{2}{*}{$\begin{array}{l}\text { Water } \\
\text { use }\end{array}$} & \multicolumn{3}{|c|}{ Pumping } & \multirow[b]{2}{*}{$\begin{array}{c}\text { Aquifer } \\
\text { lithology }\end{array}$} & \multirow{2}{*}{$\begin{array}{c}\text { Depth to } \\
\text { bedrock } \\
\text { (feet) }\end{array}$} & \multirow[b]{2}{*}{$\log$} & \multirow[b]{2}{*}{$\begin{array}{l}\text { Water } \\
\text { quality }\end{array}$} \\
\hline & & & & $\begin{array}{c}\text { Discharge } \\
\text { (gal/min) }\end{array}$ & $\begin{array}{l}\text { Drawdown } \\
\text { (feet) }\end{array}$ & $\begin{array}{c}\text { Time } \\
\text { (hours) }\end{array}$ & & & & \\
\hline COW 34 & 297 & $\mathrm{~W}$ & $\mathrm{H}$ & 1.5 & -- & -- & SAND & B20 & -- & -- \\
\hline COW 51 & 555 & $\mathrm{~W}$ & $\mathrm{H}$ & -- & -- & -- & TILL & $\mathrm{R} 15.4$ & -- & -- \\
\hline COW 59 & 340 & $\mathrm{~W}$ & $\mathrm{~N}$ & -- & -- & -- & -- & B40 & -- & -- \\
\hline COW 61 & 275 & $\mathrm{~W}$ & $\mathrm{H}$ & 12 & -- & -- & SDGL & -- & -- & -- \\
\hline COW 64 & 250 & $\mathrm{~W}$ & $\mathrm{H}$ & 2 & -- & -- & SDGL & -- & -- & -- \\
\hline COW 65 & 292 & $\mathrm{~W}$ & $\mathrm{H}$ & 6 & -- & -- & TILL & $\mathrm{R} 80$ & -- & -- \\
\hline cow 66 & 300 & $\mathrm{~W}$ & $\mathrm{H}$ & 2.5 & -- & -- & TILL & B22 & -- & -- \\
\hline COW 77 & 315 & $\mathrm{~W}$ & $\mathrm{H}$ & -- & -- & -- & -- & B35 & -- & -- \\
\hline COW 93 & 258 & $\mathrm{~W}$ & $\mathrm{H}$ & -- & -- & -- & SAND & -- & -- & -- \\
\hline COW 94 & 259 & $\mathrm{~W}$ & $\mathrm{H}$ & -- & -- & -- & SDGL & -- & -- & -- \\
\hline COW 95 & 250 & $\mathrm{~W}$ & $\mathrm{H}$ & -- & -- & -- & SAND & -- & -- & -- \\
\hline COW 96 & 257 & $\mathrm{~W}$ & $\mathrm{H}$ & -- & -- & -- & SAND & -- & -- & -- \\
\hline COW 98 & 260 & $\mathrm{~W}$ & $\mathrm{H}$ & -- & -- & -- & SDGL & -- & -- & -- \\
\hline COW 99 & 272 & $\mathrm{~W}$ & $\mathrm{H}$ & -- & -- & -- & SDGL & -- & -- & -- \\
\hline COW 100 & 262 & $\mathrm{~W}$ & $\mathrm{H}$ & -- & -- & -- & SDGL & B18 & -- & -- \\
\hline COW 101 & 290 & $\mathrm{~W}$ & $\mathrm{H}$ & -- & -- & -- & TILL & B19 & -- & -- \\
\hline COW 102 & 265 & $\mathrm{~W}$ & $\mathrm{H}$ & -- & -- & -- & SDGL & -- & -- & -- \\
\hline COW 104 & 260 & $\mathrm{~W}$ & $\mathrm{H}$ & -- & -- & -- & SDGL & -- & -- & -- \\
\hline COW 130 & 255 & $\mathrm{~W}$ & $\mathrm{H}$ & -- & -- & -- & SDGL & -- & -- & -- \\
\hline COW 136 & 262 & $\mathrm{~W}$ & $\mathrm{H}$ & 4 & -- & -- & SAND & B50 & -- & -- \\
\hline COW 154 & 315 & $\mathrm{~W}$ & $\mathrm{H}$ & -- & -- & -- & SDGL & -- & -- & -- \\
\hline COW 158 & 258 & $\mathrm{~W}$ & $\mathrm{~N}$ & -- & -- & -- & SDGL & -- & -- & -- \\
\hline COW 205 & 440 & $\mathrm{~W}$ & $\mathrm{H}$ & 2 & -- & -- & TILL & R17.9 & -- & -- \\
\hline COW 206 & 470 & $\mathrm{~W}$ & $\mathrm{H}$ & 5 & -- & -- & TILL & B10 & -- & -- \\
\hline COW 207 & 458 & $\mathrm{~W}$ & $\mathrm{H}$ & 2.5 & -- & -- & TILL & B10 & -- & -- \\
\hline COW 208 & 470 & $\mathrm{~W}$ & $\mathrm{H}$ & 1.5 & -- & -- & TILL & B8 & -- & -- \\
\hline COW 209 & 298 & $\mathrm{~W}$ & $\mathrm{~S}$ & -- & -- & -- & SDGL & -- & -- & -- \\
\hline COW 211 & 270 & $\mathrm{~W}$ & $\mathrm{H}$ & 5 & -- & -- & SDGL & B17 & -- & -- \\
\hline COW 212 & 268.75 & $\mathrm{O}$ & $\mathrm{U}$ & -- & -- & -- & SAND & -- & -- & -- \\
\hline COW 216 & 535 & $\mathrm{~W}$ & $\mathrm{H}$ & -- & -- & -- & TILL & R20.8 & -- & -- \\
\hline COW 217 & 545 & $\mathrm{~W}$ & $\mathrm{H}$ & -- & -- & -- & TILL & R13.9 & -- & -- \\
\hline COW 218 & 543 & $\mathrm{~W}$ & $\mathrm{H}$ & -- & -- & -- & TILL & $\mathrm{R} 14.7$ & -- & -- \\
\hline COW 219 & 275 & $\mathrm{~W}$ & $\mathrm{H}$ & -- & -- & -- & SDGL & B23.2 & -- & -- \\
\hline COW 220 & 280 & $\mathrm{~W}$ & $\mathrm{H}$ & 4 & -- & -- & SDGL & B14.9 & -- & -- \\
\hline COW 221 & 260 & $\mathrm{~W}$ & $\mathrm{H}$ & -- & -- & -- & SAND & -- & -- & -- \\
\hline
\end{tabular}


Table 1. Ground-water data-collection sites in the Big-Mishnock stream-aquifer system, central Rhode Island—Continued

\begin{tabular}{|c|c|c|c|c|c|c|c|c|c|c|c|}
\hline \multirow{3}{*}{ Well No. } & \multirow{3}{*}{$\begin{array}{c}\text { Latitude } \\
\text { o,' }\end{array}$} & \multirow{3}{*}{$\begin{array}{c}\text { Longitude } \\
0, \prime \prime\end{array}$} & \multirow{3}{*}{$\begin{array}{c}\text { Site } \\
\text { identification }\end{array}$} & \multicolumn{8}{|c|}{ Construction } \\
\hline & & & & \multirow{2}{*}{ Year } & \multirow{2}{*}{ Method } & \multirow{2}{*}{$\begin{array}{c}\text { Hole } \\
\text { depth } \\
\text { (feet } \\
\text { below } \\
\text { land } \\
\text { surface) }\end{array}$} & \multirow{2}{*}{$\begin{array}{l}\text { Well } \\
\text { depth } \\
\text { (feet) }\end{array}$} & \multicolumn{2}{|c|}{ Casing } & \multicolumn{2}{|c|}{$\begin{array}{l}\text { Screened interval } \\
\text { (feet below land } \\
\text { surface) }\end{array}$} \\
\hline & & & & & & & & $\begin{array}{l}\text { Diameter } \\
\text { (inches) }\end{array}$ & Finish & Top & Bottom \\
\hline COW 222 & 413936 & 713737 & 413936071373701 & -- & D & -- & 15 & 30 & $\mathrm{O}$ & -- & -- \\
\hline COW 228 & 414046 & 713809 & 414046071380901 & -- & D & -- & 15.3 & 30 & $\mathrm{O}$ & -- & -- \\
\hline COW 237 & 414004 & 714002 & 414004071400201 & -- & D & -- & 22 & 30 & $\mathrm{~W}$ & -- & -- \\
\hline COW 241 & 413932 & 713938 & 413932071393801 & 1948 & D & -- & 16.2 & 30 & $\mathrm{O}$ & -- & -- \\
\hline COW 245 & 414007 & 713826 & 414007071382601 & -- & D & -- & 20 & -- & $\mathrm{W}$ & -- & -- \\
\hline COW 246 & 414018 & 713853 & 414018071385301 & -- & $\mathrm{D}$ & -- & 12 & 30 & $\mathrm{~W}$ & -- & -- \\
\hline COW 395 & 414004 & 713638 & 414004071363801 & 1956 & $\mathrm{C}$ & -- & 120 & -- & $\mathrm{X}$ & -- & -- \\
\hline COW 422 & 414021 & 713547 & 414021071354701 & 1962 & B & -- & 72 & 4 & $\mathrm{O}$ & -- & -- \\
\hline COW 423 & 414013 & 713559 & 414013071355901 & 1962 & B & -- & 102 & 4 & $\mathrm{O}$ & -- & -- \\
\hline COW 424 & 414023 & 713628 & 414023071362801 & 1962 & B & -- & 74 & -- & $\mathrm{X}$ & -- & -- \\
\hline COW 425 & 414001 & 713646 & 414001071364601 & 1962 & B & -- & 76 & -- & $\mathrm{X}$ & -- & -- \\
\hline COW 426 & 413945 & 713610 & 413945071361001 & 1962 & B & -- & 67 & -- & -- & -- & -- \\
\hline COW 435 & 413944 & 713559 & 413944071355901 & 1964 & $\mathrm{~J}$ & -- & 57 & 2.5 & $\mathrm{O}$ & -- & -- \\
\hline COW 436 & 413943 & 713600 & 413943071360001 & 1964 & $\mathrm{~J}$ & -- & 60 & 2.5 & $\mathrm{~S}$ & 50 & 60 \\
\hline COW 437 & 413947 & 713558 & 413947071355801 & 1964 & $\mathrm{~J}$ & 91 & 80 & 2.5 & $\mathrm{O}$ & -- & -- \\
\hline COW 438 & 413946 & 713559 & 413946071355901 & 1964 & $\mathrm{~J}$ & 80 & 74 & 2.5 & $\mathrm{~S}$ & -- & -- \\
\hline COW 439 & 413947 & 713554 & 413947071355401 & 1964 & $\mathrm{~J}$ & -- & 88 & 2.5 & $\mathrm{O}$ & -- & -- \\
\hline COW 442 & 413943 & 713557 & 413943071355701 & 1964 & $\mathrm{~J}$ & 78 & 76.6 & 2.5 & $\mathrm{O}$ & -- & -- \\
\hline COW 443 & 413942 & 713601 & 413942071360102 & 1964 & $\mathrm{~J}$ & 65 & 65 & 2.5 & $\mathrm{O}$ & -- & -- \\
\hline COW 446 & 413947 & 713601 & 413947071360101 & 1964 & $\mathrm{~J}$ & -- & 69 & 2.5 & $\mathrm{O}$ & -- & -- \\
\hline COW 447 & 413950 & 713601 & 413950071360101 & 1964 & $\mathrm{~J}$ & -- & 73 & 2.5 & $\mathrm{O}$ & -- & -- \\
\hline COW 448 & 413943 & 713557 & 413943071355702 & 1964 & $\mathrm{C}$ & 87 & 80 & 8 & $\mathrm{~S}$ & 60 & 80 \\
\hline COW 449 & 413944 & 713552 & 413944071355201 & 1964 & $\mathrm{~J}$ & -- & 104 & 2.5 & $\mathrm{O}$ & -- & -- \\
\hline COW 450 & 413945 & 713552 & 413945071355201 & 1964 & $\mathrm{~J}$ & -- & 107 & 2.5 & $\mathrm{O}$ & -- & -- \\
\hline COW 451 & 413946 & 713550 & 413946071355001 & 1964 & $\mathrm{~J}$ & -- & 98 & 2.5 & $\mathrm{O}$ & -- & -- \\
\hline COW 452 & 413942 & 713550 & 413942071355001 & 1964 & $\mathrm{~J}$ & -- & 103 & 2.5 & $\mathrm{O}$ & -- & -- \\
\hline COW 453 & 413946 & 713603 & 413946071360301 & 1964 & $\mathrm{~J}$ & 89 & 80 & 2.5 & $\mathrm{~S}$ & 70 & 80 \\
\hline COW 454 & 413945 & 713602 & 413945071360201 & 1964 & $\mathrm{~J}$ & -- & 92 & 2.5 & $\mathrm{O}$ & -- & -- \\
\hline COW 455 & 413942 & 713551 & 413942071355101 & 1964 & $\mathrm{~J}$ & -- & 102 & 2.5 & $\mathrm{O}$ & -- & -- \\
\hline COW 456 & 413941 & 713605 & 413941071360501 & 1964 & $\mathrm{~J}$ & 71 & 55 & 2.5 & $\mathrm{O}$ & -- & -- \\
\hline COW 457 & 413940 & 713604 & 413940071360401 & 1964 & $\mathrm{~J}$ & 75 & 70 & 2.5 & $\mathrm{O}$ & -- & -- \\
\hline COW 459 & 413942 & 713604 & 413942071360401 & 1964 & $\mathrm{~J}$ & 81 & 75 & 2.5 & $\mathrm{O}$ & -- & -- \\
\hline COW 460 & 413942 & 713601 & 413942071360101 & -- & -- & -- & 75 & -- & -- & 55 & 75 \\
\hline COW 460 & 413942 & 713601 & 413942071360101 & 1964 & $\mathrm{C}$ & -- & 75 & 8 & $\mathrm{~S}$ & 55 & 65 \\
\hline COW 461 & 413942 & 713601 & 413942071360103 & 1965 & $\mathrm{C}$ & 75 & 75 & 18 & S & 55 & 75 \\
\hline COW 462 & 413943 & 713557 & 413943071355703 & 1966 & $\mathrm{C}$ & 89 & 88 & 18 & $\mathrm{~S}$ & 63 & 88 \\
\hline COW 467 & 413941 & 713528 & 413941071352801 & 1994 & $\mathrm{~W}$ & 125 & 110 & 2.5 & S & 100 & 110 \\
\hline COW 468 & 414007 & 713534 & 414007071353401 & 1994 & W & 147 & 134 & 2.5 & $\mathrm{~S}$ & 124 & 134 \\
\hline COW 469 & 413956 & 713530 & 413956071353001 & 1994 & W & 151 & 146 & 2.5 & $\mathrm{~S}$ & 136 & 146 \\
\hline COW 470 & 414002 & 713529 & 414002071352901 & 1994 & $\mathrm{~W}$ & -- & 124 & 2.5 & $\mathrm{~S}$ & 119 & 124 \\
\hline
\end{tabular}




\begin{tabular}{|c|c|c|c|c|c|c|c|c|c|c|}
\hline \multirow[b]{2}{*}{ Well No. } & \multirow{2}{*}{$\begin{array}{l}\text { Land surface } \\
\text { altitude } \\
\text { (feet above } \\
\text { mean sea } \\
\text { level) }\end{array}$} & \multirow[b]{2}{*}{$\begin{array}{l}\text { Site } \\
\text { use }\end{array}$} & \multirow[b]{2}{*}{$\begin{array}{l}\text { Water } \\
\text { use }\end{array}$} & \multicolumn{3}{|c|}{ Pumping } & \multirow[b]{2}{*}{$\begin{array}{l}\text { Aquifer } \\
\text { lithology }\end{array}$} & \multirow{2}{*}{$\begin{array}{l}\text { Depth to } \\
\text { bedrock } \\
\text { (feet) }\end{array}$} & \multirow[b]{2}{*}{$\log$} & \multirow[b]{2}{*}{$\begin{array}{l}\text { Water } \\
\text { quality }\end{array}$} \\
\hline & & & & $\begin{array}{c}\text { Discharge } \\
\text { (gal/min) }\end{array}$ & $\begin{array}{l}\text { Drawdown } \\
\text { (feet) }\end{array}$ & $\begin{array}{c}\text { Time } \\
\text { (hours) }\end{array}$ & & & & \\
\hline COW 222 & 263 & W & $\mathrm{H}$ & -- & -- & -- & SDGL & -- & -- & -- \\
\hline COW 228 & 390 & $\mathrm{~W}$ & $\mathrm{H}$ & -- & -- & -- & TILL & $\mathrm{R} 15.3$ & -- & -- \\
\hline COW 237 & 554 & W & $\mathrm{H}$ & -- & -- & -- & TILL & $\mathrm{R} 22$ & -- & -- \\
\hline COW 241 & 563 & W & $\mathrm{H}$ & -- & -- & -- & TILL & $\mathrm{R} 16.2$ & -- & -- \\
\hline COW 245 & 285 & W & $\mathrm{H}$ & -- & -- & -- & SAND & -- & -- & -- \\
\hline COW 246 & 385 & W & $\mathrm{H}$ & -- & -- & -- & TILL & $\mathrm{R} 12$ & -- & -- \\
\hline COW 395 & 255 & W & $\mathrm{H}$ & 1.5 & -- & -- & SAND & B75 & -- & -- \\
\hline COW 422 & 255 & $\mathrm{~T}$ & $\mathrm{U}$ & -- & -- & -- & SAND & -- & -- & -- \\
\hline COW 423 & 259 & $\mathrm{~T}$ & $\mathrm{U}$ & -- & -- & -- & SAND & -- & -- & -- \\
\hline COW 424 & 260 & $\mathrm{~T}$ & $\mathrm{U}$ & -- & -- & -- & SDGL & -- & -- & -- \\
\hline COW 425 & 265 & $\mathrm{~T}$ & $\mathrm{U}$ & -- & -- & -- & SDST & -- & -- & -- \\
\hline COW 426 & 255 & $\mathrm{~T}$ & $\mathrm{U}$ & -- & -- & -- & SDST & -- & -- & -- \\
\hline COW 435 & 253 & $\mathrm{O}$ & $\mathrm{U}$ & -- & -- & -- & SDGL & B57 & -- & -- \\
\hline COW 436 & 253 & $\mathrm{O}$ & $\mathrm{U}$ & 20 & -- & -- & SDGL & -- & -- & -- \\
\hline COW 437 & 252 & $\mathrm{O}$ & $\mathrm{U}$ & 55 & -- & -- & SDGL & -- & -- & -- \\
\hline COW 438 & 252 & $\mathrm{O}$ & $\mathrm{U}$ & 30 & -- & -- & SDGL & -- & -- & -- \\
\hline COW 439 & 247 & $\mathrm{O}$ & $\mathrm{U}$ & -- & -- & -- & SGVC & B88 & -- & -- \\
\hline COW 442 & 250 & $\mathrm{O}$ & $\mathrm{U}$ & 60 & -- & -- & SDGL & -- & -- & -- \\
\hline COW 443 & 251 & $\mathrm{~T}$ & $\mathrm{U}$ & 80 & -- & -- & SDGL & -- & -- & -- \\
\hline COW 446 & 255 & $\mathrm{O}$ & $\mathrm{U}$ & -- & -- & -- & SDGL & -- & -- & -- \\
\hline COW 447 & 255 & $\mathrm{~T}$ & $\mathrm{U}$ & -- & -- & -- & SDGL & -- & -- & -- \\
\hline COW 448 & 252 & $\mathrm{~T}$ & $\mathrm{U}$ & -- & -- & -- & SDGL & -- & -- & -- \\
\hline COW 449 & 251 & $\mathrm{~T}$ & $\mathrm{U}$ & -- & -- & -- & SDGL & -- & -- & -- \\
\hline COW 450 & 250 & $\mathrm{~T}$ & $\mathrm{U}$ & -- & -- & -- & STCL & B107 & -- & -- \\
\hline COW 451 & 250 & $\mathrm{~T}$ & $\mathrm{U}$ & -- & -- & -- & SDCL & -- & -- & -- \\
\hline COW 452 & 255 & $\mathrm{~T}$ & $\mathrm{U}$ & -- & -- & -- & STCL & -- & -- & -- \\
\hline COW 453 & 255 & $\mathrm{~T}$ & $\mathrm{U}$ & 20 & -- & -- & SDGL & -- & -- & -- \\
\hline COW 454 & 255 & $\mathrm{~T}$ & $\mathrm{U}$ & -- & -- & -- & STCL & -- & -- & -- \\
\hline COW 455 & 253 & $\mathrm{~T}$ & $\mathrm{U}$ & -- & -- & -- & STCL & -- & -- & -- \\
\hline COW 456 & 255 & $\mathrm{~T}$ & $\mathrm{U}$ & 30 & -- & -- & SDGL & -- & -- & -- \\
\hline COW 457 & 255 & $\mathrm{~T}$ & $\mathrm{U}$ & -- & -- & -- & SDGL & -- & -- & -- \\
\hline COW 459 & 255 & $\mathrm{~T}$ & $\mathrm{U}$ & 20 & -- & -- & SDGL & -- & -- & -- \\
\hline COW 460 & 251 & $\mathrm{~T}$ & $\mathrm{U}$ & -- & -- & -- & -- & -- & -- & -- \\
\hline COW 460 & 251 & $\mathrm{~T}$ & $\mathrm{U}$ & -- & -- & -- & GRVL & -- & -- & -- \\
\hline COW 461 & 251 & W & $\mathrm{P}$ & 1,080 & 36 & 48 & SDGL & -- & -- & -- \\
\hline COW 462 & 252 & W & $\mathrm{P}$ & 830 & 20.5 & 48 & SDGL & -- & -- & -- \\
\hline COW 467 & 248 & $\mathrm{~T}$ & $\mathrm{U}$ & -- & -- & -- & SGVC & -- & -- & -- \\
\hline COW 468 & 249 & $\mathrm{~T}$ & $\mathrm{U}$ & 37.6 & -- & -- & SGVC & -- & -- & -- \\
\hline COW 469 & 251 & $\mathrm{~T}$ & $\mathrm{U}$ & -- & -- & -- & SGVC & -- & -- & -- \\
\hline COW 470 & 249 & $\mathrm{~T}$ & $\mathrm{U}$ & 8 & -- & -- & SDCL & -- & -- & -- \\
\hline
\end{tabular}


Table 1. Ground-water data-collection sites in the Big-Mishnock stream-aquifer system, central Rhode Island—Continued

\begin{tabular}{|c|c|c|c|c|c|c|c|c|c|c|c|}
\hline \multirow{3}{*}{ Well No. } & \multirow{3}{*}{$\begin{array}{c}\text { Latitude } \\
\text { o,' }\end{array}$} & \multirow{3}{*}{$\begin{array}{c}\text { Longitude } \\
0, \prime \prime\end{array}$} & \multirow{3}{*}{$\begin{array}{c}\text { Site } \\
\text { identification }\end{array}$} & \multicolumn{8}{|c|}{ Construction } \\
\hline & & & & \multirow{2}{*}{ Year } & \multirow{2}{*}{ Method } & \multirow{2}{*}{$\begin{array}{c}\text { Hole } \\
\text { depth } \\
\text { (feet } \\
\text { below } \\
\text { land } \\
\text { surface) }\end{array}$} & \multirow{2}{*}{$\begin{array}{l}\text { Well } \\
\text { depth } \\
\text { (feet) }\end{array}$} & \multicolumn{2}{|c|}{ Casing } & \multicolumn{2}{|c|}{$\begin{array}{l}\text { Screened interval } \\
\text { (feet below land } \\
\text { surface) }\end{array}$} \\
\hline & & & & & & & & $\begin{array}{l}\text { Diameter } \\
\text { (inches) }\end{array}$ & Finish & Top & Bottom \\
\hline COW 471 & 413952 & 713559 & 413952071355901 & 1994 & $\mathrm{~W}$ & 103 & 95 & 2.5 & S & 90 & 95 \\
\hline COW 472 & 413950 & 713559 & 413950071355901 & 1994 & W & -- & 92 & 2.5 & $\mathrm{~S}$ & -- & -- \\
\hline COW 473 & 413936 & 713544 & 413936071354401 & 1994 & $\mathrm{~W}$ & 127 & 120 & 2.5 & $\mathrm{~S}$ & 115 & 120 \\
\hline COW 474 & 413937 & 713536 & 413937071353601 & 1994 & $\mathrm{~W}$ & 111 & 110 & 2.5 & $\mathrm{~S}$ & 100 & 110 \\
\hline COW 475 & 413937 & 713536 & 413937071353602 & 1994 & $\mathrm{~W}$ & 117 & 112 & 2.5 & $\mathrm{~S}$ & 102 & 112 \\
\hline COW 476 & 413937 & 713534 & 413937071353401 & 1994 & $\mathrm{~W}$ & 116 & 114 & 2.5 & $\mathrm{~S}$ & 104 & 114 \\
\hline COW 477 & 413937 & 713536 & 413937071353603 & 1995 & W & -- & 110 & 8 & $\mathrm{~S}$ & 95 & 110 \\
\hline COW 478 & 414043 & 713452 & 414043071345201 & 1997 & $\mathrm{~V}$ & -- & 4.2 & 1 & $\mathrm{~S}$ & 2.95 & 4.2 \\
\hline COW 479 & 413937 & 713715 & 413937071371501 & 1998 & $\mathrm{~W}$ & 63 & 63 & 2.5 & $\mathrm{O}$ & -- & -- \\
\hline COW 480 & 413945 & 713537 & 413945071353701 & 1994 & $\mathrm{~W}$ & 99 & 95 & 2.5 & $\mathrm{~S}$ & 85 & 95 \\
\hline COW 481 & 413937 & 713742 & 413937071374201 & 1997 & $\mathrm{~V}$ & -- & 3.61 & 1 & $\mathrm{~S}$ & 2.36 & 3.61 \\
\hline EXW 96 & 413506 & 713708 & 413506071370801 & 1952 & $\mathrm{C}$ & -- & 546 & 6 & $\mathrm{X}$ & -- & -- \\
\hline EXW 189 & 413522 & 713820 & 413522071382002 & 1949 & $\mathrm{C}$ & -- & 150 & 6 & $\mathrm{X}$ & -- & -- \\
\hline EXW 190 & 413522 & 713820 & 413522071382001 & -- & $\mathrm{C}$ & -- & 633 & 6 & $\mathrm{X}$ & -- & -- \\
\hline EXW 191 & 413526 & 713808 & 413526071380801 & 1951 & $\mathrm{C}$ & -- & 125 & 6 & $\mathrm{X}$ & -- & -- \\
\hline EXW 192 & 413549 & 713914 & 413549071391401 & -- & D & 25 & 25 & 30 & $\mathrm{~W}$ & -- & -- \\
\hline EXW 193 & 413556 & 713850 & 413556071385001 & -- & $\mathrm{D}$ & -- & 14 & 30 & $\mathrm{Z}$ & -- & -- \\
\hline EXW 194 & 413556 & 713845 & 413556071384501 & -- & $\mathrm{D}$ & -- & 20.2 & 30 & $\mathrm{~W}$ & -- & -- \\
\hline EXW 195 & 413600 & 713842 & 413600071384201 & -- & $\mathrm{D}$ & -- & 32.6 & 30 & W & -- & -- \\
\hline EXW 196 & 413559 & 713824 & 413559071382401 & -- & $\mathrm{D}$ & -- & 21.8 & 30 & W & -- & -- \\
\hline EXW 197 & 413556 & 713805 & 413556071380501 & 1920 & $\mathrm{C}$ & -- & 75 & 2 & $\mathrm{X}$ & -- & -- \\
\hline EXW 340 & 413602 & 713642 & 413602071364201 & -- & D & -- & 35.3 & 36 & $\mathrm{O}$ & -- & -- \\
\hline EXW 341 & 413533 & 713659 & 413533071365901 & -- & D & -- & 21.1 & 36 & W & -- & -- \\
\hline EXW 342 & 413535 & 713658 & 413535071365801 & -- & D & -- & 12.4 & 24 & W & -- & -- \\
\hline EXW 343 & 413542 & 713724 & 413542071372401 & -- & $\mathrm{D}$ & -- & 13.6 & 48 & W & -- & -- \\
\hline EXW 344 & 413538 & 713724 & 413538071372401 & -- & D & -- & 14.1 & 30 & $\mathrm{~W}$ & -- & -- \\
\hline EXW 345 & 413517 & 713707 & 413517071370701 & -- & D & -- & 12.2 & 36 & $\mathrm{O}$ & -- & -- \\
\hline WGW 1 & 413646 & 713814 & 413646071381401 & 1935 & $\mathrm{C}$ & -- & 220 & 6 & $\mathrm{X}$ & -- & -- \\
\hline WGW 5 & 413859 & 713944 & 413859071394401 & -- & D & -- & 13.8 & 30 & $\mathrm{X}$ & -- & -- \\
\hline WGW 7 & 413826 & 714013 & 413826071401301 & -- & V & -- & 29 & 2 & -- & -- & -- \\
\hline WGW 13 & 413934 & 713614 & 413934071361401 & -- & $\mathrm{V}$ & -- & 22 & 2.5 & $\mathrm{Z}$ & -- & -- \\
\hline WGW 14 & 413858 & 713431 & 413858071343101 & -- & D & -- & 19 & 24 & $\mathrm{O}$ & -- & -- \\
\hline WGW 15 & 413915 & 713317 & 413915071331701 & -- & D & -- & 36 & 30 & W & -- & -- \\
\hline WGW 16 & 413916 & 713344 & 413916071334401 & -- & $\mathrm{V}$ & -- & 47 & 1.75 & $\mathrm{~S}$ & -- & -- \\
\hline WGW 17 & 413907 & 713404 & 413907071340401 & -- & $\mathrm{D}$ & -- & 20 & 20 & $\mathrm{O}$ & -- & -- \\
\hline WGW 18 & 413914 & 713435 & 413914071343501 & -- & $\mathrm{C}$ & -- & 98 & 6 & $\mathrm{O}$ & -- & -- \\
\hline WGW 19 & 413935 & 713430 & 413935071343001 & 1947 & $\mathrm{C}$ & -- & 45 & 6 & $\mathrm{X}$ & -- & -- \\
\hline WGW 20 & 413733 & 713403 & 413733071340301 & -- & $\mathrm{C}$ & -- & 465 & 6 & $\mathrm{X}$ & -- & -- \\
\hline WGW 21 & 413906 & 713532 & 413906071353201 & 1951 & $\mathrm{~V}$ & -- & 30 & 2.5 & $\mathrm{O}$ & -- & -- \\
\hline WGW 22 & 413907 & 713513 & 413907071351301 & 1946 & D & -- & 12 & 36 & $\mathrm{O}$ & -- & -- \\
\hline
\end{tabular}




\begin{tabular}{|c|c|c|c|c|c|c|c|c|c|c|}
\hline \multirow[b]{2}{*}{ Well No. } & \multirow{2}{*}{$\begin{array}{l}\text { Land surface } \\
\text { altitude } \\
\text { (feet above } \\
\text { mean sea } \\
\text { level) }\end{array}$} & \multirow[b]{2}{*}{$\begin{array}{l}\text { Site } \\
\text { use }\end{array}$} & \multirow[b]{2}{*}{$\begin{array}{c}\text { Water } \\
\text { use }\end{array}$} & \multicolumn{3}{|c|}{ Pumping } & \multirow[b]{2}{*}{$\begin{array}{l}\text { Aquifer } \\
\text { lithology }\end{array}$} & \multirow{2}{*}{$\begin{array}{c}\text { Depth to } \\
\text { bedrock } \\
\text { (feet) }\end{array}$} & \multirow[b]{2}{*}{ Log } & \multirow[b]{2}{*}{$\begin{array}{l}\text { Water } \\
\text { quality }\end{array}$} \\
\hline & & & & $\begin{array}{c}\text { Discharge } \\
\text { (gal/min) }\end{array}$ & $\begin{array}{l}\text { Drawdown } \\
\text { (feet) }\end{array}$ & $\begin{array}{c}\text { Time } \\
\text { (hours) }\end{array}$ & & & & \\
\hline COW 471 & 251 & $\mathrm{~T}$ & $\mathrm{U}$ & -- & -- & -- & SDGL & -- & -- & -- \\
\hline COW 472 & 252 & $\mathrm{~T}$ & $\mathrm{U}$ & 21 & -- & -- & SDGL & -- & -- & -- \\
\hline COW 473 & 256 & $\mathrm{~T}$ & $\mathrm{U}$ & 6 & -- & -- & SDGL & -- & -- & -- \\
\hline COW 474 & 253 & $\mathrm{~T}$ & $\mathrm{U}$ & 52 & -- & -- & SGVC & -- & -- & -- \\
\hline COW 475 & 253 & $\mathrm{~T}$ & $\mathrm{U}$ & -- & -- & -- & SGVC & -- & -- & -- \\
\hline COW 476 & 252 & $\mathrm{~T}$ & $\mathrm{U}$ & 5 & -- & -- & SGVC & -- & -- & -- \\
\hline COW 477 & 253 & $\mathrm{~T}$ & $\mathrm{U}$ & 295 & 8.7 & 48 & SDGL & -- & -- & -- \\
\hline COW 478 & 240.58 & $\mathrm{O}$ & -- & -- & -- & -- & -- & -- & -- & -- \\
\hline COW 479 & 249.31 & $\mathrm{~T}$ & $\mathrm{U}$ & -- & -- & -- & SDST & -- & G & -- \\
\hline COW 480 & 254 & $\mathrm{~T}$ & $\mathrm{U}$ & -- & -- & -- & SGVC & -- & -- & -- \\
\hline COW 481 & 251.9 & $\mathrm{O}$ & -- & -- & -- & -- & -- & -- & -- & -- \\
\hline EXW 96 & 410 & W & $\mathrm{P}$ & -- & -- & -- & CLAY & B12 & -- & -- \\
\hline EXW 189 & 450 & W & $\mathrm{H}$ & -- & -- & -- & TILL & B10 & -- & -- \\
\hline EXW 190 & 450 & W & $\mathrm{H}$ & -- & -- & -- & TILL & B10 & -- & -- \\
\hline EXW 191 & 375 & W & $\mathrm{H}$ & -- & -- & -- & TILL & B5 & -- & -- \\
\hline EXW 192 & 520 & W & $\mathrm{H}$ & -- & -- & -- & TILL & B25 & -- & -- \\
\hline EXW 193 & 510 & W & $\mathrm{H}$ & -- & -- & -- & TILL & $\mathrm{R} 14$ & -- & -- \\
\hline EXW 194 & 525 & $\mathrm{U}$ & $\mathrm{U}$ & -- & -- & -- & TILL & $\mathrm{R} 20.2$ & -- & -- \\
\hline EXW 195 & 535 & $\mathrm{U}$ & $\mathrm{U}$ & -- & -- & -- & TILL & B15 & -- & -- \\
\hline EXW 196 & 470 & W & $\mathrm{H}$ & -- & -- & -- & TILL & $\mathrm{R} 21.8$ & -- & -- \\
\hline EXW 197 & 408 & W & $\mathrm{H}$ & -- & -- & -- & TILL & B50 & -- & -- \\
\hline EXW 340 & 380 & $\mathrm{~W}$ & $\mathrm{H}$ & -- & -- & -- & SDGL & -- & -- & -- \\
\hline EXW 341 & 380 & $\mathrm{~W}$ & $\mathrm{H}$ & -- & -- & -- & SDGL & -- & -- & -- \\
\hline EXW 342 & 375 & $\mathrm{U}$ & $\mathrm{U}$ & -- & -- & -- & SDGL & -- & -- & -- \\
\hline EXW 343 & 340 & W & $\mathrm{H}$ & -- & -- & -- & SDGL & -- & -- & -- \\
\hline EXW 344 & 340 & W & $\mathrm{H}$ & -- & -- & -- & SAND & B1.5 & -- & -- \\
\hline EXW 345 & 378 & W & $\mathrm{H}$ & -- & -- & -- & TILL & $\mathrm{R} 12.2$ & -- & -- \\
\hline WGW 1 & 475 & W & $\mathrm{P}$ & -- & -- & -- & TILL & B28 & -- & -- \\
\hline WGW 5 & 535 & W & $\mathrm{H}$ & -- & -- & -- & TILL & B13.8 & -- & -- \\
\hline WGW 7 & 403 & $\mathrm{~W}$ & $\mathrm{H}$ & -- & -- & -- & GLCL & -- & -- & -- \\
\hline WGW 13 & 272 & $\mathrm{U}$ & $\mathrm{U}$ & -- & -- & -- & SAND & -- & -- & -- \\
\hline WGW 14 & 300 & W & $\mathrm{H}$ & -- & -- & -- & SAND & -- & -- & -- \\
\hline WGW 15 & 335 & W & $\mathrm{H}$ & -- & -- & -- & SDGL & -- & -- & -- \\
\hline WGW 16 & 340 & W & $\mathrm{H}$ & -- & -- & -- & SDGL & -- & -- & -- \\
\hline WGW 17 & 320 & W & $\mathrm{H}$ & -- & -- & -- & SAND & -- & -- & -- \\
\hline WGW 18 & 345 & W & $\mathrm{H}$ & -- & -- & -- & SDGL & -- & -- & -- \\
\hline WGW 19 & 340 & W & $\mathrm{H}$ & -- & -- & -- & SDGL & B35 & -- & -- \\
\hline WGW 20 & 472 & W & $\mathrm{H}$ & -- & -- & -- & -- & B56 & -- & -- \\
\hline WGW 21 & 280 & W & $\mathrm{H}$ & -- & -- & -- & SAND & -- & -- & -- \\
\hline WGW 22 & 258 & W & $\mathrm{H}$ & -- & -- & -- & SAND & -- & -- & -- \\
\hline
\end{tabular}


Table 1. Ground-water data-collection sites in the Big-Mishnock stream-aquifer system, central Rhode Island—Continued

\begin{tabular}{|c|c|c|c|c|c|c|c|c|c|c|c|}
\hline \multirow{3}{*}{ Well No. } & \multirow{3}{*}{$\begin{array}{c}\text { Latitude } \\
0, \prime \prime\end{array}$} & \multirow{3}{*}{$\begin{array}{c}\text { Longitude } \\
\text { o," }\end{array}$} & \multirow{3}{*}{$\begin{array}{c}\text { Site } \\
\text { identification }\end{array}$} & \multicolumn{8}{|c|}{ Construction } \\
\hline & & & & \multirow{2}{*}{ Year } & \multirow{2}{*}{ Method } & \multirow{2}{*}{$\begin{array}{c}\text { Hole } \\
\text { depth } \\
\text { (feet } \\
\text { below } \\
\text { land } \\
\text { surface) }\end{array}$} & \multirow{2}{*}{$\begin{array}{l}\text { Well } \\
\text { depth } \\
\text { (feet) }\end{array}$} & \multicolumn{2}{|c|}{ Casing } & \multicolumn{2}{|c|}{$\begin{array}{l}\text { Screened interval } \\
\text { (feet below land } \\
\text { surface) }\end{array}$} \\
\hline & & & & & & & & $\begin{array}{l}\text { Diameter } \\
\text { (inches) }\end{array}$ & Finish & Top & Bottom \\
\hline WGW 23 & 413921 & 713529 & 413921071352901 & -- & $\mathrm{V}$ & -- & 15 & 1.25 & -- & -- & -- \\
\hline WGW 24 & 413919 & 713521 & 413919071352101 & -- & $\mathrm{V}$ & -- & 24 & 1.75 & -- & -- & -- \\
\hline WGW 25 & 413918 & 713437 & 413918071343701 & 1942 & $\mathrm{C}$ & -- & 100 & 6 & $\mathrm{X}$ & -- & -- \\
\hline WGW 26 & 413919 & 713440 & 413919071344001 & -- & $\mathrm{C}$ & -- & 174 & 6 & $\mathrm{X}$ & -- & -- \\
\hline WGW 27 & 413915 & 713436 & 413915071343601 & 1951 & $\mathrm{C}$ & -- & 144 & 6 & $\mathrm{X}$ & -- & -- \\
\hline WGW 28 & 413915 & 713440 & 413915071344001 & -- & $\mathrm{C}$ & -- & 105 & 6 & $\mathrm{O}$ & -- & -- \\
\hline WGW 29 & 413937 & 713422 & 413937071342201 & 1938 & $\mathrm{C}$ & -- & 90 & 6 & $\mathrm{X}$ & -- & -- \\
\hline WGW 30 & 413836 & 713727 & 413836071372701 & 1950 & $\mathrm{C}$ & -- & 104 & 6 & $\mathrm{X}$ & -- & -- \\
\hline WGW 31 & 413815 & 713732 & 413815071373201 & 1935 & $\mathrm{C}$ & -- & 175 & 6 & $\mathrm{X}$ & -- & -- \\
\hline WGW 32 & 413823 & 713728 & 413823071372801 & 1949 & $\mathrm{C}$ & -- & 38 & 6 & -- & -- & -- \\
\hline WGW 33 & 413826 & 713725 & 413826071372501 & 1949 & $\mathrm{C}$ & -- & 42 & 6 & $\mathrm{X}$ & -- & -- \\
\hline WGW 34 & 413836 & 713703 & 413836071370301 & -- & $\mathrm{D}$ & -- & 21 & 30 & $\mathrm{O}$ & -- & -- \\
\hline WGW 35 & 413836 & 713711 & 413836071371101 & -- & V & -- & 36 & 1.5 & $\mathrm{~S}$ & -- & -- \\
\hline WGW 36 & 413847 & 713636 & 413847071363601 & 1938 & $\mathrm{C}$ & -- & 112 & 6 & $\mathrm{X}$ & -- & -- \\
\hline WGW 37 & 413854 & 713617 & 413854071361701 & -- & $\mathrm{D}$ & -- & 4 & 30 & W & -- & -- \\
\hline WGW 38 & 413923 & 713615 & 413923071361501 & 1949 & $\mathrm{C}$ & -- & 40 & 6 & $\mathrm{X}$ & -- & -- \\
\hline WGW 39 & 413933 & 713612 & 413933071361201 & -- & $\mathrm{D}$ & -- & 8 & 30 & $\mathrm{O}$ & -- & -- \\
\hline WGW 40 & 413921 & 713550 & 413921071355001 & -- & $\mathrm{D}$ & -- & 7.5 & 30 & W & -- & -- \\
\hline WGW 41 & 413929 & 713607 & 413929071360701 & -- & D & -- & 8 & 30 & $\mathrm{O}$ & -- & -- \\
\hline WGW 42 & 413835 & 713628 & 413835071362802 & 1948 & $\mathrm{C}$ & -- & 58 & 6 & $\mathrm{X}$ & -- & -- \\
\hline WGW 43 & 413736 & 713527 & 413736071352701 & -- & $\mathrm{D}$ & -- & 14.6 & 30 & $\mathrm{X}$ & -- & -- \\
\hline WGW 44 & 413758 & 713455 & 413758071345501 & 1939 & V & -- & 28 & 1.25 & W & -- & -- \\
\hline WGW 45 & 413806 & 713442 & 413806071344201 & -- & $\mathrm{D}$ & -- & 22 & 30 & W & -- & -- \\
\hline WGW 46 & 413825 & 713425 & 413825071342501 & 1949 & $\mathrm{D}$ & -- & 26 & 30 & $\mathrm{O}$ & -- & -- \\
\hline WGW 47 & 413916 & 713306 & 413916071330601 & -- & $\mathrm{C}$ & -- & 162 & 6 & $\mathrm{X}$ & -- & -- \\
\hline WGW 49 & 413846 & 713400 & 413846071340001 & -- & D & -- & 25 & 30 & W & -- & -- \\
\hline WGW 51 & 413813 & 713426 & 413813071342601 & -- & $\mathrm{D}$ & -- & 12 & 48 & W & -- & -- \\
\hline WGW 53 & 413745 & 713557 & 413745071355701 & -- & $\mathrm{D}$ & -- & 18 & 30 & $\mathrm{X}$ & -- & -- \\
\hline WGW 55 & 413917 & 713559 & 413917071355901 & -- & $\mathrm{D}$ & -- & 11.2 & 26 & $\mathrm{O}$ & -- & -- \\
\hline WGW 56 & 413851 & 713551 & 413851071355101 & -- & $\mathrm{D}$ & -- & 19.7 & 30 & W & -- & -- \\
\hline WGW 57 & 413845 & 713527 & 413845071352701 & -- & $\mathrm{D}$ & 12.7 & 12.7 & 30 & W & -- & -- \\
\hline WGW 58 & 413845 & 713510 & 413845071351001 & -- & $\mathrm{D}$ & -- & 18 & 30 & W & -- & -- \\
\hline WGW 59 & 413853 & 713628 & 413853071362801 & -- & $\mathrm{C}$ & -- & 98 & 8 & $\mathrm{X}$ & -- & -- \\
\hline WGW 60 & 413759 & 713637 & 413759071363701 & -- & $\mathrm{D}$ & -- & 16 & 30 & W & -- & -- \\
\hline WGW 61 & 413807 & 713638 & 413807071363801 & 1952 & $\mathrm{D}$ & -- & 15 & 30 & $\mathrm{O}$ & -- & -- \\
\hline WGW 73 & 413817 & 714006 & 413817071400601 & -- & $\mathrm{D}$ & -- & 21.4 & 24 & W & -- & -- \\
\hline WGW 74 & 413844 & 714009 & 413844071400901 & -- & $\mathrm{D}$ & -- & 29.5 & 24 & W & -- & -- \\
\hline WGW 75 & 413900 & 713957 & 413900071395701 & -- & $\mathrm{D}$ & -- & 19.6 & 30 & W & -- & -- \\
\hline WGW 76 & 413841 & 714059 & 413841071405901 & -- & $\mathrm{D}$ & -- & 8.5 & 40 & W & -- & -- \\
\hline WGW 79 & 413845 & 714011 & 413845071401101 & -- & $\mathrm{D}$ & -- & 21.7 & 30 & W & -- & -- \\
\hline
\end{tabular}




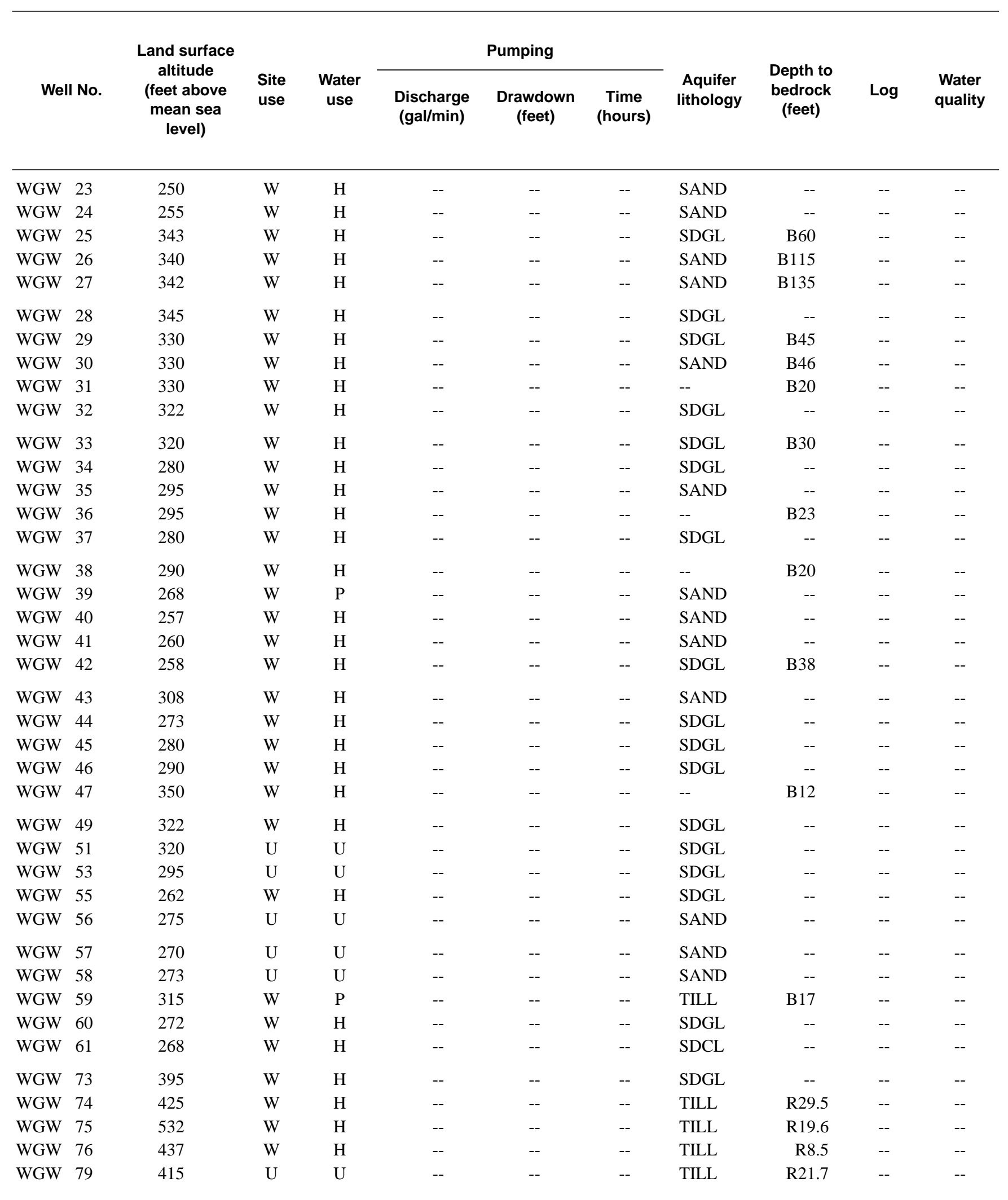


Table 1. Ground-water data-collection sites in the Big-Mishnock stream-aquifer system, central Rhode Island—Continued

\begin{tabular}{|c|c|c|c|c|c|c|c|c|c|c|c|}
\hline \multirow{3}{*}{ Well No. } & \multirow{3}{*}{$\begin{array}{c}\text { Latitude } \\
0, \prime \prime\end{array}$} & \multirow{3}{*}{$\begin{array}{c}\text { Longitude } \\
\text { o," }\end{array}$} & \multirow{3}{*}{$\begin{array}{c}\text { Site } \\
\text { identification }\end{array}$} & \multicolumn{8}{|c|}{ Construction } \\
\hline & & & & \multirow{2}{*}{ Year } & \multirow{2}{*}{ Method } & \multirow{2}{*}{$\begin{array}{c}\text { Hole } \\
\text { depth } \\
\text { (feet } \\
\text { below } \\
\text { land } \\
\text { surface) }\end{array}$} & \multirow{2}{*}{$\begin{array}{l}\text { Well } \\
\text { depth } \\
\text { (feet) }\end{array}$} & \multicolumn{2}{|c|}{ Casing } & \multicolumn{2}{|c|}{$\begin{array}{l}\text { Screened interval } \\
\text { (feet below land } \\
\text { surface) }\end{array}$} \\
\hline & & & & & & & & $\begin{array}{l}\text { Diameter } \\
\text { (inches) }\end{array}$ & Finish & Top & Bottom \\
\hline WGW 80 & 413859 & 714050 & 413859071405001 & 1951 & $\mathrm{C}$ & -- & 160 & 6 & $\mathrm{X}$ & -- & -- \\
\hline WGW 81 & 413903 & 713914 & 413903071391401 & -- & $\mathrm{D}$ & -- & 14.3 & 30 & W & -- & -- \\
\hline WGW 82 & 413902 & 713844 & 413902071384401 & -- & $\mathrm{D}$ & -- & 15.6 & 30 & W & -- & -- \\
\hline WGW 93 & 413928 & 714133 & 413928071413301 & -- & D & -- & 16.7 & 40 & W & -- & -- \\
\hline WGW 94 & 413840 & 713739 & 413840071373901 & 1944 & $\mathrm{C}$ & -- & 150 & 6 & $\mathrm{X}$ & -- & -- \\
\hline WGW 95 & 413849 & 713742 & 413849071374201 & -- & $\mathrm{D}$ & -- & 20.4 & 36 & W & -- & -- \\
\hline WGW 96 & 413850 & 713748 & 413850071374801 & 1937 & $\mathrm{C}$ & -- & 145 & 6 & $\mathrm{X}$ & -- & -- \\
\hline WGW 97 & 413848 & 713745 & 413848071374501 & 1944 & $\mathrm{C}$ & -- & 58 & 6 & $\mathrm{X}$ & -- & -- \\
\hline WGW 99 & 413834 & 713731 & 413834071373101 & -- & $\mathrm{C}$ & -- & 35 & 6 & $\mathrm{X}$ & -- & -- \\
\hline WGW 100 & 413858 & 713800 & 413858071380001 & -- & D & -- & 17.2 & 30 & W & -- & -- \\
\hline WGW 101 & 413853 & 713822 & 413853071382201 & -- & $\mathrm{D}$ & -- & 13.2 & 24 & $\mathrm{O}$ & -- & -- \\
\hline WGW 107 & 413923 & 714038 & 413923071403801 & -- & $\mathrm{D}$ & -- & 11.9 & 30 & W & -- & -- \\
\hline WGW 108 & 413928 & 714039 & 413928071403901 & -- & $\mathrm{D}$ & -- & 18.2 & 24 & W & -- & -- \\
\hline WGW 109 & 413905 & 714020 & 413905071402001 & -- & $\mathrm{D}$ & -- & 12.1 & 30 & W & -- & -- \\
\hline WGW 110 & 413830 & 713736 & 413830071373601 & -- & $\mathrm{C}$ & -- & 47 & 6 & $\mathrm{X}$ & -- & -- \\
\hline WGW 111 & 413822 & 713731 & 413822071373101 & 1932 & $\mathrm{C}$ & -- & 31 & 6 & $\mathrm{X}$ & -- & -- \\
\hline WGW 112 & 413819 & 713730 & 413819071373001 & 1949 & $\mathrm{C}$ & -- & 40 & 6 & $\mathrm{X}$ & -- & -- \\
\hline WGW 114 & 413813 & 713734 & 413813071373401 & 1948 & $\mathrm{C}$ & -- & 46 & 6 & $\mathrm{X}$ & -- & -- \\
\hline WGW 115 & 413752 & 713740 & 413752071374001 & 1931 & $\mathrm{C}$ & -- & 109 & 6 & $\mathrm{X}$ & -- & -- \\
\hline WGW 116 & 413750 & 713745 & 413750071374501 & -- & $\mathrm{D}$ & -- & 22.3 & 30 & $\mathrm{O}$ & -- & -- \\
\hline WGW 117 & 413745 & 713741 & 413745071374101 & 1948 & $\mathrm{D}$ & -- & 15 & 30 & $\mathrm{O}$ & -- & -- \\
\hline WGW 118 & 413754 & 713746 & 413754071374601 & 1951 & $\mathrm{D}$ & -- & 20 & 30 & $\mathrm{O}$ & -- & -- \\
\hline WGW 119 & 413731 & 713804 & 413731071380401 & -- & $\mathrm{D}$ & -- & 16 & 30 & W & -- & -- \\
\hline WGW 120 & 413751 & 713756 & 413751071375601 & 1951 & $\mathrm{C}$ & -- & 95 & 6 & $\mathrm{X}$ & -- & -- \\
\hline WGW 121 & 413750 & 713752 & 413750071375201 & -- & $\mathrm{J}$ & -- & 22 & 1.5 & $\mathrm{~T}$ & -- & -- \\
\hline WGW 122 & 413752 & 713755 & 413752071375501 & 1951 & $\mathrm{C}$ & -- & 38 & 6 & $\mathrm{X}$ & -- & -- \\
\hline WGW 123 & 413915 & 713950 & 413915071395001 & -- & $\mathrm{D}$ & -- & 25 & 30 & W & -- & -- \\
\hline WGW 124 & 413926 & 713945 & 413926071394501 & -- & $\mathrm{D}$ & -- & 15.6 & 30 & W & -- & -- \\
\hline WGW 125 & 413931 & 713940 & 413931071394001 & -- & $\mathrm{D}$ & -- & 16 & 30 & $\mathrm{O}$ & -- & -- \\
\hline WGW 126 & 413933 & 713810 & 413933071381001 & -- & $\mathrm{D}$ & -- & 31 & 30 & W & -- & -- \\
\hline WGW 152 & 413730 & 714014 & 413730071401401 & -- & $\mathrm{D}$ & -- & 26.5 & 30 & $\mathrm{O}$ & -- & -- \\
\hline WGW 153 & 413724 & 714011 & 413724071401101 & -- & $\mathrm{D}$ & -- & 23.9 & 30 & -- & -- & -- \\
\hline WGW 154 & 413703 & 713944 & 413703071394401 & -- & $\mathrm{D}$ & -- & 16.3 & 30 & W & -- & -- \\
\hline WGW 155 & 413716 & 713923 & 413716071392301 & -- & $\mathrm{D}$ & -- & 20.5 & 30 & W & -- & -- \\
\hline WGW 156 & 413706 & 713825 & 413706071382501 & -- & $\mathrm{D}$ & -- & 19.8 & 36 & W & -- & -- \\
\hline WGW 157 & 413705 & 713825 & 413705071382501 & 1952 & $\mathrm{D}$ & -- & 12.4 & 24 & $\mathrm{O}$ & -- & -- \\
\hline WGW 158 & 413659 & 713810 & 413659071381001 & -- & $\mathrm{D}$ & -- & 24.3 & 30 & W & -- & -- \\
\hline WGW 159 & 413657 & 713812 & 413657071381201 & -- & $\mathrm{D}$ & -- & 19 & 30 & W & -- & -- \\
\hline WGW 160 & 413652 & 713759 & 413652071375901 & -- & $\mathrm{D}$ & -- & 36.3 & 30 & $\mathrm{X}$ & -- & -- \\
\hline WGW 161 & 413644 & 713749 & 413644071374901 & -- & $\mathrm{D}$ & -- & 14.4 & 36 & W & -- & -- \\
\hline
\end{tabular}




\begin{tabular}{|c|c|c|c|c|c|c|c|c|c|c|}
\hline \multirow[b]{2}{*}{ Well No. } & \multirow{2}{*}{$\begin{array}{l}\text { Land surface } \\
\text { altitude } \\
\text { (feet above } \\
\text { mean sea } \\
\text { level) }\end{array}$} & \multirow[b]{2}{*}{$\begin{array}{l}\text { Site } \\
\text { use }\end{array}$} & \multirow[b]{2}{*}{$\begin{array}{c}\text { Water } \\
\text { use }\end{array}$} & \multicolumn{3}{|c|}{ Pumping } & \multirow[b]{2}{*}{$\begin{array}{l}\text { Aquifer } \\
\text { lithology }\end{array}$} & \multirow[b]{2}{*}{$\begin{array}{l}\text { Depth to } \\
\text { bedrock } \\
\text { (feet) }\end{array}$} & \multirow[b]{2}{*}{$\log$} & \multirow[b]{2}{*}{$\begin{array}{l}\text { Water } \\
\text { quality }\end{array}$} \\
\hline & & & & $\begin{array}{c}\text { Discharge } \\
\text { (gal/min) }\end{array}$ & $\begin{array}{l}\text { Drawdown } \\
\text { (feet) }\end{array}$ & $\begin{array}{c}\text { Time } \\
\text { (hours) }\end{array}$ & & & & \\
\hline WGW 80 & 495 & W & $\mathrm{H}$ & -- & -- & -- & TILL & B17 & -- & -- \\
\hline WGW 81 & 450 & W & $\mathrm{H}$ & -- & -- & -- & TILL & $\mathrm{R} 14.3$ & -- & -- \\
\hline WGW 82 & 425 & $\mathrm{~W}$ & $\mathrm{H}$ & -- & -- & -- & TILL & $\mathrm{R} 15.6$ & -- & -- \\
\hline WGW 93 & 585 & $\mathrm{~W}$ & $\mathrm{H}$ & -- & -- & -- & TILL & $\mathrm{R} 16.7$ & -- & -- \\
\hline WGW 94 & 348 & W & $\mathrm{H}$ & -- & -- & -- & TILL & B28 & -- & -- \\
\hline WGW 95 & 360 & $\mathrm{~W}$ & $\mathrm{H}$ & -- & -- & -- & TILL & R20.4 & -- & -- \\
\hline WGW 96 & 375 & $\mathrm{~W}$ & $\mathrm{H}$ & -- & -- & -- & TILL & B12 & -- & -- \\
\hline WGW 97 & 365 & W & $\mathrm{H}$ & -- & -- & -- & TILL & B8 & -- & -- \\
\hline WGW 99 & 328 & $\mathrm{~W}$ & $\mathrm{H}$ & -- & -- & -- & SDGL & B16 & -- & -- \\
\hline WGW 100 & 395 & W & $\mathrm{H}$ & -- & -- & -- & TILL & $\mathrm{R} 17.2$ & -- & -- \\
\hline WGW 101 & 445 & W & $\mathrm{H}$ & -- & -- & -- & TILL & $\mathrm{R} 13.2$ & -- & -- \\
\hline WGW 107 & 408 & W & $\mathrm{H}$ & -- & -- & -- & SDGL & -- & -- & -- \\
\hline WGW 108 & 430 & W & $\mathrm{H}$ & -- & -- & -- & SDGL & -- & -- & -- \\
\hline WGW 109 & 412 & $\mathrm{~W}$ & $\mathrm{H}$ & -- & -- & -- & SAND & -- & -- & -- \\
\hline WGW 110 & 345 & W & $\mathrm{H}$ & -- & -- & -- & TILL & B17 & -- & -- \\
\hline WGW 111 & 330 & $\mathrm{~W}$ & $\mathrm{H}$ & -- & -- & -- & -- & B18 & -- & -- \\
\hline WGW 112 & 320 & W & $\mathrm{H}$ & -- & -- & -- & -- & B20 & -- & -- \\
\hline WGW 114 & 335 & $\mathrm{~W}$ & $\mathrm{H}$ & -- & -- & -- & -- & B7 & -- & -- \\
\hline WGW 115 & 345 & $\mathrm{~W}$ & $\mathrm{H}$ & -- & -- & -- & SAND & B14 & -- & -- \\
\hline WGW 116 & 340 & $\mathrm{~W}$ & $\mathrm{H}$ & -- & -- & -- & SDGL & -- & -- & -- \\
\hline WGW 117 & 310 & $\mathrm{~W}$ & $\mathrm{H}$ & -- & -- & -- & TILL & B14 & -- & -- \\
\hline WGW 118 & 335 & W & $\mathrm{H}$ & -- & -- & -- & SDGL & -- & -- & -- \\
\hline WGW 119 & 315 & $\mathrm{~W}$ & $\mathrm{H}$ & -- & -- & -- & SAND & -- & -- & -- \\
\hline WGW 120 & 335 & W & $\mathrm{H}$ & -- & -- & -- & SAND & B18 & -- & -- \\
\hline WGW 121 & 332 & $\mathrm{~W}$ & $\mathrm{H}$ & -- & -- & -- & SDGL & -- & -- & -- \\
\hline WGW 122 & 335 & $\mathrm{~W}$ & $\mathrm{H}$ & -- & -- & -- & SAND & B10 & -- & -- \\
\hline WGW 123 & 575 & $\mathrm{~W}$ & $\mathrm{H}$ & -- & -- & -- & TILL & $\mathrm{R} 25$ & -- & -- \\
\hline WGW 124 & 580 & W & $\mathrm{H}$ & -- & -- & -- & TILL & R15.6 & -- & -- \\
\hline WGW 125 & 566 & W & $\mathrm{H}$ & -- & -- & -- & TILL & $\mathrm{R} 16$ & -- & -- \\
\hline WGW 126 & 395 & $\mathrm{~W}$ & $\mathrm{H}$ & -- & -- & -- & TILL & $\mathrm{R} 31$ & -- & -- \\
\hline WGW 152 & 572 & $\mathrm{~W}$ & $\mathrm{H}$ & -- & -- & -- & TILL & $\mathrm{R} 26.5$ & -- & -- \\
\hline WGW 153 & 580 & W & $\mathrm{H}$ & -- & -- & -- & TILL & R23.9 & -- & -- \\
\hline WGW 154 & 470 & $\mathrm{U}$ & $\mathrm{U}$ & -- & -- & -- & TILL & R16.3 & -- & -- \\
\hline WGW 155 & 413 & $\mathrm{~W}$ & $\mathrm{H}$ & -- & -- & -- & SDGL & -- & -- & -- \\
\hline WGW 156 & 465 & W & $\mathrm{H}$ & -- & -- & -- & TILL & R19.8 & -- & -- \\
\hline WGW 157 & 465 & $\mathrm{~W}$ & $\mathrm{H}$ & -- & -- & -- & TILL & $\mathrm{R} 12.4$ & -- & -- \\
\hline WGW 158 & 475 & W & $\mathrm{H}$ & -- & -- & -- & TILL & $\mathrm{R} 24.3$ & -- & -- \\
\hline WGW 159 & 475 & $\mathrm{U}$ & $\mathrm{U}$ & -- & -- & -- & TILL & $\mathrm{R} 19$ & -- & -- \\
\hline WGW 160 & 445 & $\mathrm{~W}$ & $\mathrm{H}$ & -- & -- & -- & TILL & B32 & -- & -- \\
\hline WGW 161 & 410 & $\mathrm{~W}$ & $\mathrm{H}$ & -- & -- & -- & TILL & $\mathrm{R} 14.4$ & -- & -- \\
\hline
\end{tabular}


Table 1. Ground-water data-collection sites in the Big-Mishnock stream-aquifer system, central Rhode Island—Continued

\begin{tabular}{|c|c|c|c|c|c|c|c|c|c|c|c|}
\hline \multirow{3}{*}{ Well No. } & \multirow{3}{*}{$\begin{array}{c}\text { Latitude } \\
0,{ }^{\prime}\end{array}$} & \multirow{3}{*}{$\begin{array}{c}\text { Longitude } \\
\text { o," }\end{array}$} & \multirow{3}{*}{$\begin{array}{c}\text { Site } \\
\text { identification }\end{array}$} & \multicolumn{8}{|c|}{ Construction } \\
\hline & & & & \multirow{2}{*}{ Year } & \multirow{2}{*}{ Method } & \multirow{2}{*}{$\begin{array}{c}\text { Hole } \\
\text { depth } \\
\text { (feet } \\
\text { below } \\
\text { land } \\
\text { surface) }\end{array}$} & \multirow{2}{*}{$\begin{array}{l}\text { Well } \\
\text { depth } \\
\text { (feet) }\end{array}$} & \multicolumn{2}{|c|}{ Casing } & \multicolumn{2}{|c|}{$\begin{array}{l}\text { Screened interval } \\
\text { (feet below land } \\
\text { surface) }\end{array}$} \\
\hline & & & & & & & & $\begin{array}{l}\text { Diameter } \\
\text { (inches) }\end{array}$ & Finish & Top & Bottom \\
\hline WGW 186 & 413630 & 713949 & 413630071394901 & -- & $\mathrm{D}$ & -- & 16.2 & 30 & W & -- & -- \\
\hline WGW 187 & 413619 & 713917 & 413619071391701 & -- & $\mathrm{D}$ & -- & 21 & 30 & W & -- & -- \\
\hline WGW 188 & 413640 & 713954 & 413640071395401 & 1938 & $\mathrm{D}$ & -- & 22 & 30 & $\mathrm{O}$ & -- & -- \\
\hline WGW 189 & 413636 & 713954 & 413636071395401 & -- & D & -- & 18.9 & 30 & W & -- & -- \\
\hline WGW 190 & 413647 & 713950 & 413647071395001 & -- & D & -- & 15.7 & 30 & W & -- & -- \\
\hline WGW 193 & 413609 & 713838 & 413609071383801 & 1945 & $\mathrm{D}$ & -- & 27.8 & 30 & $\mathrm{O}$ & -- & -- \\
\hline WGW 194 & 413637 & 713819 & 413637071381901 & 1949 & $\mathrm{D}$ & -- & 26.7 & 30 & $\mathrm{O}$ & -- & -- \\
\hline WGW 195 & 413643 & 713816 & 413643071381601 & 1953 & $\mathrm{C}$ & -- & 50 & 6 & $\mathrm{X}$ & -- & -- \\
\hline WGW 196 & 413704 & 713810 & 413704071381001 & 1948 & D & -- & 17.7 & 30 & $\mathrm{O}$ & -- & -- \\
\hline WGW 197 & 413707 & 713806 & 413707071380601 & -- & $\mathrm{C}$ & -- & 200 & 6 & $\mathrm{X}$ & -- & -- \\
\hline WGW 198 & 413714 & 713812 & 413714071381201 & -- & $\mathrm{D}$ & -- & 19.9 & 30 & W & -- & -- \\
\hline WGW 199 & 413721 & 713810 & 413721071381001 & -- & -- & -- & 16.4 & -- & -- & -- & -- \\
\hline WGW 200 & 413731 & 713802 & 413731071380201 & -- & $\mathrm{D}$ & -- & 11.7 & 24 & W & -- & -- \\
\hline WGW 209 & 413720 & 713359 & 413720071335901 & -- & $\mathrm{D}$ & -- & 17 & 36 & W & -- & -- \\
\hline WGW 210 & 413607 & 713619 & 413607071361901 & -- & $\mathrm{D}$ & -- & 16.3 & 30 & W & -- & -- \\
\hline WGW 211 & 413617 & 713629 & 413617071362901 & -- & D & 15.9 & 15.9 & -- & W & -- & -- \\
\hline WGW 215 & 413635 & 713711 & 413635071371102 & -- & $\mathrm{V}$ & -- & 10 & 2 & -- & -- & -- \\
\hline WGW 216 & 413654 & 713656 & 413654071365601 & -- & $\mathrm{D}$ & -- & 26.6 & 30 & W & -- & -- \\
\hline WGW 217 & 413653 & 713654 & 413653071365401 & -- & D & -- & 25.7 & 30 & W & -- & -- \\
\hline WGW 219 & 413923 & 713558 & 413923071355801 & 1952 & $\mathrm{C}$ & -- & 100 & 6 & $\mathrm{O}$ & -- & -- \\
\hline WGW 222 & 413842 & 713647 & 413842071364701 & -- & -- & -- & 45.5 & 2.5 & $\mathrm{O}$ & -- & -- \\
\hline WGW 226 & 413737 & 713758 & 413737071375801 & -- & -- & -- & 18.5 & 2.5 & $\mathrm{O}$ & -- & -- \\
\hline WGW 229 & 413913 & 713512 & 413913071351201 & 1952 & $\mathrm{C}$ & -- & 134 & 6 & $\mathrm{X}$ & -- & -- \\
\hline WGW 230 & 413919 & 713538 & 413919071353801 & 1953 & $\mathrm{C}$ & -- & 112 & 6 & $\mathrm{O}$ & -- & -- \\
\hline WGW 232 & 413852 & 713654 & 413852071365401 & 1956 & W & -- & 81 & 2 & $\mathrm{O}$ & -- & -- \\
\hline WGW 233 & 413852 & 713653 & 413852071365301 & 1956 & W & -- & 75 & 2 & $\mathrm{O}$ & -- & -- \\
\hline WGW 234 & 413853 & 713652 & 413853071365201 & 1956 & W & -- & 52.3 & 2 & $\mathrm{O}$ & -- & -- \\
\hline WGW 235 & 413853 & 713650 & 413853071365001 & 1956 & W & -- & 48.3 & 2 & $\mathrm{O}$ & -- & -- \\
\hline WGW 236 & 413854 & 713648 & 413854071364801 & 1956 & W & -- & 43 & 2 & $\mathrm{O}$ & -- & -- \\
\hline WGW 243 & 413903 & 713623 & 413903071362301 & 1956 & W & -- & 23.6 & 2 & $\mathrm{O}$ & -- & -- \\
\hline WGW 254 & 413933 & 713255 & 413933071325501 & 1956 & W & -- & 31 & 2 & $\mathrm{O}$ & -- & -- \\
\hline WGW 258 & 413932 & 713302 & 413932071330201 & -- & W & -- & 21.5 & 2 & $\mathrm{O}$ & -- & -- \\
\hline WGW 259 & 413906 & 713417 & 413906071341701 & -- & W & -- & 30 & 2 & $\mathrm{O}$ & -- & -- \\
\hline WGW 260 & 413855 & 713514 & 413855071351401 & -- & W & -- & 50 & 2 & $\mathrm{O}$ & -- & -- \\
\hline WGW 261 & 413857 & 713523 & 413857071352301 & -- & W & -- & 50 & 2 & $\mathrm{O}$ & -- & -- \\
\hline WGW 262 & 413859 & 713536 & 413859071353601 & -- & W & -- & 30 & 2 & $\mathrm{O}$ & -- & -- \\
\hline WGW 263 & 413859 & 713543 & 413859071354301 & -- & W & -- & 30 & 2 & $\mathrm{O}$ & -- & -- \\
\hline WGW 264 & 413901 & 713606 & 413901071360601 & 1956 & W & -- & 40 & 2 & $\mathrm{O}$ & -- & -- \\
\hline WGW 265 & 413902 & 713610 & 413902071361001 & -- & W & -- & 37.5 & 2 & $\mathrm{O}$ & -- & -- \\
\hline WGW 266 & 413902 & 713613 & 413902071361301 & -- & W & -- & 33.8 & 2 & $\mathrm{X}$ & -- & -- \\
\hline
\end{tabular}




\begin{tabular}{|c|c|c|c|c|c|c|c|c|c|c|}
\hline \multirow[b]{2}{*}{ Well No. } & \multirow{2}{*}{$\begin{array}{l}\text { Land surface } \\
\text { altitude } \\
\text { (feet above } \\
\text { mean sea } \\
\text { level) }\end{array}$} & \multirow[b]{2}{*}{$\begin{array}{l}\text { Site } \\
\text { use }\end{array}$} & \multirow[b]{2}{*}{$\begin{array}{c}\text { Water } \\
\text { use }\end{array}$} & \multicolumn{3}{|c|}{ Pumping } & \multirow[b]{2}{*}{$\begin{array}{l}\text { Aquifer } \\
\text { lithology }\end{array}$} & \multirow{2}{*}{$\begin{array}{c}\text { Depth to } \\
\text { bedrock } \\
\text { (feet) }\end{array}$} & \multirow[b]{2}{*}{ Log } & \multirow[b]{2}{*}{$\begin{array}{l}\text { Water } \\
\text { quality }\end{array}$} \\
\hline & & & & $\begin{array}{c}\text { Discharge } \\
\text { (gal/min) }\end{array}$ & $\begin{array}{l}\text { Drawdown } \\
\text { (feet) }\end{array}$ & $\begin{array}{c}\text { Time } \\
\text { (hours) }\end{array}$ & & & & \\
\hline WGW 186 & 443 & $\mathrm{~W}$ & $\mathrm{H}$ & -- & -- & -- & TILL & $\mathrm{R} 16.2$ & -- & -- \\
\hline WGW 187 & 425 & $\mathrm{~W}$ & $\mathrm{H}$ & -- & -- & -- & TILL & $\mathrm{R} 21$ & -- & -- \\
\hline WGW 188 & 480 & W & $\mathrm{H}$ & -- & -- & -- & TILL & $\mathrm{R} 22$ & -- & -- \\
\hline WGW 189 & 468 & $\mathrm{U}$ & $\mathrm{U}$ & -- & -- & -- & TILL & R18.9 & -- & -- \\
\hline WGW 190 & 475 & $\mathrm{~W}$ & $\mathrm{H}$ & -- & -- & -- & TILL & $\mathrm{R} 15.7$ & -- & -- \\
\hline WGW 193 & 515 & $\mathrm{~W}$ & $\mathrm{H}$ & -- & -- & -- & TILL & $\mathrm{R} 27.8$ & -- & -- \\
\hline WGW 194 & 500 & W & $\mathrm{H}$ & -- & -- & -- & TILL & $\mathrm{R} 26.7$ & -- & -- \\
\hline WGW 195 & 480 & W & $\mathrm{H}$ & -- & -- & -- & TILL & B12 & -- & -- \\
\hline WGW 196 & 455 & W & $\mathrm{H}$ & -- & -- & -- & TILL & $\mathrm{R} 17.7$ & -- & -- \\
\hline WGW 197 & 440 & $\mathrm{~W}$ & $\mathrm{H}$ & -- & -- & -- & TILL & B30 & -- & -- \\
\hline WGW 198 & 420 & $\mathrm{~W}$ & $\mathrm{H}$ & -- & -- & -- & TILL & R19.9 & -- & -- \\
\hline WGW 199 & 373 & $\mathrm{~W}$ & $\mathrm{H}$ & -- & -- & -- & TILL & R16.4 & -- & -- \\
\hline WGW 200 & 310 & W & $\mathrm{H}$ & -- & -- & -- & SDGL & -- & -- & -- \\
\hline WGW 209 & 467 & $\mathrm{~W}$ & $\mathrm{H}$ & -- & -- & -- & TILL & $\mathrm{R} 17$ & -- & -- \\
\hline WGW 210 & 370 & $\mathrm{U}$ & $\mathrm{U}$ & -- & -- & -- & SDGL & -- & -- & -- \\
\hline WGW 211 & 353.56 & $\mathrm{U}$ & $\mathrm{U}$ & -- & -- & -- & SAND & -- & -- & -- \\
\hline WGW 215 & 310 & $\mathrm{~W}$ & $\mathrm{H}$ & -- & -- & -- & SDGL & -- & -- & -- \\
\hline WGW 216 & 305 & W & $\mathrm{H}$ & -- & -- & -- & SDGL & -- & -- & -- \\
\hline WGW 217 & 310 & W & $\mathrm{S}$ & -- & -- & -- & SDGL & -- & -- & -- \\
\hline WGW 219 & 255 & $\mathrm{U}$ & $\mathrm{U}$ & -- & -- & -- & SDST & -- & -- & -- \\
\hline WGW 222 & 249 & $\mathrm{~T}$ & $\mathrm{U}$ & -- & -- & -- & SAND & -- & -- & -- \\
\hline WGW 226 & 264 & $\mathrm{~T}$ & $\mathrm{U}$ & -- & -- & -- & SDGL & -- & -- & -- \\
\hline WGW 229 & 272 & $\mathrm{~W}$ & $\mathrm{H}$ & 5 & -- & -- & SAND & B120 & -- & -- \\
\hline WGW 230 & 255 & W & $\mathrm{H}$ & -- & -- & -- & GRVL & -- & -- & -- \\
\hline WGW 232 & 249.9 & $\mathrm{~T}$ & $\mathrm{U}$ & -- & -- & -- & SDST & -- & -- & -- \\
\hline WGW 233 & 248.5 & $\mathrm{~T}$ & $\mathrm{U}$ & -- & -- & -- & SDGL & -- & -- & -- \\
\hline WGW 234 & 247.6 & $\mathrm{~T}$ & $\mathrm{U}$ & -- & -- & -- & SDGL & B52.3 & -- & -- \\
\hline WGW 235 & 251.9 & $\mathrm{~T}$ & $\mathrm{U}$ & -- & -- & -- & SDGL & B48.3 & -- & -- \\
\hline WGW 236 & 256.1 & $\mathrm{~T}$ & $\mathrm{U}$ & -- & -- & -- & SDGL & B43 & -- & -- \\
\hline WGW 243 & 330.55 & $\mathrm{~T}$ & $\mathrm{U}$ & -- & -- & -- & TILL & B13.6 & -- & -- \\
\hline WGW 254 & 356.7 & $\mathrm{~T}$ & $\mathrm{U}$ & -- & -- & -- & SDGL & -- & -- & -- \\
\hline WGW 258 & 325 & $\mathrm{~T}$ & $\mathrm{U}$ & -- & -- & -- & SDGL & -- & -- & -- \\
\hline WGW 259 & 315 & $\mathrm{~T}$ & $\mathrm{U}$ & -- & -- & -- & SDST & -- & -- & -- \\
\hline WGW 260 & 324.5 & $\mathrm{~T}$ & $\mathrm{U}$ & -- & -- & -- & SAND & -- & -- & -- \\
\hline WGW 261 & 310 & $\mathrm{~T}$ & $\mathrm{U}$ & -- & -- & -- & SDGL & -- & -- & -- \\
\hline WGW 262 & 331.5 & $\mathrm{~T}$ & $\mathrm{U}$ & -- & -- & -- & SDGL & -- & -- & -- \\
\hline WGW 263 & 320 & $\mathrm{~T}$ & $\mathrm{U}$ & -- & -- & -- & SAND & -- & -- & -- \\
\hline WGW 264 & 283.8 & $\mathrm{~T}$ & $\mathrm{U}$ & -- & -- & -- & SDGL & -- & -- & -- \\
\hline WGW 265 & 279 & $\mathrm{~T}$ & $\mathrm{U}$ & -- & -- & -- & SDST & -- & -- & -- \\
\hline WGW 266 & 269 & $\mathrm{~T}$ & $\mathrm{U}$ & -- & -- & -- & SDGL & B23.8 & -- & -- \\
\hline
\end{tabular}


Table 1. Ground-water data-collection sites in the Big-Mishnock stream-aquifer system, central Rhode Island—Continued

\begin{tabular}{|c|c|c|c|c|c|c|c|c|c|c|c|}
\hline \multirow{3}{*}{ Well No. } & \multirow{3}{*}{$\begin{array}{l}\text { Latitude } \\
\circ, \prime \prime\end{array}$} & \multirow{3}{*}{ Longitude } & \multirow{3}{*}{$\begin{array}{c}\text { Site } \\
\text { identification }\end{array}$} & \multicolumn{8}{|c|}{ Construction } \\
\hline & & & & \multirow{2}{*}{ Year } & \multirow{2}{*}{ Method } & \multirow{2}{*}{$\begin{array}{c}\text { Hole } \\
\text { depth } \\
\text { (feet } \\
\text { below } \\
\text { land } \\
\text { surface) }\end{array}$} & \multirow{2}{*}{$\begin{array}{l}\text { Well } \\
\text { depth } \\
\text { (feet) }\end{array}$} & \multicolumn{2}{|c|}{ Casing } & \multicolumn{2}{|c|}{$\begin{array}{l}\text { Screened interval } \\
\text { (feet below land } \\
\text { surface) }\end{array}$} \\
\hline & & & & & & & & $\begin{array}{l}\text { Diameter } \\
\text { (inches) }\end{array}$ & Finish & Top & Bottom \\
\hline WGW 267 & 413902 & 713617 & 413902071361701 & -- & W & -- & 40.3 & 2 & $\mathrm{O}$ & -- & -- \\
\hline WGW 268 & 413901 & 713619 & 413901071361901 & -- & W & -- & 16 & 2 & $\mathrm{X}$ & -- & -- \\
\hline WGW 269 & 413904 & 713630 & 413904071363001 & -- & W & -- & 20.4 & 2 & $\mathrm{X}$ & -- & -- \\
\hline WGW 270 & 413909 & 713649 & 413909071364901 & -- & W & -- & 26 & 2 & $\mathrm{X}$ & -- & -- \\
\hline WGW 271 & 413842 & 713643 & 413842071364301 & 1962 & B & -- & 44 & -- & -- & -- & -- \\
\hline WGW 272 & 413839 & 713700 & 413839071370001 & 1962 & B & -- & 52 & -- & -- & -- & -- \\
\hline WGW 273 & 413800 & 713638 & 413800071363801 & 1962 & B & -- & 78 & -- & -- & -- & -- \\
\hline WGW 274 & 413854 & 713604 & 413854071360401 & 1962 & B & -- & 54 & -- & -- & -- & -- \\
\hline WGW 275 & 413850 & 713539 & 413850071353901 & 1962 & B & -- & 122 & -- & -- & -- & -- \\
\hline WGW 276 & 413847 & 713512 & 413847071351201 & 1962 & B & -- & 107 & -- & -- & -- & -- \\
\hline WGW 277 & 413852 & 713447 & 413852071344701 & 1962 & B & -- & 10 & -- & -- & -- & -- \\
\hline WGW 278 & 413907 & 713401 & 413907071340101 & 1962 & B & -- & 29 & -- & -- & -- & -- \\
\hline WGW 285 & 413739 & 713756 & 413739071375601 & 1996 & B & 31.5 & 21 & 2 & $\mathrm{~S}$ & 18 & 21 \\
\hline WGW 286 & 413635 & 713711 & 413635071371101 & 1996 & B & 64 & 57.2 & 2 & $\mathrm{~S}$ & 54.2 & 57.2 \\
\hline WGW 287 & 413656 & 713706 & 413656071370601 & 1996 & B & 22.6 & 22.6 & 2 & S & 19.6 & 22.6 \\
\hline WGW 288 & 413720 & 713634 & 413720071363401 & 1996 & B & 23 & 23 & -- & -- & -- & -- \\
\hline WGW 289 & 413755 & 713639 & 413755071363901 & 1996 & B & 79.5 & 79.4 & 2 & $\mathrm{~S}$ & 73.7 & 79.4 \\
\hline WGW 290 & 413755 & 713639 & 413755071363902 & 1996 & B & 29.5 & 29.5 & 2 & $\mathrm{~S}$ & 26.5 & 29.5 \\
\hline WGW 291 & 413756 & 713704 & 413756071370401 & 1996 & B & 58 & 17.9 & 2 & $\mathrm{~S}$ & 14.9 & 17.9 \\
\hline WGW 292 & 413829 & 713634 & 413829071363401 & 1996 & B & 73 & 72.8 & 2 & $\mathrm{~S}$ & 67.8 & 72.8 \\
\hline WGW 293 & 413829 & 713634 & 413829071363402 & 1996 & B & 23.2 & 21 & 2 & $\mathrm{~S}$ & 18 & 21 \\
\hline WGW 294 & 413734 & 713545 & 413734071354501 & 1996 & B & 21.5 & 21.5 & 2 & $\mathrm{~S}$ & 18.5 & 21.5 \\
\hline WGW 295 & 413804 & 713448 & 413804071344801 & 1996 & B & 24 & 24 & 2 & $\mathrm{~S}$ & 21 & 24 \\
\hline WGW 296 & 413824 & 713424 & 413824071342401 & 1996 & B & 41.9 & 41.9 & 2 & $\mathrm{~S}$ & 38.9 & 41.9 \\
\hline WGW 297 & 413909 & 713431 & 413909071343101 & 1996 & B & 60.9 & 60.9 & 2 & $\mathrm{~S}$ & 57.9 & 60.9 \\
\hline WGW 298 & 413850 & 713530 & 413850071353001 & 1996 & B & 34 & 34 & 2 & $\mathrm{~S}$ & 31 & 34 \\
\hline WGW 299 & 413834 & 713455 & 413834071345501 & 1996 & B & 44.5 & 44.4 & 2 & $\mathrm{~S}$ & 41.5 & 44.5 \\
\hline WGW 300 & 413845 & 713508 & 413845071350801 & 1996 & B & 23.5 & 23.5 & 2 & $\mathrm{~S}$ & 20.5 & 23.5 \\
\hline WGW 301 & 413845 & 713508 & 413845071350802 & 1996 & B & 150 & 137 & 2 & $\mathrm{~S}$ & 127 & 137 \\
\hline WGW 302 & 413901 & 713547 & 413901071354701 & 1996 & B & 83 & 83 & 2 & $\mathrm{~S}$ & 78 & 83 \\
\hline WGW 303 & 413837 & 713711 & 413837071371101 & 1996 & B & 81 & 80.8 & 2 & $\mathrm{~S}$ & 45.8 & 50.8 \\
\hline WGW 304 & 413924 & 713736 & 413924071373601 & 1996 & B & 56 & 55.7 & 2 & $\mathrm{~S}$ & 49.7 & 55.7 \\
\hline WGW 305 & 413849 & 713708 & 413849071370801 & -- & -- & 13.9 & 13.9 & -- & -- & -- & -- \\
\hline WGW 306 & 413836 & 713513 & 413836071351301 & 1996 & W & 183 & 179 & 2.5 & $\mathrm{~S}$ & 169 & 179 \\
\hline WGW 307 & 413842 & 713509 & 413842071350901 & 1996 & $\mathrm{~W}$ & 135 & 127 & 2.5 & $S$ & 119 & 127 \\
\hline WGW 308 & 413837 & 713450 & 413837071345001 & 1996 & $\mathrm{~W}$ & 131 & 131 & 2.5 & $\mathrm{~S}$ & 126 & 131 \\
\hline WGW 309 & 413840 & 713624 & 413840071362401 & 1996 & W & 33 & -- & -- & -- & -- & -- \\
\hline WGW 310 & 413831 & 713625 & 413831071362501 & 1996 & W & 31 & -- & -- & -- & -- & -- \\
\hline WGW 311 & 413821 & 713637 & 413821071363701 & 1996 & W & 104 & -- & -- & -- & -- & -- \\
\hline WGW 312 & 413840 & 713526 & 413840071352601 & 1996 & $\mathrm{~W}$ & 150 & 146 & 2.5 & $\mathrm{~S}$ & 135 & 146 \\
\hline
\end{tabular}




\begin{tabular}{|c|c|c|c|c|c|c|c|c|c|c|}
\hline \multirow[b]{2}{*}{ Well No. } & \multirow{2}{*}{$\begin{array}{l}\text { Land surface } \\
\text { altitude } \\
\text { (feet above } \\
\text { mean sea } \\
\text { level) }\end{array}$} & \multirow[b]{2}{*}{$\begin{array}{l}\text { Site } \\
\text { use }\end{array}$} & \multirow[b]{2}{*}{$\begin{array}{l}\text { Water } \\
\text { use }\end{array}$} & \multicolumn{3}{|c|}{ Pumping } & \multirow[b]{2}{*}{$\begin{array}{l}\text { Aquifer } \\
\text { lithology }\end{array}$} & \multirow{2}{*}{$\begin{array}{l}\text { Depth to } \\
\text { bedrock } \\
\text { (feet) }\end{array}$} & \multirow[b]{2}{*}{ Log } & \multirow[b]{2}{*}{$\begin{array}{l}\text { Water } \\
\text { quality }\end{array}$} \\
\hline & & & & $\begin{array}{l}\text { Discharge } \\
\text { (gal/min) }\end{array}$ & $\begin{array}{l}\text { Drawdown } \\
\text { (feet) }\end{array}$ & $\begin{array}{c}\text { Time } \\
\text { (hours) }\end{array}$ & & & & \\
\hline WGW 267 & 289.41 & $\mathrm{~T}$ & $\mathrm{U}$ & -- & -- & -- & SDGL & -- & -- & -- \\
\hline WGW 268 & 304.16 & $\mathrm{~T}$ & $\mathrm{U}$ & -- & -- & -- & SDGL & B6 & -- & -- \\
\hline WGW 269 & 361.5 & $\mathrm{~T}$ & U & -- & -- & -- & SDGL & B10.4 & -- & -- \\
\hline WGW 270 & 343.6 & $\mathrm{~T}$ & $\mathrm{U}$ & -- & -- & -- & SDGL & B16 & -- & -- \\
\hline WGW 271 & 262 & $\mathrm{~T}$ & $\mathrm{U}$ & -- & -- & -- & SAND & B44 & -- & -- \\
\hline WGW 272 & 275 & $\mathrm{~T}$ & $\mathrm{U}$ & -- & -- & -- & SDST & -- & -- & -- \\
\hline WGW 273 & 275 & $\mathrm{~T}$ & $\mathrm{U}$ & -- & -- & -- & SDGL & -- & -- & -- \\
\hline WGW 274 & 298 & $\mathrm{~T}$ & $\mathrm{U}$ & -- & -- & -- & SDST & -- & -- & -- \\
\hline WGW 275 & 270 & $\mathrm{~T}$ & $\mathrm{U}$ & -- & -- & -- & SDGL & -- & -- & -- \\
\hline WGW 276 & 277 & $\mathrm{~T}$ & $\mathrm{U}$ & -- & -- & -- & SDST & -- & -- & -- \\
\hline WGW 277 & 282 & $\mathrm{~T}$ & $\mathrm{U}$ & -- & -- & -- & SAND & -- & -- & -- \\
\hline WGW 278 & 325 & $\mathrm{~T}$ & $\mathrm{U}$ & -- & -- & -- & SDST & -- & -- & -- \\
\hline WGW 285 & 272.45 & $\mathrm{O}$ & $\mathrm{U}$ & -- & -- & -- & -- & -- & G & Y \\
\hline WGW 286 & 307.49 & $\mathrm{O}$ & $\mathrm{U}$ & -- & -- & -- & -- & -- & G & $\mathrm{Y}$ \\
\hline WGW 287 & 280.65 & $\mathrm{O}$ & $\mathrm{U}$ & -- & -- & -- & -- & -- & G & Y \\
\hline WGW 288 & 346 & $\mathrm{~T}$ & $\mathrm{U}$ & -- & -- & -- & -- & -- & G & $\mathrm{Y}$ \\
\hline WGW 289 & 278.28 & $\mathrm{O}$ & $\mathrm{U}$ & -- & -- & -- & -- & -- & G & $\mathrm{Y}$ \\
\hline WGW 290 & 278.13 & $\mathrm{O}$ & $\mathrm{U}$ & -- & -- & -- & -- & -- & G & $\mathrm{Y}$ \\
\hline WGW 291 & 255.96 & $\mathrm{O}$ & $\mathrm{U}$ & -- & -- & -- & -- & -- & G & $\mathrm{Y}$ \\
\hline WGW 292 & 265.23 & $\mathrm{O}$ & $\mathrm{U}$ & -- & -- & -- & -- & -- & G & $\mathrm{Y}$ \\
\hline WGW 293 & 265.11 & $\mathrm{O}$ & $\mathrm{U}$ & -- & -- & -- & -- & -- & G & $\mathrm{Y}$ \\
\hline WGW 294 & 287.79 & $\mathrm{O}$ & $\mathrm{U}$ & -- & -- & -- & -- & -- & G & Y \\
\hline WGW 295 & 267.09 & $\mathrm{O}$ & $\mathrm{U}$ & -- & -- & -- & -- & -- & G & Y \\
\hline WGW 296 & 296.69 & $\mathrm{O}$ & $\mathrm{U}$ & -- & -- & -- & -- & -- & $\mathrm{G}$ & Y \\
\hline WGW 297 & 326.62 & $\mathrm{O}$ & $\mathrm{U}$ & -- & -- & -- & -- & -- & G & $\mathrm{Y}$ \\
\hline WGW 298 & 272.96 & $\mathrm{O}$ & $\mathrm{U}$ & -- & -- & -- & -- & -- & G & Y \\
\hline WGW 299 & 288.28 & $\mathrm{O}$ & $\mathrm{U}$ & -- & -- & -- & -- & -- & G & Y \\
\hline WGW 300 & 271.86 & $\mathrm{O}$ & $\mathrm{U}$ & -- & -- & -- & -- & -- & G & Y \\
\hline WGW 301 & 271.58 & $\mathrm{O}$ & $\mathrm{U}$ & -- & -- & -- & -- & -- & $\mathrm{G}$ & $\mathrm{Y}$ \\
\hline WGW 302 & 313.69 & $\mathrm{O}$ & $\mathrm{U}$ & -- & -- & -- & -- & -- & G & $\mathrm{Y}$ \\
\hline WGW 303 & 286.86 & $\mathrm{O}$ & $\mathrm{U}$ & -- & -- & -- & -- & -- & G & $\mathrm{Y}$ \\
\hline WGW 304 & 273.14 & $\mathrm{O}$ & $\mathrm{U}$ & -- & -- & -- & -- & -- & G & -- \\
\hline WGW 305 & 263.7 & $\mathrm{O}$ & $\mathrm{U}$ & -- & -- & -- & -- & -- & -- & $\mathrm{Y}$ \\
\hline WGW 306 & 284.38 & $\mathrm{O}$ & $\mathrm{U}$ & -- & -- & -- & -- & -- & G & Y \\
\hline WGW 307 & 269.15 & $\mathrm{O}$ & $\mathrm{U}$ & -- & -- & -- & -- & -- & G & $\mathrm{Y}$ \\
\hline WGW 308 & 289.32 & $\mathrm{O}$ & $\mathrm{U}$ & -- & -- & -- & -- & -- & G & $\mathrm{Y}$ \\
\hline WGW 309 & 260 & $\mathrm{U}$ & -- & -- & -- & -- & -- & -- & G & -- \\
\hline WGW 310 & 259 & $\mathrm{U}$ & -- & -- & -- & -- & -- & -- & G & -- \\
\hline WGW 311 & 280 & $\mathrm{U}$ & -- & -- & -- & -- & -- & -- & G & -- \\
\hline WGW 312 & 262.94 & $\mathrm{O}$ & $\mathrm{U}$ & -- & -- & -- & -- & -- & G & Y \\
\hline
\end{tabular}


Table 1. Ground-water data-collection sites in the Big-Mishnock stream-aquifer system, central Rhode Island—Continued

\begin{tabular}{|c|c|c|c|c|c|c|c|c|c|c|c|}
\hline \multirow{3}{*}{ Well No. } & \multirow{3}{*}{ Latitude } & \multirow{3}{*}{ Longitude } & \multirow{3}{*}{$\begin{array}{c}\text { Site } \\
\text { identification }\end{array}$} & \multicolumn{8}{|c|}{ Construction } \\
\hline & & & & \multirow{2}{*}{ Year } & \multirow{2}{*}{ Method } & \multirow{2}{*}{$\begin{array}{c}\text { Hole } \\
\text { depth } \\
\text { (feet } \\
\text { below } \\
\text { land } \\
\text { surface) }\end{array}$} & \multirow{2}{*}{$\begin{array}{l}\text { Well } \\
\text { depth } \\
\text { (feet) }\end{array}$} & \multicolumn{2}{|c|}{ Casing } & \multicolumn{2}{|c|}{$\begin{array}{c}\text { Screened interval } \\
\text { (feet below land } \\
\text { surface) }\end{array}$} \\
\hline & & & & & & & & $\begin{array}{c}\text { Diameter } \\
\text { (inches) }\end{array}$ & Finish & Top & Bottom \\
\hline WGW 313 & 413858 & 713712 & 413858071371201 & 1996 & W & 134 & 112 & 2.5 & $\mathrm{~S}$ & 101 & 112 \\
\hline WGW 314 & 413904 & 713712 & 413904071371201 & 1996 & $\mathrm{~W}$ & 156 & -- & -- & -- & -- & -- \\
\hline WGW 315 & 413934 & 713544 & 413934071354401 & 1994 & $\mathrm{~W}$ & 129 & 120 & 2.5 & S & 115 & 120 \\
\hline WGW 316 & 413934 & 713539 & 413934071353901 & 1994 & $\mathrm{~W}$ & 120 & 110 & 2.5 & $\mathrm{~S}$ & 100 & 110 \\
\hline WGW 317 & 413934 & 713528 & 413934071352801 & 1994 & $\mathrm{~W}$ & 115 & 110 & 2.5 & $\mathrm{~S}$ & 100 & 110 \\
\hline WGW 318 & 413931 & 713552 & 413931071355201 & 1994 & W & 125 & 103 & 2.5 & S & 93 & 103 \\
\hline WGW 319 & 413738 & 713816 & 413738071381601 & 1997 & B & 12 & 10.4 & 2 & $\mathrm{~S}$ & 5.18 & 9.98 \\
\hline WGW 320 & 413729 & 713718 & 413729071371801 & 1997 & B & 41 & 39.7 & 2 & $\mathrm{~S}$ & 34.9 & 39.7 \\
\hline WGW 321 & 413856 & 713429 & 413856071342901 & 1997 & B & 43 & 39.2 & 2 & $\mathrm{~S}$ & 34.5 & 39.2 \\
\hline WGW 322 & 413735 & 713756 & 413735071375601 & 1997 & $\mathrm{~V}$ & -- & 3.62 & 1 & S & 2.37 & 3.62 \\
\hline WGW 323 & 413646 & 713720 & 413646071372001 & 1997 & V & -- & 4.6 & 1 & S & 3.22 & 4.47 \\
\hline WGW 324 & 413648 & 713708 & 413648071370801 & 1997 & V & -- & 3.52 & 1 & $S$ & 2.27 & 3.52 \\
\hline WGW 325 & 413840 & 713648 & 413840071364801 & 1997 & V & -- & 3.85 & 1 & $S$ & 2.6 & 3.85 \\
\hline WGW 326 & 413835 & 713632 & 413835071363201 & 1997 & V & -- & 3.88 & 1 & $S$ & 2.63 & 3.88 \\
\hline WGW 327 & 413755 & 713706 & 413755071370601 & 1997 & $\mathrm{~V}$ & -- & 6.64 & 1 & S & 5.39 & 6.64 \\
\hline WGW 328 & 413802 & 713453 & 413802071345301 & 1997 & V & -- & 6.74 & 1 & $S$ & 5.49 & 6.74 \\
\hline WGW 329 & 413855 & 713433 & 413855071343301 & 1997 & $\mathrm{~V}$ & -- & 4.31 & 1 & S & 3.06 & 4.31 \\
\hline WGW 330 & 413850 & 713448 & 413850071344801 & 1997 & $\mathrm{~V}$ & -- & 4.7 & 1 & S & 3.45 & 4.7 \\
\hline WGW 331 & 413842 & 713509 & 413842071350902 & 1997 & V & -- & 6.44 & 1 & S & 5.19 & 6.44 \\
\hline WGW 332 & 413923 & 713600 & 413923071360001 & 1997 & V & -- & 4.78 & 1 & $\mathrm{~S}$ & 3.53 & 4.78 \\
\hline WGW 333 & 413920 & 713530 & 413920071353001 & 1997 & $\mathrm{~V}$ & -- & 4.7 & 1 & $\mathrm{~S}$ & 3.45 & 4.7 \\
\hline WGW 335 & 413732 & 713552 & 413732071355201 & 1997 & $\mathrm{~V}$ & -- & 3.22 & 1 & $\mathrm{~S}$ & 1.97 & 3.22 \\
\hline WGW 336 & 413840 & 713525 & 413840071352501 & 1997 & B & 140 & 138 & 2 & $\mathrm{~S}$ & 128 & 138 \\
\hline WGW 337 & 413840 & 713523 & 413840071352301 & 1997 & B & 142 & 138 & 2 & $\mathrm{~S}$ & 128 & 138 \\
\hline WGW 338 & 413840 & 713522 & 413840071352201 & 1997 & B & 146 & 137 & 2 & S & 127 & 137 \\
\hline WGW 339 & 413841 & 713526 & 413841071352601 & 1997 & B & -- & 140 & 2 & S & 130 & 140 \\
\hline WGW 340 & 413842 & 713525 & 413842071352501 & 1997 & B & 150 & 144 & 2 & S & 134 & 144 \\
\hline WGW 341 & 413840 & 713528 & 413840071352801 & 1997 & B & -- & 149 & 2 & S & 139 & 149 \\
\hline WGW 342 & 413843 & 713508 & 413843071350801 & 1997 & B & 129 & 129 & 2 & $\mathrm{~S}$ & 119 & 129 \\
\hline WGW 343 & 413842 & 713507 & 413842071350701 & 1997 & B & 131 & 128 & 2 & S & 118 & 128 \\
\hline WGW 344 & 413840 & 713508 & 413840071350801 & 1997 & B & 131 & 118 & 2 & S & 108 & 118 \\
\hline WGW 345 & 413839 & 713507 & 413839071350701 & 1997 & B & 151 & 78.9 & 2 & S & 58.9 & 78.9 \\
\hline WGW 346 & 413858 & 713709 & 413858071370901 & 1997 & B & 112 & 109 & 2 & S & 99.2 & 109 \\
\hline WGW 347 & 413858 & 713708 & 413858071370801 & 1997 & B & 95 & 90.8 & 2 & S & 80.1 & 90.1 \\
\hline WGW 348 & 413856 & 713711 & 413856071371101 & 1997 & B & 120 & 89.8 & 2 & S & 79.8 & 89.8 \\
\hline WGW 349 & 413854 & 713709 & 413854071370901 & 1997 & B & 120 & 119 & 2 & S & 109 & 119 \\
\hline WGW 350 & 413853 & 713716 & 413853071371601 & 1997 & B & 109 & 90.1 & 2 & S & 80.1 & 90.1 \\
\hline WGW 351 & 413859 & 713712 & 413859071371201 & 1997 & B & 111 & 110 & 2 & S & 100 & 110 \\
\hline WGW 352 & 413837 & 713510 & 413837071351001 & 1997 & B & 118 & 78.5 & 2 & $\mathrm{~S}$ & 68.5 & 78.5 \\
\hline WGW 353 & 413836 & 713512 & 413836071351201 & 1997 & B & 88 & 86.3 & 2 & $\mathrm{~S}$ & 76.3 & 86.3 \\
\hline
\end{tabular}




\begin{tabular}{|c|c|c|c|c|c|c|c|c|c|c|}
\hline \multirow[b]{2}{*}{ Well No. } & \multirow{2}{*}{$\begin{array}{l}\text { Land surface } \\
\text { altitude } \\
\text { (feet above } \\
\text { mean sea } \\
\text { level) }\end{array}$} & \multirow[b]{2}{*}{$\begin{array}{l}\text { Site } \\
\text { use }\end{array}$} & \multirow[b]{2}{*}{$\begin{array}{l}\text { Water } \\
\text { use }\end{array}$} & \multicolumn{3}{|c|}{ Pumping } & \multirow[b]{2}{*}{$\begin{array}{l}\text { Aquifer } \\
\text { lithology }\end{array}$} & \multirow{2}{*}{$\begin{array}{l}\text { Depth to } \\
\text { bedrock } \\
\text { (feet) }\end{array}$} & \multirow[b]{2}{*}{ Log } & \multirow[b]{2}{*}{$\begin{array}{l}\text { Water } \\
\text { quality }\end{array}$} \\
\hline & & & & $\begin{array}{l}\text { Discharge } \\
\text { (gal/min) }\end{array}$ & $\begin{array}{l}\text { Drawdown } \\
\text { (feet) }\end{array}$ & $\begin{array}{c}\text { Time } \\
\text { (hours) }\end{array}$ & & & & \\
\hline WGW 313 & 261.35 & $\mathrm{O}$ & $\mathrm{U}$ & -- & -- & -- & -- & -- & G & Y \\
\hline WGW 314 & 253 & $\mathrm{U}$ & -- & -- & -- & -- & -- & -- & G & -- \\
\hline WGW 315 & 256 & $\mathrm{~T}$ & $\mathrm{U}$ & -- & -- & -- & SGVC & -- & -- & -- \\
\hline WGW 316 & 254 & $\mathrm{~T}$ & $\mathrm{U}$ & -- & -- & -- & SGVC & -- & -- & -- \\
\hline WGW 317 & 248 & $\mathrm{~T}$ & $\mathrm{U}$ & -- & -- & -- & SGVC & -- & -- & -- \\
\hline WGW 318 & 257 & $\mathrm{~T}$ & $\mathrm{U}$ & -- & -- & -- & SGVC & -- & -- & -- \\
\hline WGW 319 & 305.48 & $\mathrm{O}$ & $\mathrm{U}$ & -- & -- & -- & -- & -- & -- & -- \\
\hline WGW 320 & 269.31 & $\mathrm{O}$ & $\mathrm{U}$ & -- & -- & -- & SDGL & B41 & -- & -- \\
\hline WGW 321 & 304.08 & $\mathrm{O}$ & $\mathrm{U}$ & -- & -- & -- & -- & -- & -- & -- \\
\hline WGW 322 & 261.96 & $\mathrm{O}$ & $\mathrm{U}$ & -- & -- & -- & -- & -- & -- & -- \\
\hline WGW 323 & 270.15 & $\mathrm{O}$ & -- & -- & -- & -- & -- & -- & -- & -- \\
\hline WGW 324 & 261.65 & $\mathrm{O}$ & $\mathrm{U}$ & -- & -- & -- & -- & -- & -- & -- \\
\hline WGW 325 & 246.93 & $\mathrm{O}$ & $\mathrm{U}$ & -- & -- & -- & -- & -- & -- & -- \\
\hline WGW 326 & 248.08 & $\mathrm{O}$ & $\mathrm{U}$ & -- & -- & -- & -- & -- & -- & -- \\
\hline WGW 327 & 248.39 & $\mathrm{O}$ & -- & -- & -- & -- & -- & -- & -- & -- \\
\hline WGW 328 & 259.85 & $\mathrm{O}$ & -- & -- & -- & -- & -- & -- & -- & -- \\
\hline WGW 329 & 288.25 & $\mathrm{O}$ & -- & -- & -- & -- & -- & -- & -- & -- \\
\hline WGW 330 & 274.66 & $\mathrm{O}$ & -- & -- & -- & -- & -- & -- & -- & -- \\
\hline WGW 331 & 265.3 & $\mathrm{O}$ & -- & -- & -- & -- & -- & -- & -- & -- \\
\hline WGW 332 & 255.74 & $\mathrm{O}$ & -- & -- & -- & -- & -- & -- & -- & -- \\
\hline WGW 333 & 248.93 & $\mathrm{O}$ & -- & -- & -- & -- & -- & -- & -- & -- \\
\hline WGW 335 & 277.58 & $\mathrm{O}$ & $\mathrm{U}$ & -- & -- & -- & -- & -- & -- & -- \\
\hline WGW 336 & 261.49 & $\mathrm{O}$ & $\mathrm{U}$ & 7 & -- & -- & -- & -- & G & -- \\
\hline WGW 337 & 260.05 & $\mathrm{O}$ & $\mathrm{U}$ & 21.4 & -- & -- & -- & -- & $\mathrm{G}$ & -- \\
\hline WGW 338 & 260.85 & $\mathrm{O}$ & $\mathrm{U}$ & -- & -- & -- & -- & -- & G & -- \\
\hline WGW 339 & 263.26 & $\mathrm{O}$ & $\mathrm{U}$ & -- & -- & -- & -- & -- & $\mathrm{G}$ & -- \\
\hline WGW 340 & 264.37 & $\mathrm{O}$ & $\mathrm{U}$ & -- & -- & -- & -- & -- & G & -- \\
\hline WGW 341 & 263 & $\mathrm{O}$ & $\mathrm{U}$ & -- & -- & -- & -- & -- & G & -- \\
\hline WGW 342 & 271.04 & $\mathrm{O}$ & $\mathrm{U}$ & -- & -- & -- & -- & -- & G & -- \\
\hline WGW 343 & 270.99 & $\mathrm{O}$ & $\mathrm{U}$ & -- & -- & -- & -- & -- & G & -- \\
\hline WGW 344 & 279.43 & $\mathrm{O}$ & $\mathrm{U}$ & -- & -- & -- & -- & -- & G & -- \\
\hline WGW 345 & 287.12 & $\mathrm{O}$ & $\mathrm{U}$ & -- & -- & -- & -- & -- & $\mathrm{G}$ & -- \\
\hline WGW 346 & 262.77 & $\mathrm{O}$ & $\mathrm{U}$ & -- & -- & -- & -- & -- & $\mathrm{G}$ & -- \\
\hline WGW 347 & 268.5 & $\mathrm{O}$ & $\mathrm{U}$ & -- & -- & -- & -- & -- & $\mathrm{G}$ & -- \\
\hline WGW 348 & 270.42 & $\mathrm{O}$ & $\mathrm{U}$ & -- & -- & -- & -- & -- & G & -- \\
\hline WGW 349 & 266.43 & $\mathrm{O}$ & $\mathrm{U}$ & -- & -- & -- & -- & -- & G & -- \\
\hline WGW 350 & 286.91 & $\mathrm{O}$ & $\mathrm{U}$ & -- & -- & -- & -- & -- & $\mathrm{G}$ & -- \\
\hline WGW 351 & 259.86 & $\mathrm{O}$ & $\mathrm{U}$ & -- & -- & -- & -- & -- & G & Y \\
\hline WGW 352 & 288.74 & $\mathrm{O}$ & $\mathrm{U}$ & -- & -- & -- & -- & -- & $\mathrm{G}$ & -- \\
\hline WGW 353 & 285.99 & $\mathrm{O}$ & $\mathrm{U}$ & 6 & -- & -- & -- & -- & $\mathrm{G}$ & -- \\
\hline
\end{tabular}


Table 1. Ground-water data-collection sites in the Big-Mishnock stream-aquifer system, central Rhode Island—Continued

\begin{tabular}{|c|c|c|c|c|c|c|c|c|c|c|c|}
\hline \multirow{3}{*}{ Well No. } & \multirow{3}{*}{ Latitude } & \multirow{3}{*}{ Longitude } & \multirow{3}{*}{$\begin{array}{c}\text { Site } \\
\text { identification }\end{array}$} & \multicolumn{8}{|c|}{ Construction } \\
\hline & & & & \multirow{2}{*}{ Year } & \multirow{2}{*}{ Method } & \multirow{2}{*}{$\begin{array}{c}\text { Hole } \\
\text { depth } \\
\text { (feet } \\
\text { below } \\
\text { land } \\
\text { surface) }\end{array}$} & \multirow{2}{*}{$\begin{array}{l}\text { Well } \\
\text { depth } \\
\text { (feet) }\end{array}$} & \multicolumn{2}{|c|}{ Casing } & \multicolumn{2}{|c|}{$\begin{array}{c}\text { Screened interval } \\
\text { (feet below land } \\
\text { surface) }\end{array}$} \\
\hline & & & & & & & & $\begin{array}{l}\text { Diameter } \\
\text { (inches) }\end{array}$ & Finish & Top & Bottom \\
\hline WGW 354 & 413840 & 713526 & 413840071352602 & 1997 & $\mathrm{C}$ & 145 & 145 & 8 & $\mathrm{~S}$ & 125 & 145 \\
\hline WGW 355 & 413842 & 713509 & 413842071350903 & 1998 & $\mathrm{C}$ & 133 & 133 & 8 & S & 113 & 133 \\
\hline WGW 356 & 413858 & 713712 & 413858071371202 & 1998 & W & 111 & 110 & 8 & $\mathrm{~S}$ & 89.6 & 110 \\
\hline WGW 357 & 413753 & 713700 & 413753071370001 & 1998 & $\mathrm{~W}$ & 60 & 60 & 1.25 & $\mathrm{~S}$ & 45 & 60 \\
\hline WGW 358 & 413756 & 713639 & 413756071363901 & 1998 & $\mathrm{~W}$ & 67.7 & 67.7 & 2.5 & $\mathrm{~S}$ & 62.7 & 67.7 \\
\hline WGW 359 & 413757 & 713621 & 413757071362101 & 1998 & $\mathrm{~W}$ & 47 & 47 & 2.5 & $\mathrm{O}$ & -- & -- \\
\hline WGW 360 & 413755 & 713623 & 413755071362301 & 1998 & $\mathrm{~W}$ & 64 & 64 & 2.5 & $\mathrm{~S}$ & 52 & 64 \\
\hline WGW 361 & 413748 & 713643 & 413748071364301 & 1998 & $\mathrm{~W}$ & 25 & 25 & 2.5 & $\mathrm{O}$ & -- & -- \\
\hline WGW 362 & 413834 & 713629 & 413834071362901 & 1998 & $\mathrm{~W}$ & 20.5 & 20.5 & 2.5 & $\mathrm{O}$ & -- & -- \\
\hline WGW 363 & 413832 & 713652 & 413832071365201 & 1998 & $\mathrm{~W}$ & 99 & 98.5 & 2.5 & S & 86 & 98.5 \\
\hline WGW 364 & 413741 & 713707 & 413741071370701 & 1998 & $\mathrm{~W}$ & 64 & 60 & 2.5 & S & 48.5 & 60 \\
\hline WGW 365 & 413744 & 713659 & 413744071365901 & 1998 & $\mathrm{~W}$ & 46.7 & 46.7 & 2.5 & $\mathrm{O}$ & -- & -- \\
\hline WGW 366 & 413814 & 713652 & 413814071365201 & 1998 & $\mathrm{~W}$ & 125 & 125 & 2.5 & $\mathrm{~S}$ & 113 & 125 \\
\hline WGW 367 & 413814 & 713656 & 413814071365601 & 1998 & $\mathrm{~W}$ & 70 & 70 & 2.5 & $\mathrm{~S}$ & 58 & 70 \\
\hline WGW 368 & 413811 & 713641 & 413811071364101 & 1998 & $\mathrm{~W}$ & 76.2 & 76.2 & 2.5 & $\mathrm{O}$ & -- & -- \\
\hline WGW 369 & 413729 & 713709 & 413729071370901 & 1998 & $\mathrm{~W}$ & 56.9 & 56.9 & 2.5 & $\mathrm{O}$ & -- & -- \\
\hline WGW 370 & 413720 & 713715 & 413720071371501 & 1998 & $\mathrm{~W}$ & -- & 31.9 & 2.5 & $\mathrm{O}$ & -- & -- \\
\hline WGW 371 & 413925 & 713727 & 413925071372701 & 1998 & $\mathrm{~W}$ & 63.8 & 63 & 2.5 & $S$ & 57 & 63 \\
\hline WGW 372 & 413916 & 713731 & 413916071373101 & 1998 & $\mathrm{~W}$ & 39 & 39 & 2.5 & $\mathrm{O}$ & -- & -- \\
\hline WGW 373 & 413929 & 713713 & 413929071371301 & 1998 & $\mathrm{~W}$ & 84 & 84 & 2.5 & $\mathrm{O}$ & -- & -- \\
\hline WGW 374 & 413836 & 713513 & 413836071351302 & 1999 & A & -- & 183 & 10 & S & 163 & 183 \\
\hline WGW 375 & 413835 & 713513 & 413835071351301 & 1999 & A & -- & 185 & 2 & $P$ & 165 & 185 \\
\hline WGW 376 & 413836 & 713512 & 413836071351202 & 1999 & A & -- & 183 & 2 & $\mathrm{P}$ & 163 & 183 \\
\hline WGW 377 & 413837 & 713510 & 413837071351002 & 1999 & A & -- & 182 & 2 & $P$ & 162 & 182 \\
\hline WGW 378 & 413857 & 713619 & 413857071361901 & 1976 & W & -- & 22 & 2.5 & $\mathrm{X}$ & -- & -- \\
\hline WGW 379 & 413901 & 713611 & 413901071361101 & 1976 & $\mathrm{~W}$ & -- & 49 & 2.5 & $\mathrm{x}$ & -- & -- \\
\hline WGW 380 & 413954 & 713603 & 413954071360301 & 1976 & $\mathrm{~W}$ & -- & 62 & 2.5 & $\mathrm{O}$ & -- & -- \\
\hline WGW 381 & 413854 & 713548 & 413854071354801 & 1976 & $\mathrm{~W}$ & -- & 147 & 2.5 & $\mathrm{O}$ & -- & -- \\
\hline WGW 382 & 413857 & 713533 & 413857071353301 & 1976 & $\mathrm{~W}$ & -- & 178 & 2.5 & $\mathrm{X}$ & -- & -- \\
\hline WGW 383 & 413849 & 713516 & 413849071351601 & 1976 & $\mathrm{~W}$ & -- & 190 & 2.5 & $\mathrm{O}$ & -- & -- \\
\hline WGW 384 & 413856 & 713504 & 413856071350401 & 1976 & $\mathrm{~W}$ & -- & 146 & 2.5 & $\mathrm{O}$ & -- & -- \\
\hline WGW 385 & 413857 & 713453 & 413857071345301 & 1976 & $\mathrm{~W}$ & -- & 87 & 2.5 & $\mathrm{O}$ & -- & -- \\
\hline WGW 386 & 413854 & 713438 & 413854071343801 & 1976 & $\mathrm{~W}$ & -- & 87 & 2.5 & $\mathrm{X}$ & -- & -- \\
\hline WGW 387 & 413904 & 713427 & 413904071342701 & 1976 & $\mathrm{~W}$ & -- & 47.8 & 2.5 & $\mathrm{O}$ & -- & -- \\
\hline WGW 388 & 413904 & 713403 & 413904071340301 & 1976 & $\mathrm{~W}$ & -- & 41 & 2.5 & $\mathrm{O}$ & -- & -- \\
\hline WGW 389 & 413913 & 713350 & 413913071335001 & 1976 & $\mathrm{~W}$ & -- & 114 & 2.5 & $\mathrm{O}$ & -- & -- \\
\hline WGW 390 & 413836 & 713407 & 413836071340701 & 1976 & $\mathrm{~W}$ & -- & 30.5 & 2.5 & $\mathrm{O}$ & -- & -- \\
\hline WGW 391 & 413839 & 713430 & 413839071343001 & 1976 & $\mathrm{~W}$ & -- & 50 & 2.5 & $\mathrm{O}$ & -- & -- \\
\hline WGW 392 & 413844 & 713627 & 413844071362701 & 1983 & W & 39.2 & 39.2 & 2.5 & $\mathrm{X}$ & -- & -- \\
\hline WGW 393 & 413914 & 713600 & 413914071360001 & 1983 & $\mathrm{~W}$ & 63 & 56 & 1.25 & $\mathrm{X}$ & 46 & 56 \\
\hline
\end{tabular}




\begin{tabular}{|c|c|c|c|c|c|c|c|c|c|c|}
\hline \multirow[b]{2}{*}{ Well No. } & \multirow{2}{*}{$\begin{array}{l}\text { Land surface } \\
\text { altitude } \\
\text { (feet above } \\
\text { mean sea } \\
\text { level) }\end{array}$} & \multirow[b]{2}{*}{$\begin{array}{l}\text { Site } \\
\text { use }\end{array}$} & \multirow[b]{2}{*}{$\begin{array}{c}\text { Water } \\
\text { use }\end{array}$} & \multicolumn{3}{|c|}{ Pumping } & \multirow[b]{2}{*}{$\begin{array}{l}\text { Aquifer } \\
\text { lithology }\end{array}$} & \multirow{2}{*}{$\begin{array}{c}\text { Depth to } \\
\text { bedrock } \\
\text { (feet) }\end{array}$} & \multirow[b]{2}{*}{$\log$} & \multirow[b]{2}{*}{$\begin{array}{l}\text { Water } \\
\text { quality }\end{array}$} \\
\hline & & & & $\begin{array}{c}\text { Discharge } \\
\text { (gal/min) }\end{array}$ & $\begin{array}{l}\text { Drawdown } \\
\text { (feet) }\end{array}$ & $\begin{array}{c}\text { Time } \\
\text { (hours) }\end{array}$ & & & & \\
\hline WGW 354 & 262 & $\mathrm{~T}$ & $\mathrm{U}$ & 353 & 81.3 & 48 & SDGL & -- & $\mathrm{G}$ & $\mathrm{Y}$ \\
\hline WGW 355 & 269.15 & $\mathrm{~T}$ & $\mathrm{U}$ & 400 & 55.1 & 48 & SDGL & -- & $\mathrm{G}$ & $\mathrm{Y}$ \\
\hline WGW 356 & -- & $\mathrm{O}$ & $\mathrm{U}$ & -- & -- & -- & -- & -- & $\mathrm{G}$ & $\mathrm{Y}$ \\
\hline WGW 357 & 270 & $\mathrm{~T}$ & $\mathrm{U}$ & -- & -- & -- & SGVC & -- & $\mathrm{G}$ & -- \\
\hline WGW 358 & 279.6 & $\mathrm{~T}$ & $\mathrm{U}$ & -- & -- & -- & SDGL & -- & G & $\mathrm{Y}$ \\
\hline WGW 359 & 280 & $\mathrm{~T}$ & $\mathrm{U}$ & -- & -- & -- & SDGL & -- & G & -- \\
\hline WGW 360 & 272 & $\mathrm{~T}$ & $\mathrm{U}$ & -- & -- & -- & SDGL & -- & $\mathrm{G}$ & $\mathrm{Y}$ \\
\hline WGW 361 & 330 & $\mathrm{~T}$ & $\mathrm{U}$ & -- & -- & -- & SDGL & -- & $\mathrm{G}$ & -- \\
\hline WGW 362 & 258 & $\mathrm{O}$ & $\mathrm{U}$ & -- & -- & -- & TILL & $\mathrm{R} 20.5$ & $\mathrm{G}$ & -- \\
\hline WGW 363 & 257 & $\mathrm{~T}$ & $\mathrm{U}$ & 41 & -- & -- & SDST & -- & G & -- \\
\hline WGW 364 & 278 & $\mathrm{~T}$ & $\mathrm{U}$ & -- & -- & -- & SDGL & -- & $\mathrm{G}$ & -- \\
\hline WGW 365 & 297 & $\mathrm{~T}$ & $\mathrm{U}$ & -- & -- & -- & SDGL & -- & G & -- \\
\hline WGW 366 & 302 & $\mathrm{~T}$ & $\mathrm{U}$ & -- & -- & -- & SDGL & -- & $\mathrm{G}$ & -- \\
\hline WGW 367 & 280 & $\mathrm{~T}$ & $\mathrm{U}$ & 38 & -- & -- & SDST & -- & $\mathrm{G}$ & -- \\
\hline WGW 368 & 272 & $\mathrm{~T}$ & $\mathrm{U}$ & -- & -- & -- & SDST & -- & $\mathrm{G}$ & -- \\
\hline WGW 369 & 260 & $\mathrm{~T}$ & $\mathrm{U}$ & -- & -- & -- & SDST & -- & $\mathrm{G}$ & -- \\
\hline WGW 370 & 258 & $\mathrm{~T}$ & $\mathrm{U}$ & -- & -- & -- & SDST & -- & $\mathrm{G}$ & -- \\
\hline WGW 371 & 257.93 & $\mathrm{~T}$ & $\mathrm{U}$ & -- & -- & -- & SAND & -- & $\mathrm{G}$ & $\mathrm{Y}$ \\
\hline WGW 372 & 270 & $\mathrm{~T}$ & $\mathrm{U}$ & -- & -- & -- & SDGL & -- & $\mathrm{G}$ & -- \\
\hline WGW 373 & 258 & $\mathrm{~T}$ & $\mathrm{U}$ & -- & -- & -- & SDST & -- & $\mathrm{G}$ & -- \\
\hline WGW 374 & 284 & $\mathrm{~T}$ & $\mathrm{U}$ & 736 & 63.3 & 48 & SDGL & -- & $\mathrm{G}$ & $\mathrm{Y}$ \\
\hline WGW 375 & 285.77 & $\mathrm{O}$ & $\mathrm{U}$ & 40 & -- & -- & SDGL & -- & $\mathrm{G}$ & -- \\
\hline WGW 376 & 285.89 & $\mathrm{O}$ & $\mathrm{U}$ & 40 & -- & -- & SDGL & -- & $\mathrm{G}$ & -- \\
\hline WGW 377 & 288.9 & $\mathrm{O}$ & $\mathrm{U}$ & 35 & -- & -- & SAND & -- & $\mathrm{G}$ & -- \\
\hline WGW 378 & 294 & $\mathrm{~T}$ & $\mathrm{U}$ & -- & -- & -- & SDGL & B12 & -- & -- \\
\hline WGW 379 & 279 & $\mathrm{~T}$ & $\mathrm{U}$ & -- & -- & -- & SDGL & B39 & -- & -- \\
\hline WGW 380 & 302.3 & $\mathrm{~T}$ & $\mathrm{U}$ & -- & -- & -- & SDST & -- & -- & -- \\
\hline WGW 381 & 300.6 & $\mathrm{~T}$ & $\mathrm{U}$ & -- & -- & -- & SDGL & -- & -- & -- \\
\hline WGW 382 & 290.5 & $\mathrm{~T}$ & $\mathrm{U}$ & -- & -- & -- & SDST & B173 & -- & -- \\
\hline WGW 383 & 278.3 & $\mathrm{~T}$ & $\mathrm{U}$ & -- & -- & -- & SDGL & -- & -- & -- \\
\hline WGW 384 & 298.6 & $\mathrm{~T}$ & $\mathrm{U}$ & -- & -- & -- & SAND & -- & -- & -- \\
\hline WGW 385 & 286 & $\mathrm{~T}$ & $\mathrm{U}$ & -- & -- & -- & SDGL & -- & -- & -- \\
\hline WGW 386 & 285.7 & $\mathrm{~T}$ & $\mathrm{U}$ & -- & -- & -- & SDGL & B77 & -- & -- \\
\hline WGW 387 & 311 & $\mathrm{~T}$ & $\mathrm{U}$ & -- & -- & -- & SDGL & -- & -- & -- \\
\hline WGW 388 & 320 & $\mathrm{~T}$ & $\mathrm{U}$ & -- & -- & -- & SDST & -- & -- & -- \\
\hline WGW 389 & 341.4 & $\mathrm{~T}$ & $\mathrm{U}$ & -- & -- & -- & SDST & -- & -- & -- \\
\hline WGW 390 & 319 & $\mathrm{~T}$ & $\mathrm{U}$ & -- & -- & -- & SDGL & -- & -- & -- \\
\hline WGW 391 & 331.7 & $\mathrm{~T}$ & $\mathrm{U}$ & -- & -- & -- & SDGL & -- & -- & -- \\
\hline WGW 392 & 272.82 & $\mathrm{~T}$ & $\mathrm{U}$ & -- & -- & -- & SDGL & B29.2 & -- & -- \\
\hline WGW 393 & 262 & $\mathrm{~T}$ & $\mathrm{U}$ & -- & -- & -- & SGVC & B53 & -- & -- \\
\hline
\end{tabular}


Table 1. Ground-water data-collection sites in the Big-Mishnock stream-aquifer system, central Rhode Island—Continued

\begin{tabular}{|c|c|c|c|c|c|c|c|c|c|c|c|}
\hline \multirow{3}{*}{ Well No. } & \multirow{3}{*}{$\begin{array}{l}\text { Latitude } \\
\circ, \prime \prime\end{array}$} & \multirow{3}{*}{$\begin{array}{c}\text { Longitude } \\
\text { o," }\end{array}$} & \multirow{3}{*}{$\begin{array}{c}\text { Site } \\
\text { identification }\end{array}$} & \multicolumn{8}{|c|}{ Construction } \\
\hline & & & & \multirow{2}{*}{ Year } & \multirow{2}{*}{ Method } & \multirow{2}{*}{$\begin{array}{c}\text { Hole } \\
\text { depth } \\
\text { (feet } \\
\text { below } \\
\text { land } \\
\text { surface) }\end{array}$} & \multirow{2}{*}{$\begin{array}{l}\text { Well } \\
\text { depth } \\
\text { (feet) }\end{array}$} & \multicolumn{2}{|c|}{ Casing } & \multicolumn{2}{|c|}{$\begin{array}{l}\text { Screened interval } \\
\text { (feet below land } \\
\text { surface) }\end{array}$} \\
\hline & & & & & & & & $\begin{array}{l}\text { Diameter } \\
\text { (inches) }\end{array}$ & Finish & Top & Bottom \\
\hline WGW 394 & 413904 & 713608 & 413904071360801 & 1983 & W & 25 & 25 & 2.5 & $\mathrm{X}$ & -- & -- \\
\hline WGW 395 & 413846 & 713606 & 413846071360601 & 1983 & W & 66.5 & 40 & 1.25 & $\mathrm{P}$ & 30 & 40 \\
\hline WGW 396 & 413914 & 713537 & 413914071353701 & 1983 & W & 144 & 144 & 2.5 & $\mathrm{X}$ & -- & -- \\
\hline WGW 397 & 413859 & 713547 & 413859071354701 & 1983 & W & 144 & 80 & 1.25 & -- & 70 & 80 \\
\hline WGW 398 & 413845 & 713544 & 413845071354401 & 1983 & W & 96 & 40 & 1.25 & $\mathrm{P}$ & 30 & 40 \\
\hline WGW 399 & 413905 & 713526 & 413905071352601 & 1983 & W & 169 & 169 & 2.5 & $\mathrm{X}$ & -- & -- \\
\hline WGW 400 & 413856 & 713525 & 413856071352501 & 1983 & $\mathrm{~W}$ & 189 & 189 & 2.5 & $\mathrm{X}$ & -- & -- \\
\hline WGW 401 & 413841 & 713521 & 413841071352101 & 1983 & $\mathrm{~W}$ & 163 & 40 & 1.25 & $\mathrm{P}$ & 30 & 40 \\
\hline WGW 402 & 413856 & 713506 & 413856071350601 & 1983 & W & 197 & 80 & 1.25 & S & 70 & 80 \\
\hline WGW 403 & 413845 & 713504 & 413845071350401 & 1983 & $\mathrm{~W}$ & 138 & 50 & 1.25 & $P$ & 40 & 50 \\
\hline WGW 404 & 413910 & 713454 & 413910071345401 & 1983 & W & 166 & 108 & 1.25 & $\mathrm{P}$ & 98 & 108 \\
\hline WGW 405 & 413856 & 713446 & 413856071344601 & 1983 & $\mathrm{~W}$ & 80.2 & 64 & 1.25 & $P$ & 54 & 64 \\
\hline WGW 406 & 413851 & 713441 & 413851071344101 & 1983 & W & 86 & 86 & 2.5 & $\mathrm{X}$ & -- & -- \\
\hline WGW 407 & 413910 & 713435 & 413910071343501 & 1983 & W & 128 & 128 & 2.5 & $\mathrm{X}$ & -- & -- \\
\hline WGW 408 & 413859 & 713430 & 413859071343001 & 1983 & W & 66.2 & 61 & 1.25 & S & 51 & 61 \\
\hline WGW 409 & 413912 & 713514 & 413912071351401 & 1983 & $\mathrm{~W}$ & 159 & 159 & 2.5 & $\mathrm{X}$ & -- & -- \\
\hline WGW 410 & 413756 & 713639 & 413756071363902 & 1999 & A & 81 & 80.4 & 10 & S & 60.4 & 80.4 \\
\hline WGW 411 & 413925 & 713727 & 413925071372702 & 1999 & A & 77.5 & 75 & 10 & S & 55 & 75 \\
\hline WGW 412 & 413927 & 713724 & 413927071372401 & 1999 & A & 76.2 & 74.8 & 2 & $P$ & 54.8 & 74.8 \\
\hline WGW 413 & 413926 & 713725 & 413926071372501 & 1999 & A & 76.5 & 75.5 & 2 & $\mathrm{P}$ & 55.5 & 75.5 \\
\hline WGW 414 & 413925 & 713728 & 413925071372801 & 1999 & A & 67 & 65.4 & 2 & $\mathrm{P}$ & 45.4 & 65.4 \\
\hline WGW 415 & 413924 & 713728 & 413924071372801 & 1999 & $\mathrm{P}$ & 86 & 84.8 & 2 & $\mathrm{P}$ & 64.8 & 84.8 \\
\hline WGW 416 & 413923 & 713732 & 413923071373201 & 1999 & A & 74.8 & 74.4 & 2 & $\mathrm{P}$ & 54.4 & 74.4 \\
\hline WGW 417 & 413754 & 713644 & 413754071364401 & 1999 & A & 77 & 76.6 & 2 & $\mathrm{P}$ & 56.5 & 76.6 \\
\hline WGW 418 & 413756 & 713637 & 413756071363701 & 1999 & A & -- & 78.1 & 2 & $\mathrm{P}$ & 58 & 78.1 \\
\hline WGW 419 & 413756 & 713636 & 413756071363601 & 1999 & A & 84 & 81.2 & 2 & $\mathrm{P}$ & 61.2 & 81.2 \\
\hline WGW 420 & 413800 & 713639 & 413800071363901 & 1999 & A & 87 & 84.1 & 2 & $\mathrm{P}$ & 64.1 & 84.1 \\
\hline WGW 421 & 413758 & 713637 & 413758071363701 & 1999 & A & 85.2 & 85.2 & 2 & $\mathrm{P}$ & 65.2 & 85.2 \\
\hline WGW 422 & 413836 & 713618 & 413836071361801 & 2000 & W & 14.5 & 14.5 & 2.5 & S & -- & -- \\
\hline WGW 423 & 413837 & 713617 & 413837071361701 & 2000 & W & 27.7 & 23.7 & 2.5 & S & -- & -- \\
\hline WGW 424 & 413837 & 713616 & 413837071361601 & 2000 & W & 22.5 & 22.5 & 2.5 & $S$ & -- & -- \\
\hline WGW 425 & 413838 & 713615 & 413836071361501 & 2000 & W & 37.3 & 37.3 & 2.5 & S & -- & -- \\
\hline
\end{tabular}




\begin{tabular}{|c|c|c|c|c|c|c|c|c|c|c|}
\hline \multirow[b]{2}{*}{ Well No. } & \multirow{2}{*}{$\begin{array}{l}\text { Land surface } \\
\text { altitude } \\
\text { (feet above } \\
\text { mean sea } \\
\text { level) }\end{array}$} & \multirow[b]{2}{*}{$\begin{array}{l}\text { Site } \\
\text { use }\end{array}$} & \multirow[b]{2}{*}{$\begin{array}{l}\text { Water } \\
\text { use }\end{array}$} & \multicolumn{3}{|c|}{ Pumping } & \multirow[b]{2}{*}{$\begin{array}{l}\text { Aquifer } \\
\text { lithology }\end{array}$} & \multirow{2}{*}{$\begin{array}{l}\text { Depth to } \\
\text { bedrock } \\
\text { (feet) }\end{array}$} & \multirow[b]{2}{*}{ Log } & \multirow[b]{2}{*}{$\begin{array}{l}\text { Water } \\
\text { quality }\end{array}$} \\
\hline & & & & $\begin{array}{l}\text { Discharge } \\
\text { (gal/min) }\end{array}$ & $\begin{array}{l}\text { Drawdown } \\
\text { (feet) }\end{array}$ & $\begin{array}{l}\text { Time } \\
\text { (hours) }\end{array}$ & & & & \\
\hline WGW 394 & 272.8 & $\mathrm{~T}$ & U & -- & -- & -- & SDST & -- & -- & -- \\
\hline WGW 395 & 262.34 & $\mathrm{~T}$ & $\mathrm{U}$ & -- & -- & -- & SDST & B61.5 & -- & -- \\
\hline WGW 396 & 251.4 & $\mathrm{~T}$ & $\mathrm{U}$ & -- & -- & -- & SGVC & B134 & -- & -- \\
\hline WGW 397 & 312.8 & $\mathrm{~T}$ & U & -- & -- & -- & SDST & B139 & -- & -- \\
\hline WGW 398 & 262.12 & $\mathrm{~T}$ & $\mathrm{U}$ & -- & -- & -- & SGVC & B85.6 & -- & -- \\
\hline WGW 399 & 267.5 & $\mathrm{~T}$ & $\mathrm{U}$ & -- & -- & -- & SDST & B158 & -- & -- \\
\hline WGW 400 & 270.7 & $\mathrm{~T}$ & $\mathrm{U}$ & -- & -- & -- & SDST & B179 & -- & -- \\
\hline WGW 401 & 264 & $\mathrm{~T}$ & $\mathrm{U}$ & -- & -- & -- & SDST & B151 & -- & -- \\
\hline WGW 402 & 308.3 & $\mathrm{~T}$ & $\mathrm{U}$ & -- & -- & -- & SDST & B187 & -- & -- \\
\hline WGW 403 & 273.7 & $\mathrm{~T}$ & $\mathrm{U}$ & -- & -- & -- & SDST & B133 & -- & -- \\
\hline WGW 404 & 333.3 & $\mathrm{~T}$ & $\mathrm{U}$ & -- & -- & -- & SDGL & B163 & -- & -- \\
\hline WGW 405 & 297.6 & $\mathrm{~T}$ & $\mathrm{U}$ & -- & -- & -- & SDGL & -- & -- & -- \\
\hline WGW 406 & 292.9 & $\mathrm{~T}$ & $\mathrm{U}$ & -- & -- & -- & SDGL & B76 & -- & -- \\
\hline WGW 407 & 328.6 & $\mathrm{~T}$ & $\mathrm{U}$ & -- & -- & -- & SGVC & B116 & -- & -- \\
\hline WGW 408 & 301.5 & $\mathrm{~T}$ & $\mathrm{U}$ & -- & -- & -- & SDST & B56.2 & -- & -- \\
\hline WGW 409 & 279.7 & $\mathrm{~T}$ & $\mathrm{U}$ & -- & -- & -- & SDGL & B156 & -- & -- \\
\hline WGW 410 & 278 & $\mathrm{~T}$ & $\mathrm{U}$ & 923 & 31 & 48 & SDGL & B81 & G & $\mathrm{Y}$ \\
\hline WGW 411 & 258 & $\mathrm{~T}$ & $\mathrm{U}$ & 326 & 38.2 & 49 & SDGL & -- & $\mathrm{G}$ & Y \\
\hline WGW 412 & 258.06 & $\mathrm{O}$ & $\mathrm{U}$ & 55 & -- & -- & SDGL & -- & $\mathrm{G}$ & -- \\
\hline WGW 413 & 255.81 & $\mathrm{O}$ & $\mathrm{U}$ & 25 & -- & -- & SAND & -- & G & -- \\
\hline WGW 414 & 262.28 & $\mathrm{O}$ & $\mathrm{U}$ & 25 & -- & -- & SAND & -- & G & -- \\
\hline WGW 415 & 267.94 & $\mathrm{O}$ & $\mathrm{U}$ & 25 & -- & -- & SDGL & -- & G & -- \\
\hline WGW 416 & 270.52 & $\mathrm{O}$ & $\mathrm{U}$ & -- & -- & -- & SAND & -- & $\mathrm{G}$ & -- \\
\hline WGW 417 & 267.7 & $\mathrm{O}$ & $\mathrm{U}$ & 30 & -- & -- & SDGL & -- & G & -- \\
\hline WGW 418 & 276.93 & $\mathrm{O}$ & $\mathrm{U}$ & 30 & -- & -- & SDGL & -- & G & -- \\
\hline WGW 419 & 277.27 & $\mathrm{O}$ & $\mathrm{U}$ & 30 & -- & -- & SDGL & -- & G & -- \\
\hline WGW 420 & 270.64 & $\mathrm{O}$ & $\mathrm{U}$ & 30 & -- & -- & SDGL & -- & G & -- \\
\hline WGW 421 & 272.6 & $\mathrm{O}$ & $\mathrm{U}$ & 30 & -- & -- & SDGL & -- & G & -- \\
\hline WGW 422 & 262 & $\mathrm{U}$ & $\mathrm{U}$ & -- & -- & -- & SDGL & -- & -- & -- \\
\hline WGW 423 & 260 & $\mathrm{U}$ & $\mathrm{U}$ & -- & -- & -- & SDGL & -- & -- & -- \\
\hline WGW 424 & 259 & $\mathrm{U}$ & $\mathrm{U}$ & -- & -- & -- & SDGL & -- & -- & -- \\
\hline WGW 425 & 258 & $\mathrm{U}$ & $\mathrm{U}$ & -- & -- & -- & SDGL & -- & -- & -- \\
\hline
\end{tabular}


Table 2. Selected water levels measured monthly in observation wells in the Big-Mishnock stream-aquifer system, central Rhode Island, 1996-98

[Site locations are shown on plate 1.Water levels in feet below land surface; +, indicates a water level above land surface; WGW, West Greenwich well; --, no data available]

\begin{tabular}{|c|c|c|c|c|c|c|c|c|c|}
\hline Date & $\begin{array}{l}\text { Water } \\
\text { level } \\
\text { (feet) }\end{array}$ & Date & $\begin{array}{l}\text { Water } \\
\text { level } \\
\text { (feet) }\end{array}$ & Date & $\begin{array}{l}\text { Water } \\
\text { level } \\
\text { (feet) }\end{array}$ & Date & $\begin{array}{l}\text { Water } \\
\text { level } \\
\text { (feet) }\end{array}$ & Date & $\begin{array}{l}\text { Water } \\
\text { level } \\
\text { (feet) }\end{array}$ \\
\hline \multicolumn{2}{|c|}{ Well No.: WGW 211} & \multicolumn{3}{|c|}{ Site Identification No.: $\mathbf{4 1 3 6 1 7 0 7 1 3 6 2 9 0 1}$} & & & & & \\
\hline OCT 18,1996 & 12.19 & MAR 20, 1997 & 9.30 & AUG 27, 1997 & 12.19 & JAN 15, 1998 & 12.19 & JUN 25, 1998 & 7.52 \\
\hline NOV 22 & 12.19 & APR 14 & 8.80 & SEP 18 & 12.19 & FEB 17 & 10.98 & JUL 15 & 8.22 \\
\hline DEC 18 & 10.61 & MAY 20 & 9.22 & OCT 16 & 12.19 & MAR 24 & 7.95 & AUG 26 & 11.07 \\
\hline JAN 23, 1997 & 9.52 & JUN 17 & 10.13 & NOV 12 & 12.19 & APR 14 & 7.93 & SEP 29 & 12.19 \\
\hline FEB 20 & 8.92 & JUL 15 & 11.22 & DEC 09 & 12.19 & MAY 19 & 7.52 & OCT 27 & 12.19 \\
\hline \multicolumn{2}{|c|}{ Well No.: WGW 285} & \multicolumn{3}{|c|}{ Site Identification No.: 413739071375601} & & & & & \\
\hline JUL 15, 1996 & 7.22 & JAN 23, 1997 & 7.45 & JUL 16, 1997 & 8.61 & JAN 15, 1998 & 7.32 & JUN 25, 1998 & 7.32 \\
\hline AUG 15 & 8.43 & FEB 20 & 7.46 & AUG 27 & 8.36 & FEB 17 & 7.28 & JUL 15 & 8.11 \\
\hline SEP 30 & 8.27 & MAR 20 & 7.49 & SEP 18 & 8.46 & MAR 25 & 6.88 & AUG 24 & 8.66 \\
\hline OCT 17 & 8.23 & APR 14 & 6.72 & OCT 16 & 8.63 & APR 14 & 7.31 & SEP 29 & 8.64 \\
\hline NOV 21 & 7.94 & MAY 20 & 7.66 & NOV 12 & 7.65 & MAY 20 & 7.48 & OCT 27 & 8.48 \\
\hline DEC 18 & 6.47 & JUN 17 & 8.27 & DEC 09 & 8.10 & & & & \\
\hline \multicolumn{2}{|c|}{ Well No.: WGW 286} & \multicolumn{3}{|c|}{ Site Identification No.: $\mathbf{4 1 3 6 3 5 0 7 1 3 7 1 1 0 1}$} & & & & & \\
\hline JUL 15, 1996 & 21.26 & JAN 23, 1997 & 20.20 & JUL 15, 1997 & 21.78 & JAN 15, 1998 & 22.07 & JUN 25, 1998 & 18.66 \\
\hline AUG 15 & 21.96 & FEB 20 & 19.84 & AUG 27 & 22.46 & FEB 17 & 20.63 & JUL 15 & 19.19 \\
\hline SEP 30 & 22.42 & MAR 20 & 20.14 & SEP 18 & 22.67 & MAR 24 & 18.97 & AUG 26 & 20.81 \\
\hline OCT 17 & 22.39 & APR 14 & 19.76 & OCT 16 & 23.11 & APR 14 & 18.99 & SEP 29 & 21.71 \\
\hline NOV 22 & 21.70 & MAY 20 & 20.04 & NOV 12 & 22.69 & MAY 19 & 18.75 & OCT 27 & 22.08 \\
\hline DEC 18 & 20.77 & JUN 17 & 20.86 & DEC 09 & 22.61 & & & & \\
\hline \multicolumn{2}{|c|}{ Well No.: WGW 287} & \multicolumn{3}{|c|}{ Site Identification No.: 413656071370601} & & & & & \\
\hline JUL 15, 1996 & 6.39 & JAN 23, 1997 & 5.43 & JUL 15, 1997 & 8.20 & JAN, 1998 & -- & JUN 25, 1998 & 3.13 \\
\hline AUG 15 & 8.42 & FEB 20 & 4.63 & AUG 27 & 9.60 & FEB 17 & 6.23 & JUL 15 & 4.51 \\
\hline SEP 30 & 9.58 & MAR 20 & 4.94 & SEP 18 & 9.90 & MAR 24 & 2.62 & AUG 26 & 7.11 \\
\hline OCT 17 & 9.61 & APR 14 & 4.00 & OCT 16 & 10.87 & APR 14 & 3.08 & SEP 29 & 8.65 \\
\hline NOV 21 & 8.66 & MAY 20 & 5.01 & NOV 12 & 10.56 & MAY 19 & 3.10 & OCT 27 & 9.31 \\
\hline DEC 18 & 6.21 & JUN 17 & 6.57 & DEC 09 & 10.37 & & & & \\
\hline \multicolumn{2}{|c|}{ Well No.: WGW 289} & \multicolumn{3}{|c|}{ Site Identification No.: $\mathbf{4 1 3 7 5 5 0 7 1 3 6 3 9 0 1}$} & & & & & \\
\hline JUL 11, 1996 & 15.50 & JAN 23, 1997 & 14.18 & JUL 17, 1997 & 15.87 & JAN 14, 1998 & 15.83 & JUN 25, 1998 & 12.80 \\
\hline AUG 15 & 15.99 & FEB 20 & 13.79 & AUG 27 & 16.61 & FEB 17 & 14.31 & JUL 15 & 13.45 \\
\hline SEP 30 & 16.65 & MAR 20 & 14.13 & SEP 17 & 16.57 & MAR 24 & 12.60 & AUG 26 & 14.99 \\
\hline OCT 17 & 16.60 & APR 15 & 13.70 & OCT 16 & 17.05 & APR 14 & 12.74 & SEP 29 & 15.85 \\
\hline NOV 21 & 15.84 & MAY 20 & 14.13 & NOV 12 & 16.76 & MAY 20 & 12.54 & OCT 27 & 16.24 \\
\hline DEC 18 & 14.71 & JUN 17 & 14.91 & DEC 09 & 16.44 & & & & \\
\hline \multicolumn{2}{|c|}{ Well No.: WGW 290} & \multicolumn{3}{|c|}{ Site Identification No.: 413755071363902} & & & & & \\
\hline JUL 15, 1996 & 15.16 & JAN 23, 1997 & 14.05 & JUL 15, 1997 & 15.73 & JAN 14, 1998 & 15.70 & JUN 25, 1998 & 12.69 \\
\hline AUG 15 & 15.86 & FEB 20 & 13.65 & AUG 27 & 16.48 & FEB 17 & 14.21 & JUL 15 & 13.31 \\
\hline SEP 30 & 16.49 & MAR 20 & 14.01 & SEP 17 & 16.46 & MAR 24 & 12.47 & AUG 26 & 14.87 \\
\hline OCT 18 & 16.57 & APR 15 & 13.58 & OCT 16 & 16.94 & APR 14 & 12.63 & SEP 29 & 15.72 \\
\hline NOV 21 & 15.71 & MAY 20 & 13.97 & NOV 12 & 16.61 & MAY 20 & 12.38 & OCT 27 & 16.09 \\
\hline DEC 18 & 14.57 & JUN 17 & 14.76 & DEC 09 & 16.30 & & & & \\
\hline
\end{tabular}


Table 2. Selected water levels measured monthly in observation wells in the Big-Mishnock stream-aquifer system, central Rhode Island, 1996-98-Continued

\begin{tabular}{|c|c|c|c|c|c|c|c|c|c|}
\hline Date & $\begin{array}{l}\text { Water } \\
\text { level } \\
\text { (feet) }\end{array}$ & Date & $\begin{array}{l}\text { Water } \\
\text { level } \\
\text { (feet) }\end{array}$ & Date & $\begin{array}{l}\text { Water } \\
\text { level } \\
\text { (feet) }\end{array}$ & Date & $\begin{array}{l}\text { Water } \\
\text { level } \\
\text { (feet) }\end{array}$ & Date & $\begin{array}{l}\text { Water } \\
\text { level } \\
\text { (feet) }\end{array}$ \\
\hline \multicolumn{10}{|c|}{ Well No.: WGW 291} \\
\hline JUL 15, 1996 & 1.56 & JAN 23, 1997 & 1.21 & JUL 15, 1997 & 2.85 & JAN 14, 1998 & 1.69 & JUN 25, 1998 & 0.77 \\
\hline AUG 15 & 2.39 & FEB 20 & 1.16 & AUG 27 & 2.80 & FEB 17 & 1.33 & JUL 15 & 1.48 \\
\hline SEP 30 & 2.65 & MAR 20 & 1.37 & SEP 17 & 2.71 & MAR 24 & .58 & AUG 26 & 2.26 \\
\hline OCT 18 & 2.41 & APR 15 & .97 & OCT 16 & 3.03 & APR 14 & .90 & SEP 29 & 2.61 \\
\hline NOV 21 & 2.00 & MAY 20 & 1.50 & NOV 12 & 2.24 & MAY 20 & .94 & OCT 27 & 2.51 \\
\hline DEC 18 & .97 & JUN 17 & 2.16 & DEC 09 & 2.28 & & & & \\
\hline \multicolumn{2}{|c|}{ Well No.: WGW 292} & \multicolumn{8}{|c|}{ Site Identification No.: 413829071363401} \\
\hline JUL 15, 1996 & 13.05 & JAN 23, 1997 & 12.46 & JUL 15, 1997 & 13.79 & JAN 15, 1998 & 12.57 & JUN 25, 1998 & 11.85 \\
\hline AUG 15 & 13.57 & FEB 20 & 12.53 & AUG 27 & 13.72 & FEB 17 & 12.13 & JUL 16 & 12.57 \\
\hline SEP 30 & 13.42 & MAR 20 & 12.50 & SEP 17 & 13.56 & MAR 25 & 11.43 & AUG 26 & 13.51 \\
\hline OCT 17 & 13.30 & APR 14 & 11.91 & OCT 16 & 13.91 & APR 14 & 11.93 & SEP 29 & 13.72 \\
\hline NOV 21 & 13.02 & MAY 20 & 12.23 & NOV 12 & 13.20 & MAY 19 & 11.72 & OCT 27 & 13.55 \\
\hline DEC 18 & 11.90 & JUN 17 & 13.14 & DEC 09 & 13.11 & & & & \\
\hline \multicolumn{5}{|c|}{ Well No.: WGW 293} & & & & & \\
\hline JUL 15, 1996 & 12.94 & JAN 23, 1997 & 12.32 & JUL 15, 1997 & 13.76 & JAN 15, 1998 & 12.48 & JUN 25, 1998 & 11.75 \\
\hline AUG 15 & 13.41 & FEB 20 & 12.14 & AUG 27 & 13.67 & FEB 17 & 12.04 & JUL 16 & 12.51 \\
\hline SEP 30 & 13.34 & MAR 20 & 12.42 & SEP 17 & 13.51 & MAR 25 & 11.30 & AUG 26 & 13.51 \\
\hline OCT 17 & 13.18 & APR 14 & 11.83 & OCT 16 & 13.88 & APR 14 & 11.86 & SEP 29 & 13.71 \\
\hline NOV 22 & 12.85 & MAY 20 & 12.90 & NOV 12 & 13.13 & MAY 19 & 11.60 & OCT 27 & 13.52 \\
\hline DEC 18 & 11.70 & JUN 17 & 13.09 & DEC 09 & 13.05 & & & & \\
\hline \multicolumn{5}{|c|}{ Well No.: WGW 294} & & & & & \\
\hline JUL 15, 1996 & 2.01 & JAN 23, 1997 & 1.81 & JUL 15, 1997 & 4.70 & JAN 14, 1998 & 1.78 & JUN 25, 1998 & 2.00 \\
\hline AUG 15 & 3.04 & FEB 20 & 1.95 & AUG 27 & 3.91 & FEB 17 & 1.86 & JUL 15 & 2.78 \\
\hline SEP 30 & 2.80 & MAR 20 & 2.01 & SEP 17 & 3.54 & MAR 24 & 1.51 & AUG 26 & 3.78 \\
\hline OCT 18 & 2.55 & APR 14 & 1.72 & OCT 16 & 4.08 & APR 14 & 1.95 & SEP 29 & 4.28 \\
\hline NOV 21 & 2.20 & MAY 20 & 2.10 & NOV 12 & 2.10 & MAY 20 & 2.11 & OCT 27 & 3.59 \\
\hline DEC 18 & 1.35 & JUN 18 & 3.23 & DEC 09 & 2.26 & & & & \\
\hline \multicolumn{5}{|c|}{ Well No.: WGW 295} & & & & & \\
\hline JUL 15, 1996 & 3.26 & JAN 23, 1997 & 2.97 & JUL 15, 1997 & 4.34 & JAN14, 1998 & 2.90 & JUN 25, 1998 & 2.49 \\
\hline AUG 15 & 3.91 & FEB 20 & 2.92 & AUG 28 & 3.91 & FEB 18 & 1.99 & JUL 15 & 3.23 \\
\hline SEP 30 & 3.88 & MAR 20 & 3.13 & SEP 17 & 3.86 & MAR 24 & 2.07 & AUG 24 & 4.20 \\
\hline OCT 18 & 3.74 & APR 15 & 2.69 & OCT 16 & 4.08 & APR 13 & 2.54 & SEP 29 & 4.09 \\
\hline NOV 21 & 3.48 & MAY 21 & 3.29 & NOV 13 & 3.31 & MAY 19 & 2.52 & OCT 27 & 3.83 \\
\hline DEC 18 & 2.43 & JUN 18 & 3.99 & DEC 09 & 3.45 & & & & \\
\hline \multicolumn{2}{|c|}{ Well No.: WGW 296} & \multicolumn{3}{|c|}{ Site Identification No.: 413824071342401} & & & & & \\
\hline JUL 15, 1996 & 21.29 & JAN 23, 1997 & 20.61 & JUL 15, 1997 & 22.00 & JAN 14, 1998 & 25.00 & JUN 25, 1998 & 15.77 \\
\hline AUG 15 & 22.64 & FEB 20 & 19.65 & AUG 28 & 24.34 & FEB 17 & 22.23 & JUL 15 & 16.24 \\
\hline SEP 30 & 24.80 & MAR 20 & 19.76 & SEP 17 & 24.71 & MAR 24 & 17.85 & AUG 24 & 19.15 \\
\hline OCT 18 & 24.85 & APR 15 & 19.17 & OCT 16 & 25.60 & APR 13 & 17.12 & SEP 29 & 21.83 \\
\hline NOV 21 & 23.89 & MAY 21 & 19.06 & NOV 13 & 26.03 & MAY 19 & 15.95 & OCT 27 & 23.34 \\
\hline DEC 18 & 22.73 & JUN 18 & 20.22 & DEC 09 & 25.59 & & & & \\
\hline
\end{tabular}


Table 2. Selected water levels measured monthly in observation wells in the Big-Mishnock stream-aquifer system, central Rhode Island, 1996-98-Continued

\begin{tabular}{|c|c|c|c|c|c|c|c|c|c|}
\hline Date & $\begin{array}{l}\text { Water } \\
\text { level } \\
\text { (feet) }\end{array}$ & Date & $\begin{array}{l}\text { Water } \\
\text { level } \\
\text { (feet) }\end{array}$ & Date & $\begin{array}{l}\text { Water } \\
\text { level } \\
\text { (feet) }\end{array}$ & Date & $\begin{array}{l}\text { Water } \\
\text { level } \\
\text { (feet) }\end{array}$ & Date & $\begin{array}{l}\text { Water } \\
\text { level } \\
\text { (feet) }\end{array}$ \\
\hline \multicolumn{5}{|c|}{ Well No.: WGW 297} & & & & & \\
\hline JUL 15, 1996 & 40.16 & JAN 23, 1997 & 40.53 & JUL 16, 1997 & 40.64 & JAN 15, 1998 & 41.61 & JUN 25, 1998 & 38.25 \\
\hline AUG 15 & 40.74 & FEB 20 & 40.15 & AUG 27 & 40.15 & FEB 17 & 41.20 & JUL 16 & 37.99 \\
\hline SEP 30 & 41.22 & MAR 20 & 39.69 & SEP 18 & 41.37 & MAR 25 & 40.04 & AUG 26 & 38.94 \\
\hline OCT 18 & 41.39 & APR 15 & 40.02 & OCT 16 & 41.51 & APR 13 & 38.94 & SEP 29 & 40.26 \\
\hline NOV 21 & 41.37 & MAY 21 & 39.85 & NOV 12 & 41.61 & MAY 19 & 38.40 & OCT 27 & 40.85 \\
\hline DEC 18 & 41.31 & JUN 18 & 40.14 & DEC 09 & 41.67 & & & & \\
\hline \multicolumn{10}{|c|}{ Well No.: WGW $298 \quad$ Site Identification No.: 413850071353001} \\
\hline JUL 1996 & -- & JAN 23, 1997 & 13.53 & JUL 16, 1997 & 15.38 & JAN 15, 1998 & 15.23 & JUN 25, 1998 & 11.56 \\
\hline AUG 15 & 15.43 & FEB 20 & 13.12 & AUG 27 & 15.96 & FEB 16 & 13.84 & JUL 15 & 12.43 \\
\hline SEP 30 & 15.91 & MAR 20 & 13.48 & SEP 1 & 15.91 & MAR 25 & 11.95 & AUG 24 & 14.17 \\
\hline OCT 18 & 15.87 & APR 15 & 12.88 & OCT 16 & 16.42 & APR 14 & 12.24 & SEP 29 & 14.97 \\
\hline NOV 22 & 15.16 & MAY 21 & 13.65 & NOV 12 & 16.11 & MAY 19 & 11.66 & OCT 27 & 15.23 \\
\hline DEC 04 & 14.89 & JUN 18 & 14.50 & DEC 09 & 15.76 & & & & \\
\hline \multicolumn{2}{|c|}{ Well No.: WGW 299} & Site Identificatio & No.: 413 & 34071345501 & & & & & \\
\hline JUL 15, 1996 & 24.25 & JAN 23, 1997 & 23.04 & JUL 16, 1997 & 24.08 & JAN 14, 1998 & 25.73 & JUN 25, 1998 & 20.31 \\
\hline AUG 15 & 24.37 & FEB 20 & 22.78 & AUG 28 & 25.34 & FEB 17 & 24.21 & JUL 15 & 20.08 \\
\hline SEP 30 & 25.31 & MAR 20 & 22.93 & SEP 17 & 25.11 & MAR 25 & 21.97 & AUG 26 & 21.86 \\
\hline OCT 18 & 25.45 & APR 15 & 22.78 & OCT 16 & 25.64 & APR 14 & 21.36 & SEP 29 & 23.32 \\
\hline NOV 21 & 24.57 & MAY 21 & 22.53 & NOV 12 & 26.09 & MAY 20 & 20.62 & OCT 27 & 24.21 \\
\hline DEC 18 & 24.38 & JUN 17 & 23.25 & DEC 09 & 25.90 & & & & \\
\hline \multicolumn{2}{|c|}{ Well No.: WGW 300} & \multicolumn{3}{|c|}{ Site Identification No.: $\mathbf{4 1 3 8 4 5 0 7 1 3 5 0 8 0 1}$} & & & & & \\
\hline JUL 15, 1996 & 9.84 & JAN 27, 1997 & 9.65 & JUL 16, 1997 & 12.91 & JAN 14, 1998 & 10.69 & JUN 25, 1998 & 7.20 \\
\hline AUG 15 & 12.78 & FEB 20 & 9.21 & AUG 28 & 12.29 & FEB 16 & 9.60 & JUL 15 & 8.44 \\
\hline SEP 30 & 12.25 & MAR 20 & 9.71 & SEP 17 & 12.93 & MAR 25 & 7.91 & AUG 26 & 11.36 \\
\hline OCT 18 & 11.63 & APR 15 & 8.63 & OCT 16 & 13.89 & APR 14 & 8.18 & SEP 29 & 11.74 \\
\hline NOV 22 & 10.94 & MAY 21 & 10.44 & NOV 13 & 11.32 & MAY 20 & 7.77 & OCT 27 & 11.96 \\
\hline DEC 04 & 10.79 & JUN 17 & 11.79 & DEC 09 & 12.31 & & & & \\
\hline \multicolumn{2}{|c|}{ Well No.: WGW 301} & \multicolumn{3}{|c|}{ Site Identification No.: 413845071350802} & & & & & \\
\hline JUL 16, 1996 & 15.79 & JAN 23, 1997 & 10.76 & JUL 16, 1997 & 12.33 & JAN 14, 1998 & 12.31 & JUN 25, 1998 & 8.71 \\
\hline AUG 15 & 12.40 & FEB 20 & 10.46 & AUG 28 & 12.76 & FEB 16 & 11.18 & JUL 15 & 9.13 \\
\hline SEP 30 & 12.78 & MAR 20 & 10.70 & SEP 17 & 12.82 & MAR 25 & 9.63 & AUG 26 & 10.81 \\
\hline OCT 18 & 12.66 & APR 15 & 10.36 & OCT 16 & 13.33 & APR 14 & 9.51 & SEP 29 & 11.60 \\
\hline NOV 22 & 12.22 & MAY 21 & 10.73 & NOV 13 & 12.70 & MAY 20 & 9.01 & OCT 27 & 12.04 \\
\hline DEC 18 & 11.05 & JUN 17 & 11.49 & DEC 09 & 12.85 & & & & \\
\hline \multicolumn{2}{|c|}{ Well No.: WGW 302} & \multicolumn{3}{|c|}{ Site Identification No.: 413901071354701} & & & & & \\
\hline JUL 17, 1996 & 62.15 & JAN 23, 1997 & 61.01 & JUL 16, 1997 & 61.65 & JAN 15, 1998 & 61.64 & JUN 25, 1998 & 60.38 \\
\hline AUG 15 & 61.74 & FEB 20 & 59.99 & AUG 28 & 61.91 & FEB 17 & 61.00 & JUL 16 & 60.60 \\
\hline SEP 30 & 61.93 & MAR 20 & 61.03 & SEP 18 & 61.94 & MAR 25 & 60.52 & AUG 26 & 61.22 \\
\hline OCT 18 & 61.93 & APR 14 & 60.88 & OCT 15 & 62.08 & APR 13 & 60.62 & SEP 29 & 61.42 \\
\hline NOV 22 & 61.61 & MAY 21 & 60.93 & NOV 12 & 61.90 & MAY 19 & 60.36 & OCT 27 & 61.46 \\
\hline DEC 18 & 61.29 & JUN 18 & 61.28 & DEC 09 & 61.79 & & & & \\
\hline
\end{tabular}


Table 2. Selected water levels measured monthly in observation wells in the Big-Mishnock stream-aquifer system, central Rhode Island, 1996-98-Continued

\begin{tabular}{|c|c|c|c|c|c|c|c|c|c|}
\hline Date & $\begin{array}{l}\text { Water } \\
\text { level } \\
\text { (feet) }\end{array}$ & Date & $\begin{array}{l}\text { Water } \\
\text { level } \\
\text { (feet) }\end{array}$ & Date & $\begin{array}{l}\text { Water } \\
\text { level } \\
\text { (feet) }\end{array}$ & Date & $\begin{array}{l}\text { Water } \\
\text { level } \\
\text { (feet) }\end{array}$ & Date & $\begin{array}{l}\text { Water } \\
\text { level } \\
\text { (feet) }\end{array}$ \\
\hline \multicolumn{10}{|c|}{ Well No.: WGW $303 \quad$ Site Identification No.: 413837071371101} \\
\hline JUL 17, 1996 & 28.20 & JAN 23, 1997 & 26.90 & JUL 15, 1997 & 28.59 & JAN 15, 1998 & 30.36 & JUN 25, 1998 & 25.22 \\
\hline AUG 15 & 28.70 & FEB 20 & 26.59 & AUG 27 & 30.30 & FEB 17 & 28.16 & JUL 16 & 25.59 \\
\hline SEP 30 & 29.93 & MAR 20 & 26.88 & SEP 18 & 30.59 & MAR 24 & 26.28 & AUG 26 & 27.67 \\
\hline OCT 17 & 30.09 & APR 14 & 26.77 & OCT 15 & 31.06 & APR 14 & 25.20 & SEP 29 & 29.16 \\
\hline NOV 21 & 29.15 & MAY 20 & 26.55 & NOV 12 & 31.34 & MAY 20 & 24.94 & OCT 27 & 29.95 \\
\hline DEC 19 & 28.43 & JUN 17 & 27.39 & DEC 09 & 30.88 & & & & \\
\hline \multicolumn{10}{|c|}{ Well No.: WGW $304 \quad$ Site Identification No.: 413924071373601} \\
\hline JUL 17, 1996 & 20.50 & JAN 23, 1997 & 17.08 & JUL 15, 1997 & 20.65 & JAN 15, 1998 & 20.70 & JUN 25, 1998 & 15.47 \\
\hline AUG 15 & 20.88 & FEB 20 & 16.76 & AUG 27 & 22.21 & FEB 17 & 17.01 & JUL 16 & 16.71 \\
\hline SEP 30 & 21.84 & MAR 20 & 17.90 & SEP 18 & 22.46 & MAR 25 & 14.70 & AUG 25 & 19.96 \\
\hline OCT 17 & 21.89 & APR 14 & 16.92 & OCT 15 & 22.80 & APR 13 & 15.32 & SEP & -- \\
\hline NOV 21 & 20.14 & MAY 20 & 17.51 & NOV 12 & 22.73 & MAY 19 & 14.93 & OCT 27 & 21.92 \\
\hline DEC 18 & 17.61 & JUN 17 & 18.99 & DEC 09 & 22.17 & & & & \\
\hline \multicolumn{10}{|c|}{ Well No.: WGW $305 \quad$ Site Identification No.: 413849071370801} \\
\hline OCT 18,1996 & 7.66 & MAR 20, 1997 & 4.74 & AUG 27,1997 & 7.97 & JAN 1998 & -- & JUN 25, 1998 & 3.02 \\
\hline NOV 26 & 6.86 & APR 14 & 4.09 & SEP 18 & 8.17 & FEB & -- & JUL 16 & 3.94 \\
\hline DEC 19 & 5.08 & MAY 20 & 4.89 & OCT 15 & 8.70 & MAR 25 & 3.28 & AUG 26 & 5.73 \\
\hline JAN 23, 1997 & 4.91 & JUN 17 & 5.78 & NOV 13 & 8.42 & APR 14 & 3.55 & SEP 29 & 6.91 \\
\hline FEB 20 & 4.32 & JUL 15 & 6.91 & DEC 09 & 7.99 & MAY 20 & 3.12 & OCT 27 & 7.52 \\
\hline \multicolumn{10}{|c|}{ Well No.: WGW $306 \quad$ Site Identification No.: 413836071351301} \\
\hline NOV 27, 1996 & 24.60 & APR 15, 1997 & 23.48 & SEP 17,1997 & 25.42 & FEB 16, 1998 & 24.11 & JUL 15, 1998 & 22.92 \\
\hline DEC 20 & 23.82 & MAY 21 & 23.87 & OCT 16 & 25.85 & MAR 25 & 23.00 & AUG 26 & 24.10 \\
\hline JAN 23, 1997 & 23.98 & JUN 17 & 24.45 & NOV 12 & 25.29 & APR 14 & 23.04 & SEP 29 & 24.72 \\
\hline FEB 20 & 23.78 & JUL 16 & 25.11 & DEC 09 & 25.37 & MAY 20 & 22.69 & OCT 27 & 24.97 \\
\hline MAR 20 & 23.85 & AUG 28 & 25.44 & JAN 14, 1998 & 24.89 & JUN 25 & 22.54 & & \\
\hline \multicolumn{10}{|c|}{ Well No.: WGW $307 \quad$ Site Identification No.: 413842071350901} \\
\hline DEC 20, 1996 & 8.28 & MAY 21, 1997 & 8.15 & OCT 16, 1997 & 10.65 & MAR 25, 1998 & 6.72 & JUL 15, 1998 & 6.32 \\
\hline JAN 23, 1997 & 8.32 & JUN 17 & 8.86 & NOV 12 & 9.99 & APR 14 & 6.65 & AUG 26 & 7.89 \\
\hline FEB 16 & 7.93 & JUL 16 & 9.66 & DEC 09 & 10.16 & MAY 20 & 6.17 & SEP 26 & 8.68 \\
\hline MAR 20 & 8.11 & AUG 28 & 10.12 & JAN 14, 1998 & 9.61 & JUN 25 & 5.93 & OCT 29 & 9.07 \\
\hline APR 15 & 7.66 & SEP 17 & 10.12 & FEB 16 & 8.47 & & & & \\
\hline \multicolumn{10}{|c|}{ Well No.: WGW $308 \quad$ Site Identification No.: 413837071345001} \\
\hline DEC 20, 1996 & 25.34 & MAY 21, 1997 & 24.20 & OCT 16,1997 & 27.17 & MAR 25, 1998 & 23.46 & JUL 15, 1998 & 22.05 \\
\hline JAN 23, 1997 & 24.59 & JUN 17 & 24.91 & NOV 12 & 27.25 & APR 14 & 23.06 & AUG 26 & 23.76 \\
\hline FEB 20 & 24.25 & JUL 16 & 25.77 & DEC 09 & 27.11 & MAY 20 & 22.32 & SEP 29 & 25.02 \\
\hline MAR 20 & 24.44 & AUG 28 & 26.78 & JAN 14, 1998 & 26.80 & JUN 25 & 21.95 & OCT 27 & 25.74 \\
\hline APR 15 & 24.15 & SEP 17 & 26.54 & FEB 17 & 25.43 & & & & \\
\hline
\end{tabular}


Table 2. Selected water levels measured monthly in observation wells in the Big-Mishnock stream-aquifer system, central Rhode Island, 1996-98-Continued

\begin{tabular}{|c|c|c|c|c|c|c|c|c|c|}
\hline Date & $\begin{array}{l}\text { Water } \\
\text { level } \\
\text { (feet) }\end{array}$ & Date & $\begin{array}{l}\text { Water } \\
\text { level } \\
\text { (feet) }\end{array}$ & Date & $\begin{array}{l}\text { Water } \\
\text { level } \\
\text { (feet) }\end{array}$ & Date & $\begin{array}{l}\text { Water } \\
\text { level } \\
\text { (feet) }\end{array}$ & Date & $\begin{array}{l}\text { Water } \\
\text { level } \\
\text { (feet) }\end{array}$ \\
\hline \multicolumn{10}{|c|}{ Well No.: WGW $312 \quad$ Site Identification No.: 413840071352601} \\
\hline DEC 19, 1996 & 3.70 & MAY 21,1997 & 3.84 & OCT 17,1997 & 5.49 & MAR 24, 1998 & 2.91 & JUL 15, 1998 & 3. \\
\hline JAN 23, 1997 & 3.83 & JUN 18 & 4.36 & NOV & -- & APR 14 & 3.05 & AUG 26 & \\
\hline FEB 20 & 3.68 & JUL 16 & 4.94 & DEC 09 & 4.82 & MAY 20 & 2.80 & SEP 29 & \\
\hline MAR 20 & 3.77 & AUG 28 & 5.12 & JAN 15, 1998 & 4.31 & JUN 25 & 2.69 & OCT 27 & \\
\hline APR 15 & 3.47 & SEP 17 & 5.10 & FEB 16 & 3.72 & & & & \\
\hline
\end{tabular}

Well No.: WGW 313 Site Identification No.: 413858071371201

$\begin{array}{lllllllll}\text { DEC 23, 1996 } & 6.38 & \text { MAY 20, 1997 } & 6.53 & \text { OCT 15, 1997 } & 9.32 & \text { MAR 25, 1998 } & 5.52 & \text { JUL 16, 1998 } \\ \text { JAN 23, 1997 } & 6.63 & \text { JUN 17 } & 7.13 & \text { NOV 13 } & 9.03 & \text { APR 14 } & 5.72 & \text { AUG 26 } \\ \text { FEB 20 } & 6.53 & \text { JUL 15 } & 8.08 & \text { DEC 09 } & 8.56 & \text { MAY 20 } & 5.43 & \text { SEP 29 } \\ \text { MAR 20 } & 6.85 & \text { AUG 28 } & 8.97 & \text { JAN 15, 1998 } & 7.86 & \text { JUN 25 } & 5.63 & \text { OCT 27 } \\ \text { APR 14 } & 6.29 & \text { SEP 18 } & 8.91 & \text { FEB 17 } & 6.80 & & & 8.24\end{array}$

Well No.: WGW 319 Site Identification No.: 413738071381601

\begin{tabular}{|c|c|c|c|c|c|c|c|c|c|}
\hline MAY 20, 1997 & 4.77 & SEP 18, 1997 & 5.11 & JAN 15, 1998 & 4.29 & MAY 20, 1998 & 4.77 & AUG 26, 1998 & 6.24 \\
\hline JUN 17 & 5.50 & OCT 16 & 5.82 & FEB 17 & 4.44 & JUN 25 & 4.59 & SEP 29 & 5.94 \\
\hline JUL 16 & 6.35 & NOV 12 & 4.08 & MAR 25 & 4.08 & JUL 16 & 5.37 & OCT 27 & 5.40 \\
\hline AUG 28 & 5.25 & DEC 09 & 4.85 & APR 14 & 4.45 & & & & \\
\hline
\end{tabular}

Well No.: WGW 320 Site Identification No.: 413729071371801

\begin{tabular}{|c|c|c|c|c|c|c|c|c|c|}
\hline MAY 20, 1997 & 2.95 & SEP 18, 1997 & 6.19 & JAN 15, 1998 & 2.50 & MAY 20, 1998 & 2.29 & AUG 26, 1998 & 6.53 \\
\hline JUN 17 & 4.68 & OCT 16 & 7.56 & FEB 17 & 1.81 & JUN 25 & 1.93 & SEP 29 & 7.25 \\
\hline JUL 16 & 7.18 & NOV 12 & 4.70 & MAR & -- & JUL 16 & 3.47 & OCT 27 & 6.19 \\
\hline AUG 27 & 7.03 & DEC 09 & 4.15 & APR 14 & 1.94 & & & & \\
\hline
\end{tabular}

Well No.: WGW 321 Site Identification No.: 413856071342901

$\begin{array}{lrlrlllll}\text { MAY 21, 1997 } & 9.05 & \text { SEP 17, 1997 } & 9.84 & \text { JAN 14, 1998 } & 8.39 & \text { MAY 19, 1998 } & 8.46 & \text { AUG 26, 1998 } \\ \text { JUN 17 } & 9.74 & \text { OCT 16 } & 10.38 & \text { FEB 17 } & 8.39 & \text { JUN 25 } & 8.31 & \text { SEP 29 } \\ \text { JUL 16 } & 10.64 & \text { NOV 12 } & 8.96 & \text { MAR 25 } & 8.02 & \text { JUL 15 } & 9.22 & \text { OCT 27 } \\ \text { AUG 28 } & 9.76 & \text { DEC 09 } & 9.13 & \text { APR 14 } & 8.46 & & & \end{array}$

Well No.: WGW 336 Site Identification No.: 413840071352501

\begin{tabular}{|c|c|c|c|c|c|c|c|c|c|}
\hline JUL 30, 1997 & 3.57 & NOV 12, 1997 & 3.32 & FEB 18, 1998 & 2.34 & MAY 20, 1998 & 1.38 & AUG 26, 1998 & 2.54 \\
\hline AUG 28 & 3.61 & DEC 09 & 3.42 & MAR 25 & 1.51 & JUN 25 & 1.27 & SEP 29 & 3.04 \\
\hline SEP 17 & 3.58 & JAN 15, 1998 & 2.95 & APR 14 & 1.63 & JUL 15 & 1.65 & OCT 27 & 3.21 \\
\hline OCT 16 & 3.98 & & & & & & & & \\
\hline
\end{tabular}

Well No.: WGW 337 Site Identification No.: 413840071352301

$\begin{array}{lllllrlrr}\text { JUL 31, 1997 } & 2.29 & \text { NOV 12, 1997 } & 1.97 & \text { FEB 16, 1998 } & 0.97 & \text { MAY 20, 1998 } & +0.04 & \text { AUG 20, 1998 } \\ \text { AUG 28 } & 2.25 & \text { DEC 09 } & 2.09 & \text { MAR 25 } & .12 & \text { JUN 25 } & +.17 & \text { SEP 29 } \\ \text { SEP 17 } & 2.22 & \text { JAN 15, 1998 } & 1.61 & \text { APR 14 } & .23 & \text { JUL 15 } & .24 & \text { OCT 27 } \\ \text { OCT 17 } & 2.63 & & & & & & & 1.69\end{array}$

\section{Well No.: WGW 338 Site Identification No.: 413840071352201}

\begin{tabular}{|c|c|c|c|c|c|c|c|c|c|}
\hline AUG 28, 1997 & 2.94 & NOV 12, 1997 & 2.66 & FEB 16, 1998 & 1.60 & MAY 20, 1998 & 0.44 & AUG 26, 1998 & 1.73 \\
\hline SEP 17 & 2.90 & DEC 09 & 2.79 & MAR 25 & .71 & JUN 25 & .30 & SEP 29 & 2.29 \\
\hline OCT 17 & 3.31 & JAN 15, 1998 & 2.29 & APR 14 & .73 & JUL 15 & .70 & OCT 27 & 2.49 \\
\hline
\end{tabular}


Table 2. Selected water levels measured monthly in observation wells in the Big-Mishnock stream-aquifer system, central Rhode Island, 1996-98-Continued

\begin{tabular}{|c|c|c|c|c|c|c|c|c|c|}
\hline Date & $\begin{array}{l}\text { Water } \\
\text { level } \\
\text { (feet) }\end{array}$ & Date & $\begin{array}{l}\text { Water } \\
\text { level } \\
\text { (feet) }\end{array}$ & Date & $\begin{array}{l}\text { Water } \\
\text { level } \\
\text { (feet) }\end{array}$ & Date & $\begin{array}{l}\text { Water } \\
\text { level } \\
\text { (feet) }\end{array}$ & Date & $\begin{array}{l}\text { Water } \\
\text { level } \\
\text { (feet) }\end{array}$ \\
\hline \multicolumn{10}{|c|}{ Well No.: WGW $339 \quad$ Site Identification No.: 413841071352601} \\
\hline AUG 28, 1997 & 5.71 & NOV 12,1997 & 5.40 & FEB 16, 1998 & 4.42 & MAY 20, 1998 & 3.46 & AUG 26, 1998 & \\
\hline SEP 17 & 5.67 & DEC 09 & 5.51 & MAR 25 & 3.59 & JUN 25 & 3.34 & SEP & -- \\
\hline OCT 17 & 6.07 & JAN 15, 1998 & 5.05 & APR 14 & 3.71 & JUL 15 & 3.74 & OCT 27 & \\
\hline
\end{tabular}

Well No.: WGW 340 Site Identification No.: 413842071352501

\begin{tabular}{|c|c|c|c|c|c|c|c|c|c|}
\hline AUG 28, 1997 & 6.89 & NOV 12, 1997 & 6.59 & FEB 16, 1998 & 5.58 & MAY 20, 1998 & 4.59 & AUG 26, 1998 & 5.81 \\
\hline SEP 17 & 6.86 & DEC 09 & 6.71 & MAR 25 & 4.72 & JUN 25 & 4.47 & SEP 29 & 6.32 \\
\hline OCT 17 & 7.25 & JAN 15, 1998 & 6.22 & APR 14 & 4.85 & JUL 15 & 4.87 & OCT 27 & 6.47 \\
\hline
\end{tabular}

Well No.: WGW 341 Site Identification No.: 413840071352801

\begin{tabular}{|c|c|c|c|c|c|c|c|c|c|}
\hline AUG 28, 1997 & 5.31 & NOV 12, 1997 & 5.02 & FEB 16, 1998 & 4.08 & MAY 20, 1998 & 3.21 & AUG 26, 1998 & 4.33 \\
\hline SEP 17 & 5.27 & DEC 09 & 5.13 & MAR 25 & 3.65 & JUN 25 & 3.10 & SEP 29 & 4.82 \\
\hline OCT 17 & 5.66 & JAN 15, 1998 & 4.66 & APR 14 & 3.48 & JUL 15 & 3.48 & OCT 27 & 4.96 \\
\hline
\end{tabular}

Well No.: WGW 342 Site Identification No.: 413843071350801

\begin{tabular}{|c|c|c|c|c|c|c|c|c|c|}
\hline AUG 28, 1997 & 12.21 & NOV 12, 1997 & 12.01 & FEB 16, 1998 & 10.59 & MAY 20, 1998 & 8.43 & AUG 26, 1998 & 10.30 \\
\hline SEP 17 & 12.28 & DEC 09 & 12.27 & MAR 25 & 9.01 & JUN 25 & 8.14 & SEP 29 & 11.07 \\
\hline OCT 16 & 12.82 & JAN 14, 1998 & 11.65 & APR 14 & 8.93 & JUL 15 & 8.59 & OCT 27 & 11.49 \\
\hline
\end{tabular}

Well No.: WGW 343 Site Identification No.: 413842071350701

\begin{tabular}{|c|c|c|c|c|c|c|c|c|c|}
\hline AUG 28, 1997 & 11.78 & NOV 12, 1997 & 11.70 & FEB 16, 1998 & 10.17 & MAY 20, 1998 & 7.97 & AUG 26, 1998 & 9.72 \\
\hline SEP 17 & 11.80 & DEC 09 & 11.87 & MAR 25 & 8.60 & JUN 25 & 7.69 & SEP 29 & 10.55 \\
\hline OCT 16 & 12.38 & JAN 14, 1998 & 11.28 & APR 14 & 8.49 & JUL 15 & 8.09 & OCT 27 & 10.98 \\
\hline
\end{tabular}

Well No.: WGW 344 Site Identification No.: 413840071350801

\begin{tabular}{|c|c|c|c|c|c|c|c|c|c|}
\hline AUG 28, 1997 & 20.13 & NOV 12, 1997 & 20.05 & FEB 16, 1998 & 18.56 & MAY 20, 1998 & 16.33 & AUG 26, 1998 & 18.12 \\
\hline SEP 17 & 20.13 & DEC 09 & 20.17 & MAR 25 & 16.95 & JUN 25 & 16.08 & SEP 29 & 18.94 \\
\hline OCT 16 & 20.65 & JAN 14, 1998 & 19.64 & APR 14 & 16.85 & JUL 15 & 16.46 & OCT 27 & 19.37 \\
\hline
\end{tabular}

Well No.: WGW 345 Site Identification No.: 413839071350701

\begin{tabular}{|c|c|c|c|c|c|c|c|c|c|}
\hline AUG 28, 1997 & 27.92 & NOV 12, 1997 & 27.89 & FEB 16, 1998 & 26.33 & MAY 20, 1998 & 24.03 & AUG 26, 1998 & 25.92 \\
\hline SEP 17 & 27.89 & DEC 09 & 27.96 & MAR 25 & 24.65 & JUN 25 & 23.87 & SEP 29 & 26.74 \\
\hline OCT 16 & 28.45 & JAN 14, 1998 & 27.45 & APR 14 & 24.55 & JUL 15 & 24.19 & OCT 27 & 27.16 \\
\hline \multicolumn{10}{|c|}{ Site Identification No.: 413858071370901} \\
\hline OCT 17,1997 & 10.73 & JAN 15,1998 & 9.27 & APR 14, 1998 & 7.12 & JUL 16, 1998 & 7.56 & SEP 29, 1998 & 9.70 \\
\hline NOV 13 & 10.45 & FEB 17 & 8.18 & MAY 20 & 6.78 & AUG 26 & 8.92 & OCT 27 & 10.11 \\
\hline DEC 09 & 9.98 & MAR 25 & 6.93 & JUN 25 & 7.03 & & & & \\
\hline
\end{tabular}

Well No.: WGW 347 Site Identification No.: 413858071370801

$\begin{array}{lllllllll}\text { OCT 17, 1997 } & 16.44 & \text { JAN 15, 1998 } & 14.98 & \text { APR 14, 1998 } & 12.80 & \text { JUL 16, 1998 } & 13.25 & \text { SEP 29, 1998 } \\ \text { NOV 13 } & 16.17 & \text { FEB 17 } & 13.89 & \text { MAY 20 } & 12.51 & \text { AUG 26 } & 14.62 & \text { OCT 27 } \\ \text { DEC 09 } & 15.70 & \text { MAR 25 } & 12.60 & \text { JUN 25 } & 12.72 & & & 15.81\end{array}$

Well No.: WGW 348 Site Identification No.: 413856071371101

$\begin{array}{lllllllll}\text { SEP 25, 1997 } & 17.74 & \text { DEC 09, 1997 } & 17.04 & \text { MAR 25, 1998 } & 13.78 & \text { JUN 25, 1998 } & 13.88 & \text { SEP 29, 1998 } \\ \text { OCT 17 } & 17.90 & \text { JAN 15, 1998 } & 16.35 & \text { APR 14 } & 13.96 & \text { JUL 16 } & 14.43 & \text { OCT 27 } \\ \text { NOV 13 } & 17.61 & \text { FEB 17 } & 15.12 & \text { MAY 20 } & 13.63 & \text { AUG 26 } & 15.92 & 17.24\end{array}$


Table 2. Selected water levels measured monthly in observation wells in the Big-Mishnock stream-aquifer system, central Rhode Island, 1996-98-Continued

\begin{tabular}{|c|c|c|c|c|c|c|c|c|c|}
\hline Date & $\begin{array}{l}\text { Water } \\
\text { level } \\
\text { (feet) }\end{array}$ & Date & $\begin{array}{l}\text { Water } \\
\text { level } \\
\text { (feet) }\end{array}$ & Date & $\begin{array}{l}\text { Water } \\
\text { level } \\
\text { (feet) }\end{array}$ & Date & $\begin{array}{l}\text { Water } \\
\text { level } \\
\text { (feet) }\end{array}$ & Date & $\begin{array}{l}\text { Water } \\
\text { level } \\
\text { (feet) }\end{array}$ \\
\hline \multicolumn{10}{|c|}{ Well No.: WGW $349 \quad$ Site Identification No.: 413854071370901} \\
\hline SEP 24, 1997 & 13.34 & DEC 09, 1997 & 12.78 & MAR 25, 1998 & 9.26 & JUN 25, 1998 & 9.34 & SEP 29, 1998 & 12.47 \\
\hline OCT 17 & 13.64 & JAN 15, 1998 & 12.09 & APR 14 & 9.41 & JUL 16 & 9.91 & OCT 27 & 12.93 \\
\hline NOV 13 & 13.38 & FEB 17 & 10.72 & MAY 20 & 9.08 & AUG 26 & 11.51 & & \\
\hline \multicolumn{10}{|c|}{ Well No.: WGW $350 \quad$ Site Identification No.: 413853071371601} \\
\hline OCT 17,1997 & 33.86 & JAN 15, 1998 & 32.12 & APR 14, 1998 & 29.26 & JUL 16, 1998 & 29.82 & SEP 29, 1998 & 32.62 \\
\hline NOV 13 & 33.63 & FEB 17 & 30.64 & MAY 20 & 28.99 & AUG 26 & 31.57 & OCT 27 & 33.09 \\
\hline DEC 09 & 32.83 & MAR 25 & 29.09 & JUN 25 & 29.19 & & & & \\
\hline \multicolumn{10}{|c|}{ Well No.: WGW $351 \quad$ Site Identification No.: 413859071371201} \\
\hline SEP 26, 1997 & 7.79 & DEC 09, 1997 & 7.32 & MAR 25, 1998 & 4.45 & JUN 25, 1998 & 4.56 & SEP 29, 1998 & 7.07 \\
\hline OCT 17 & 8.03 & JAN 15, 1998 & 6.61 & APR 14 & 4.64 & JUL 16 & 5.08 & OCT 27 & 7.46 \\
\hline NOV 13 & 7.76 & FEB 17 & 5.62 & MAY 20 & 4.38 & AUG 26 & 6.34 & & \\
\hline \multicolumn{10}{|c|}{ Well No.: WGW $352 \quad$ Site Identification No.: 413837071351001} \\
\hline OCT 30, 1997 & 30.42 & JAN 14, 1998 & 29.24 & APR 14, 1998 & 26.70 & JUL 15, 1998 & 26.45 & SEP 29, 1998 & 28.78 \\
\hline NOV 12 & 29.69 & FEB 16 & 28.19 & MAY 20 & 26.23 & AUG 26 & 28.03 & OCT 27 & 29.13 \\
\hline DEC 09 & 29.79 & MAR 25 & 26.70 & JUN 25 & 26.10 & & & & \\
\hline \multicolumn{10}{|c|}{ Well No.: WGW 353} \\
\hline OCT 16,1997 & 27.66 & JAN 14, 1998 & 26.58 & APR 14, 1998 & 24.17 & JUL 15, 1998 & 23.96 & SEP 29, 1998 & 26.21 \\
\hline NOV 12 & 27.03 & FEB 17 & 25.47 & MAY 20 & 23.73 & AUG 26 & 25.49 & OCT 27 & 26.54 \\
\hline DEC 09 & 27.10 & MAR 25 & 24.14 & JUN 25 & 23.60 & & & & \\
\hline
\end{tabular}


Table 3. Water levels measured monthly in streambed piezometers in the Big-Mishnock stream-aquifer system, central Rhode Island, 1997-98

[Site locations are shown on plate 1. Water levels are in feet below measuring point. COW, Coventry well; MP, altitude of measuring point datum (top of pipe) in feet above sea level; WGW, West Greenwich well; *, measured top of an ice plug; >, water level greater than depth of piezometer; --, no measurement]

\begin{tabular}{|c|c|c|c|c|c|c|c|c|}
\hline \multirow[b]{2}{*}{ Date } & \multicolumn{2}{|c|}{ Water level } & \multirow[b]{2}{*}{ Date } & \multicolumn{2}{|c|}{ Water level } & \multirow[b]{2}{*}{ Date } & \multicolumn{2}{|c|}{ Water level } \\
\hline & $\begin{array}{c}\text { Ground } \\
\text { water }\end{array}$ & $\begin{array}{c}\text { Surface } \\
\text { water }\end{array}$ & & $\begin{array}{l}\text { Ground } \\
\text { water }\end{array}$ & $\begin{array}{c}\text { Surface } \\
\text { water }\end{array}$ & & $\begin{array}{l}\text { Ground } \\
\text { water }\end{array}$ & $\begin{array}{c}\text { Surface } \\
\text { water }\end{array}$ \\
\hline \multicolumn{2}{|c|}{ Piezometer No.: COW 478} & \multicolumn{3}{|c|}{ Site Identification No.: 414043071345201} & \multicolumn{2}{|c|}{ MP: 242.58 feet } & & \\
\hline MAY 21, 1997 & 0.43 & 0.41 & NOV 12, 1997 & 0.43 & 0.38 & APR 13,1998 & 0.24 & 0.26 \\
\hline JUN 18 & .69 & .66 & DEC 09 & .59 & .57 & MAY 19 & .28 & .29 \\
\hline JUL 16 & .78 & .71 & JAN 14, 1998 & .39 & .37 & JUN 26 & .32 & .33 \\
\hline AUG 28 & .70 & .65 & FEB 17 & .31 & .33 & JUL 16 & .57 & .54 \\
\hline SEP 18 & .73 & .68 & MAR 25 & .18 & .18 & AUG 25 & .77 & .72 \\
\hline OCT 15 & .80 & .75 & & & & & & \\
\hline \multicolumn{2}{|c|}{ Piezometer No.: COW 481} & \multicolumn{3}{|c|}{ Site Identification No.: $\mathbf{4 1 3 9 3 7 0 7 1 3 7 4 2 0}$} & \multicolumn{2}{|c|}{ MP: 254.49 feet } & & \\
\hline MAY 20, 1997 & 0.86 & 0.89 & NOV 12, 1997 & 1.10 & 0.95 & APR 13, 1998 & 0.68 & 0.84 \\
\hline JUN 17 & 1.03 & 1.04 & DEC 09 & 1.09 & .99 & MAY 19 & .73 & .83 \\
\hline JUL 15 & 1.31 & 1.21 & JAN 15, 1998 & $* .79$ & .82 & JUN 26 & .75 & .83 \\
\hline AUG 27 & 1.25 & 1.16 & FEB 17 & .52 & .70 & JUL 16 & 1.01 & 1.02 \\
\hline SEP 18 & 1.29 & 1.13 & MAR & -- & -- & AUG 25 & 1.24 & 1.17 \\
\hline OCT 15 & 1.31 & 1.14 & & & & & & \\
\hline \multicolumn{2}{|c|}{ Piezometer No.: WGW 322} & \multicolumn{3}{|c|}{ Site Identification No.: $\mathbf{4 1 3 7 3 5 0 7 1 3 7 5 6 0 1}$} & \multicolumn{2}{|c|}{ MP: 261.96 feet } & & \\
\hline MAY 20, 1997 & 1.35 & 1.33 & NOV 12, 1997 & 1.55 & 1.51 & APR 13, 1998 & 1.22 & 1.18 \\
\hline JUN 17 & 1.74 & 1.71 & DEC 09 & 1.66 & 1.63 & MAY 19 & 1.19 & 1.05 \\
\hline JUL 16 & 1.89 & 1.85 & JAN 15, 1998 & $* 1.30$ & 1.32 & JUN 25 & 1.12 & 1.09 \\
\hline AUG 27 & 1.80 & 1.76 & FEB 17 & 1.27 & 1.23 & JUL 15 & 1.56 & 1.52 \\
\hline SEP 18 & 1.88 & 1.83 & MAR 25 & 1.00 & .96 & AUG 24 & 1.86 & 1.83 \\
\hline OCT 16 & 1.97 & 1.92 & & & & & & \\
\hline \multicolumn{2}{|c|}{ Piezometer No.: WGW 323} & \multicolumn{3}{|c|}{ Site Identification No.: 413646071372001} & \multicolumn{2}{|c|}{ MP: 271.88 feet } & & \\
\hline MAY 20, 1997 & 0.60 & 0.63 & NOV 12, 1997 & 0.83 & 0.86 & APR 13, 1998 & 0.50 & 0.55 \\
\hline JUN 17 & .96 & .98 & DEC 09 & .87 & .90 & MAY 19 & .48 & .51 \\
\hline JUL 15 & 1.31 & 1.31 & JAN 15, 1998 & $* .57$ & .57 & JUN 25 & .34 & .39 \\
\hline AUG 27 & 1.18 & 1.19 & FEB 17 & .59 & .58 & JUL 15 & .79 & .79 \\
\hline SEP 18 & 1.12 & 1.13 & MAR 25 & .36 & .39 & AUG 24 & 1.08 & 1.08 \\
\hline OCT 16 & 1.23 & 1.24 & & & & & & \\
\hline \multicolumn{2}{|c|}{ Piezometer No.: WGW 324} & \multicolumn{3}{|c|}{ Site Identification No.: 41364807137080} & \multicolumn{2}{|c|}{ MP: 264.33 feet } & & \\
\hline MAY 20, 1997 & 1.78 & 1.99 & NOV 12, 1997 & 1.87 & 2.04 & APR 13, 1998 & 1.75 & 1.97 \\
\hline JUN 17 & 1.90 & 2.05 & DEC 09 & 1.89 & 2.05 & MAY 19 & 1.76 & 1.91 \\
\hline JUL 15 & 1.91 & 2.06 & JAN 15, 1998 & $* 1.70$ & 2.01 & JUN 25 & 1.77 & 1.88 \\
\hline AUG 27 & 1.93 & 2.07 & FEB 17 & 1.76 & 1.91 & JUL 15 & 1.83 & 2.05 \\
\hline SEP 18 & 1.89 & 2.06 & MAR 25 & 1.70 & 1.87 & AUG 24 & 1.89 & 2.05 \\
\hline OCT 16 & 1.89 & 2.04 & & & & & & \\
\hline \multicolumn{2}{|c|}{ Piezometer No.: WGW 325} & \multicolumn{3}{|c|}{ Site Identification No.: $\mathbf{4 1 3 8 4 0 0 7 1 3 6 4 8 0}$} & & 8 feet & & \\
\hline MAY 20, 1997 & 0.88 & 0.97 & NOV 12, 1997 & 1.75 & 2.16 & APR 13, 1998 & 0.48 & 0.87 \\
\hline JUN 17 & 1.40 & 1.48 & DEC 09 & 2.18 & 2.35 & MAY 19 & .38 & .76 \\
\hline JUL 15 & 2.30 & $>2.23$ & JAN 15, 1998 & $* 1.35$ & 1.63 & JUN 25 & .43 & .53 \\
\hline AUG 27 & 1.93 & 2.01 & FEB 17 & 1.58 & 1.68 & JUL 15 & .99 & 1.11 \\
\hline SEP 18 & 1.40 & 1.48 & MAR 25 & .21 & .73 & AUG 25 & 1.53 & 1.61 \\
\hline OCT 15 & 1.98 & 2.05 & & & & & & \\
\hline
\end{tabular}


Table 3. Water levels measured monthly in streambed piezometers in the Big-Mishnock stream-aquifer system, central Rhode Island, 1997-98-Continued

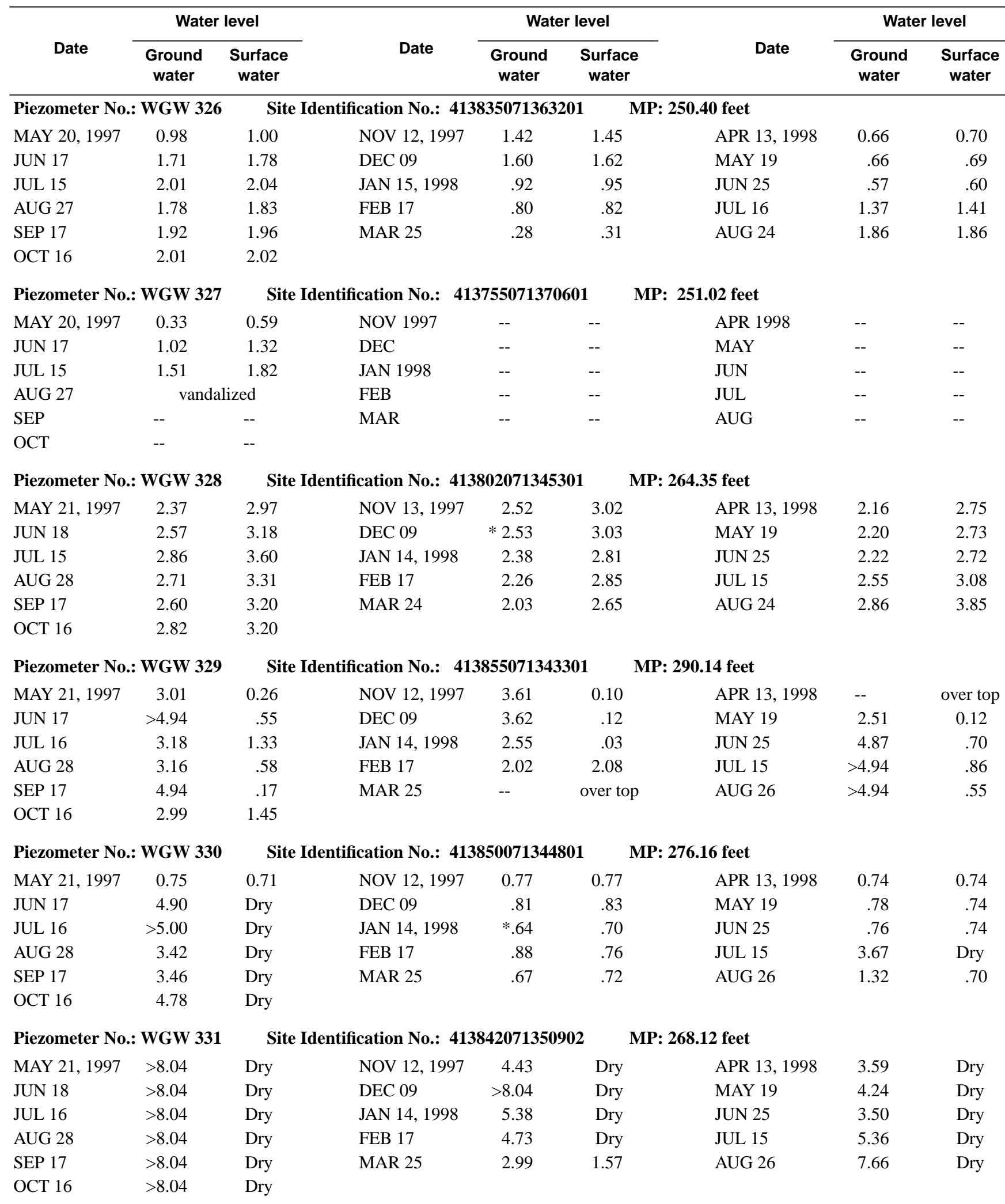


Table 3. Water levels measured monthly in streambed piezometers in the Big-Mishnock stream-aquifer system, central Rhode Island, 1997-98-Continued

\begin{tabular}{|c|c|c|c|c|c|c|c|c|}
\hline \multirow[b]{2}{*}{ Date } & \multicolumn{2}{|c|}{ Water level } & \multirow[b]{2}{*}{ Date } & \multicolumn{2}{|c|}{ Water level } & \multirow[b]{2}{*}{ Date } & \multicolumn{2}{|c|}{ Water level } \\
\hline & $\begin{array}{c}\text { Ground } \\
\text { water }\end{array}$ & $\begin{array}{l}\text { Surface } \\
\text { water }\end{array}$ & & $\begin{array}{l}\text { Ground } \\
\text { water }\end{array}$ & $\begin{array}{c}\text { Surface } \\
\text { water }\end{array}$ & & $\begin{array}{l}\text { Ground } \\
\text { water }\end{array}$ & $\begin{array}{c}\text { Surface } \\
\text { water }\end{array}$ \\
\hline \multicolumn{2}{|c|}{ Piezometer No.: WGW 332} & \multicolumn{4}{|c|}{ Site Identification No.: $\mathbf{4 1 3 9 2 3 0 7 1 3 6 0 0 0 1}$} & 6 feet & & \\
\hline MAY 21, 1997 & 1.16 & 1.07 & NOV 12, 1997 & 1.31 & 1.09 & APR 13, 1998 & 1.04 & 0.99 \\
\hline JUN 18 & 1.34 & 1.17 & DEC 09 & 1.39 & 1.13 & MAY 19 & 1.05 & .99 \\
\hline JUL 16 & 1.48 & 1.19 & JAN 15, 1998 & 1.13 & 1.16 & JUN 26 & 1.05 & .99 \\
\hline AUG & -- & -- & FEB 17 & .99 & .99 & JUL 16 & 1.23 & 1.07 \\
\hline SEP 18 & 1.53 & 1.19 & MAR 25 & .94 & .92 & AUG 25 & 1.61 & 1.20 \\
\hline OCT 15 & 1.59 & 1.22 & & & & & & \\
\hline \multicolumn{2}{|c|}{ Piezometer No.: WGW 333} & \multicolumn{3}{|c|}{ Site Identification No.: 41392007135300} & & 3 feet & & \\
\hline MAY 21, 1997 & 0.35 & 0.34 & NOV 12, 1997 & 0.38 & 0.38 & APR 13, 1998 & 0.35 & 0.37 \\
\hline JUN 18 & .51 & .45 & DEC 09 & .43 & .33 & MAY 19 & .34 & .30 \\
\hline JUL 16 & .65 & .57 & JAN 15, 1998 & .41 & .37 & JUN 26 & .37 & .32 \\
\hline AUG 28 & .66 & .63 & FEB 17 & .31 & .33 & JUL 16 & .45 & .37 \\
\hline SEP 18 & .71 & .65 & MAR 25 & .32 & .30 & AUG 25 & .62 & .47 \\
\hline OCT 15 & .66 & .57 & & & & & & \\
\hline \multicolumn{2}{|c|}{ Piezometer No.: WGW 335} & \multicolumn{3}{|c|}{ Site Identification No.: 41373207135520} & & 5 feet & & \\
\hline MAY 20, 1997 & 1.29 & 1.33 & NOV 12, 1997 & 1.75 & 1.79 & APR 1998 & -- & -- \\
\hline JUN 18 & 1.51 & 1.53 & $\mathrm{DEC}$ & -- & -- & MAY & -- & -- \\
\hline JUL 15 & 3.00 & 2.99 & JAN 1998 & -- & -- & JUN & -- & -- \\
\hline AUG 27 & 3.51 & 3.56 & FEB & -- & -- & JUL & -- & -- \\
\hline SEP 17 & 3.66 & 3.72 & MAR & -- & -- & AUG & -- & -- \\
\hline OCT 16 & 4.97 & 4.90 & & & & & & \\
\hline
\end{tabular}


Table 4. Historical water levels measured from wells in the Big-Mishnock stream-aquifer system, central Rhode Island, 1938-96

[Site locations are shown on plate 1. Well No.: COW, Coventry well; EXW, Exeter well; WGW, West Greenwich well. Latitude and longitude are in degrees, minutes, and seconds. Water levels in feet below land surface. No., Number; -, indicates water level above land surface]

\begin{tabular}{|c|c|c|c|c|c|}
\hline Well No. & $\begin{array}{c}\text { Latitude } \\
\circ, \prime \prime\end{array}$ & $\begin{array}{c}\text { Longitude } \\
0, " 1\end{array}$ & Site identification No. & Date & $\begin{array}{l}\text { Water level } \\
\text { (feet) }\end{array}$ \\
\hline COW 34 & 414022 & 713814 & 414022071381401 & $7-19-47$ & 22 \\
\hline COW 51 & 414002 & 713959 & 414002071395901 & $10-13-49$ & 15.06 \\
\hline COW 61 & 414051 & 713522 & 414051071352201 & $8-10-51$ & 15 \\
\hline COW 65 & 414031 & 713646 & 414031071364601 & $8-13-51$ & 30.2 \\
\hline COW 66 & 414038 & 713649 & 414038071364901 & 1948 & 16 \\
\hline \multirow[t]{2}{*}{ COW 77} & 414004 & 713410 & 414004071341001 & $5-01-45$ & 25 \\
\hline & & & & $8-14-51$ & 25 \\
\hline COW 93 & 413953 & 713606 & 413953071360601 & $8-22-51$ & 6 \\
\hline COW 94 & 414008 & 713603 & 414008071360301 & $8-22-51$ & 15 \\
\hline COW 95 & 414002 & 713610 & 414002071361001 & $8-22-51$ & 13 \\
\hline COW 98 & 413949 & 713724 & 413949071372401 & $9-04-51$ & 12.4 \\
\hline COW 101 & 414003 & 713727 & 414003071372701 & $9-04-51$ & 17 \\
\hline COW 102 & 413959 & 713649 & 413959071364901 & $9-04-51$ & 15 \\
\hline COW 104 & 414010 & 713608 & 414010071360801 & $9-04-51$ & 26 \\
\hline COW 130 & 414024 & 713544 & 414024071354401 & $9-06-51$ & 6.68 \\
\hline COW 136 & 414003 & 713657 & 414003071365701 & $9-01-51$ & 22 \\
\hline COW 154 & 414002 & 713416 & 414002071341601 & $6-24-52$ & 7.4 \\
\hline COW 158 & 414000 & 713604 & 414000071360401 & $4-01-50$ & 24 \\
\hline COW 205 & 414035 & 713908 & 414035071390801 & $6-16-53$ & 10.1 \\
\hline COW 206 & 414033 & 713859 & 414033071385901 & 1950 & 30 \\
\hline COW 207 & 414033 & 713851 & 414033071385101 & 1949 & 30 \\
\hline COW 209 & 414023 & 713821 & 414023071382101 & $6-17-53$ & 19.98 \\
\hline COW 211 & 414007 & 713736 & 414007071373601 & 1948 & 8 \\
\hline \multirow[t]{2}{*}{ COW 212} & 414006 & 713737 & 414006071373701 & $6-01-53$ & 8 \\
\hline & & & & $6-17-53$ & 7.5 \\
\hline \multirow[t]{2}{*}{ COW 216} & 414037 & 714000 & 414037071400001 & $6-23-53$ & 10.9 \\
\hline & & & & $6-23-63$ & 10.9 \\
\hline COW 217 & 414026 & 714001 & 414026071400101 & $6-23-53$ & 8.1 \\
\hline COW 218 & 414011 & 714000 & 414011071400001 & $6-23-53$ & 4.6 \\
\hline COW 219 & 413955 & 713741 & 413955071374101 & $6-23-53$ & 18.9 \\
\hline COW 220 & 413948 & 713759 & 413948071375901 & $6-23-53$ & 14.49 \\
\hline COW 221 & 413945 & 713747 & 413945071374701 & $6-23-53$ & 7 \\
\hline COW 222 & 413936 & 713737 & 413936071373701 & $6-23-53$ & 10 \\
\hline COW 228 & 414046 & 713809 & 414046071380901 & $7-02-53$ & 9.6 \\
\hline COW 241 & 413932 & 713938 & 413932071393801 & $7-06-53$ & 11.3 \\
\hline COW 422 & 414021 & 713547 & 414021071354701 & $5-15-62$ & 11 \\
\hline COW 423 & 414013 & 713559 & 414013071355901 & $5-15-62$ & 6 \\
\hline COW 424 & 414023 & 713628 & 414023071362801 & $5-15-62$ & 10 \\
\hline COW 425 & 414001 & 713646 & 414001071364601 & $5-16-62$ & 5 \\
\hline COW 426 & 413945 & 713610 & 413945071361001 & $5-16-62$ & 5 \\
\hline
\end{tabular}


Table 4. Historical water levels measured from wells in the Big-Mishnock stream-aquifer system, central Rhode Island, 1938-96-Continued

\begin{tabular}{|c|c|c|c|c|c|}
\hline Well No. & $\begin{array}{c}\text { Latitude } \\
0,1,\end{array}$ & $\underset{\substack{\text { Longitude } \\
\text { Le }}}{ }$ & Site identification No. & Date & $\begin{array}{l}\text { Water level } \\
\text { (feet) }\end{array}$ \\
\hline COW 435 & 413944 & 713559 & 413944071355901 & $3-18-64$ & 3.4 \\
\hline COW 436 & 413943 & 713600 & 413943071360001 & $3-19-64$ & 3.4 \\
\hline COW 437 & 413947 & 713558 & 413947071355801 & $4-23-64$ & 1.3 \\
\hline COW 438 & 413946 & 713559 & 413946071355901 & $3-24-64$ & 2.2 \\
\hline COW 439 & 413947 & 713554 & 413947071355401 & $3-25-64$ & 2.2 \\
\hline COW 442 & 413943 & 713557 & 413943071355701 & $3-31-64$ & 1.08 \\
\hline COW 443 & 413942 & 713601 & 413942071360102 & $4-23-64$ & -.32 \\
\hline COW 446 & 413947 & 713601 & 413947071360101 & $4-07-64$ & 3.3 \\
\hline COW 448 & 413943 & 713557 & 413943071355702 & $4-29-64$ & .5 \\
\hline COW 449 & 413944 & 713552 & 413944071355201 & $5-18-64$ & 3.2 \\
\hline COW 453 & 413946 & 713603 & 413946071360301 & $5-27-64$ & 6.3 \\
\hline COW 454 & 413945 & 713602 & 413945071360201 & $5-28-64$ & 6.2 \\
\hline COW 455 & 413942 & 713551 & 413942071355101 & $5-26-64$ & 4.2 \\
\hline COW 456 & 413941 & 713605 & 413941071360501 & $6-04-64$ & 4.5 \\
\hline COW 457 & 413940 & 713604 & 413940071360401 & $6-06-64$ & 5 \\
\hline COW 459 & 413942 & 713604 & 413942071360401 & $6-11-64$ & 4.7 \\
\hline COW 460 & 413942 & 713601 & 413942071360101 & $6-01-64$ & 1 \\
\hline COW 461 & 413942 & 713601 & 413942071360103 & $2-08-65$ & 2 \\
\hline COW 467 & 413941 & 713528 & 413941071352801 & $7-13-94$ & 0 \\
\hline COW 468 & 414007 & 713534 & 414007071353401 & $7-26-94$ & 4 \\
\hline COW 469 & 413956 & 713530 & 413956071353001 & $7-28-94$ & 1.6 \\
\hline COW 470 & 414002 & 713529 & 414002071352901 & $11-30-94$ & 1.89 \\
\hline COW 471 & 413952 & 713559 & 413952071355901 & $12-19-94$ & 6.5 \\
\hline COW 472 & 413950 & 713559 & 413950071355901 & $12-22-94$ & 5.9 \\
\hline COW 473 & 413936 & 713544 & 413936071354401 & $7-05-94$ & 4.28 \\
\hline COW 474 & 413937 & 713536 & 413937071353601 & $12-14-94$ & 3.8 \\
\hline COW 475 & 413937 & 713536 & 413937071353602 & $12-03-94$ & 3.8 \\
\hline COW 476 & 413937 & 713534 & 413937071353401 & $12-12-94$ & 2.3 \\
\hline COW 477 & 413937 & 713536 & 413937071353603 & $4-17-95$ & 4.7 \\
\hline COW 480 & 413945 & 713537 & 413945071353701 & $7-11-94$ & 4.9 \\
\hline EXW 96 & 413506 & 713708 & 413506071370801 & $1-15-59$ & 18 \\
\hline EXW 192 & 413549 & 713914 & 413549071391401 & $11-12-53$ & 20.2 \\
\hline EXW 196 & 413559 & 713824 & 413559071382401 & $11-13-53$ & 20.9 \\
\hline EXW 340 & 413602 & 713642 & 413602071364201 & $9-17-53$ & 29.84 \\
\hline EXW 340 & 413602 & 713642 & 413602071364201 & $9-17-54$ & 29.84 \\
\hline EXW 341 & 413533 & 713659 & 413533071365901 & $9-20-54$ & 14.3 \\
\hline EXW 342 & 413535 & 713658 & 413535071365801 & $9-20-54$ & 7 \\
\hline EXW 343 & 413542 & 713724 & 413542071372401 & $9-20-54$ & 9.6 \\
\hline EXW 344 & 413538 & 713724 & 413538071372401 & $9-20-54$ & 7.5 \\
\hline EXW 345 & 413517 & 713707 & 413517071370701 & $9-20-54$ & 5.8 \\
\hline WGW 5 & 413859 & 713944 & 413859071394401 & $10-13-49$ & 13.1 \\
\hline WGW 14 & 413858 & 713431 & 413858071343101 & $8-08-51$ & 13.4 \\
\hline WGW 15 & 413915 & 713317 & 413915071331701 & $8-08-51$ & 32 \\
\hline WGW 17 & 413907 & 713404 & 413907071340401 & $8-08-51$ & 14 \\
\hline WGW 19 & 413935 & 713430 & 413935071343001 & 1947 & 16 \\
\hline
\end{tabular}


Table 4. Historical water levels measured from wells in the Big-Mishnock stream-aquifer system, central Rhode Island, 1938-96-Continued

\begin{tabular}{|c|c|c|c|c|c|}
\hline Well No. & $\begin{array}{l}\text { Latitude } \\
0^{\prime}, "\end{array}$ & $\underset{\substack{\text { Longitude } \\
\text { Lond }}}{ }$ & Site identification No. & Date & $\begin{array}{l}\text { Water level } \\
\text { (feet) }\end{array}$ \\
\hline WGW 20 & 413733 & 713403 & 413733071340301 & $8-09-51$ & 65 \\
\hline WGW 21 & 413906 & 713532 & 413906071353201 & $8-09-51$ & 22 \\
\hline WGW 22 & 413907 & 713513 & 413907071351301 & $8-09-51$ & 3 \\
\hline WGW 24 & 413919 & 713521 & 413919071352101 & $8-09-51$ & 8 \\
\hline WGW 26 & 413919 & 713440 & 413919071344001 & $8-09-51$ & 35 \\
\hline WGW 27 & 413915 & 713436 & 413915071343601 & $7-01-51$ & 40 \\
\hline WGW 28 & 413915 & 713440 & 413915071344001 & $8-09-51$ & 35 \\
\hline WGW 29 & 413937 & 713422 & 413937071342201 & $8-09-51$ & 25 \\
\hline WGW 30 & 413836 & 713727 & 413836071372701 & $8-21-51$ & 12 \\
\hline WGW 32 & 413823 & 713728 & 413823071372801 & $11-01-49$ & 14 \\
\hline WGW 33 & 413826 & 713725 & 413826071372501 & $7-01-49$ & 20 \\
\hline WGW 34 & 413836 & 713703 & 413836071370301 & $8-22-51$ & 15.5 \\
\hline WGW 35 & 413836 & 713711 & 413836071371101 & $8-22-51$ & 27 \\
\hline WGW 36 & 413847 & 713636 & 413847071363601 & $12-17-38$ & 16 \\
\hline WGW 37 & 413854 & 713617 & 413854071361701 & $8-22-51$ & 1 \\
\hline WGW 38 & 413923 & 713615 & 413923071361501 & $8-22-51$ & 18 \\
\hline WGW 39 & 413933 & 713612 & 413933071361201 & $8-22-51$ & 5.5 \\
\hline WGW 40 & 413921 & 713550 & 413921071355001 & $8-22-51$ & 5 \\
\hline WGW 41 & 413929 & 713607 & 413929071360701 & $8-22-51$ & 5 \\
\hline WGW 42 & 413835 & 713628 & 413835071362802 & 1948 & 8 \\
\hline WGW 43 & 413736 & 713527 & 413736071352701 & $8-23-51$ & 11.6 \\
\hline WGW 44 & 413758 & 713455 & 413758071345501 & $8-23-51$ & 16 \\
\hline WGW 45 & 413806 & 713442 & 413806071344201 & $8-23-51$ & 19.3 \\
\hline WGW 49 & 413846 & 713400 & 413846071340001 & $8-23-51$ & 22 \\
\hline WGW 51 & 413813 & 713426 & 413813071342601 & $8-28-51$ & 8 \\
\hline WGW 53 & 413745 & 713557 & 413745071355701 & $8-29-51$ & 14 \\
\hline WGW 55 & 413917 & 713559 & 413917071355901 & $8-08-51$ & 6.6 \\
\hline WGW 56 & 413851 & 713551 & 413851071355101 & $6-30-52$ & 18.8 \\
\hline WGW 57 & 413845 & 713527 & 413845071352701 & $6-30-52$ & 4.91 \\
\hline WGW 58 & 413845 & 713510 & 413845071351001 & $6-30-52$ & 16.91 \\
\hline WGW 60 & 413759 & 713637 & 413759071363701 & $7-29-52$ & 13 \\
\hline WGW 61 & 413807 & 713638 & 413807071363801 & $7-29-52$ & 5 \\
\hline WGW 73 & 413817 & 714006 & 413817071400601 & $5-21-53$ & 16.6 \\
\hline WGW 74 & 413844 & 714009 & 413844071400901 & $5-21-53$ & 19.92 \\
\hline WGW 75 & 413900 & 713957 & 413900071395701 & $5-21-53$ & 5.5 \\
\hline WGW 76 & 413841 & 714059 & 413841071405901 & $5-21-53$ & 4 \\
\hline WGW 79 & 413845 & 714011 & 413845071401101 & $5-22-53$ & 15.85 \\
\hline WGW 80 & 413859 & 714050 & 413859071405001 & $9-01-51$ & 35 \\
\hline WGW 81 & 413903 & 713914 & 413903071391401 & $5-22-53$ & 7.66 \\
\hline WGW 82 & 413902 & 713844 & 413902071384401 & $5-22-53$ & 8.94 \\
\hline WGW 93 & 413928 & 714133 & 413928071413301 & $5-25-53$ & 7.2 \\
\hline WGW 94 & 413840 & 713739 & 413840071373901 & 1944 & 8 \\
\hline WGW 95 & 413849 & 713742 & 413849071374201 & $5-26-53$ & 14.99 \\
\hline WGW 96 & 413850 & 713748 & 413850071374801 & $5-26-53$ & 15 \\
\hline WGW 97 & 413848 & 713745 & 413848071374501 & 1944 & 8 \\
\hline
\end{tabular}


Table 4. Historical water levels measured from wells in the Big-Mishnock stream-aquifer system, central Rhode Island, 1938-96-Continued

\begin{tabular}{|c|c|c|c|c|c|}
\hline Well No. & 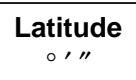 & $\underset{0,1 "}{\text { Longitude }}$ & Site identification No. & Date & $\begin{array}{l}\text { Water level } \\
\text { (feet) }\end{array}$ \\
\hline WGW 99 & 413834 & 713731 & 413834071373101 & $5-26-53$ & 12 \\
\hline WGW 100 & 413858 & 713800 & 413858071380001 & $5-26-53$ & 12.2 \\
\hline WGW 101 & 413853 & 713822 & 413853071382201 & $5-26-53$ & 3.8 \\
\hline WGW 107 & 413923 & 714038 & 413923071403801 & $6-02-53$ & 5.66 \\
\hline WGW 108 & 413928 & 714039 & 413928071403901 & $6-02-53$ & 14.38 \\
\hline WGW 109 & 413905 & 714020 & 413905071402001 & $6-02-53$ & 9.1 \\
\hline WGW 111 & 413822 & 713731 & 413822071373101 & $6-08-53$ & 23 \\
\hline WGW 116 & 413750 & 713745 & 413750071374501 & $6-08-53$ & 14.2 \\
\hline WGW 117 & 413745 & 713741 & 413745071374101 & $6-07-53$ & 7 \\
\hline WGW 118 & 413754 & 713746 & 413754071374601 & $6-03-53$ & 2 \\
\hline WGW 119 & 413731 & 713804 & 413731071380401 & $6-09-53$ & 13.5 \\
\hline WGW 122 & 413752 & 713755 & 413752071375501 & $6-09-53$ & 17 \\
\hline WGW 123 & 413915 & 713950 & 413915071395001 & $7-06-53$ & 23 \\
\hline WGW 124 & 413926 & 713945 & 413926071394501 & $7-06-53$ & 11.4 \\
\hline WGW 125 & 413931 & 713940 & 413931071394001 & $7-06-53$ & 11 \\
\hline WGW 126 & 413933 & 713810 & 413933071381001 & $7-06-53$ & 16 \\
\hline WGW 152 & 413730 & 714014 & 413730071401401 & $9-03-53$ & 21.71 \\
\hline WGW 153 & 413724 & 714011 & 413724071401101 & $9-03-53$ & 16.4 \\
\hline WGW 154 & 413703 & 713944 & 413703071394401 & $9-03-53$ & 15.8 \\
\hline WGW 155 & 413716 & 713923 & 413716071392301 & $9-04-53$ & 20 \\
\hline WGW 156 & 413706 & 713825 & 413706071382501 & $9-04-53$ & 12.33 \\
\hline WGW 157 & 413705 & 713825 & 413705071382501 & $9-04-53$ & 8.8 \\
\hline WGW 158 & 413659 & 713810 & 413659071381001 & $9-04-53$ & 16 \\
\hline WGW 159 & 413657 & 713812 & 413657071381201 & $9-04-53$ & 12.4 \\
\hline WGW 160 & 413652 & 713759 & 413652071375901 & $9-04-53$ & 29.74 \\
\hline WGW 161 & 413644 & 713749 & 413644071374901 & $9-04-53$ & 13.15 \\
\hline WGW 186 & 413630 & 713949 & 413630071394901 & $11-12-53$ & 11.61 \\
\hline WGW 187 & 413619 & 713917 & 413619071391701 & $11-12-53$ & 19.23 \\
\hline WGW 188 & 413640 & 713954 & 413640071395401 & $11-12-53$ & 19.49 \\
\hline WGW 189 & 413636 & 713954 & 413636071395401 & $11-12-53$ & 17.3 \\
\hline WGW 190 & 413647 & 713950 & 413647071395001 & $11-12-53$ & 11.19 \\
\hline WGW 193 & 413609 & 713838 & 413609071383801 & $11-23-53$ & 16.5 \\
\hline WGW 194 & 413637 & 713819 & 413637071381901 & $11-23-53$ & 17.5 \\
\hline WGW 195 & 413643 & 713816 & 413643071381601 & $11-01-53$ & 7 \\
\hline WGW 196 & 413704 & 713810 & 413704071381001 & $11-23-53$ & 10.64 \\
\hline WGW 198 & 413714 & 713812 & 413714071381201 & $11-23-53$ & 10.15 \\
\hline WGW 199 & 413721 & 713810 & 413721071381001 & $11-23-53$ & 8.65 \\
\hline WGW 200 & 413731 & 713802 & 413731071380201 & $11-23-53$ & 7.92 \\
\hline WGW 209 & 413720 & 713359 & 413720071335901 & $9-16-54$ & 12 \\
\hline WGW 210 & 413607 & 713619 & 413607071361901 & $9-17-54$ & 6.81 \\
\hline \multirow[t]{5}{*}{ WGW 211} & 413617 & 713629 & 413617071362901 & $9-17-54$ & 11 \\
\hline & & & & $9-23-54$ & 10.79 \\
\hline & & & & $9-30-54$ & 10.82 \\
\hline & & & & $10-07-54$ & 11.03 \\
\hline & & & & $10-15-54$ & 11.2 \\
\hline
\end{tabular}


Table 4. Historical water levels measured from wells in the Big-Mishnock stream-aquifer system, central Rhode Island, 1938-96-Continued

\begin{tabular}{|c|c|c|c|c|}
\hline $\begin{array}{l}\text { Latitude } \\
\circ, 1\end{array}$ & $\begin{array}{c}\text { Longitude } \\
0,1\end{array}$ & Site identification No. & Date & $\begin{array}{l}\text { Water level } \\
\text { (feet) }\end{array}$ \\
\hline \multirow[t]{45}{*}{ WGW 211-Continued } & & & $10-22-54$ & 11.4 \\
\hline & & & $10-29-54$ & 11.52 \\
\hline & & & $11-05-54$ & 11.49 \\
\hline & & & $11-12-54$ & 11.34 \\
\hline & & & $11-19-54$ & 11.46 \\
\hline & & & $11-26-54$ & 11.28 \\
\hline & & & $12-28-54$ & 9.84 \\
\hline & & & $1-27-55$ & 9.93 \\
\hline & & & $2-25-55$ & 9.86 \\
\hline & & & $3-29-55$ & 9.58 \\
\hline & & & $4-28-55$ & 10.38 \\
\hline & & & $5-27-55$ & 10.84 \\
\hline & & & $6-29-55$ & 11.74 \\
\hline & & & $7-28-55$ & 12.57 \\
\hline & & & $9-01-55$ & 12.77 \\
\hline & & & $9-29-55$ & 13.48 \\
\hline & & & $10-28-55$ & 11.3 \\
\hline & & & $11-29-55$ & 9.65 \\
\hline & & & $12-30-55$ & 10.48 \\
\hline & & & $1-27-56$ & 10.68 \\
\hline & & & $2-29-56$ & 10.03 \\
\hline & & & $3-29-56$ & 9.62 \\
\hline & & & $4-27-56$ & 8.65 \\
\hline & & & $5-28-56$ & 9.75 \\
\hline & & & $6-27-56$ & 10.69 \\
\hline & & & $7-30-56$ & 11.67 \\
\hline & & & $8-29-56$ & 12.74 \\
\hline & & & $9-26-56$ & 13.7 \\
\hline & & & $10-25-56$ & 14.46 \\
\hline & & & $11-27-56$ & 15.13 \\
\hline & & & $12-26-56$ & 14.3 \\
\hline & & & $1-30-57$ & 13.64 \\
\hline & & & $2-27-57$ & 13.15 \\
\hline & & & $3-28-57$ & 12.55 \\
\hline & & & $4-29-57$ & 11.07 \\
\hline & & & $5-28-57$ & 11.63 \\
\hline & & & $6-27-57$ & 12.45 \\
\hline & & & $7-31-57$ & 13.64 \\
\hline & & & $8-29-57$ & 14.68 \\
\hline & & & $9-26-57$ & 15.56 \\
\hline & & & $10-30-57$ & Dry \\
\hline & & & $11-27-57$ & Dry \\
\hline & & & $12-30-57$ & 15.27 \\
\hline & & & $2-04-58$ & 12.62 \\
\hline & & & $3-06-58$ & 11.4 \\
\hline
\end{tabular}


Table 4. Historical water levels measured from wells in the Big-Mishnock stream-aquifer system, central Rhode Island, 1938-96-Continued

\begin{tabular}{|c|c|c|c|c|}
\hline $\begin{array}{c}\text { Latitude } \\
0^{\prime \prime \prime \prime}\end{array}$ & $\begin{array}{c}\text { Longitude } \\
0, \prime \prime\end{array}$ & Site identification No. & Date & $\begin{array}{l}\text { Water level } \\
\text { (feet) }\end{array}$ \\
\hline \multirow[t]{45}{*}{ WGW 211-Continued } & & & $4-02-58$ & 9.93 \\
\hline & & & $4-25-58$ & 8.49 \\
\hline & & & $5-23-58$ & 8.27 \\
\hline & & & $6-27-58$ & 9.46 \\
\hline & & & $7-30-58$ & 10.8 \\
\hline & & & $8-27-58$ & 11.73 \\
\hline & & & $9-25-58$ & 12.42 \\
\hline & & & $10-23-58$ & 12.48 \\
\hline & & & $11-21-58$ & 12.27 \\
\hline & & & $12-29-58$ & 12.37 \\
\hline & & & $1-29-59$ & 12.53 \\
\hline & & & $2-26-59$ & 12.09 \\
\hline & & & $10-02-61$ & 11.49 \\
\hline & & & $10-10-61$ & 10.81 \\
\hline & & & $10-17-61$ & 11.47 \\
\hline & & & $10-24-61$ & 11.6 \\
\hline & & & $10-31-61$ & 11.74 \\
\hline & & & $11-07-61$ & 11.95 \\
\hline & & & $11-14-61$ & 12.14 \\
\hline & & & $11-21-61$ & 12.3 \\
\hline & & & $11-28-61$ & 12.29 \\
\hline & & & $12-05-61$ & 12.27 \\
\hline & & & $12-12-61$ & 12.41 \\
\hline & & & $12-19-61$ & 12.51 \\
\hline & & & $12-26-61$ & 12.51 \\
\hline & & & $1-02-62$ & 12.45 \\
\hline & & & $1-09-62$ & 11.91 \\
\hline & & & $1-16-62$ & 11.33 \\
\hline & & & $1-23-62$ & 11.08 \\
\hline & & & $1-30-62$ & 11 \\
\hline & & & $2-06-62$ & 11.12 \\
\hline & & & $2-13-62$ & 11.29 \\
\hline & & & $2-20-62$ & 11.44 \\
\hline & & & $2-27-62$ & 11.51 \\
\hline & & & $3-07-62$ & 11.53 \\
\hline & & & $3-13-62$ & 10.9 \\
\hline & & & $3-20-62$ & 10.66 \\
\hline & & & $3-27-62$ & 10.39 \\
\hline & & & $4-03-62$ & 9.87 \\
\hline & & & $4-10-62$ & 9.39 \\
\hline & & & $4-17-62$ & 9.28 \\
\hline & & & $4-24-62$ & 9.43 \\
\hline & & & $5-01-62$ & 9.69 \\
\hline & & & $5-08-62$ & 9.94 \\
\hline & & & $5-15-62$ & 10.18 \\
\hline
\end{tabular}


Table 4. Historical water levels measured from wells in the Big-Mishnock stream-aquifer system, central Rhode Island, 1938-96-Continued

\begin{tabular}{|c|c|c|c|c|}
\hline $\begin{array}{c}\text { Latitude } \\
\circ, 11\end{array}$ & 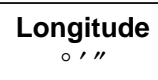 & Site identification No. & Date & $\begin{array}{l}\text { Water level } \\
\text { (feet) }\end{array}$ \\
\hline \multirow[t]{45}{*}{ WGW 211-Continued } & & & $5-22-62$ & 10.32 \\
\hline & & & $5-29-62$ & 10.56 \\
\hline & & & $6-05-62$ & 10.74 \\
\hline & & & $6-12-62$ & 10.37 \\
\hline & & & $6-19-62$ & 10.55 \\
\hline & & & $6-26-62$ & 10.72 \\
\hline & & & $7-03-62$ & 10.87 \\
\hline & & & $7-10-62$ & 11.1 \\
\hline & & & $7-17-62$ & 11.32 \\
\hline & & & $7-24-62$ & 11.55 \\
\hline & & & $7-31-62$ & 11.7 \\
\hline & & & $8-07-62$ & 12.01 \\
\hline & & & $8-14-62$ & 12.23 \\
\hline & & & $8-21-62$ & 12.49 \\
\hline & & & $8-28-62$ & 12.71 \\
\hline & & & $9-01-62$ & 12.84 \\
\hline & & & $9-08-62$ & 13.06 \\
\hline & & & $9-15-62$ & 13.1 \\
\hline & & & $9-22-62$ & 13.5 \\
\hline & & & $9-29-62$ & 13.7 \\
\hline & & & $10-8-62$ & 13.35 \\
\hline & & & $10-13-62$ & 12.83 \\
\hline & & & $10-20-62$ & 12.78 \\
\hline & & & $10-27-62$ & 12.86 \\
\hline & & & $11-04-62$ & 12.86 \\
\hline & & & $11-11-62$ & 12.6 \\
\hline & & & $11-17-62$ & 12.22 \\
\hline & & & $11-24-62$ & 12.02 \\
\hline & & & $12-01-62$ & 11.7 \\
\hline & & & $12-08-62$ & 11.56 \\
\hline & & & $12-15-62$ & 11.33 \\
\hline & & & $12-22-62$ & 11.17 \\
\hline & & & $12-29-62$ & 11.19 \\
\hline & & & $2-23-63$ & 10.96 \\
\hline & & & $3-02-63$ & 11.02 \\
\hline & & & $3-09-63$ & 10.74 \\
\hline & & & $3-16-63$ & 10.63 \\
\hline & & & $3-23-63$ & 10.6 \\
\hline & & & $3-30-63$ & 10.5 \\
\hline & & & $4-06-63$ & 11.28 \\
\hline & & & $4-13-63$ & 11.36 \\
\hline & & & $4-20-63$ & 11.47 \\
\hline & & & $4-27-63$ & 12.14 \\
\hline & & & $5-04-63$ & 11.6 \\
\hline & & & $5-11-63$ & 11.44 \\
\hline
\end{tabular}


Table 4. Historical water levels measured from wells in the Big-Mishnock stream-aquifer system, central Rhode Island, 1938-96-Continued

\begin{tabular}{|c|c|c|c|c|c|}
\hline Well No. & $\begin{array}{c}\text { Latitude } \\
\circ, \prime \prime\end{array}$ & $\begin{array}{c}\text { Longitude } \\
0,1\end{array}$ & Site identification No. & Date & $\begin{array}{l}\text { Water level } \\
\text { (feet) }\end{array}$ \\
\hline \multirow{31}{*}{\multicolumn{2}{|c|}{ WGW 211-Continued }} & & & $5-18-63$ & 11.48 \\
\hline & & & & $5-25-63$ & 11.46 \\
\hline & & & & $6-01-63$ & 11.54 \\
\hline & & & & $6-08-63$ & 11.55 \\
\hline & & & & $6-15-63$ & 11.69 \\
\hline & & & & $6-22-63$ & 11.82 \\
\hline & & & & $6-28-63$ & 11.96 \\
\hline & & & & $7-05-63$ & 12.12 \\
\hline & & & & $7-12-63$ & 12.33 \\
\hline & & & & $7-19-63$ & 12.51 \\
\hline & & & & $7-26-63$ & 12.72 \\
\hline & & & & $8-02-63$ & 13 \\
\hline & & & & $8-09-63$ & 13.11 \\
\hline & & & & $8-16-63$ & 13.34 \\
\hline & & & & $8-23-63$ & 13.54 \\
\hline & & & & $8-30-63$ & 13.77 \\
\hline & & & & $9-07-63$ & 14.04 \\
\hline & & & & $9-14-63$ & 14.26 \\
\hline & & & & $9-21-63$ & 14.47 \\
\hline & & & & $9-28-63$ & 14.71 \\
\hline & & & & $10-05-63$ & 14.91 \\
\hline & & & & $10-12-63$ & Dry \\
\hline & & & & $10-19-63$ & Dry \\
\hline & & & & $10-26-63$ & Dry \\
\hline & & & & $11-02-63$ & Dry \\
\hline & & & & $11-09-63$ & Dry \\
\hline & & & & $11-16-63$ & Dry \\
\hline & & & & $11-23-63$ & Dry \\
\hline & & & & $11-30-63$ & Dry \\
\hline & & & & $12-07-63$ & Dry \\
\hline & & & & $12-14-63$ & Dry \\
\hline WGW 216 & 413654 & 713656 & 413654071365601 & $9-17-54$ & 18.02 \\
\hline WGW 217 & 413653 & 713654 & 413653071365401 & $9-17-54$ & 16.37 \\
\hline WGW 229 & 413913 & 713512 & 413913071351201 & $4-01-52$ & 30 \\
\hline WGW 230 & 413919 & 713538 & 413919071353801 & $9-01-53$ & 2 \\
\hline WGW 243 & 413903 & 713623 & 413903071362301 & $2-01-56$ & 11.8 \\
\hline WGW 271 & 413842 & 713643 & 413842071364301 & $5-16-62$ & 25 \\
\hline WGW 272 & 413839 & 713700 & 413839071370001 & $5-16-62$ & 15 \\
\hline WGW 273 & 413800 & 713638 & 413800071363801 & $5-17-62$ & 10 \\
\hline WGW 274 & 413854 & 713604 & 413854071360401 & $5-18-62$ & 15 \\
\hline WGW 275 & 413850 & 713539 & 413850071353901 & $5-18-62$ & 9 \\
\hline WGW 276 & 413847 & 713512 & 413847071351201 & $5-18-62$ & 12 \\
\hline WGW 278 & 413907 & 713401 & 413907071340101 & $5-22-62$ & 7 \\
\hline WGW 380 & 413954 & 713603 & 413954071360301 & $3-25-76$ & 42 \\
\hline WGW 382 & 413857 & 713533 & 413857071353301 & $7-09-76$ & 22.83 \\
\hline
\end{tabular}


Table 4. Historical water levels measured from wells in the Big-Mishnock stream-aquifer system, central Rhode Island, 1938-96-Continued

\begin{tabular}{lccccc}
\hline Well No. & $\begin{array}{c}\text { Latitude } \\
\text { o' }\end{array}$ & $\begin{array}{c}\text { Longitude } \\
\text { o' }{ }^{\prime \prime}\end{array}$ & Site identification No. & Date & $\begin{array}{c}\text { Water level } \\
\text { (feet) }\end{array}$ \\
\hline WGW 384 & 413856 & 713504 & 413856071350401 & $8-26-76$ & 10.5 \\
WGW 386 & 413854 & 713438 & 413854071343801 & $3-26-76$ & 22 \\
WGW 387 & 413904 & 713427 & 413904071342701 & $4-13-76$ & 9.5 \\
WGW 388 & 413904 & 713403 & 413904071340301 & $4-12-76$ & 4 \\
WGW 389 & 413913 & 713350 & 413913071335001 & $4-02-76$ & 32 \\
WGW 390 & 413836 & 713407 & 413836071340701 & $6-21-76$ & 12 \\
WGW 391 & 413839 & 713430 & 413839071343001 & $6-22-76$ & 42.5 \\
WGW 393 & 413914 & 713600 & 413914071360001 & $8-04-83$ & 8 \\
WGW 394 & 413904 & 713608 & 413904071360801 & $8-01-83$ & 14.5 \\
WGW 396 & 413914 & 713537 & 413914071353701 & $8-31-83$ & 3 \\
WGW 399 & 413905 & 713526 & 413905071352601 & $8-25-83$ & 13.75 \\
WGW 401 & 413841 & 713521 & 413841071352101 & $9-14-83$ & 5.6 \\
WGW 402 & 413856 & 713506 & 413856071350601 & $9-14-83$ & 50 \\
WGW 403 & 413845 & 713504 & 413845071350401 & $9-01-83$ & 17.5 \\
WGW 404 & 413910 & 713454 & 413910071345401 & $8-05-83$ & 51 \\
WGW 406 & 413851 & 713441 & 413851071344101 & $8-17-83$ & 24 \\
WGW 408 & 413859 & 713430 & 413859071343001 & $8-16-83$ & 14.8 \\
\hline
\end{tabular}

Table 5. Average daily withdrawal rates by month from public-supply wells in the Mishnock River Basin, central Rhode Island, 1995-99

[Site locations are shown on plate 1. Withdrawal rates in million gallons per day. COW, Coventry well; No., number]

\begin{tabular}{|c|c|c|c|c|c|c|c|c|c|c|c|c|c|}
\hline \multirow{2}{*}{ Year } & \multicolumn{12}{|c|}{ Average daily withdrawal rates } & \multirow{2}{*}{$\begin{array}{c}\text { Annual } \\
\text { average } \\
\text { daily } \\
\text { with- } \\
\text { drawal } \\
\text { rates }\end{array}$} \\
\hline & January & February & March & April & May & June & July & August & September & October & November & December & \\
\hline \multicolumn{14}{|c|}{ Kent County Water Authority—Mishnock Well \#1, Well No. COW 461} \\
\hline 1995 & 0.55 & 0.53 & 0.36 & 0.82 & 0.80 & 0.25 & 0.16 & 0.56 & 0 & 0 & 0 & 0 & 0.34 \\
\hline 1996 & .11 & .56 & .35 & .45 & .39 & 0 & 0 & 0 & 0 & 0 & 0 & 0 & .15 \\
\hline 1997 & 0 & 0 & 0 & 0 & 0 & .01 & .52 & .45 & .45 & .49 & .54 & .53 & .25 \\
\hline 1998 & .54 & .54 & .50 & .54 & .50 & .40 & .18 & .37 & .45 & .45 & .41 & .44 & .44 \\
\hline 1999 & .45 & .48 & .53 & .53 & .55 & .51 & .48 & .47 & .47 & .50 & .55 & .54 & .50 \\
\hline \multicolumn{14}{|c|}{ Kent County Water Authority—Mishnock Well \#2, Well No. COW 462} \\
\hline 1995 & .56 & .56 & .23 & 0 & 0 & .92 & .83 & .10 & 69 & .70 & 66 & .62 & .49 \\
\hline 1996 & .47 & .02 & .29 & .17 & .24 & .65 & .64 & .62 & 60 & 60 & .59 & .57 & .46 \\
\hline 1997 & .57 & .57 & .56 & .58 & .60 & .58 & .25 & .52 & .50 & .02 & 0 & 0 & .39 \\
\hline 1998 & 0 & 0 & 0 & 0 & .13 & .14 & .55 & .52 & .37 & .43 & .40 & .41 & .25 \\
\hline 1999 & .42 & .35 & 0 & 0 & 0 & .35 & .46 & .42 & .46 & .29 & 0 & 0 & .23 \\
\hline
\end{tabular}


Table 6. Ground-water levels recorded during an aquifer test conducted at West Greenwich Well 354, central Rhode Island, July 1998

[Site locations are shown on plate 1. WGW 354 (West Greenwich well) was pumped at 350 gallons per minute for 48 hours. D, radial distance from pumped well in feet; MP, altitude of measuring point datum at local well in feet above sea level; min, minutes; --, no data available]

\begin{tabular}{|c|c|c|c|c|c|c|c|c|c|c|c|}
\hline \multirow{3}{*}{ Date } & \multirow{3}{*}{$\begin{array}{l}\text { Time } \\
\text { (min) }\end{array}$} & \multicolumn{10}{|c|}{ Water level (feet below measuring point) } \\
\hline & & \multirow{2}{*}{$\begin{array}{c}\text { Pumped well } \\
\text { WGW } 354 \\
\text { MP 264.27 }\end{array}$} & \multicolumn{9}{|c|}{ Observation well } \\
\hline & & & $\begin{array}{c}\text { WGW } 312 \\
\text { D } 4.8 \\
\text { MP } 264.54\end{array}$ & $\begin{array}{c}\text { WGW } 336 \\
\text { D } 72 \\
\text { MP } 262.84\end{array}$ & $\begin{array}{c}\text { WGW } 341 \\
\text { D } 155 \\
\text { MP } 263.90\end{array}$ & $\begin{array}{c}\text { WGW } 337 \\
\text { D } 165 \\
\text { MP } 261.61\end{array}$ & $\begin{array}{c}\text { WGW } 339 \\
\text { D } 189 \\
\text { MP } 263.66\end{array}$ & $\begin{array}{c}\text { WGW } 340 \\
\text { D } 271 \\
\text { MP } 266.59\end{array}$ & $\begin{array}{c}\text { WGW } 338 \\
\text { D } 321 \\
\text { MP } 263.82\end{array}$ & $\begin{array}{c}\text { WGW } 306 \\
\text { D } 1,000 \\
\text { MP } 285.38\end{array}$ & $\begin{array}{c}\text { WGW } 307 \\
\text { D } 1,300 \\
\text { MP } 272.15\end{array}$ \\
\hline \multicolumn{12}{|c|}{ Prior to pumping } \\
\hline $7-15-98$ & -- & -- & 4.67 & 3.00 & 4.38 & 1.80 & 4.14 & 7.09 & 3.67 & 23.92 & 9.32 \\
\hline $7-17-98$ & -- & 4.54 & 4.74 & 3.06 & 4.45 & 1.86 & 4.21 & 7.16 & 3.74 & 23.99 & 9.42 \\
\hline $7-20-98$ & -- & 4.54 & -- & 3.17 & 4.54 & 1.96 & 4.32 & 7.27 & 3.85 & 24.13 & 9.59 \\
\hline $7-21-98$ & -- & 4.59 & -- & 3.18 & 4.58 & 1.98 & 4.33 & 7.29 & 3.88 & 24.17 & 9.65 \\
\hline \multicolumn{12}{|c|}{ Pumping begins } \\
\hline \multirow[t]{20}{*}{$7-21-98$} & 0 & 4.54 & -- & 3.18 & 4.58 & 1.98 & 4.33 & 7.29 & 3.88 & 24.17 & 9.65 \\
\hline & .25 & -- & -- & 3.26 & 4.68 & 1.99 & 4.34 & 7.29 & 3.88 & -- & -- \\
\hline & .5 & -- & 8.83 & 3.52 & 4.93 & 2.08 & 4.40 & 7.31 & 3.89 & -- & -- \\
\hline & .75 & -- & -- & 3.86 & 5.42 & 2.19 & 4.49 & 7.32 & 3.90 & -- & -- \\
\hline & 1 & -- & 10.23 & 4.18 & 7.74 & 2.29 & 4.58 & 7.36 & 3.93 & -- & -- \\
\hline & 1.5 & -- & 11.12 & 4.68 & 6.36 & 2.45 & 4.75 & 7.40 & 3.99 & -- & -- \\
\hline & 2 & -- & 11.42 & 4.98 & 6.79 & 2.57 & 4.87 & 7.46 & 4.05 & -- & -- \\
\hline & 3 & -- & 11.86 & 5.33 & 7.32 & 2.73 & 5.02 & 7.56 & 4.13 & -- & -- \\
\hline & 4 & -- & 12.13 & 5.53 & 7.63 & 2.85 & 5.13 & 7.63 & 4.22 & -- & -- \\
\hline & 5 & -- & 12.32 & 5.66 & 7.81 & 2.94 & 5.22 & 7.69 & 4.28 & -- & -- \\
\hline & 6 & 84.33 & -- & 5.77 & 7.94 & 3.02 & 5.29 & 7.74 & 4.34 & -- & -- \\
\hline & 7 & -- & 12.58 & 5.86 & 8.03 & 3.07 & 5.33 & 7.79 & 4.38 & -- & -- \\
\hline & 8 & -- & 12.65 & 5.92 & 8.11 & 3.12 & 5.39 & 7.83 & 4.42 & -- & -- \\
\hline & 9 & -- & 12.70 & 5.98 & 8.17 & 3.16 & 5.44 & 7.87 & 4.46 & -- & -- \\
\hline & 10 & -- & 12.75 & 6.02 & 8.22 & 3.20 & 5.47 & 7.91 & 4.49 & -- & -- \\
\hline & 11 & 83.06 & -- & -- & -- & -- & -- & -- & -- & -- & -- \\
\hline & 12 & -- & -- & 6.08 & 8.30 & 3.26 & 5.53 & 7.97 & 4.54 & -- & -- \\
\hline & 13 & & 13.30 & -- & -- & -- & -- & -- & -- & -- & -- \\
\hline & 14 & -- & -- & 6.35 & 8.61 & 3.40 & 5.65 & 8.04 & 4.60 & -- & -- \\
\hline & 16 & -- & -- & 6.48 & 8.77 & 3.47 & 5.74 & 8.11 & 4.67 & -- & -- \\
\hline
\end{tabular}


Table 6. Ground-water levels recorded during an aquifer test conducted at West Greenwich Well 354, central Rhode Island, July 1998—Continued

\begin{tabular}{|c|c|c|c|c|c|c|c|c|c|c|c|}
\hline \multirow{3}{*}{ Date } & \multirow{3}{*}{$\begin{array}{l}\text { Time } \\
\text { (min) }\end{array}$} & \multicolumn{10}{|c|}{ Water level (feet below measuring point) } \\
\hline & & \multirow{2}{*}{$\begin{array}{c}\text { Pumped well } \\
\text { WGW } 354 \\
\text { MP 264.27 }\end{array}$} & \multicolumn{9}{|c|}{ Observation well } \\
\hline & & & $\begin{array}{c}\text { WGW } 312 \\
\text { D } 4.8 \\
\text { MP } 264.54\end{array}$ & $\begin{array}{c}\text { WGW } 336 \\
\text { D } 72 \\
\text { MP } 262.84\end{array}$ & $\begin{array}{c}\text { WGW } 341 \\
\text { D } 155 \\
\text { MP } 263.90\end{array}$ & $\begin{array}{c}\text { WGW } 337 \\
\text { D } 165 \\
\text { MP 261.61 }\end{array}$ & $\begin{array}{c}\text { WGW } 339 \\
\text { D } 189 \\
\text { MP } 263.66\end{array}$ & $\begin{array}{c}\text { WGW } 340 \\
\text { D } 271 \\
\text { MP } 266.59\end{array}$ & $\begin{array}{c}\text { WGW } 338 \\
\text { D } 321 \\
\text { MP } 263.82\end{array}$ & $\begin{array}{c}\text { WGW } 306 \\
\text { D } 1,000 \\
\text { MP } 285.38\end{array}$ & $\begin{array}{c}\text { WGW } 307 \\
\text { D } 1,300 \\
\text { MP } 272.15\end{array}$ \\
\hline \multicolumn{12}{|c|}{ Pumping-Continued } \\
\hline \multirow[t]{25}{*}{$7-21-98$} & 18 & & 13.30 & 6.45 & 8.72 & 3.50 & 5.77 & 8.16 & 4.70 & -- & -- \\
\hline & 19 & 86.00 & -- & -- & -- & -- & -- & -- & -- & -- & -- \\
\hline & 20 & -- & -- & 6.41 & 8.66 & 3.52 & 5.79 & 8.19 & 4.73 & -- & -- \\
\hline & 23 & -- & 13.16 & 6.39 & 8.62 & 3.53 & 5.81 & 8.23 & 4.76 & -- & -- \\
\hline & 26 & -- & -- & 6.42 & 8.63 & 3.55 & 5.84 & 8.27 & 4.78 & -- & -- \\
\hline & 30 & 85.58 & 13.23 & 6.45 & 8.67 & 3.61 & 5.88 & 8.31 & 4.82 & -- & -- \\
\hline & 35 & 85.50 & 13.28 & 6.48 & 8.70 & 3.64 & 5.93 & 8.35 & 4.85 & -- & -- \\
\hline & 40 & 85.30 & -- & 6.51 & 8.74 & 3.68 & 5.96 & 8.39 & 4.88 & -- & -- \\
\hline & 45 & -- & 13.30 & 6.54 & 8.76 & 3.69 & 5.99 & 8.42 & 4.90 & -- & -- \\
\hline & 50 & 85.44 & 13.31 & 6.56 & 8.79 & 3.72 & 6.02 & 8.44 & 4.93 & -- & -- \\
\hline & 60 & 85.41 & 13.34 & 6.59 & 8.81 & 3.74 & 6.06 & 8.48 & 4.95 & -- & -- \\
\hline & 70 & 85.40 & 13.35 & 6.61 & 8.85 & 3.75 & 6.09 & 8.52 & 4.97 & -- & 9.76 \\
\hline & 80 & 85.40 & 13.36 & 6.63 & 8.85 & 3.77 & 6.10 & -- & 4.99 & 24.36 & -- \\
\hline & 90 & 85.42 & 13.39 & 6.64 & 8.88 & 3.81 & 6.11 & 8.54 & 5.01 & -- & -- \\
\hline & 100 & 85.43 & 13.40 & 6.66 & 8.90 & 3.81 & 6.13 & -- & 5.02 & -- & -- \\
\hline & 120 & 85.90 & 13.46 & 6.68 & 8.92 & 3.83 & 6.17 & 8.58 & 5.04 & -- & -- \\
\hline & 150 & 85.73 & 13.45 & 6.71 & 8.94 & 3.85 & 6.19 & 8.61 & 5.06 & 24.39 & 9.79 \\
\hline & 180 & 85.30 & 13.42 & 6.71 & 8.93 & 3.86 & 6.20 & 8.63 & 5.08 & -- & -- \\
\hline & 210 & 85.40 & 13.45 & 6.72 & 8.94 & 3.87 & 6.21 & 8.64 & 5.09 & -- & -- \\
\hline & 240 & 85.39 & 13.44 & 6.74 & 8.95 & 3.89 & 6.22 & 8.65 & 5.09 & -- & -- \\
\hline & 300 & 85.35 & 13.45 & 6.75 & 8.97 & 3.90 & 6.24 & 8.67 & 5.11 & 24.55 & 9.82 \\
\hline & 360 & 85.35 & 13.47 & 6.76 & 8.98 & 3.91 & 6.25 & 8.68 & 5.12 & -- & -- \\
\hline & 420 & 85.33 & 13.45 & 6.77 & 8.99 & 3.92 & 6.26 & 8.69 & 5.13 & -- & 9.85 \\
\hline & 480 & 85.31 & 13.45 & 6.78 & 9.00 & 3.93 & 6.27 & 8.70 & 5.14 & 24.57 & -- \\
\hline & 540 & 85.31 & 13.46 & 6.79 & 9.01 & 3.93 & 6.29 & 8.72 & 5.16 & 24.59 & 9.86 \\
\hline
\end{tabular}


Table 6. Ground-water levels recorded during an aquifer test conducted at West Greenwich Well 354, central Rhode Island, July 1998-Continued

\begin{tabular}{|c|c|c|c|c|c|c|c|c|c|c|c|}
\hline \multirow{3}{*}{ Date } & \multirow{3}{*}{$\begin{array}{l}\text { Time } \\
(\min )\end{array}$} & \multicolumn{10}{|c|}{ Water level (feet below measuring point) } \\
\hline & & \multirow{2}{*}{$\begin{array}{c}\text { Pumped well } \\
\text { WGW } 354 \\
\text { MP 264.27 }\end{array}$} & \multicolumn{9}{|c|}{ Observation well } \\
\hline & & & $\begin{array}{c}\text { WGW } 312 \\
\text { D } 4.8 \\
\text { MP 264.54 }\end{array}$ & $\begin{array}{c}\text { WGW } 336 \\
\text { D } 72 \\
\text { MP } 262.84\end{array}$ & $\begin{array}{c}\text { WGW } 341 \\
\text { D } 155 \\
\text { MP 263.90 }\end{array}$ & $\begin{array}{c}\text { WGW } 337 \\
\text { D } 165 \\
\text { MP } 261.61\end{array}$ & $\begin{array}{c}\text { WGW } 339 \\
\text { D } 189 \\
\text { MP } 263.66\end{array}$ & $\begin{array}{c}\text { WGW } 340 \\
\text { D } 271 \\
\text { MP } 266.59\end{array}$ & $\begin{array}{c}\text { WGW } 338 \\
\text { D } 321 \\
\text { MP } 263.82\end{array}$ & $\begin{array}{c}\text { WGW } 306 \\
\text { D 1,000 } \\
\text { MP } 285.38\end{array}$ & $\begin{array}{c}\text { WGW } 307 \\
\text { D 1,300 } \\
\text { MP 272.15 }\end{array}$ \\
\hline \multicolumn{12}{|c|}{ Pumping-Continued } \\
\hline \multirow[t]{5}{*}{$7-21-98$} & 600 & 85.32 & 13.47 & 6.79 & 9.02 & 3.94 & 6.30 & 8.72 & 5.16 & -- & -- \\
\hline & 660 & 87.03 & 13.56 & 6.86 & 9.10 & 3.98 & 6.32 & 8.75 & 5.18 & 24.61 & 9.87 \\
\hline & 720 & 85.29 & 13.50 & 6.81 & 9.03 & 3.96 & 6.30 & 8.74 & 5.17 & -- & -- \\
\hline & 780 & 85.30 & 13.49 & 6.81 & 9.04 & 3.97 & 6.30 & 8.73 & 5.18 & 24.61 & 9.88 \\
\hline & 840 & 85.26 & 13.47 & 6.81 & 9.04 & 3.98 & 6.31 & 8.74 & 5.18 & -- & -- \\
\hline \multirow[t]{20}{*}{$7-22-98$} & 900 & 85.34 & 13.50 & 6.81 & 9.03 & 3.97 & 6.31 & 8.74 & 5.18 & 24.61 & 9.88 \\
\hline & 960 & 85.34 & 13.50 & 6.82 & 9.04 & 3.98 & 6.32 & 8.75 & 5.18 & -- & -- \\
\hline & 1,020 & 85.36 & 13.50 & 6.83 & 9.04 & 3.98 & 6.32 & 8.75 & 5.19 & 24.61 & 9.88 \\
\hline & 1,080 & 85.40 & 13.51 & 6.83 & 9.05 & 3.99 & 6.32 & 8.75 & 5.19 & -- & -- \\
\hline & 1,140 & 85.45 & 13.50 & 6.84 & 9.05 & 3.99 & 6.32 & 8.76 & 5.20 & 24.62 & 9.90 \\
\hline & 1,200 & 85.50 & 13.52 & 6.85 & 9.06 & 4.00 & 6.33 & 8.76 & 5.21 & -- & -- \\
\hline & 1,260 & 85.44 & 13.52 & 6.85 & 9.06 & 4.00 & 6.34 & 8.77 & 5.21 & 24.63 & 9.90 \\
\hline & 1,320 & 86.59 & 13.61 & 6.89 & 9.12 & 4.03 & 6.36 & 8.79 & 5.23 & -- & -- \\
\hline & 1,380 & 85.56 & 13.53 & 6.87 & 9.08 & 4.02 & 6.36 & 8.79 & 5.23 & 24.65 & 9.92 \\
\hline & 1,440 & 85.56 & 13.55 & 6.88 & 9.09 & 4.03 & 6.36 & 8.79 & 5.24 & -- & -- \\
\hline & 1,500 & 85.59 & 13.55 & 6.89 & 9.10 & 4.04 & 6.37 & 8.80 & 5.24 & -- & -- \\
\hline & 1,560 & 85.87 & 13.57 & 6.90 & 9.12 & 4.05 & 6.38 & 8.82 & 5.25 & 24.66 & 9.93 \\
\hline & 1,620 & 85.88 & 13.59 & 6.91 & 9.13 & 4.06 & 6.39 & 8.82 & 5.26 & -- & -- \\
\hline & 1,680 & 85.92 & 13.60 & 6.92 & 9.13 & 4.07 & 6.40 & 8.82 & 5.27 & 24.67 & 9.95 \\
\hline & 1,740 & 85.96 & 13.60 & 6.92 & 9.14 & 4.07 & 6.41 & 8.84 & 5.28 & -- & -- \\
\hline & 1,800 & 85.97 & 13.60 & 6.93 & 9.15 & 4.07 & 6.41 & 8.85 & 5.28 & -- & -- \\
\hline & 1,860 & 85.95 & 13.61 & 6.93 & 9.15 & 4.08 & 6.42 & 8.85 & 5.29 & -- & -- \\
\hline & 1,920 & 85.97 & 13.62 & 6.95 & 9.16 & 4.09 & 6.43 & 8.86 & 5.28 & 24.69 & 9.96 \\
\hline & 2,040 & 85.98 & 13.63 & 6.98 & 9.17 & 4.10 & 6.44 & 8.87 & 5.30 & 24.71 & 9.98 \\
\hline & 2,100 & 85.99 & 13.64 & 6.96 & 9.19 & 4.10 & 6.44 & 8.87 & 5.30 & -- & -- \\
\hline
\end{tabular}


Table 6. Ground-water levels recorded during an aquifer test conducted at West Greenwich Well 354, central Rhode Island, July 1998—Continued

\begin{tabular}{|c|c|c|c|c|c|c|c|c|c|c|c|}
\hline \multirow{3}{*}{ Date } & \multirow{3}{*}{$\begin{array}{l}\text { Time } \\
(\min )\end{array}$} & \multicolumn{10}{|c|}{ Water level (feet below measuring point) } \\
\hline & & \multirow{2}{*}{$\begin{array}{c}\text { Pumped well } \\
\text { WGW } 354 \\
\text { MP 264.27 }\end{array}$} & \multicolumn{9}{|c|}{ Observation well } \\
\hline & & & $\begin{array}{c}\text { WGW } 312 \\
\text { D } 4.8 \\
\text { MP 264.54 }\end{array}$ & $\begin{array}{c}\text { WGW } 336 \\
\text { D } 72 \\
\text { MP } 262.84\end{array}$ & $\begin{array}{c}\text { WGW } 341 \\
\text { D } 155 \\
\text { MP } 263.90\end{array}$ & $\begin{array}{c}\text { WGW } 337 \\
\text { D } 165 \\
\text { MP 261.61 }\end{array}$ & $\begin{array}{c}\text { WGW } 339 \\
\text { D } 189 \\
\text { MP } 263.66\end{array}$ & $\begin{array}{c}\text { WGW } 340 \\
\text { D } 271 \\
\text { MP } 266.59\end{array}$ & $\begin{array}{c}\text { WGW } 338 \\
\text { D } 321 \\
\text { MP 263.82 }\end{array}$ & $\begin{array}{c}\text { WGW } 306 \\
\text { D } 1,000 \\
\text { MP } 285.38\end{array}$ & $\begin{array}{c}\text { WGW } 307 \\
\text { D } 1,300 \\
\text { MP } 272.15\end{array}$ \\
\hline \multicolumn{12}{|c|}{ Pumping-Continued } \\
\hline \multirow[t]{14}{*}{$7-22-98$} & 2,160 & 86.00 & 13.64 & 6.96 & 9.19 & 4.12 & 6.46 & 8.88 & 5.31 & -- & -- \\
\hline & 2,220 & 86.02 & 13.64 & 6.96 & 9.19 & 4.12 & 6.45 & 8.88 & 5.32 & -- & -- \\
\hline & 2,280 & 85.96 & 13.63 & 6.97 & 9.19 & 4.12 & 6.46 & 8.88 & 5.31 & 24.72 & 10.01 \\
\hline & 2,340 & 85.96 & 13.63 & 6.97 & 9.18 & 4.11 & 6.45 & 8.88 & 5.32 & -- & -- \\
\hline & 2,400 & 85.96 & 13.63 & 6.96 & 9.18 & 4.11 & 6.45 & 8.88 & 5.32 & -- & -- \\
\hline & 2,460 & 85.95 & 13.63 & 6.96 & 9.18 & 4.12 & 6.45 & 8.88 & 5.32 & -- & -- \\
\hline & 2,520 & 85.96 & 13.63 & 6.97 & 9.18 & 4.12 & 6.45 & 8.88 & 5.32 & 24.72 & 10.01 \\
\hline & 2,580 & 85.91 & 13.63 & 6.97 & 9.18 & 4.12 & 6.45 & 8.88 & 5.32 & -- & -- \\
\hline & 2,640 & 85.90 & 13.64 & 6.97 & 9.19 & 4.13 & 6.46 & 8.89 & 5.33 & -- & -- \\
\hline & 2,700 & 85.90 & 13.63 & 6.97 & 9.19 & 4.13 & 6.46 & 8.90 & 5.33 & 24.73 & 10.01 \\
\hline & 2,760 & 85.90 & 13.63 & 6.98 & 9.20 & 4.13 & 6.46 & 8.90 & 5.33 & -- & -- \\
\hline & 2,820 & 85.90 & 13.66 & 6.98 & 9.19 & 4.14 & 6.46 & 8.91 & 5.34 & 24.74 & 10.02 \\
\hline & 2,885 & 85.90 & -- & 7.02 & 9.24 & 4.14 & 6.47 & 8.92 & 5.35 & -- & -- \\
\hline & 2,890 & -- & 13.66 & -- & 9.21 & -- & 6.47 & 8.92 & 5.35 & -- & -- \\
\hline
\end{tabular}


Table 7. Ground-water levels recorded during an aquifer test conducted at West Greenwich Well 355, central Rhode Island, February 1998

[Site locations are shown on plate 1. WGW 355 (West Greenwich well) was pumped at 400 gallons per minute for 48 hours. D, radial distance from pumped well in feet; MP, altitude of measuring point datum at local well in feet above sea level; min, minutes; --, no data available]

\begin{tabular}{|c|c|c|c|c|c|c|c|c|c|c|c|}
\hline \multirow{3}{*}{ Date } & \multirow{3}{*}{$\begin{array}{l}\text { Time } \\
(\min )\end{array}$} & \multirow{3}{*}{$\begin{array}{c}\text { Pumped well } \\
\text { WGW } 355 \\
\text { MP } 271.84\end{array}$} & \multicolumn{9}{|c|}{ Water level (feet below measuring point) } \\
\hline & & & \multicolumn{9}{|c|}{ Observation well } \\
\hline & & & $\begin{array}{c}\text { WGW } 307 \\
\text { D } 2 \\
\text { MP } 272.15\end{array}$ & $\begin{array}{c}\text { WGW } 343 \\
\text { D } 102 \\
\text { MP } 272.34\end{array}$ & $\begin{array}{l}\text { WGW } 344 \\
\text { D } 200 \\
\text { MP } 281.54\end{array}$ & $\begin{array}{c}\text { WGW } 301 \\
\text { D } 300 \\
\text { MP } 273.47\end{array}$ & $\begin{array}{c}\text { WGW } 306 \\
\text { D } 643 \\
\text { MP } 285.38\end{array}$ & $\begin{array}{c}\text { WGW } 338 \\
\text { D } 977 \\
\text { MP } 263.82\end{array}$ & $\begin{array}{c}\text { WGW } 337 \\
\text { D } 1,133 \\
\text { MP } 261.61\end{array}$ & $\begin{array}{c}\text { WGW } 312 \\
\text { D } 1,306 \\
\text { MP } 264.54\end{array}$ & $\begin{array}{c}\text { WGW } 341 \\
\text { D } 1,457 \\
\text { MP } 263.90\end{array}$ \\
\hline \multicolumn{12}{|c|}{ Prior to pumping } \\
\hline $1-30-98$ & -- & -- & -- & 11.85 & 20.99 & 13.46 & 25.25 & 4.69 & 2.62 & 5.39 & 5.04 \\
\hline $1-31-98$ & -- & -- & -- & 11.85 & 20.98 & 13.47 & 25.26 & 4.69 & 2.64 & 5.41 & 5.05 \\
\hline $2-01-98$ & -- & -- & -- & 11.84 & 20.97 & 13.48 & 25.26 & 4.71 & 2.65 & 5.42 & 5.07 \\
\hline $2-02-98$ & -- & -- & -- & 11.83 & 20.96 & 13.47 & 25.27 & 4.70 & 2.64 & 5.42 & 5.07 \\
\hline \multicolumn{12}{|c|}{ Pumping begins } \\
\hline \multirow[t]{20}{*}{$2-02-98$} & 0 & 11.47 & 25.27 & 11.83 & 20.96 & 13.47 & 25.27 & -- & 2.90 & 5.42 & 5.07 \\
\hline & .25 & -- & 25.27 & 11.99 & 20.98 & 13.47 & 25.27 & -- & -- & -- & -- \\
\hline & .5 & -- & 25.27 & 12.22 & & 13.47 & 25.27 & -- & -- & -- & -- \\
\hline & .75 & -- & 25.27 & 12.43 & 21.04 & 13.54 & 25.27 & -- & -- & -- & -- \\
\hline & 1 & -- & 25.28 & 12.55 & & 13.63 & 25.28 & -- & -- & -- & -- \\
\hline & 1.5 & -- & 25.29 & 12.79 & 21.25 & 13.80 & 25.29 & -- & -- & -- & -- \\
\hline & 2 & -- & 25.32 & 13.40 & 21.46 & 14.00 & 25.32 & -- & -- & -- & -- \\
\hline & 2.5 & -- & -- & -- & 21.61 & -- & -- & -- & -- & -- & -- \\
\hline & 3 & 64.18 & 25.41 & 14.03 & 21.84 & 14.35 & 25.41 & -- & -- & -- & -- \\
\hline & 3.5 & -- & -- & -- & 22.01 & -- & -- & -- & -- & -- & -- \\
\hline & 4 & 63.88 & 25.49 & 14.65 & 22.15 & 14.52 & 25.49 & -- & -- & -- & -- \\
\hline & 5 & 64 & 25.57 & 15.10 & 22.39 & 14.66 & 25.57 & -- & -- & -- & -- \\
\hline & 6 & 64.1 & 25.64 & 15.30 & 22.63 & 14.75 & 25.64 & -- & -- & -- & -- \\
\hline & 7 & 64.18 & 25.69 & 15.53 & 22.79 & 14.87 & 25.69 & -- & -- & -- & -- \\
\hline & 8 & 64.26 & 25.75 & 15.71 & 22.95 & 14.92 & 25.75 & -- & -- & -- & -- \\
\hline & 9 & 64.36 & 25.8 & 15.86 & 23.05 & 14.97 & 25.80 & -- & -- & -- & -- \\
\hline & 10 & 64.42 & 25.83 & 15.96 & 23.14 & 15.03 & 25.83 & -- & -- & -- & -- \\
\hline & 12 & 64.5 & 25.9 & 16.11 & 23.29 & 15.10 & 25.90 & -- & -- & -- & -- \\
\hline & 14 & 65.15 & 25.96 & 16.23 & 23.39 & 15.17 & 25.96 & -- & -- & -- & -- \\
\hline & 16 & 65.19 & 26.01 & 16.32 & 23.48 & 15.22 & 26.01 & -- & -- & -- & -- \\
\hline
\end{tabular}


Table 7. Ground-water levels recorded during an aquifer test conducted at West Greenwich Well 355, central Rhode Island, February 1998—Continued

\begin{tabular}{|c|c|c|c|c|c|c|c|c|c|c|c|}
\hline \multirow{3}{*}{ Date } & \multirow{3}{*}{$\begin{array}{l}\text { Time } \\
\text { (min) }\end{array}$} & \multirow{3}{*}{$\begin{array}{c}\text { Pumped well } \\
\text { WGW } 355 \\
\text { MP 271.84 }\end{array}$} & \multicolumn{9}{|c|}{ Water level (feet below measuring point) } \\
\hline & & & \multicolumn{9}{|c|}{ Observation well } \\
\hline & & & $\begin{array}{c}\text { WGW } 307 \\
\text { D } 2 \\
\text { MP } 272.15\end{array}$ & $\begin{array}{l}\text { WGW } 343 \\
\text { D } 102 \\
\text { MP } 272.34\end{array}$ & $\begin{array}{l}\text { WGW } 344 \\
\text { D } 200 \\
\text { MP } 281.54\end{array}$ & $\begin{array}{c}\text { WGW } 301 \\
\text { D } 300 \\
\text { MP 273.47 }\end{array}$ & $\begin{array}{c}\text { WGW } 306 \\
\text { D } 643 \\
\text { MP } 285.38\end{array}$ & $\begin{array}{c}\text { WGW } 338 \\
\text { D } 977 \\
\text { MP } 263.82\end{array}$ & $\begin{array}{l}\text { WGW } 337 \\
\text { D 1,133 } \\
\text { MP } 261.61\end{array}$ & $\begin{array}{l}\text { WGW } 312 \\
\text { D } 1,306 \\
\text { MP } 264.54\end{array}$ & $\begin{array}{c}\text { WGW } 341 \\
\text { D } 1,457 \\
\text { MP } 263.90\end{array}$ \\
\hline \multicolumn{12}{|c|}{ Pumping-Continued } \\
\hline \multirow[t]{25}{*}{ 2-02-98 } & 18 & 65.23 & 26.05 & 16.39 & 23.54 & 15.26 & 26.05 & -- & -- & -- & -- \\
\hline & 20 & 65.25 & 26.08 & 16.44 & 23.60 & 15.29 & 26.08 & -- & -- & -- & -- \\
\hline & 23 & 65.25 & 26.11 & 16.49 & 23.64 & 15.32 & 26.11 & -- & -- & -- & -- \\
\hline & 26 & 65.23 & 26.14 & 16.53 & 23.67 & 15.34 & 26.14 & -- & -- & -- & -- \\
\hline & 30 & 65.25 & 26.18 & 16.57 & 23.70 & 15.36 & 26.18 & -- & -- & -- & -- \\
\hline & 35 & 65.3 & 26.21 & 16.60 & 23.73 & 15.39 & 26.21 & -- & -- & -- & -- \\
\hline & 40 & 65.43 & 26.23 & 16.64 & 23.77 & 15.43 & 26.23 & -- & -- & -- & -- \\
\hline & 45 & 65.47 & 26.26 & 16.67 & 23.79 & 15.43 & 26.26 & -- & -- & -- & -- \\
\hline & 50 & 65.52 & 26.28 & 16.70 & 23.81 & 15.45 & 26.28 & -- & -- & -- & -- \\
\hline & 60 & 65.6 & 26.31 & 16.71 & 23.83 & 15.48 & 26.31 & -- & -- & -- & -- \\
\hline & 76 & 65.71 & 26.33 & 16.75 & 23.85 & 15.50 & 26.33 & 5.09 & 2.95 & 5.63 & 5.25 \\
\hline & 82 & 65.73 & 26.32 & 16.77 & 23.87 & 15.52 & 26.32 & -- & -- & -- & -- \\
\hline & 93 & 65.71 & 26.33 & 16.77 & 23.88 & 15.53 & 26.33 & -- & -- & -- & -- \\
\hline & 100 & 65.71 & 26.33 & 16.78 & 23.89 & 15.54 & 26.33 & -- & -- & -- & -- \\
\hline & 120 & 65.79 & 26.35 & 16.80 & 23.89 & 15.55 & 26.35 & -- & -- & -- & -- \\
\hline & 150 & 65.85 & 26.36 & 16.82 & 23.92 & 15.56 & 26.36 & 5.16 & -- & 5.67 & 5.29 \\
\hline & 180 & 65.8 & 26.42 & 16.82 & 23.93 & 15.58 & 26.42 & 5.18 & 2.98 & 5.69 & 5.31 \\
\hline & 210 & 65.93 & 26.43 & 16.84 & 23.95 & 15.61 & 26.43 & -- & -- & -- & -- \\
\hline & 240 & 66.06 & 26.44 & 16.86 & 23.97 & 15.63 & 26.44 & 5.19 & 2.99 & 5.71 & 5.32 \\
\hline & 300 & 66.01 & 26.44 & 16.89 & 24.00 & 15.68 & 26.44 & 5.21 & 3.02 & 5.72 & 5.34 \\
\hline & 360 & 66.02 & 26.48 & 16.90 & 24.02 & 15.69 & 26.48 & 5.23 & 3.02 & 5.73 & 5.35 \\
\hline & 480 & 65.99 & 26.47 & 16.92 & 24.05 & 15.70 & 26.47 & 5.25 & 3.04 & 5.75 & 5.36 \\
\hline & 600 & 66.05 & 26.49 & 16.95 & 24.08 & 15.71 & 26.49 & 5.27 & 3.05 & 5.76 & 5.37 \\
\hline & 720 & 66.05 & 26.51 & 16.98 & 24.10 & 15.75 & 26.51 & 5.29 & 3.06 & 5.77 & 5.39 \\
\hline & 840 & 66.07 & 26.53 & 16.99 & 24.13 & 15.76 & 26.53 & 5.30 & 3.08 & 5.78 & 5.40 \\
\hline
\end{tabular}


Table 7. Ground-water levels recorded during an aquifer test conducted at West Greenwich Well 355, central Rhode Island, February 1998—Continued

\begin{tabular}{|c|c|c|c|c|c|c|c|c|c|c|c|}
\hline \multirow{3}{*}{ Date } & \multirow{3}{*}{$\begin{array}{l}\text { Time } \\
(\min )\end{array}$} & & \multicolumn{9}{|c|}{ Water level (feet below measuring point) } \\
\hline & & \multirow{2}{*}{$\begin{array}{c}\text { Pumped well } \\
\text { WGW } 355 \\
\text { MP 271.84 }\end{array}$} & \multicolumn{9}{|c|}{ Observation well } \\
\hline & & & $\begin{array}{c}\text { WGW } 307 \\
\text { D } 2 \\
\text { MP } 272.15\end{array}$ & $\begin{array}{c}\text { WGW } 343 \\
\text { D } 102 \\
\text { MP } 272.34\end{array}$ & $\begin{array}{l}\text { WGW } 344 \\
\text { D 200 } \\
\text { MP 281.54 }\end{array}$ & $\begin{array}{c}\text { WGW } 301 \\
\text { D } 300 \\
\text { MP } 273.47\end{array}$ & $\begin{array}{c}\text { WGW } 306 \\
\text { D } 643 \\
\text { MP } 285.38\end{array}$ & $\begin{array}{c}\text { WGW } 338 \\
\text { D } 977 \\
\text { MP } 263.82\end{array}$ & $\begin{array}{c}\text { WGW } 337 \\
\text { D } 1,133 \\
\text { MP } 261.61\end{array}$ & $\begin{array}{c}\text { WGW } 312 \\
\text { D } 1,306 \\
\text { MP } 264.54\end{array}$ & $\begin{array}{c}\text { WGW } 341 \\
\text { D } 1,457 \\
\text { MP } 263.90\end{array}$ \\
\hline \multicolumn{12}{|c|}{ Pumping-Continued } \\
\hline \multirow[t]{12}{*}{$2-3-98$} & 960 & 66.08 & 26.55 & 17.02 & 24.16 & 15.77 & 26.55 & 5.31 & 3.10 & 5.80 & 5.42 \\
\hline & 1,080 & 66.13 & 26.57 & 17.04 & 24.18 & 15.79 & 26.57 & 5.32 & 3.10 & 5.80 & 5.43 \\
\hline & 1,200 & 66.16 & 26.58 & 17.06 & 24.20 & 15.81 & 26.58 & 5.34 & 3.12 & 5.81 & 5.43 \\
\hline & 1,320 & 66.2 & 26.6 & 17.07 & 24.22 & 15.83 & 26.60 & 5.35 & 3.13 & 5.83 & 5.44 \\
\hline & 1,440 & 66.27 & 26.61 & 17.10 & 24.24 & 15.87 & 26.61 & 5.37 & 3.15 & 5.85 & 5.46 \\
\hline & 1,560 & 66.37 & 26.61 & 17.11 & 24.26 & 15.88 & 26.61 & 5.38 & 3.15 & 5.85 & 5.46 \\
\hline & 1,680 & 66.43 & 26.63 & 17.13 & 24.28 & 15.90 & 26.63 & 5.39 & 3.17 & 5.86 & 5.48 \\
\hline & 1,800 & 66.39 & 26.64 & 17.14 & 24.29 & 15.91 & 26.64 & 5.40 & 3.17 & 5.87 & 5.48 \\
\hline & 1,920 & 66.37 & 26.64 & 17.15 & 24.30 & 15.92 & 26.64 & 5.41 & 3.17 & 5.88 & 5.49 \\
\hline & 2,040 & 66.42 & 26.65 & 17.16 & 24.31 & 15.92 & 26.65 & 5.42 & 3.19 & 5.88 & 5.49 \\
\hline & 2,160 & 66.42 & 26.66 & 17.17 & 24.33 & 15.94 & 26.66 & 5.43 & 3.19 & 5.89 & 5.50 \\
\hline & 2,280 & 66.41 & 26.67 & 17.17 & 24.33 & 15.95 & 26.67 & 5.43 & 3.20 & 5.89 & 5.50 \\
\hline \multirow[t]{5}{*}{$2-4-98$} & 2,400 & 66.41 & 26.69 & 17.19 & 24.34 & 15.95 & 26.69 & 5.45 & 3.21 & 5.90 & 5.51 \\
\hline & 2,520 & 66.44 & 26.69 & 17.20 & 24.36 & 15.97 & 26.69 & 5.46 & 3.23 & 5.92 & 5.53 \\
\hline & 2,640 & 66.47 & 26.7 & 17.21 & 24.38 & 15.97 & 26.70 & 5.48 & 3.23 & 5.92 & 5.53 \\
\hline & 2,760 & 66.47 & 26.74 & 17.23 & -- & 15.98 & 26.74 & 5.47 & 3.23 & 5.94 & 5.55 \\
\hline & 2,880 & 66.54 & -- & -- & -- & -- & -- & -- & -- & -- & -- \\
\hline
\end{tabular}


Table 8. Ground-water levels recorded during an aquifer test conducted at West Greenwich Well 356, central Rhode Island, July 1998

[Site locations are shown on plate 1. WGW 356 (West Greenwich well) was pumped at 550 gallons per minute for 48 hours. D, radial distance from pumped well in feet; MP, altitude of measuring point datum at local well in feet above sea level; min, minutes; --, no data available]

\begin{tabular}{|c|c|c|c|c|c|c|c|c|c|}
\hline \multirow{3}{*}{ Date } & \multirow{3}{*}{$\begin{array}{l}\text { Time } \\
\text { (min) }\end{array}$} & \multicolumn{8}{|c|}{ Water level (feet below measuring point) } \\
\hline & & \multirow{2}{*}{$\begin{array}{c}\begin{array}{c}\text { Pumped } \\
\text { well }\end{array} \\
\text { WGW } 356 \\
\text { MP 262.33 }\end{array}$} & \multicolumn{7}{|c|}{ Observation well } \\
\hline & & & $\begin{array}{c}\text { WGW } 313 \\
\text { D } 2 \\
\text { MP } 263.35\end{array}$ & $\begin{array}{c}\text { WGW } 351 \\
\text { D } 75 \\
\text { MP } 263.79\end{array}$ & $\begin{array}{c}\text { WGW } 346 \\
\text { D } 149 \\
\text { MP } 266.73\end{array}$ & $\begin{array}{c}\text { WGW } 347 \\
\text { D } 241 \\
\text { MP } 271.30\end{array}$ & $\begin{array}{c}\text { WGW } 348 \\
\text { D } 225 \\
\text { MP } 274.14\end{array}$ & $\begin{array}{c}\text { WGW } 349 \\
\text { D } 385 \\
\text { MP } 287.28\end{array}$ & $\begin{array}{c}\text { WGW } 350 \\
\text { D } 575 \\
\text { MP } 290.25\end{array}$ \\
\hline \multicolumn{10}{|c|}{ Prior to pumping } \\
\hline $7-25-98$ & & -- & 8.40 & 8.30 & 11.80 & 16.35 & 17.37 & 13.15 & -- \\
\hline $7-27-98$ & & 7.41 & 8.43 & 8.35 & 11.85 & 16.41 & 17.45 & 13.21 & 33.61 \\
\hline \multicolumn{10}{|c|}{ Pumping begins } \\
\hline \multirow[t]{30}{*}{$7-27-98$} & 0 & 7.41 & 8.43 & 8.35 & 11.84 & 16.41 & 17.45 & 13.21 & 33.61 \\
\hline & .25 & -- & & 8.85 & 11.90 & 16.41 & 17.47 & 13.22 & 33.61 \\
\hline & .5 & -- & 13.54 & 9.37 & 12.00 & 16.41 & 17.53 & 13.23 & 33.61 \\
\hline & .75 & -- & & 9.37 & 12.20 & 16.42 & 17.57 & 13.23 & 33.61 \\
\hline & 1 & -- & 14.48 & 10.06 & 12.37 & 16.42 & 17.62 & 13.24 & 33.61 \\
\hline & 1.5 & -- & 14.94 & 10.48 & 12.72 & 16.46 & 17.78 & 13.26 & 33.61 \\
\hline & 2 & -- & 15.17 & 10.75 & 13.02 & 16.51 & 17.90 & 13.30 & 33.62 \\
\hline & 3 & 59.55 & 15.82 & 11.15 & 13.43 & 16.67 & 18.10 & 13.38 & 33.62 \\
\hline & 4 & -- & 15.92 & 11.42 & 13.78 & 16.87 & 18.26 & 13.47 & 33.62 \\
\hline & 5 & -- & 16.09 & 11.63 & 14.02 & 17.08 & 18.37 & 13.54 & 33.63 \\
\hline & 6 & -- & 16.28 & 11.78 & 14.22 & 17.28 & 18.47 & 13.60 & 33.63 \\
\hline & 7 & -- & 16.38 & 11.89 & 14.37 & 17.47 & 18.54 & 13.66 & 33.64 \\
\hline & 8 & -- & 16.48 & 12.00 & 14.51 & 17.68 & 18.61 & 13.71 & 33.64 \\
\hline & 9 & -- & 16.55 & 12.08 & 14.63 & 17.78 & 18.66 & 13.75 & 33.65 \\
\hline & 10 & -- & 16.61 & 12.16 & 14.72 & 17.93 & 18.70 & 13.79 & 33.65 \\
\hline & 10.75 & 60.05 & -- & -- & -- & -- & -- & -- & -- \\
\hline & 12 & -- & 16.73 & 12.28 & 14.89 & 18.15 & 18.78 & 13.86 & 33.65 \\
\hline & 13.33 & 60.16 & -- & -- & -- & -- & -- & -- & -- \\
\hline & 14 & -- & 16.82 & 12.38 & 15.04 & 18.33 & 18.83 & 13.91 & 33.65 \\
\hline & 15 & 60.14 & -- & -- & -- & -- & -- & -- & -- \\
\hline & 16 & -- & 16.87 & 12.46 & 15.13 & 18.48 & 18.88 & 13.93 & 33.66 \\
\hline & 18 & -- & 16.93 & 12.53 & 15.22 & 18.60 & 18.92 & 13.96 & 33.67 \\
\hline & 21 & 60.30 & 16.99 & 12.59 & 15.30 & 18.71 & 18.96 & 13.99 & 33.67 \\
\hline & 23 & -- & 17.08 & 12.66 & 15.40 & 18.84 & 19.00 & 14.07 & 33.67 \\
\hline & 27 & 60.38 & 17.1 & 12.72 & 15.48 & 18.95 & 19.04 & 14.11 & 33.67 \\
\hline & 30 & -- & 17.18 & 12.79 & 15.57 & 19.06 & 19.09 & 14.16 & 33.68 \\
\hline & 32 & 60.44 & -- & -- & -- & -- & -- & -- & -- \\
\hline & 35 & 60.49 & 17.21 & 12.86 & 15.67 & 19.19 & 19.13 & 14.20 & 33.69 \\
\hline & 41 & 60.52 & 17.28 & 12.92 & 15.74 & 19.28 & 19.16 & 14.24 & 33.69 \\
\hline & 45 & -- & 17.33 & 12.97 & 15.80 & 19.37 & 19.20 & 14.27 & 33.70 \\
\hline
\end{tabular}


Table 8. Ground-water levels recorded during an aquifer test conducted at West Greenwich Well 356, central Rhode Island, July 1998-Continued

\begin{tabular}{|c|c|c|c|c|c|c|c|c|c|}
\hline \multirow{3}{*}{ Date } & \multirow{3}{*}{$\begin{array}{l}\text { Time } \\
\text { (min) }\end{array}$} & \multicolumn{8}{|c|}{ Water level (feet below measuring point) } \\
\hline & & \multirow{2}{*}{$\begin{array}{c}\begin{array}{c}\text { Pumped } \\
\text { well }\end{array} \\
\text { WGW } 356 \\
\text { MP } 262.33\end{array}$} & \multicolumn{7}{|c|}{ Observation well } \\
\hline & & & $\begin{array}{c}\text { WGW } 313 \\
\text { D } 2 \\
\text { MP } 263.35\end{array}$ & $\begin{array}{c}\text { WGW } 351 \\
\text { D } 75 \\
\text { MP } 263.79\end{array}$ & $\begin{array}{c}\text { WGW } 346 \\
\text { D } 149 \\
\text { MP } 266.73\end{array}$ & $\begin{array}{c}\text { WGW } 347 \\
\text { D } 241 \\
\text { MP } 271.30\end{array}$ & $\begin{array}{c}\text { WGW } 348 \\
\text { D } 225 \\
\text { MP } 274.14\end{array}$ & $\begin{array}{c}\text { WGW } 349 \\
\text { D } 385 \\
\text { MP } 287.28\end{array}$ & $\begin{array}{c}\text { WGW } 350 \\
\text { D } 575 \\
\text { MP } 290.25\end{array}$ \\
\hline \multicolumn{10}{|c|}{ Pumping-Continued } \\
\hline \multirow[t]{22}{*}{$7-27-98$} & 47.5 & 60.57 & -- & -- & -- & -- & -- & -- & -- \\
\hline & 50 & 60.61 & 17.37 & 13.01 & 15.86 & 19.44 & 19.22 & 14.30 & 33.70 \\
\hline & 60 & 60.62 & 17.42 & 13.09 & 15.95 & 19.55 & 19.27 & 14.35 & 33.70 \\
\hline & 70 & 60.82 & 17.51 & 13.16 & 16.03 & 19.64 & 19.31 & 14.39 & 33.71 \\
\hline & 80 & 60.88 & 17.55 & 13.20 & 16.11 & 19.74 & 19.35 & 14.43 & 33.72 \\
\hline & 90 & 60.72 & 17.57 & 13.24 & 16.15 & 19.80 & 19.37 & 14.46 & 33.73 \\
\hline & 100 & 60.79 & 17.61 & 13.29 & 16.19 & 19.84 & 19.41 & 14.48 & 33.73 \\
\hline & 120 & 60.81 & 17.65 & 13.35 & 16.27 & 19.93 & 19.46 & 14.53 & 33.75 \\
\hline & 150 & 60.94 & 17.75 & 13.43 & 16.38 & 20.04 & 19.54 & 14.60 & 33.78 \\
\hline & 180 & 61.00 & 17.84 & 13.51 & 16.45 & 20.12 & 19.60 & 14.64 & 33.81 \\
\hline & 210 & 61.12 & 17.9 & 13.58 & 16.51 & 20.19 & 19.66 & 14.69 & 33.83 \\
\hline & 240 & 61.16 & 17.96 & 13.63 & 16.56 & 20.25 & 19.71 & 14.73 & 33.85 \\
\hline & 300 & 61.22 & 18.04 & 13.72 & 16.67 & 20.35 & 19.78 & 14.82 & 33.89 \\
\hline & 360 & 61.67 & 18.13 & 13.80 & 16.75 & 20.43 & 19.86 & 14.88 & 33.93 \\
\hline & 420 & 61.69 & 18.2 & 13.87 & 16.81 & 20.50 & 19.93 & 14.94 & 33.98 \\
\hline & 480 & 61.95 & 18.31 & 13.95 & 16.89 & 20.57 & 20.00 & 15.00 & 34.01 \\
\hline & 540 & 62.09 & 18.36 & 13.99 & 16.94 & 20.62 & 20.04 & 15.06 & 34.05 \\
\hline & 600 & 62.10 & 18.4 & 14.04 & 17.00 & 20.66 & 20.10 & 15.09 & 34.10 \\
\hline & 660 & 62.19 & 18.47 & 14.10 & 17.05 & 20.73 & 20.17 & 15.14 & 34.14 \\
\hline & 720 & 62.23 & 18.52 & 14.15 & 17.11 & 20.79 & 20.22 & 15.19 & 34.19 \\
\hline & 780 & 62.26 & 18.57 & 14.20 & 17.20 & 20.82 & 20.26 & 15.22 & 34.22 \\
\hline & 840 & 62.28 & 18.61 & 14.26 & 17.22 & 20.87 & 20.36 & 15.27 & 34.26 \\
\hline \multirow[t]{18}{*}{$7-28-98$} & 900 & 62.34 & 18.64 & 14.29 & 17.23 & 20.90 & 20.37 & 15.32 & 34.29 \\
\hline & 960 & 62.36 & 18.67 & 14.32 & 17.26 & 20.93 & 20.41 & 15.35 & 34.34 \\
\hline & 1,020 & 62.39 & 18.7 & 14.35 & 17.30 & 20.97 & 20.45 & 15.39 & 34.38 \\
\hline & 1,080 & 62.42 & 18.74 & 14.40 & 17.34 & 21.01 & 20.49 & 15.41 & 34.41 \\
\hline & 1,140 & 62.44 & 18.79 & 14.43 & 17.37 & 21.03 & 20.54 & 15.47 & 34.45 \\
\hline & 1,200 & 62.48 & 18.82 & 14.47 & 17.41 & 21.08 & 20.58 & 15.49 & 34.49 \\
\hline & 1,260 & 62.53 & 18.85 & 14.49 & 17.43 & 21.10 & -- & 15.53 & 34.52 \\
\hline & 1,320 & 62.54 & 18.88 & 14.52 & 17.46 & 21.13 & 20.64 & 15.54 & 34.55 \\
\hline & 1,380 & 62.57 & 18.93 & 14.56 & 17.50 & 21.17 & 20.69 & 15.60 & 34.59 \\
\hline & 1,440 & 62.59 & 19.06 & 14.59 & 17.53 & 21.19 & 20.71 & 15.63 & 34.62 \\
\hline & 1,500 & 62.54 & 19.01 & 14.62 & 17.56 & 21.22 & 20.75 & 15.66 & 34.66 \\
\hline & 1,560 & 62.61 & 19.02 & 14.65 & 17.58 & 21.25 & 20.78 & 15.69 & 34.69 \\
\hline & 1,620 & 62.68 & 19.06 & 14.68 & 17.62 & 21.28 & 20.82 & 15.72 & 34.72 \\
\hline & 1,680 & 62.72 & 19.08 & 14.71 & 17.65 & 21.31 & 20.85 & 15.75 & 34.75 \\
\hline & 1,740 & 62.75 & 19.12 & 14.73 & 17.67 & 21.33 & 20.88 & 15.78 & 34.78 \\
\hline & 1,800 & 62.78 & 19.16 & 14.75 & 17.70 & 21.35 & 20.91 & 15.80 & 34.82 \\
\hline & 1,860 & 62.81 & 19.18 & 14.78 & 17.73 & 21.38 & 20.94 & 15.83 & 34.84 \\
\hline & 1,920 & 62.82 & 19.2 & 14.81 & 17.75 & 21.41 & 20.97 & 15.86 & 34.87 \\
\hline
\end{tabular}


Table 8. Ground-water levels recorded during an aquifer test conducted at West Greenwich Well 356, central Rhode Island, July 1998-Continued

\begin{tabular}{|c|c|c|c|c|c|c|c|c|c|}
\hline \multirow{3}{*}{ Date } & \multirow{3}{*}{$\begin{array}{l}\text { Time } \\
(\min )\end{array}$} & \multicolumn{8}{|c|}{ Water level (feet below measuring point) } \\
\hline & & \multirow{2}{*}{$\begin{array}{c}\begin{array}{c}\text { Pumped } \\
\text { well }\end{array} \\
\text { WGW } 356 \\
\text { MP } 262.33\end{array}$} & \multicolumn{7}{|c|}{ Observation well } \\
\hline & & & $\begin{array}{c}\text { WGW } 313 \\
\text { D } 2 \\
\text { MP } 263.35\end{array}$ & $\begin{array}{c}\text { WGW } 351 \\
\text { D } 75 \\
\text { MP } 263.79\end{array}$ & $\begin{array}{c}\text { WGW } 346 \\
\text { D } 149 \\
\text { MP } 266.73\end{array}$ & $\begin{array}{c}\text { WGW } 347 \\
\text { D } 241 \\
\text { MP } 271.30\end{array}$ & $\begin{array}{c}\text { WGW } 348 \\
\text { D } 225 \\
\text { MP } 274.14\end{array}$ & $\begin{array}{c}\text { WGW } 349 \\
\text { D } 385 \\
\text { MP 287.28 }\end{array}$ & $\begin{array}{l}\text { WGW } 350 \\
\text { D } 575 \\
\text { MP } 290.25\end{array}$ \\
\hline \multicolumn{10}{|c|}{ Pumping-Continued } \\
\hline \multirow[t]{6}{*}{$7-28-98$} & 1,980 & 62.84 & 19.22 & 14.82 & 17.77 & 21.43 & 20.99 & 15.88 & 34.90 \\
\hline & 2,040 & 62.87 & 19.24 & 14.84 & 17.79 & 21.45 & 21.01 & 15.90 & 34.93 \\
\hline & 2,100 & 62.90 & 19.26 & 14.86 & 17.81 & 21.47 & 21.04 & 15.93 & 34.96 \\
\hline & 2,160 & 62.89 & 19.29 & 14.89 & 17.84 & 21.49 & 21.08 & 15.95 & 34.99 \\
\hline & 2,220 & 62.91 & 19.31 & 14.92 & 17.86 & 21.51 & 21.10 & 15.98 & 35.01 \\
\hline & 2,280 & 62.91 & 19.31 & 14.94 & 17.88 & 21.54 & 21.13 & 16.03 & 35.04 \\
\hline \multirow[t]{11}{*}{$7-29-98$} & 2,340 & 62.93 & 19.32 & 14.95 & 17.90 & 21.55 & 21.14 & 16.02 & 35.07 \\
\hline & 2,400 & 62.97 & 19.34 & 14.97 & 17.92 & 21.57 & 21.16 & 16.03 & 35.09 \\
\hline & 2,460 & 62.98 & 19.37 & 14.99 & 17.93 & 21.59 & 21.19 & 16.07 & 35.13 \\
\hline & 2,520 & 62.99 & 19.38 & 15.01 & 17.96 & 21.61 & 21.21 & 16.08 & 35.14 \\
\hline & 2,580 & 63.02 & 19.4 & 15.05 & 17.99 & 21.65 & 21.26 & 16.13 & -- \\
\hline & 2,640 & 63.05 & 19.42 & 15.07 & 18.01 & 21.67 & 21.27 & 16.15 & 35.19 \\
\hline & 2,700 & 63.04 & 19.44 & 15.08 & 18.03 & 21.68 & 21.30 & 16.17 & 35.22 \\
\hline & 2,760 & 63.04 & 19.48 & 15.10 & 18.05 & 21.70 & 21.32 & 16.19 & 35.24 \\
\hline & 2,820 & 63.05 & 19.5 & 15.13 & 18.07 & 21.72 & 21.35 & 16.20 & 35.26 \\
\hline & 2,880 & 63.07 & 19.51 & 15.13 & 18.07 & 21.74 & 21.36 & 16.22 & 35.29 \\
\hline & 2,900 & -- & -- & -- & -- & -- & -- & 16.22 & 35.30 \\
\hline
\end{tabular}


Table 9. Ground-water levels recorded during an aquifer test conducted at West Greenwich Well 374, central Rhode Island, May 1999

[Site locations are shown on plate 1. WGW 374 (West Greenwich well) was pumped at 740 gallons per minute for 48 hours. D, radial distance from pumped well in feet; MP, altitude of measuring point datum at local well in feet above sea level; min, minutes; --, no data available]

\begin{tabular}{|c|c|c|c|c|c|c|c|c|c|c|c|c|}
\hline \multirow{3}{*}{ Date } & \multirow{3}{*}{$\begin{array}{l}\text { Time } \\
(\min )\end{array}$} & \multicolumn{11}{|c|}{ Water level (feet below measuring point) } \\
\hline & & \multirow{2}{*}{$\begin{array}{c}\begin{array}{c}\text { Pumped } \\
\text { well }\end{array} \\
\text { WGW } 374 \\
\text { MP 286.78 }\end{array}$} & \multicolumn{10}{|c|}{ Observation well } \\
\hline & & & $\begin{array}{l}\text { WGW } 306 \\
\text { D 3.8 } \\
\text { MP 285.38 }\end{array}$ & $\begin{array}{l}\text { WGW } 375 \\
\text { D } 92 \\
\text { MP 288.21 }\end{array}$ & $\begin{array}{c}\text { WGW } 376 \\
\text { D } 150 \\
\text { MP } 288.67\end{array}$ & $\begin{array}{c}\text { WGW } 377 \\
\text { D } 300 \\
\text { MP } 290.85\end{array}$ & $\begin{array}{c}\text { WGW } 307 \\
\text { D } 643 \\
\text { MP } 272.15\end{array}$ & $\begin{array}{c}\text { WGW } 338 \\
\text { D } 750 \\
\text { MP } 263.82\end{array}$ & $\begin{array}{c}\text { WGW } 301 \\
\text { D } 950 \\
\text { MP } 273.53\end{array}$ & $\begin{array}{c}\text { WGW } 312 \\
\text { D } 1,050 \\
\text { MP } 264.54\end{array}$ & $\begin{array}{c}\text { WGW } 341 \\
\text { D } 1,200 \\
\text { MP } 263.90\end{array}$ & $\begin{array}{c}\text { WGW } 308 \\
\text { D } 1,800 \\
\text { MP } 291.32\end{array}$ \\
\hline \multicolumn{13}{|c|}{ Prior to pumping } \\
\hline $5-03-99$ & -- & -- & 25.41 & 28.19 & 28.57 & 30.44 & 11.49 & 5.00 & 13.42 & -- & 5.46 & 26.99 \\
\hline $5-05-99$ & -- & -- & 25.36 & 28.14 & 28.52 & 30.42 & 11.46 & 4.93 & 13.4 & 5.64 & 5.37 & 27.00 \\
\hline $5-07-99$ & -- & -- & 25.36 & 28.15 & 28.52 & 30.41 & 11.43 & 4.95 & 13.35 & 5.67 & 5.39 & 27.03 \\
\hline $5-10-99$ & -- & 26.80 & 25.40 & 28.18 & 28.57 & 30.47 & 11.47 & 4.97 & 13.39 & 5.71 & 5.42 & 27.06 \\
\hline \multicolumn{13}{|c|}{ Pumping begins } \\
\hline \multirow[t]{15}{*}{$5-10-99$} & 0 & 26.80 & 34.30 & 28.18 & 28.57 & 30.47 & 11.47 & 4.99 & 13.39 & 5.71 & 5.43 & 27.06 \\
\hline & .25 & -- & & -- & -- & 30.49 & -- & 4.99 & -- & 5.78 & -- & -- \\
\hline & .5 & -- & 35.70 & 31.10 & 32.78 & 30.68 & -- & 5.00 & -- & 5.92 & -- & -- \\
\hline & .75 & -- & 36.40 & -- & -- & 30.76 & -- & 5.02 & -- & -- & -- & -- \\
\hline & 1.0 & -- & 36.85 & 33.43 & 33.84 & 30.95 & -- & 5.05 & -- & -- & -- & -- \\
\hline & 1.5 & -- & 37.30 & -- & 34.30 & 31.32 & -- & 5.07 & -- & -- & -- & -- \\
\hline & 2 & -- & 37.70 & 35.70 & 34.79 & 31.96 & -- & 5.15 & -- & -- & -- & -- \\
\hline & 3 & -- & 37.90 & 35.98 & -- & 32.43 & 11.78 & -- & -- & -- & -- & -- \\
\hline & 3.5 & -- & -- & 36.61 & -- & -- & -- & -- & -- & -- & -- & -- \\
\hline & 4 & -- & 38.60 & 36.92 & 35.93 & 32.85 & 11.87 & -- & -- & -- & -- & -- \\
\hline & 4.5 & -- & -- & -- & -- & -- & 11.93 & -- & -- & -- & -- & -- \\
\hline & 5 & -- & 39.00 & 37.44 & -- & 33.05 & 11.98 & -- & -- & -- & -- & -- \\
\hline & 6 & -- & 39.40 & 37.82 & 36.5 & 33.53 & 12.08 & 5.56 & -- & -- & -- & -- \\
\hline & 7 & -- & 39.70 & 38.14 & -- & 33.87 & 12.17 & 5.67 & -- & -- & -- & -- \\
\hline & 8 & -- & 39.95 & 38.40 & 36.9 & 33.99 & 12.24 & -- & -- & -- & -- & -- \\
\hline
\end{tabular}


Table 9. Ground-water levels recorded during an aquifer test conducted at West Greenwich Well 374, central Rhode Island, May 1999—Continued

\begin{tabular}{|c|c|c|c|c|c|c|c|c|c|c|c|c|}
\hline \multirow{3}{*}{ Date } & \multirow{3}{*}{$\begin{array}{l}\text { Time } \\
\text { (min) }\end{array}$} & \multicolumn{11}{|c|}{ Water level (feet below measuring point) } \\
\hline & & \multirow{2}{*}{$\begin{array}{c}\begin{array}{c}\text { Pumped } \\
\text { well }\end{array} \\
\text { WGW } 374 \\
\text { MP } 286.78\end{array}$} & \multicolumn{10}{|c|}{ Observation well } \\
\hline & & & $\begin{array}{c}\text { WGW } 306 \\
\text { D } 3.8 \\
\text { MP } 285.38\end{array}$ & $\begin{array}{c}\text { WGW } 375 \\
\text { D } 92 \\
\text { MP } 288.21\end{array}$ & $\begin{array}{c}\text { WGW } 376 \\
\text { D } 150 \\
\text { MP } 288.67\end{array}$ & $\begin{array}{c}\text { WGW } 377 \\
\text { D } 300 \\
\text { MP } 290.85\end{array}$ & $\begin{array}{c}\text { WGW } 307 \\
\text { D } 643 \\
\text { MP } 272.15\end{array}$ & $\begin{array}{c}\text { WGW } 338 \\
\text { D } 750 \\
\text { MP } 263.82\end{array}$ & $\begin{array}{c}\text { WGW } 301 \\
\text { D } 950 \\
\text { MP } 273.53\end{array}$ & $\begin{array}{c}\text { WGW } 312 \\
\text { D } 1,050 \\
\text { MP } 264.54\end{array}$ & $\begin{array}{c}\text { WGW } 341 \\
\text { D } 1,200 \\
\text { MP } 263.90\end{array}$ & $\begin{array}{c}\text { WGW } 308 \\
\text { D } 1,800 \\
\text { MP } 291.32\end{array}$ \\
\hline \multicolumn{13}{|c|}{ Pumping-Continued } \\
\hline \multirow[t]{25}{*}{$5-10-99$} & 9 & -- & 40.15 & 38.61 & -- & 34.11 & 12.30 & -- & -- & -- & -- & -- \\
\hline & 10 & 84.90 & 40.35 & 38.79 & 37.2 & 34.25 & 12.37 & 5.89 & -- & -- & -- & -- \\
\hline & 11 & -- & -- & -- & -- & -- & 12.42 & -- & -- & -- & -- & -- \\
\hline & 12 & 85.10 & 40.60 & 39.09 & 37.5 & 34.47 & 12.47 & 6.00 & -- & -- & -- & -- \\
\hline & 13 & -- & -- & -- & -- & -- & 12.52 & -- & -- & -- & -- & -- \\
\hline & 14 & 85.30 & 40.75 & 39.28 & 37.6 & 34.64 & -- & -- & -- & 6.09 & -- & -- \\
\hline & 15 & -- & -- & -- & -- & -- & -- & 6.10 & 14.00 & -- & -- & -- \\
\hline & 16 & 85.50 & 40.85 & 39.45 & 37.8 & 34.78 & -- & -- & -- & -- & -- & -- \\
\hline & 17 & -- & -- & -- & -- & -- & 12.64 & -- & -- & 6.15 & -- & -- \\
\hline & 18 & 85.65 & 41.00 & 39.57 & 37.84 & 34.98 & 12.67 & -- & -- & -- & -- & -- \\
\hline & 19 & -- & -- & -- & -- & -- & 12.69 & -- & -- & -- & 5.75 & -- \\
\hline & 20 & 85.75 & 41.10 & 39.67 & 37.95 & 34.97 & 12.71 & -- & -- & -- & -- & -- \\
\hline & 21 & -- & -- & -- & -- & -- & -- & 6.25 & -- & -- & -- & -- \\
\hline & 23 & 85.80 & 41.15 & 39.79 & 38.05 & 35.07 & -- & -- & 13.87 & 6.23 & -- & -- \\
\hline & 24 & -- & -- & -- & -- & -- & -- & 6.32 & -- & -- & -- & -- \\
\hline & 25 & -- & -- & -- & -- & -- & 12.80 & -- & -- & -- & -- & -- \\
\hline & 26 & 85.90 & 41.30 & 39.89 & 38.15 & 35.15 & -- & -- & 13.94 & 6.29 & -- & -- \\
\hline & 27 & -- & -- & -- & -- & -- & 12.83 & -- & -- & -- & -- & -- \\
\hline & 28 & -- & -- & -- & -- & -- & -- & 6.37 & -- & -- & -- & -- \\
\hline & 29 & -- & -- & -- & -- & -- & 12.85 & -- & -- & -- & -- & -- \\
\hline & 30 & & 41.40 & 39.98 & 38.24 & 35.24 & -- & -- & -- & 6.32 & 5.89 & -- \\
\hline & 32.5 & -- & -- & -- & -- & -- & -- & -- & -- & -- & -- & 27.18 \\
\hline & 35 & -- & 41.50 & 40.07 & 38.3 & 35.31 & 12.90 & 6.43 & -- & -- & -- & -- \\
\hline & 36 & -- & -- & -- & -- & -- & 12.91 & -- & -- & 6.37 & -- & -- \\
\hline & 40 & -- & 41.55 & 40.14 & 38.34 & 35.37 & 12.94 & 6.48 & -- & 6.40 & -- & -- \\
\hline
\end{tabular}


Table 9. Ground-water levels recorded during an aquifer test conducted at West Greenwich Well 374, central Rhode Island, May 1999—Continued

\begin{tabular}{|c|c|c|c|c|c|c|c|c|c|c|c|c|}
\hline \multirow{3}{*}{ Date } & \multirow{3}{*}{$\begin{array}{l}\text { Time } \\
\text { (min) }\end{array}$} & \multicolumn{11}{|c|}{ Water level (feet below measuring point) } \\
\hline & & \multirow{2}{*}{$\begin{array}{c}\begin{array}{c}\text { Pumped } \\
\text { well }\end{array} \\
\text { WGW } 374 \\
\text { MP 286.78 }\end{array}$} & \multicolumn{10}{|c|}{ Observation well } \\
\hline & & & $\begin{array}{c}\text { WGW } 306 \\
\text { D } 3.8 \\
\text { MP } 285.38\end{array}$ & $\begin{array}{c}\text { WGW } 375 \\
\text { D } 92 \\
\text { MP } 288.21\end{array}$ & $\begin{array}{c}\text { WGW } 376 \\
\text { D } 150 \\
\text { MP } 288.67\end{array}$ & $\begin{array}{c}\text { WGW } 377 \\
\text { D } 300 \\
\text { MP } 290.85\end{array}$ & $\begin{array}{c}\text { WGW } 307 \\
\text { D } 643 \\
\text { MP } 272.15\end{array}$ & $\begin{array}{c}\text { WGW } 338 \\
\text { D } 750 \\
\text { MP } 263.82\end{array}$ & $\begin{array}{c}\text { WGW } 301 \\
\text { D } 950 \\
\text { MP } 273.53\end{array}$ & $\begin{array}{c}\text { WGW } 312 \\
\text { D } 1,050 \\
\text { MP } 264.54\end{array}$ & $\begin{array}{c}\text { WGW } 341 \\
\text { D } 1,200 \\
\text { MP } 263.90\end{array}$ & $\begin{array}{c}\text { WGW } 308 \\
\text { D } 1,800 \\
\text { MP } 291.32\end{array}$ \\
\hline \multicolumn{13}{|c|}{ Pumping-Continued } \\
\hline \multirow[t]{22}{*}{$5-10-99$} & 45 & 86.15 & 41.60 & 40.19 & 38.38 & 35.41 & 12.96 & 6.50 & 14.00 & 6.43 & 5.98 & -- \\
\hline & 50 & 86.30 & 41.60 & 40.22 & 38.42 & 35.45 & 12.99 & 6.54 & 14.03 & 6.45 & 6.01 & -- \\
\hline & 60 & 86.40 & 41.65 & 40.29 & 38.49 & 35.52 & 13.03 & 6.59 & 14.08 & 6.49 & 6.05 & 27.27 \\
\hline & 70 & 86.50 & 41.70 & 40.31 & 38.51 & 35.54 & 13.05 & 6.61 & 14.10 & 6.52 & 6.07 & -- \\
\hline & 80 & 86.55 & 41.70 & 40.33 & 38.5 & 35.56 & 13.07 & 6.64 & 14.11 & 6.54 & 6.08 & \\
\hline & 90 & 86.60 & 41.75 & 40.35 & 38.55 & & 13.08 & 6.65 & -- & 6.55 & -- & 27.34 \\
\hline & 95 & -- & -- & -- & -- & 35.54 & -- & -- & 14 & -- & 6.10 & -- \\
\hline & 100 & 86.70 & 41.75 & 40.37 & 38.53 & -- & 13.10 & 6.66 & 14.12 & 6.57 & 6.11 & 27.38 \\
\hline & 120 & 86.70 & 41.75 & 40.37 & 38.52 & 35.57 & 13.11 & 6.68 & 14.13 & 6.58 & 6.13 & -- \\
\hline & 150 & 86.80 & 41.75 & 40.4 & 38.58 & 35.61 & 13.15 & -- & -- & -- & -- & -- \\
\hline & 160 & -- & -- & -- & -- & -- & -- & 6.71 & -- & 6.61 & 6.15 & -- \\
\hline & 170 & -- & -- & -- & -- & -- & -- & -- & 14.16 & -- & -- & 27.42 \\
\hline & 180 & 86.95 & 41.75 & 40.4 & 38.55 & 35.62 & 13.16 & 6.73 & 14.21 & 6.62 & 6.16 & -- \\
\hline & 210 & 87.10 & 41.75 & -- & -- & -- & -- & -- & -- & -- & -- & 27.43 \\
\hline & 240 & 87.30 & 41.70 & 40.42 & 38.59 & 35.63 & 13.16 & 6.73 & 14.18 & 6.62 & 6.17 & 27.43 \\
\hline & 300 & 87.50 & 41.75 & 40.41 & 38.63 & 35.66 & 13.18 & 6.75 & 14.21 & 6.64 & 6.21 & 27.45 \\
\hline & 360 & 87.70 & 41.75 & -- & 38.61 & 35.66 & 13.20 & 6.77 & 14.22 & 6.65 & 6.21 & 27.45 \\
\hline & 420 & 87.70 & 41.70 & 40.41 & 38.62 & 35.67 & 13.21 & 6.78 & 14.23 & 6.66 & 6.22 & 27.45 \\
\hline & 480 & 87.90 & 41.75 & 40.45 & 38.63 & 35.69 & 13.23 & 6.80 & 14.25 & 6.69 & -- & 27.45 \\
\hline & 540 & 88.00 & 41.75 & 40.43 & 38.63 & 35.70 & 13.25 & 6.81 & 14.26 & 6.71 & 6.24 & 27.47 \\
\hline & 600 & 88.05 & 41.75 & 40.45 & 38.66 & 35.72 & 13.26 & 6.82 & 14.30 & 6.71 & 6.25 & 27.49 \\
\hline & 660 & 88.20 & 41.75 & -- & -- & -- & -- & -- & -- & -- & -- & -- \\
\hline \multirow[t]{3}{*}{ 5-11-99 } & 720 & 88.25 & 41.75 & 40.44 & 38.65 & 35.74 & 13.29 & 6.84 & 14.29 & 6.73 & 6.27 & 27.50 \\
\hline & 780 & 88.30 & 41.75 & -- & -- & -- & -- & -- & -- & -- & -- & -- \\
\hline & 840 & 88.45 & 41.75 & 40.45 & 38.66 & 35.75 & 13.30 & 6.85 & 14.31 & 6.73 & 6.27 & 27.51 \\
\hline
\end{tabular}


Table 9. Ground-water levels recorded during an aquifer test conducted at West Greenwich Well 374, central Rhode Island, May 1999—Continued

\begin{tabular}{|c|c|c|c|c|c|c|c|c|c|c|c|c|}
\hline \multirow{3}{*}{ Date } & \multirow{3}{*}{$\begin{array}{l}\text { Time } \\
(\min )\end{array}$} & \multicolumn{11}{|c|}{ Water level (feet below measuring point) } \\
\hline & & \multirow{2}{*}{$\begin{array}{c}\begin{array}{c}\text { Pumped } \\
\text { well }\end{array} \\
\text { WGW } 374 \\
\text { MP 286.78 }\end{array}$} & \multicolumn{10}{|c|}{ Observation well } \\
\hline & & & $\begin{array}{c}\text { WGW } 306 \\
\text { D } 3.8 \\
\text { MP } 285.38\end{array}$ & $\begin{array}{l}\text { WGW } 375 \\
\text { D } 92 \\
\text { MP } 288.21\end{array}$ & $\begin{array}{c}\text { WGW } 376 \\
\text { D } 150 \\
\text { MP } 288.67\end{array}$ & $\begin{array}{c}\text { WGW } 377 \\
\text { D } 300 \\
\text { MP } 290.85\end{array}$ & $\begin{array}{c}\text { WGW } 307 \\
\text { D } 643 \\
\text { MP } 272.15\end{array}$ & $\begin{array}{c}\text { WGW } 338 \\
\text { D } 750 \\
\text { MP } 263.82\end{array}$ & $\begin{array}{c}\text { WGW } 301 \\
\text { D } 950 \\
\text { MP } 273.53\end{array}$ & $\begin{array}{c}\text { WGW } 312 \\
\text { D } 1,050 \\
\text { MP } 264.54\end{array}$ & $\begin{array}{c}\text { WGW } 341 \\
\text { D } 1,200 \\
\text { MP } 263.90\end{array}$ & $\begin{array}{c}\text { WGW } 308 \\
\text { D } 1,800 \\
\text { MP } 291.32\end{array}$ \\
\hline \multicolumn{13}{|c|}{ Pumping-Continued } \\
\hline \multirow[t]{10}{*}{$5-11-99$} & 900 & 88.55 & 41.75 & -- & -- & -- & -- & -- & -- & -- & -- & -- \\
\hline & 960 & 88.60 & 41.75 & 40.46 & 38.66 & 35.77 & 13.32 & 6.86 & 14.33 & 6.75 & 6.30 & 27.52 \\
\hline & 1,020 & 88.70 & 41.75 & -- & -- & -- & -- & -- & -- & -- & -- & -- \\
\hline & 1,080 & -- & 41.75 & 40.47 & 38.68 & 35.79 & 13.34 & 6.88 & 14.35 & 6.76 & 6.31 & 27.52 \\
\hline & 1,140 & -- & 41.72 & -- & -- & -- & -- & -- & -- & -- & -- & -- \\
\hline & 1,183 & 88.84 & -- & -- & -- & -- & -- & -- & -- & -- & -- & -- \\
\hline & 1,200 & 88.87 & 41.73 & 40.5 & 38.71 & 35.81 & 13.37 & 6.91 & 14.36 & 6.78 & 6.32 & 27.53 \\
\hline & 1,260 & 88.82 & 41.75 & -- & -- & -- & -- & -- & -- & -- & -- & -- \\
\hline & 1,320 & 89.02 & 41.75 & 40.52 & 38.73 & 35.83 & 13.39 & 6.92 & 14.37 & 6.80 & 6.34 & 27.54 \\
\hline & 1,380 & 89.07 & 41.74 & -- & -- & -- & -- & -- & -- & -- & -- & -- \\
\hline \multirow[t]{15}{*}{$5-12-99$} & 1,440 & 89.07 & 41.74 & 40.51 & 38.74 & 35.83 & 13.40 & 6.94 & 14.43 & 6.80 & 6.34 & 27.53 \\
\hline & 1,500 & 89.07 & 41.74 & -- & -- & -- & -- & -- & -- & -- & -- & -- \\
\hline & 1,560 & 89.10 & 41.70 & 40.5 & 38.72 & 35.84 & 13.41 & 6.93 & 14.40 & 6.81 & 6.35 & 27.53 \\
\hline & 1,680 & 89.12 & 41.70 & 40.81 & 38.72 & 35.86 & 13.42 & 6.94 & 14.41 & 6.83 & 6.35 & 27.53 \\
\hline & 1,740 & 89.17 & 41.70 & -- & -- & -- & -- & -- & -- & -- & -- & -- \\
\hline & 1,800 & 89.12 & 41.70 & 40.47 & 38.73 & 35.85 & 13.42 & 6.95 & 14.41 & 6.82 & 6.35 & -- \\
\hline & 1,860 & 89.22 & 41.70 & -- & -- & -- & -- & -- & -- & -- & -- & -- \\
\hline & 1,920 & 89.37 & 41.70 & 40.52 & 38.75 & 35.87 & 13.44 & 6.96 & 14.44 & 6.83 & 6.37 & 27.54 \\
\hline & 1,980 & 89.37 & 41.70 & -- & -- & -- & -- & -- & -- & -- & -- & -- \\
\hline & 2,040 & 89.22 & 41.74 & 40.5 & 38.76 & 35.98 & 13.45 & 6.98 & 14.44 & 6.85 & 6.39 & 27.53 \\
\hline & 2,100 & 89.37 & 41.74 & -- & -- & -- & -- & -- & -- & -- & -- & -- \\
\hline & 2,160 & 89.37 & 41.74 & 40.54 & 38.76 & 35.90 & 13.46 & & 14.46 & 6.86 & 6.39 & 27.55 \\
\hline & 2,220 & 89.65 & 41.75 & -- & -- & -- & -- & -- & -- & -- & -- & -- \\
\hline & 2,280 & 89.65 & 41.75 & 40.55 & 38.78 & 35.91 & 13.47 & 6.99 & 14.47 & 6.86 & 6.39 & 27.56 \\
\hline & 2,340 & 89.93 & 41.75 & -- & -- & -- & -- & -- & -- & -- & -- & -- \\
\hline
\end{tabular}


Table 9. Ground-water levels recorded during an aquifer test conducted at West Greenwich Well 374, central Rhode Island, May 1999—Continued

\begin{tabular}{|c|c|c|c|c|c|c|c|c|c|c|c|c|}
\hline \multirow{3}{*}{ Date } & \multirow{3}{*}{$\begin{array}{l}\text { Time } \\
(\min )\end{array}$} & \multicolumn{11}{|c|}{ Water level (feet below measuring point) } \\
\hline & & \multirow{2}{*}{$\begin{array}{c}\begin{array}{c}\text { Pumped } \\
\text { well }\end{array} \\
\text { WGW } 374 \\
\text { MP } 286.78\end{array}$} & \multicolumn{10}{|c|}{ Observation well } \\
\hline & & & $\begin{array}{c}\text { WGW } 306 \\
\text { D } 3.8 \\
\text { MP } 285.38\end{array}$ & $\begin{array}{l}\text { WGW } 375 \\
\text { D } 92 \\
\text { MP } 288.21\end{array}$ & $\begin{array}{c}\text { WGW } 376 \\
\text { D } 150 \\
\text { MP } 288.67\end{array}$ & $\begin{array}{c}\text { WGW } 377 \\
\text { D } 300 \\
\text { MP } 290.85\end{array}$ & $\begin{array}{c}\text { WGW } 307 \\
\text { D } 643 \\
\text { MP } 272.15\end{array}$ & $\begin{array}{c}\text { WGW } 338 \\
\text { D } 750 \\
\text { MP } 263.82\end{array}$ & $\begin{array}{c}\text { WGW } 301 \\
\text { D } 950 \\
\text { MP } 273.53\end{array}$ & $\begin{array}{c}\text { WGW } 312 \\
\text { D } 1,050 \\
\text { MP } 264.54\end{array}$ & $\begin{array}{c}\text { WGW } 341 \\
\text { D } 1,200 \\
\text { MP } 263.90\end{array}$ & $\begin{array}{c}\text { WGW } 308 \\
\text { D } 1,800 \\
\text { MP } 291.32\end{array}$ \\
\hline \multicolumn{13}{|c|}{ Pumping-Continued } \\
\hline \multirow[t]{9}{*}{$5-12-99$} & 2,400 & 89.97 & 41.75 & -- & -- & -- & -- & -- & -- & -- & -- & -- \\
\hline & 2,460 & 90.05 & 41.75 & 40.58 & 38.81 & 35.94 & 13.50 & 7.00 & 14.49 & 6.87 & 6.42 & 27.56 \\
\hline & 2,520 & 90.04 & 41.80 & -- & -- & -- & -- & -- & -- & -- & -- & -- \\
\hline & 2,580 & 90.12 & 41.80 & 40.6 & 38.82 & 35.95 & 13.51 & 7.02 & 14.50 & 6.90 & 6.43 & 27.57 \\
\hline & 2,640 & 90.15 & 41.80 & -- & -- & -- & -- & -- & -- & -- & -- & -- \\
\hline & 2,700 & 90.27 & 41.80 & 40.61 & 38.83 & 35.97 & 13.54 & 7.04 & 14.51 & 6.91 & 6.44 & 27.58 \\
\hline & 2,760 & 90.32 & 41.85 & -- & -- & -- & -- & -- & -- & -- & -- & -- \\
\hline & 2,820 & 90.17 & 41.81 & 40.62 & 38.84 & 35.98 & 13.55 & -- & 14.53 & -- & -- & 27.59 \\
\hline & 2,880 & 90.12 & -- & -- & -- & 35.98 & -- & 7.06 & -- & -- & 6.45 & -- \\
\hline
\end{tabular}


Table 10. Ground-water levels recorded during an aquifer test conducted at West Greenwich Well 410, central Rhode Island, October 1999

[Site locations are shown on plate 1. WGW 410 (West Greenwich well) was pumped at 920 gallons per minute for 48 hours. D, radial distance from pumped well in feet; MP, altitude of measuring point datum at local well in feet above sea level; min, minutes; --, no data available]

\begin{tabular}{|c|c|c|c|c|c|c|c|c|c|c|}
\hline \multirow{3}{*}{ Date } & \multirow{3}{*}{$\begin{array}{l}\text { Time } \\
\text { (min) }\end{array}$} & \multicolumn{9}{|c|}{ Water level (feet below measuring point) } \\
\hline & & \multirow{2}{*}{$\begin{array}{c}\text { Pumped well } \\
\text { WGW } 410 \\
\text { MP 279.68 }\end{array}$} & \multicolumn{8}{|c|}{ Observation well } \\
\hline & & & $\begin{array}{c}\text { WGW } 358 \\
\text { D } 3.25 \\
\text { MP } 279.60\end{array}$ & $\begin{array}{c}\text { WGW } 289 \\
\text { D } 80 \\
\text { MP 279.55 }\end{array}$ & $\begin{array}{c}\text { WGW } 418 \\
\text { D } 115 \\
\text { MP } 278.73\end{array}$ & $\begin{array}{c}\text { WGW } 419 \\
\text { D } 172 \\
\text { MP } 279.17\end{array}$ & $\begin{array}{c}\text { WGW 421 } \\
\text { D } 210 \\
\text { MP 274.30 }\end{array}$ & $\begin{array}{c}\text { WGW } 420 \\
\text { D } 357 \\
\text { MP } 272.54\end{array}$ & $\begin{array}{c}\text { WGW } 417 \\
\text { D } 430 \\
\text { MP } 269.80\end{array}$ & $\begin{array}{c}\text { WGW } 360 \\
\text { D } 1,130 \\
\text { MP } 272.00\end{array}$ \\
\hline \multicolumn{11}{|c|}{ Prior to pumping } \\
\hline $10-14-99$ & -- & -- & 17.76 & 17.47 & 16.70 & 17.00 & 12.73 & 11.11 & 8.96 & 11.21 \\
\hline $10-15-99$ & -- & 19.07 & 17.78 & 17.49 & 16.70 & 17.00 & 12.73 & 11.11 & 8.99 & 11.21 \\
\hline $10-16-99$ & -- & -- & 17.88 & 17.59 & 16.79 & 17.10 & 12.81 & 11.20 & 9.04 & 11.23 \\
\hline $10-18-99$ & -- & 19.10 & 17.84 & 17.56 & 16.75 & 17.04 & 12.76 & 11.13 & 9.01 & 11.21 \\
\hline \multicolumn{11}{|c|}{ Pumping begins } \\
\hline \multirow[t]{20}{*}{$10-18-99$} & 0.00 & 19.05 & 17.82 & 17.56 & 16.75 & 17.04 & 12.76 & 12.76 & 9.01 & 11.21 \\
\hline & .25 & -- & 17.90 & -- & 16.75 & 17.04 & 12.76 & 12.76 & 9.01 & -- \\
\hline & .5 & -- & 17.90 & 17.57 & 16.75 & 17.04 & 12.76 & 12.76 & 9.01 & -- \\
\hline & .75 & -- & 22.10 & -- & 16.96 & 17.08 & 12.76 & 12.76 & 9.01 & -- \\
\hline & 1 & -- & 26.40 & 19.43 & 17.05 & 17.22 & 12.81 & 12.81 & 9.01 & -- \\
\hline & 1.5 & -- & 26.80 & 19.99 & 17.50 & 17.39 & 12.90 & 12.90 & 9.02 & -- \\
\hline & 2 & -- & 26.75 & 20.16 & 17.66 & 17.45 & 12.92 & 12.92 & 9.02 & -- \\
\hline & 3 & -- & 26.75 & 20.25 & 17.76 & 17.50 & 12.94 & 12.94 & 9.02 & -- \\
\hline & 4 & -- & 26.75 & 20.28 & 17.78 & 17.53 & 12.95 & 12.95 & 9.03 & -- \\
\hline & 5 & 45.97 & 26.76 & 20.30 & 17.80 & 17.54 & 12.96 & 12.96 & 9.03 & -- \\
\hline & 6 & -- & 26.80 & 20.32 & 17.82 & 17.55 & 12.97 & 12.97 & 9.03 & -- \\
\hline & 7 & -- & 26.81 & 20.34 & 17.84 & 17.56 & 12.97 & 12.97 & 9.03 & -- \\
\hline & 8 & -- & 26.82 & 20.36 & 17.85 & 17.57 & 12.97 & 12.97 & 9.03 & -- \\
\hline & 9 & -- & 26.85 & 20.37 & 17.86 & 17.58 & 12.98 & 12.98 & 9.03 & -- \\
\hline & 10 & 46.10 & 26.85 & 20.38 & 17.87 & 17.58 & 12.99 & 12.99 & 9.03 & -- \\
\hline & 12 & -- & 26.86 & 20.41 & 17.89 & 17.59 & 12.99 & 12.99 & 9.04 & -- \\
\hline & 14 & -- & 26.87 & 20.44 & 17.90 & 17.60 & 13.00 & 13.00 & -- & -- \\
\hline & 16 & 46.10 & 26.89 & 20.46 & 17.92 & 17.62 & 13.00 & 13.00 & -- & -- \\
\hline & 18 & 46.11 & 26.93 & 20.46 & 17.93 & 17.63 & 13.01 & 13.01 & -- & -- \\
\hline & 20 & 46.11 & 26.95 & 20.48 & 17.95 & 17.64 & 13.02 & 13.02 & 9.04 & -- \\
\hline
\end{tabular}


Table 10. Ground-water levels recorded during an aquifer test conducted at West Greenwich Well 410, central Rhode Island, October 1999—Continued

\begin{tabular}{|c|c|c|c|c|c|c|c|c|c|c|}
\hline \multirow{3}{*}{ Date } & \multirow{3}{*}{$\begin{array}{l}\text { Time } \\
(\min )\end{array}$} & \multicolumn{9}{|c|}{ Water level (feet below measuring point) } \\
\hline & & \multirow{2}{*}{$\begin{array}{c}\text { Pumped well } \\
\text { WGW } 410 \\
\text { MP } 279.68\end{array}$} & \multicolumn{8}{|c|}{ Observation well } \\
\hline & & & $\begin{array}{c}\text { WGW } 358 \\
\text { D } 3.25 \\
\text { MP } 279.60\end{array}$ & $\begin{array}{l}\text { WGW } 289 \\
\text { D } 80 \\
\text { MP } 279.55\end{array}$ & $\begin{array}{l}\text { WGW } 418 \\
\text { D } 115 \\
\text { MP } 278.73\end{array}$ & $\begin{array}{c}\text { WGW } 419 \\
\text { D } 172 \\
\text { MP } 279.17\end{array}$ & $\begin{array}{c}\text { WGW } 421 \\
\text { D } 210 \\
\text { MP } 274.30\end{array}$ & $\begin{array}{c}\text { WGW } 420 \\
\text { D } 357 \\
\text { MP } 272.54\end{array}$ & $\begin{array}{c}\text { WGW } 417 \\
\text { D } 430 \\
\text { MP } 269.80\end{array}$ & $\begin{array}{c}\text { WGW } 360 \\
\text { D } 1,130 \\
\text { MP } 272.00\end{array}$ \\
\hline \multicolumn{11}{|c|}{ Pumping-Continued } \\
\hline \multirow[t]{25}{*}{$10-18-99$} & 23 & 46.12 & 26.95 & 20.50 & 17.97 & 17.65 & 13.02 & 13.02 & 9.05 & -- \\
\hline & 26 & 46.15 & 26.97 & 20.53 & 18.00 & 17.67 & 13.03 & 13.03 & -- & -- \\
\hline & 30 & 46.20 & 27.00 & 20.55 & 18.02 & 17.69 & 13.04 & 13.04 & 9.05 & -- \\
\hline & 35 & 46.30 & 27.03 & 20.59 & 18.05 & 17.71 & 13.05 & 13.05 & 9.06 & -- \\
\hline & 40 & 46.31 & 27.08 & 20.62 & 18.07 & 17.74 & 13.06 & 13.06 & 9.06 & -- \\
\hline & 45 & 46.36 & 27.10 & 20.65 & 18.10 & 17.76 & 13.08 & 13.08 & 9.07 & -- \\
\hline & 50 & 46.37 & 27.14 & 20.67 & 18.12 & 17.78 & 13.09 & 13.09 & 9.07 & -- \\
\hline & 60 & 46.41 & 27.18 & 20.72 & 18.17 & 17.81 & 13.11 & 13.11 & 9.08 & -- \\
\hline & 70 & 46.60 & 27.28 & 20.78 & 18.20 & 17.84 & 13.13 & 13.13 & 9.09 & -- \\
\hline & 80 & 46.65 & 27.30 & 20.83 & 18.25 & 17.88 & 13.15 & 13.15 & 9.10 & -- \\
\hline & 90 & 46.70 & 27.36 & 20.87 & 18.27 & 17.90 & 13.16 & 13.16 & 9.10 & 11.21 \\
\hline & 100 & 46.71 & 27.38 & 20.90 & 18.30 & 17.93 & 13.17 & 13.17 & 9.11 & -- \\
\hline & 120 & 46.88 & 27.50 & 21.00 & 18.41 & 18.00 & 13.22 & 13.22 & 9.12 & -- \\
\hline & 150 & 46.96 & 27.51 & 21.05 & 18.44 & 18.03 & 13.27 & 13.27 & 9.15 & -- \\
\hline & 180 & 47.20 & 27.68 & 21.14 & 18.51 & 18.09 & 13.23 & 13.23 & 9.16 & -- \\
\hline & 210 & 47.32 & 27.77 & 21.22 & 18.58 & 18.14 & 13.30 & 13.30 & 9.17 & -- \\
\hline & 240 & 47.40 & 27.85 & 21.29 & 18.64 & 18.19 & 13.34 & 13.34 & 9.19 & -- \\
\hline & 300 & 47.50 & 27.97 & 21.41 & 18.75 & 18.28 & 13.40 & 13.40 & 9.23 & 11.21 \\
\hline & 360 & 47.70 & 28.10 & 21.52 & 18.86 & 18.37 & 13.46 & 13.46 & 9.29 & -- \\
\hline & 420 & 47.78 & 28.20 & 21.62 & 18.95 & 18.46 & 13.51 & 13.51 & 9.32 & 11.22 \\
\hline & 480 & 47.78 & 28.30 & 21.70 & 19.04 & 18.53 & 13.56 & 13.56 & 9.37 & 11.24 \\
\hline & 540 & 48.05 & 28.41 & 21.79 & 19.11 & 18.58 & 13.61 & 13.61 & 9.41 & -- \\
\hline & 600 & 48.19 & 28.49 & 21.87 & 19.18 & 18.65 & 13.65 & 13.65 & 9.45 & 11.24 \\
\hline & 660 & 48.27 & 28.58 & 21.95 & 19.26 & 18.72 & 13.70 & 13.70 & 9.48 & -- \\
\hline & 720 & 48.39 & 28.66 & 22.03 & 19.32 & 18.77 & 13.74 & 13.74 & 9.51 & -- \\
\hline
\end{tabular}


Table 10. Ground-water levels recorded during an aquifer test conducted at West Greenwich Well 410, central Rhode Island, October 1999—Continued

\begin{tabular}{|c|c|c|c|c|c|c|c|c|c|c|}
\hline \multirow{3}{*}{ Date } & \multirow{3}{*}{$\begin{array}{l}\text { Time } \\
(\min )\end{array}$} & \multicolumn{9}{|c|}{ Water level (feet below measuring point) } \\
\hline & & \multirow{2}{*}{$\begin{array}{c}\text { Pumped well } \\
\text { WGW } 410 \\
\text { MP 279.68 }\end{array}$} & \multicolumn{8}{|c|}{ Observation well } \\
\hline & & & $\begin{array}{c}\text { WGW } 358 \\
\text { D } 3.25 \\
\text { MP } 279.60\end{array}$ & $\begin{array}{l}\text { WGW } 289 \\
\text { D } 80 \\
\text { MP } 279.55\end{array}$ & $\begin{array}{c}\text { WGW } 418 \\
\text { D } 115 \\
\text { MP } 278.73\end{array}$ & $\begin{array}{c}\text { WGW } 419 \\
\text { D } 172 \\
\text { MP } 279.17\end{array}$ & $\begin{array}{c}\text { WGW } 421 \\
\text { D } 210 \\
\text { MP } 274.30\end{array}$ & $\begin{array}{c}\text { WGW } 420 \\
\text { D } 357 \\
\text { MP } 272.54\end{array}$ & $\begin{array}{c}\text { WGW } 417 \\
\text { D } 430 \\
\text { MP } 269.80\end{array}$ & $\begin{array}{c}\text { WGW } 360 \\
\text { D } 1,130 \\
\text { MP } 272.00\end{array}$ \\
\hline \multicolumn{11}{|c|}{ Pumping-Continued } \\
\hline \multirow[t]{2}{*}{$10-18-99$} & 780 & 48.46 & 28.76 & 22.18 & -- & -- & -- & -- & -- & -- \\
\hline & 840 & 48.60 & 28.87 & 22.30 & 19.44 & 18.87 & 13.80 & 13.80 & 9.58 & 11.25 \\
\hline \multirow[t]{18}{*}{$10-19-99$} & 900 & 48.68 & 28.91 & 22.42 & -- & -- & -- & -- & -- & -- \\
\hline & 960 & 48.78 & 28.99 & 22.53 & 19.54 & 18.97 & 13.88 & 13.88 & 9.64 & -- \\
\hline & 1,020 & 48.81 & 29.04 & 22.62 & -- & -- & -- & -- & -- & -- \\
\hline & 1,080 & 48.93 & 29.12 & -- & 19.66 & 19.08 & 13.95 & 13.95 & 9.71 & 11.27 \\
\hline & 1,140 & 49.02 & 29.22 & 22.70 & -- & -- & -- & -- & -- & -- \\
\hline & 1,200 & 49.05 & 29.26 & -- & 19.76 & 19.16 & 14.02 & 14.02 & 9.76 & -- \\
\hline & 1,260 & 49.10 & 29.30 & 22.79 & -- & -- & -- & -- & -- & -- \\
\hline & 1,320 & 49.15 & 29.35 & 22.83 & 19.84 & 19.22 & 14.09 & 14.09 & 9.82 & -- \\
\hline & 1,380 & 49.18 & 29.37 & 22.86 & -- & -- & -- & -- & -- & 11.30 \\
\hline & 1,440 & 49.18 & 29.43 & 22.92 & 19.93 & 19.29 & 14.15 & 14.15 & 9.87 & -- \\
\hline & 1,500 & 49.20 & 29.47 & 23.00 & -- & -- & -- & -- & -- & 11.30 \\
\hline & 1,560 & 49.20 & 29.49 & 23.04 & 20.01 & 19.36 & 14.21 & 14.21 & 9.92 & -- \\
\hline & 1,620 & 49.24 & 29.54 & 23.07 & 20.05 & 19.40 & 14.24 & 14.24 & 9.95 & -- \\
\hline & 1,680 & 49.32 & 29.60 & 23.10 & 20.08 & 19.43 & 14.27 & 14.27 & 9.98 & 11.32 \\
\hline & 1,740 & 49.36 & 29.65 & 23.15 & 20.11 & 19.47 & 14.30 & 14.30 & 10.01 & -- \\
\hline & 1,800 & 49.36 & 29.68 & 23.18 & -- & -- & -- & -- & -- & -- \\
\hline & 1,860 & 49.45 & 29.75 & 23.26 & 20.20 & 19.56 & 14.36 & 14.36 & 10.07 & 11.33 \\
\hline & 1,920 & 49.48 & 29.80 & 23.33 & 20.24 & 19.59 & 14.39 & 14.39 & 10.09 & -- \\
\hline \multirow[t]{5}{*}{$10-20-99$} & 1,980 & 49.50 & 29.81 & 23.38 & 20.26 & 19.62 & 14.42 & 14.42 & 10.12 & -- \\
\hline & 2,040 & 49.51 & 29.86 & 23.43 & 20.30 & 19.65 & 14.44 & 14.44 & 10.14 & 11.35 \\
\hline & 2,100 & 49.59 & 29.87 & 23.51 & 20.34 & 19.69 & 14.47 & 14.47 & 10.16 & -- \\
\hline & 2,160 & 49.61 & 29.92 & 23.56 & 20.38 & 19.72 & 14.49 & 14.49 & 10.19 & -- \\
\hline & 2,220 & 49.65 & 29.96 & -- & 20.42 & 19.77 & 14.54 & 14.54 & 10.24 & 11.36 \\
\hline
\end{tabular}


Table 10. Ground-water levels recorded during an aquifer test conducted at West Greenwich Well 410, central Rhode Island, October 1999—Continued

\begin{tabular}{|c|c|c|c|c|c|c|c|c|c|c|}
\hline \multirow{3}{*}{ Date } & \multirow{3}{*}{$\begin{array}{l}\text { Time } \\
(\min )\end{array}$} & \multicolumn{9}{|c|}{ Water level (feet below measuring point) } \\
\hline & & \multirow{2}{*}{$\begin{array}{c}\text { Pumped well } \\
\text { WGW } 410 \\
\text { MP } 279.68\end{array}$} & \multicolumn{8}{|c|}{ Observation well } \\
\hline & & & $\begin{array}{c}\text { WGW } 358 \\
\text { D } 3.25 \\
\text { MP } 279.60\end{array}$ & $\begin{array}{c}\text { WGW } 289 \\
\text { D } 80 \\
\text { MP } 279.55\end{array}$ & $\begin{array}{c}\text { WGW } 418 \\
\text { D } 115 \\
\text { MP } 278.73\end{array}$ & $\begin{array}{l}\text { WGW } 419 \\
\text { D } 172 \\
\text { MP } 279.17\end{array}$ & $\begin{array}{c}\text { WGW } 421 \\
\text { D } 210 \\
\text { MP } 274.30\end{array}$ & $\begin{array}{c}\text { WGW } 420 \\
\text { D } 357 \\
\text { MP } 272.54\end{array}$ & $\begin{array}{c}\text { WGW } 417 \\
\text { D } 430 \\
\text { MP } 269.80\end{array}$ & $\begin{array}{c}\text { WGW } 360 \\
\text { D } 1,130 \\
\text { MP } 272.00\end{array}$ \\
\hline \multicolumn{11}{|c|}{ Pumping-Continued } \\
\hline \multirow[t]{11}{*}{$10-20-99$} & 2,280 & 49.71 & 30.00 & 23.55 & -- & -- & -- & -- & -- & -- \\
\hline & 2,340 & 49.78 & 30.05 & -- & -- & -- & -- & -- & -- & -- \\
\hline & 2,400 & 49.79 & 30.07 & -- & 20.49 & 19.82 & 14.59 & 14.59 & 10.28 & -- \\
\hline & 2,460 & 49.80 & 30.09 & -- & 20.55 & 19.88 & 14.63 & 14.63 & 10.32 & 11.40 \\
\hline & 2,520 & 49.84 & 30.12 & -- & -- & -- & -- & -- & -- & -- \\
\hline & 2,580 & 49.96 & 30.15 & -- & -- & -- & -- & -- & -- & -- \\
\hline & 2,640 & 49.86 & 30.17 & -- & 20.61 & 19.93 & 14.67 & 14.67 & 10.37 & -- \\
\hline & 2,700 & 49.90 & 30.23 & -- & -- & -- & -- & -- & -- & -- \\
\hline & 2,760 & 49.95 & 30.27 & -- & 20.67 & 19.98 & 14.71 & 14.71 & 10.40 & -- \\
\hline & 2,820 & 49.97 & 30.30 & -- & -- & -- & -- & -- & -- & -- \\
\hline & 2,880 & 50.00 & 30.31 & -- & 20.74 & 20.04 & 14.76 & 14.76 & 10.43 & -- \\
\hline
\end{tabular}


Table 11. Ground-water levels recorded during an aquifer test conducted at West Greenwich Well 411, central Rhode Island, October 1999

[Site locations are shown on plate 1. WGW 411 (West Greenwich well) was pumped at 325 gallons per minute for 49 hours. D, radial distance from pumped well in feet; MP, altitude of measuring point datum at local well in feet above sea level; min, minutes; --, no data available]

\begin{tabular}{|c|c|c|c|c|c|c|c|c|c|}
\hline \multirow{3}{*}{ Date } & \multirow{3}{*}{$\begin{array}{l}\text { Time } \\
\text { (min) }\end{array}$} & \multicolumn{8}{|c|}{ Water level (feet below measuring point) } \\
\hline & & \multirow{2}{*}{$\begin{array}{c}\begin{array}{c}\text { Pumped } \\
\text { well }\end{array} \\
\text { WGW } 411 \\
\text { MP } 259.93\end{array}$} & \multicolumn{7}{|c|}{ Observation well } \\
\hline & & & $\begin{array}{c}\text { WGW } 371 \\
\text { D } 3.3 \\
\text { MP } 257.93\end{array}$ & $\begin{array}{c}\text { WGW } 414 \\
\text { D } 64 \\
\text { MP 264.08 }\end{array}$ & $\begin{array}{l}\text { WGW } 415 \\
\text { D } 125 \\
\text { MP } 269.85\end{array}$ & $\begin{array}{c}\text { WGW } 413 \\
\text { D } 159 \\
\text { MP } 257.51\end{array}$ & $\begin{array}{c}\text { WGW } 416 \\
\text { D } 300 \\
\text { MP } 272.42\end{array}$ & $\begin{array}{c}\text { WGW } 412 \\
\text { D } 320 \\
\text { MP } 260.16\end{array}$ & $\begin{array}{c}\text { WGW } 304 \\
\text { D } 635 \\
\text { MP } 274.64\end{array}$ \\
\hline \multicolumn{10}{|c|}{ Prior to pumping } \\
\hline $10-08-99$ & -- & -- & 7.08 & 13.10 & 19.70 & 6.12 & 20.80 & 10.56 & 22.93 \\
\hline $10-11-99$ & -- & -- & 7.02 & 13.04 & 19.66 & 6.08 & 20.77 & 10.50 & 22.91 \\
\hline $10-12-99$ & -- & 9.84 & 7.02 & 13.07 & 19.68 & 6.07 & 20.77 & 10.53 & 22.94 \\
\hline \multicolumn{10}{|c|}{ Pumping begins } \\
\hline \multirow[t]{30}{*}{$10-12-99$} & 0 & 9.84 & 7.02 & 13.07 & 19.68 & 6.07 & 20.78 & 10.53 & 22.94 \\
\hline & .25 & -- & 11.70 & -- & 19.68 & 6.07 & 20.79 & 10.53 & 22.94 \\
\hline & .5 & -- & 14.60 & -- & 19.74 & 6.08 & 20.79 & 10.53 & 22.94 \\
\hline & .75 & -- & 16.50 & 13.20 & 19.80 & 6.09 & 20.79 & 10.53 & 22.94 \\
\hline & .8 & -- & & 13.40 & -- & -- & -- & -- & -- \\
\hline & 1 & -- & 17.30 & 13.70 & 20.03 & 6.11 & 20.79 & 10.54 & 22.94 \\
\hline & 1.5 & -- & 18.20 & 13.90 & 20.40 & 6.19 & -- & 10.54 & 22.94 \\
\hline & 2 & 45.80 & 18.50 & 14.40 & 20.61 & 6.30 & 20.82 & 10.54 & 22.94 \\
\hline & 3 & 46.20 & 19.00 & 14.70 & 20.94 & 6.50 & 20.86 & 10.57 & 22.94 \\
\hline & 4 & -- & 19.30 & 14.80 & 21.12 & 6.64 & 20.88 & 10.59 & 22.94 \\
\hline & 5 & -- & 19.37 & 14.80 & 21.22 & 6.74 & 20.92 & 10.61 & 22.94 \\
\hline & 6 & -- & 19.42 & 14.90 & 21.29 & 6.82 & 20.94 & 10.65 & 22.94 \\
\hline & 7 & -- & 19.47 & 14.90 & 21.33 & 6.86 & 20.94 & 10.66 & 22.94 \\
\hline & 8 & -- & 19.48 & 14.90 & 21.37 & 6.91 & 20.95 & 10.69 & 22.94 \\
\hline & 9 & -- & 19.49 & 14.90 & 21.39 & 6.94 & 20.95 & 10.72 & 22.94 \\
\hline & 10 & 46.26 & 19.50 & 15.00 & 21.41 & 6.97 & 20.96 & 10.73 & 22.94 \\
\hline & 12 & -- & 19.50 & 15.00 & 21.43 & 7.02 & 20.97 & 10.77 & -- \\
\hline & 14 & 46.30 & 19.52 & 15.00 & 21.45 & 7.05 & 20.97 & 10.80 & -- \\
\hline & 16 & 46.30 & 19.52 & 15.00 & 21.48 & 7.08 & 20.98 & 10.83 & -- \\
\hline & 18 & 46.28 & 19.51 & 15.00 & 21.49 & 7.11 & 20.98 & 10.85 & 22.94 \\
\hline & 20 & 46.28 & 19.50 & 15.10 & 21.50 & 7.13 & 20.99 & 10.87 & 22.94 \\
\hline & 23 & -- & 19.51 & 15.10 & -- & 7.16 & 20.99 & 10.89 & 22.94 \\
\hline & 26 & -- & 19.55 & 15.10 & 21.53 & 7.18 & 21.00 & 10.91 & 22.94 \\
\hline & 30 & -- & 19.57 & 15.12 & -- & 7.21 & 21.02 & 10.96 & 22.94 \\
\hline & 35 & 46.32 & 19.57 & 15.15 & 21.57 & 7.24 & 21.03 & 10.96 & 22.94 \\
\hline & 40 & 46.38 & 19.58 & 15.17 & 21.59 & 7.26 & 21.03 & 10.99 & 22.94 \\
\hline & 45 & -- & 19.58 & 15.17 & 21.60 & 7.29 & 21.03 & 11.01 & 22.94 \\
\hline & 50 & 46.39 & 19.60 & 15.21 & 21.61 & 7.30 & 21.03 & 11.02 & 22.94 \\
\hline & 60 & 46.40 & 19.60 & 15.25 & 21.64 & 7.33 & 21.05 & 11.05 & 22.94 \\
\hline & 70 & 46.41 & 19.60 & 15.27 & 21.66 & 7.35 & 21.06 & 11.05 & 22.94 \\
\hline
\end{tabular}


Table 11. Ground-water levels recorded during an aquifer test conducted at West Greenwich Well 411, central Rhode Island, October 1999-Continued

\begin{tabular}{|c|c|c|c|c|c|c|c|c|c|}
\hline \multirow{3}{*}{ Date } & \multirow{3}{*}{$\begin{array}{l}\text { Time } \\
\text { (min) }\end{array}$} & \multicolumn{8}{|c|}{ Water level (feet below measuring point) } \\
\hline & & \multirow{2}{*}{$\begin{array}{c}\begin{array}{c}\text { Pumped } \\
\text { well }\end{array} \\
\text { WGW } 411 \\
\text { MP } 259.93\end{array}$} & \multicolumn{7}{|c|}{ Observation well } \\
\hline & & & $\begin{array}{c}\text { WGW } 371 \\
\text { D } 3.3 \\
\text { MP } 257.93\end{array}$ & $\begin{array}{c}\text { WGW } 414 \\
\text { D } 64 \\
\text { MP } 264.08\end{array}$ & $\begin{array}{c}\text { WGW 415 } \\
\text { D } 125 \\
\text { MP } 269.85\end{array}$ & $\begin{array}{c}\text { WGW } 413 \\
\text { D } 159 \\
\text { MP 257.51 }\end{array}$ & $\begin{array}{c}\text { WGW } 416 \\
\text { D } 300 \\
\text { MP } 272.42\end{array}$ & $\begin{array}{c}\text { WGW } 412 \\
\text { D } 320 \\
\text { MP } 260.16\end{array}$ & $\begin{array}{c}\text { WGW } 304 \\
\text { D } 635 \\
\text { MP } 274.64\end{array}$ \\
\hline \multicolumn{10}{|c|}{ Pumping-Continued } \\
\hline \multirow[t]{19}{*}{$10-12-99$} & 80 & 46.43 & 19.62 & 15.29 & 21.69 & 7.37 & 21.07 & 11.07 & 22.94 \\
\hline & 90 & 46.48 & 19.65 & 15.33 & -- & 7.39 & 21.08 & 11.08 & 22.94 \\
\hline & 100 & 46.53 & 19.70 & 15.36 & 21.74 & 7.42 & 21.09 & 11.10 & 22.94 \\
\hline & 120 & 46.56 & 19.72 & 15.42 & 21.78 & 7.45 & 21.11 & 11.13 & 22.94 \\
\hline & 150 & 46.62 & 19.72 & 15.50 & 21.82 & 7.50 & 21.13 & 11.16 & 22.94 \\
\hline & 180 & 46.70 & 19.80 & 15.57 & 21.88 & 7.55 & 21.15 & 11.19 & 22.94 \\
\hline & 210 & 46.69 & 19.85 & 15.64 & 21.93 & 7.59 & 21.18 & 11.22 & 22.94 \\
\hline & 240 & 46.78 & 19.90 & 15.70 & 21.97 & 7.62 & 21.20 & 11.25 & 22.94 \\
\hline & 300 & 47.00 & 20.08 & 15.84 & 22.06 & 7.71 & 21.25 & 11.31 & 22.95 \\
\hline & 360 & 47.20 & 20.12 & 15.92 & 22.14 & 7.78 & 21.30 & 11.35 & 22.96 \\
\hline & 420 & 47.25 & 20.20 & 16.03 & 22.21 & 7.83 & 21.34 & 11.40 & 22.97 \\
\hline & 480 & 47.33 & 20.27 & 16.11 & 22.27 & 7.89 & 21.37 & 11.42 & 22.97 \\
\hline & 500 & -- & -- & 16.13 & 22.28 & 7.91 & 21.38 & 11.43 & 22.98 \\
\hline & 540 & 47.25 & 20.30 & 16.18 & 22.32 & 7.93 & 21.40 & 11.46 & 22.98 \\
\hline & 600 & 47.43 & 20.40 & 16.25 & 22.37 & 7.98 & 21.43 & 11.48 & 22.98 \\
\hline & 660 & 47.45 & 20.41 & -- & 22.41 & 8.02 & 21.46 & 11.52 & 22.99 \\
\hline & 720 & 47.39 & 20.47 & 16.38 & 22.47 & 8.06 & 21.49 & 11.54 & 23.00 \\
\hline & 780 & 47.45 & 20.50 & 16.42 & 22.50 & 8.09 & 21.52 & 11.57 & 23.01 \\
\hline & 840 & 47.51 & 20.51 & 16.49 & 22.55 & 8.12 & 21.54 & 11.59 & 23.02 \\
\hline \multirow[t]{21}{*}{$10-13-99$} & 900 & 47.51 & 20.35 & -- & -- & -- & -- & -- & -- \\
\hline & 960 & 47.55 & 20.36 & 16.59 & 22.62 & 8.19 & 21.58 & 11.64 & 23.02 \\
\hline & 1,020 & 47.59 & 20.41 & -- & -- & -- & -- & -- & -- \\
\hline & 1,080 & 47.60 & 20.71 & 16.69 & 22.68 & 8.25 & 21.62 & 11.68 & 23.03 \\
\hline & 1,140 & 47.66 & 20.77 & -- & -- & -- & -- & -- & -- \\
\hline & 1,200 & 47.76 & 20.78 & 16.76 & 22.74 & 8.31 & 21.67 & 11.71 & 23.05 \\
\hline & 1,260 & 47.76 & 20.89 & -- & -- & -- & -- & -- & -- \\
\hline & 1,320 & 47.78 & 20.88 & 16.84 & 22.80 & 8.36 & 21.72 & 11.76 & 23.06 \\
\hline & 1,380 & 47.81 & 20.88 & 16.87 & 22.83 & 8.38 & 21.74 & 11.78 & 23.07 \\
\hline & 1,440 & 47.78 & 20.90 & 16.89 & 22.85 & 8.40 & 21.75 & 11.79 & 23.07 \\
\hline & 1,500 & 47.77 & 20.90 & 16.92 & 22.87 & 8.42 & 21.77 & 11.81 & 23.08 \\
\hline & 1,560 & 47.77 & 20.92 & 16.94 & 22.89 & 8.44 & 21.79 & 11.83 & 23.08 \\
\hline & 1,620 & 47.76 & 20.92 & 16.97 & 22.91 & 8.46 & 21.80 & 11.84 & 23.09 \\
\hline & 1,680 & 47.72 & 20.94 & 16.99 & 22.93 & 8.47 & 21.82 & 11.85 & 23.09 \\
\hline & 1,740 & 47.76 & 20.96 & 17.02 & 22.95 & 8.49 & 21.84 & 11.87 & 23.10 \\
\hline & 1,800 & 47.78 & 21.00 & 17.04 & 22.97 & 8.51 & 21.85 & 11.88 & 23.10 \\
\hline & 1,860 & 47.78 & 21.00 & 17.05 & 22.99 & 8.52 & 21.86 & 11.88 & 23.11 \\
\hline & 1,920 & 47.80 & 21.00 & 17.07 & 23.01 & 8.54 & 21.88 & 11.90 & 23.11 \\
\hline & 1,980 & 47.80 & 21.00 & 17.10 & 23.03 & 8.56 & 21.89 & 11.91 & 23.12 \\
\hline & 2,040 & 47.82 & 21.01 & 17.12 & 23.04 & 8.57 & 21.91 & 11.91 & 23.13 \\
\hline & 2,100 & 47.82 & 21.03 & 17.13 & 23.06 & 8.58 & 21.92 & 11.93 & 23.13 \\
\hline
\end{tabular}


Table 11. Ground-water levels recorded during an aquifer test conducted at West Greenwich Well 411, central Rhode Island, October 1999-Continued

\begin{tabular}{|c|c|c|c|c|c|c|c|c|c|}
\hline \multirow{3}{*}{ Date } & \multirow{3}{*}{$\begin{array}{l}\text { Time } \\
\text { (min) }\end{array}$} & \multicolumn{8}{|c|}{ Water level (feet below measuring point) } \\
\hline & & \multirow{2}{*}{$\begin{array}{c}\begin{array}{c}\text { Pumped } \\
\text { well }\end{array} \\
\text { WGW } 411 \\
\text { MP } 259.93\end{array}$} & \multicolumn{7}{|c|}{ Observation well } \\
\hline & & & $\begin{array}{c}\text { WGW } 371 \\
\text { D } 3.3 \\
\text { MP } 257.93\end{array}$ & $\begin{array}{c}\text { WGW } 414 \\
\text { D } 64 \\
\text { MP } 264.08\end{array}$ & $\begin{array}{c}\text { WGW } 415 \\
\text { D } 125 \\
\text { MP } 269.85\end{array}$ & $\begin{array}{c}\text { WGW } 413 \\
\text { D } 159 \\
\text { MP } 257.51\end{array}$ & $\begin{array}{c}\text { WGW } 416 \\
\text { D } 300 \\
\text { MP } 272.42\end{array}$ & $\begin{array}{c}\text { WGW } 412 \\
\text { D } 320 \\
\text { MP } 260.16\end{array}$ & $\begin{array}{c}\text { WGW } 304 \\
\text { D } 635 \\
\text { MP } 274.64\end{array}$ \\
\hline \multicolumn{10}{|c|}{ Pumping-Continued } \\
\hline \multirow[t]{4}{*}{$10-13-99$} & 2,160 & 47.82 & 21.03 & 17.17 & 23.08 & 8.60 & 21.94 & 11.95 & 23.14 \\
\hline & 2,220 & 47.82 & 21.05 & 17.18 & 23.10 & 8.61 & 21.95 & 11.96 & 23.14 \\
\hline & 2,280 & 47.82 & 21.05 & -- & -- & -- & -- & -- & -- \\
\hline & 2,340 & 47.82 & 21.07 & 17.22 & 23.12 & 8.64 & 21.98 & 11.97 & 23.14 \\
\hline \multirow[t]{12}{*}{ 10-14-99 } & 2,400 & 47.82 & 21.10 & -- & -- & -- & -- & -- & -- \\
\hline & 2,460 & 47.83 & 21.10 & 17.26 & 23.16 & 8.66 & 22.00 & 11.98 & 23.16 \\
\hline & 2,520 & 47.83 & 21.11 & -- & -- & -- & -- & -- & -- \\
\hline & 2,580 & 47.83 & 21.12 & 17.29 & 23.17 & 8.67 & 22.02 & 12.00 & 23.16 \\
\hline & 2,640 & 47.85 & 21.12 & -- & -- & -- & -- & -- & -- \\
\hline & 2,700 & 47.86 & 21.15 & 17.32 & 23.21 & 8.70 & 22.04 & 12.02 & 23.18 \\
\hline & 2,760 & 47.88 & 21.16 & -- & -- & -- & -- & -- & -- \\
\hline & 2,820 & 47.91 & 21.21 & 17.34 & 23.24 & 8.73 & 22.06 & 12.03 & 23.19 \\
\hline & 2,860 & -- & -- & -- & 23.25 & -- & -- & 12.05 & -- \\
\hline & 2,880 & 47.93 & 21.27 & 17.36 & 23.26 & 8.76 & 22.07 & 12.05 & 23.19 \\
\hline & 2,920 & -- & -- & -- & -- & -- & 22.08 & -- & 23.20 \\
\hline & 2,940 & 48.00 & 21.32 & 17.38 & 23.27 & -- & 22.09 & 12.07 & -- \\
\hline
\end{tabular}


Table 12. Chemical analyses and physical properties of ground water in the Big-Mishnock stream-aquifer system, central Rhode Island, 1997-99

[Site locations are shown on plate 1. Data Sources: 1, U.S. Geological Survey; 2, Rhode Island Department of Health; 3, University of Rhode Island Department of Geosciences. CaCO 3 , calcium carbonate; WGW, West Greenwich well; ${ }^{\circ} \mathrm{C}$, degrees Celsius; $\mathrm{mm}$ of $\mathrm{Hg}$, millimeters of mercury; $\mathrm{mg} / \mathrm{L}$, milligrams per liter; $\mu \mathrm{S} / \mathrm{cm}$, microsiemens per centimeter; <, actual value is less than detection limit shown; --, no data]

\begin{tabular}{|c|c|c|c|c|c|c|c|c|c|c|c|c|c|c|c|}
\hline $\begin{array}{c}\text { Local } \\
\text { Well No. }\end{array}$ & Date & $\begin{array}{l}\text { Data } \\
\text { source }\end{array}$ & $\begin{array}{c}\text { Specific } \\
\text { conduc- } \\
\text { tance } \\
(\mu \mathrm{S} / \mathrm{cm})\end{array}$ & $\begin{array}{c}\mathrm{pH}, \\
\text { whole } \\
\text { water, } \\
\text { field }\end{array}$ & $\begin{array}{c}\text { Temp- } \\
\text { erature, } \\
\text { water } \\
\left({ }^{\circ} \mathrm{C}\right)\end{array}$ & $\begin{array}{c}\text { Baro- } \\
\text { metric } \\
\text { pressure } \\
(\mathrm{mm} \text { of } \\
\mathrm{Hg})\end{array}$ & $\begin{array}{l}\text { Oxygen, } \\
\text { dissolved } \\
(\mathrm{mg} / \mathrm{L})\end{array}$ & $\begin{array}{l}\text { Cal- } \\
\text { cium, } \\
\text { dis- } \\
\text { solved } \\
\text { (mg/L) }\end{array}$ & $\begin{array}{l}\text { Magne- } \\
\text { sium, } \\
\text { dis- } \\
\text { solved } \\
\text { (mg/L) }\end{array}$ & $\begin{array}{l}\text { Sodium, } \\
\text { dissolved } \\
(\mathrm{mg} / \mathrm{L})\end{array}$ & $\begin{array}{l}\text { Potas- } \\
\text { sium, } \\
\text { dis- } \\
\text { solved } \\
\text { (mg/L) }\end{array}$ & $\begin{array}{c}\text { Alka- } \\
\text { linity, } \\
\text { lab } \\
(\mathrm{mg} / \mathrm{L} \\
\mathrm{as} \\
\left.\mathrm{CaCO}_{3}\right)\end{array}$ & $\begin{array}{l}\text { Sulfate, } \\
\text { dissolved } \\
(\mathrm{mg} / \mathrm{L})\end{array}$ & $\begin{array}{l}\text { Chloride, } \\
\text { dissolved } \\
(\mathrm{mg} / \mathrm{L})\end{array}$ & $\begin{array}{l}\text { Fluo- } \\
\text { ride, } \\
\text { dis- } \\
\text { solved } \\
\text { (mg/L) }\end{array}$ \\
\hline WGW 285 & 5-03-99 & 1 & 354 & 5.53 & 12.2 & 754 & 7.4 & 3.7 & 0.41 & 64.7 & 0.91 & -- & 11 & 88 & 0.22 \\
\hline WGW 285 & 11-08-99 & 1 & 205 & 5.74 & 14.3 & 762 & -- & 2.0 & .25 & 36.5 & .64 & -- & 15 & 51 & .20 \\
\hline WGW 286 & 5-03-99 & 1 & 104 & 6.13 & 11.5 & 754 & 7.1 & 6.5 & 1.4 & 8.14 & 2.1 & -- & 6.0 & 16 & $<.1$ \\
\hline WGW 286 & 11-08-99 & 1 & 88 & 6.71 & 10.5 & 756 & -- & 5.8 & 1.3 & 7.32 & 1.7 & -- & 6.5 & 13 & $<.1$ \\
\hline WGW 287 & $3-07-97$ & 3 & 53 & 6.00 & 10.0 & -- & 11 & 2.1 & .50 & 3.6 & .8 & 3.2 & 6.0 & 4.4 & .3 \\
\hline WGW 289 & $3-01-97$ & 3 & 53 & 6.40 & 8.9 & -- & 9.8 & 2.3 & .40 & 3.7 & 1.2 & 5.6 & 5.9 & 3.6 & .4 \\
\hline WGW 289 & 5-03-99 & 1 & 45 & 6.34 & 9.6 & 752 & 11 & 2.9 & .42 & 3.98 & 1.2 & -- & 5.9 & 4.6 & .41 \\
\hline WGW 289 & 11-08-99 & 1 & 41 & 6.23 & 9.3 & 756 & -- & 2.8 & .45 & 3.41 & 1.1 & -- & 6.1 & 4.2 & .37 \\
\hline WGW 290 & $3-01-97$ & 3 & 45 & 5.50 & 9.0 & -- & 11 & 1.3 & .40 & 3.3 & .8 & 1.9 & 6.2 & 4.0 & .1 \\
\hline WGW 290 & 5-03-99 & 1 & 36 & 5.40 & 9.0 & 752 & 11 & 1.6 & .46 & 3.31 & 1.1 & -- & 6.4 & 3.5 & .16 \\
\hline WGW 290 & 11-08-99 & 1 & 32 & 6.17 & 9.5 & 756 & -- & 1.4 & .44 & 2.81 & .78 & -- & 6.1 & 3.1 & .15 \\
\hline WGW 292 & $2-20-97$ & 3 & 118 & 7.70 & 9.5 & -- & 6.4 & 6.4 & .90 & 10.6 & 1.9 & 32 & 3.3 & 5.1 & 2.1 \\
\hline WGW 292 & 5-03-99 & 1 & 92 & 6.82 & 12.0 & 752 & 4.4 & 7.7 & 1.1 & 8.99 & .9 & -- & 3.1 & 3.0 & 2.0 \\
\hline WGW 292 & 11-08-99 & 1 & 87 & 6.93 & 12.2 & 756 & -- & 8.2 & 1.2 & 8.23 & 2.0 & -- & 3.4 & 3.3 & 2.1 \\
\hline WGW 293 & $2-15-97$ & 3 & 147 & 6.05 & 10.0 & -- & 7.1 & 5.7 & .80 & 22 & 2.8 & 11 & 5.4 & 35 & $<.1$ \\
\hline WGW 293 & 5-03-99 & 1 & 60 & 6.28 & 9.0 & 752 & 8.6 & 4.6 & .69 & 4.13 & 2.1 & -- & 5.2 & 5.5 & $<.1$ \\
\hline WGW 293 & 11-08-99 & 1 & 56 & 6.44 & 10.9 & 756 & -- & 5.0 & .81 & 3.63 & 2.3 & -- & 5.8 & 4.3 & $<.1$ \\
\hline WGW 295 & $5-05-99$ & 1 & 75 & 5.66 & 11.5 & 751 & 8 & 6.3 & 1.3 & 5.01 & .56 & -- & 8.1 & 2.6 & $<.1$ \\
\hline WGW 295 & 11-09-99 & 1 & 66 & 5.93 & 12.9 & 759 & 8.1 & 6.1 & 1.3 & 4.47 & .63 & -- & 9.2 & 2.1 & $<.1$ \\
\hline WGW 296 & 3-02-97 & 3 & 68 & 6.70 & 11.5 & -- & 7.6 & 2.9 & .60 & 4.7 & 1.1 & 11 & 5.8 & 4.6 & .3 \\
\hline WGW 297 & $3-07-97$ & 3 & 102 & 7.40 & 9.0 & -- & 5.5 & 5.0 & .60 & 7.4 & 3.2 & 31 & .4 & 3.4 & 1.1 \\
\hline WGW 299 & $3-01-97$ & 3 & 59 & 6.20 & 10.0 & -- & 9 & 2.9 & .30 & 2.3 & .9 & 3.0 & 7.2 & 3.2 & $<.1$ \\
\hline WGW 300 & 5-05-99 & 1 & 204 & 5.55 & 10.5 & 751 & 11 & 3.7 & .86 & 31.76 & .42 & -- & 6.9 & 49 & $<.1$ \\
\hline WGW 300 & 11-09-99 & 1 & 157 & 5.63 & 10.3 & 761 & 9.7 & 2.6 & .59 & 28.9 & .33 & -- & 15 & 37 & $<.1$ \\
\hline WGW 301 & $2-16-97$ & 3 & 76 & 6.27 & 10.4 & -- & 9.2 & 4.9 & .80 & 5.2 & 1.4 & 11 & 5.9 & 5.3 & $<.1$ \\
\hline WGW 301 & $5-05-99$ & 1 & 61 & 5.89 & 10.2 & 751 & 11 & 4.3 & .81 & 4.87 & .93 & -- & 6.0 & 5.8 & $<.1$ \\
\hline WGW 301 & 11-09-99 & 1 & 56 & 5.89 & 10.0 & 761 & 10 & 4.3 & .85 & 4.52 & .98 & -- & 6.0 & 6.1 & $<.1$ \\
\hline WGW 302 & $5-05-99$ & 1 & 159 & 5.87 & 11.0 & 751 & 11 & 2.7 & .83 & 25.5 & .55 & -- & 7.8 & 43 & $<.1$ \\
\hline WGW 302 & 11-08-99 & 1 & 153 & 6.59 & 9.7 & 755 & -- & 3.4 & 1.1 & 23.4 & .56 & -- & 7.8 & 44 & $<.1$ \\
\hline WGW 303 & 5-03-99 & 1 & 248 & 5.52 & 10.0 & 752 & 11 & 4.3 & .89 & 39.3 & .96 & -- & 26 & 46 & $<.1$ \\
\hline
\end{tabular}


Table 12. Chemical analyses and physical properties of ground water in the Big-Mishnock stream-aquifer system, central Rhode Island, 1997-99—Continued

\begin{tabular}{|c|c|c|c|c|c|c|c|c|c|c|c|c|c|c|c|}
\hline $\begin{array}{l}\text { Local } \\
\text { Well No. }\end{array}$ & Date & $\begin{array}{l}\text { Data } \\
\text { source }\end{array}$ & $\begin{array}{c}\text { Specific } \\
\text { conduc- } \\
\text { tance } \\
(\mu \mathrm{S} / \mathrm{cm})\end{array}$ & $\begin{array}{l}\mathrm{pH}, \\
\text { whole } \\
\text { water, } \\
\text { field }\end{array}$ & $\begin{array}{l}\text { Temp- } \\
\text { erature, } \\
\text { water } \\
\left({ }^{\circ} \mathrm{C}\right)\end{array}$ & $\begin{array}{c}\text { Baro- } \\
\text { metric } \\
\text { pressure } \\
(\mathrm{mm} \text { of } \\
\mathrm{Hg})\end{array}$ & $\begin{array}{l}\text { Oxygen, } \\
\text { dissolved } \\
\text { (mg/L) }\end{array}$ & $\begin{array}{l}\text { Cal- } \\
\text { cium, } \\
\text { dis- } \\
\text { solved } \\
\text { (mg/L) }\end{array}$ & $\begin{array}{l}\text { Magne- } \\
\text { sium, } \\
\text { dis- } \\
\text { solved } \\
\text { (mg/L) }\end{array}$ & $\begin{array}{l}\text { Sodium, } \\
\text { dissolved } \\
\text { (mg/L) }\end{array}$ & $\begin{array}{l}\text { Potas- } \\
\text { sium, } \\
\text { dis- } \\
\text { solved } \\
\text { (mg/L) }\end{array}$ & $\begin{array}{c}\text { Alka- } \\
\text { linity, } \\
\text { lab } \\
(\mathrm{mg} / \mathrm{L} \\
\text { as } \\
\left.\mathrm{CaCO}_{3}\right)\end{array}$ & $\begin{array}{l}\text { Sulfate, } \\
\text { dissolved } \\
\text { (mg/L) }\end{array}$ & $\begin{array}{l}\text { Chloride, } \\
\text { dissolved } \\
\text { (mg/L) }\end{array}$ & $\begin{array}{l}\text { Fluo- } \\
\text { ride, } \\
\text { dis- } \\
\text { solved } \\
\text { (mg/L) }\end{array}$ \\
\hline WGW 303 & 11-09-99 & 1 & 202 & 5.66 & 10.6 & 762 & -- & 2.7 & 0.69 & 36.9 & 0.89 & -- & 21 & 47 & $<0.1$ \\
\hline WGW 305 & 2-28-97 & 3 & 55 & $5 . .00$ & 7.4 & -- & 7.6 & 2.0 & .50 & 3.4 & .6 & 5.3 & 5.5 & 3.9 & .1 \\
\hline WGW 306 & $12-05-96$ & 2 & 63 & -- & 9.9 & -- & -- & -- & -- & -- & -- & -- & -- & 4.0 & -- \\
\hline WGW 307 & $12-05-96$ & 2 & 69 & -- & -- & -- & -- & -- & -- & -- & -- & -- & -- & 3.8 & -- \\
\hline WGW 308 & $12-09-96$ & 2 & 67 & -- & 11.5 & -- & -- & -- & -- & -- & -- & -- & -- & 7.6 & -- \\
\hline WGW 312 & 12-19-96 & 2 & 59 & -- & 10.1 & -- & -- & -- & -- & -- & -- & -- & -- & 4.3 & -- \\
\hline WGW 313 & $12-31-96$ & 2 & 53 & -- & 9.8 & -- & -- & -- & -- & -- & -- & -- & -- & 6.7 & -- \\
\hline WGW 351 & 5-05-99 & 1 & 55 & 5.64 & 10.0 & 751 & 10 & 3.4 & .74 & 4.60 & .96 & -- & 7.0 & 5.4 & .14 \\
\hline WGW 351 & 11-09-99 & 1 & 51 & 5.74 & 9.2 & 764 & -- & 3.4 & .79 & 4.18 & .66 & -- & 6.9 & 5.7 & .12 \\
\hline WGW 354 & 2-04-98 & 2 & -- & -- & -- & -- & -- & -- & -- & -- & -- & -- & -- & 4.3 & -- \\
\hline WGW 355 & 2-04-98 & 2 & -- & -- & -- & -- & -- & -- & -- & -- & -- & -- & -- & 4.9 & -- \\
\hline WGW 356 & 2-04-98 & 2 & -- & -- & -- & -- & -- & -- & -- & -- & -- & -- & -- & 11.4 & -- \\
\hline WGW 358 & 2-04-98 & 2 & -- & -- & -- & -- & -- & -- & -- & -- & -- & -- & -- & 4.1 & -- \\
\hline WGW 360 & 2-04-98 & 2 & -- & -- & -- & -- & -- & -- & -- & -- & -- & -- & -- & 3.7 & -- \\
\hline WGW 371 & 2-04-98 & 2 & -- & -- & -- & -- & -- & -- & -- & -- & -- & -- & -- & 3.4 & -- \\
\hline WGW 374 & 2-04-98 & 2 & -- & -- & -- & -- & -- & -- & -- & -- & -- & -- & -- & 5.8 & -- \\
\hline WGW 410 & 2-04-98 & 2 & -- & -- & -- & -- & -- & -- & -- & -- & -- & -- & -- & 3.5 & -- \\
\hline WGW 411 & 2-04-98 & 2 & -- & -- & -- & -- & -- & -- & -- & -- & -- & -- & -- & 3.1 & -- \\
\hline
\end{tabular}


Table 12. Chemical analyses and physical properties of ground water in the Big-Mishnock stream-aquifer system, central Rhode Island, 1997-99—Continued

\begin{tabular}{|c|c|c|c|c|c|c|c|c|c|c|c|c|c|}
\hline $\begin{array}{l}\text { Local } \\
\text { Well No. }\end{array}$ & Date & $\begin{array}{c}\text { Bromide, } \\
\text { dis- } \\
\text { solved } \\
\text { (mg/L) }\end{array}$ & $\begin{array}{c}\text { Silica, } \\
\text { dis- } \\
\text { solved } \\
\text { (mg/L) }\end{array}$ & $\begin{array}{l}\text { Solids, } \\
\text { residue at } \\
180^{\circ} \mathrm{C}, \\
\text { dissolved } \\
(\mathrm{mg} / \mathrm{L})\end{array}$ & $\begin{array}{c}\text { Nitrogen, } \\
\text { nitrate, } \\
\text { calculated } \\
(\mathrm{mg} / \mathrm{L} \text { as } \mathrm{N})\end{array}$ & $\begin{array}{c}\text { Nitrogen, } \\
\text { nitrite, } \\
\text { dissolved } \\
\text { (mg/L as N) }\end{array}$ & $\begin{array}{c}\text { Nitrogen } \\
\text { nitrite + } \\
\text { nitrate } \\
\text { dissolved } \\
\text { (mg/L as N) }\end{array}$ & $\begin{array}{l}\text { Nitrogen, } \\
\text { ammonia, } \\
\text { dissolved } \\
\text { (mg/L as N) }\end{array}$ & $\begin{array}{c}\text { Nitrogen, } \\
\text { ammonia + } \\
\text { organic, } \\
\text { dissolved } \\
\text { (mg/L as N) }\end{array}$ & $\begin{array}{c}\text { Phos- } \\
\text { phorus, } \\
\text { dis- } \\
\text { solved } \\
\text { (mg/L } \\
\text { as } \mathrm{P})\end{array}$ & $\begin{array}{c}\text { Phos- } \\
\text { phorus, } \\
\text { ortho, } \\
\text { dissolved } \\
\text { (mg/L as } \mathrm{P})\end{array}$ & $\begin{array}{c}\text { Iron, } \\
\text { dis- } \\
\text { solved } \\
(\mathrm{mg} / \mathrm{L})\end{array}$ & $\begin{array}{c}\text { Manga- } \\
\text { nese, } \\
\text { dis- } \\
\text { solved } \\
(\mu \mathrm{g} / \mathrm{L})\end{array}$ \\
\hline WGW 285 & 5-03-99 & 0.03 & 8.9 & 185 & -- & $<0.01$ & 0.29 & 0.04 & $<0.1$ & $<0.004$ & 0.013 & 21.4 & 21.3 \\
\hline WGW 285 & $11-08-99$ & .02 & 9.9 & 124 & -- & $<.01$ & .15 & $<.02$ & $<.1$ & $<.006$ & $<.01$ & 91.2 & 13.4 \\
\hline WGW 286 & $5-03-99$ & .02 & 14 & 73 & -- & $<.01$ & 1.58 & .04 & $<.1$ & $<.004$ & .013 & $<10$ & 272 \\
\hline WGW 286 & 11-08-99 & .02 & 15 & 66 & -- & $<.01$ & 1.61 & $<.02$ & $<.1$ & $<.006$ & $<.01$ & 37.0 & 212 \\
\hline WGW 287 & $3-07-97$ & -- & 11 & -- & -- & -- & .16 & -- & -- & -- & -- & -- & -- \\
\hline WGW 289 & $3-01-97$ & -- & 13 & -- & -- & -- & .03 & -- & -- & -- & -- & -- & -- \\
\hline WGW 289 & 5-03-99 & .01 & 12 & 37 & -- & $<.01$ & $<.05$ & .04 & $<.1$ & $<.004$ & .013 & $<10$ & 8.28 \\
\hline WGW 289 & 11-08-99 & .01 & 12 & 38 & -- & $<.01$ & $<.05$ & $<.02$ & $<.1$ & $<.006$ & $<.01$ & $<10$ & 11.9 \\
\hline WGW 290 & $3-01-97$ & -- & 12 & -- & -- & -- & .03 & -- & -- & -- & -- & -- & -- \\
\hline WGW 290 & 5-03-99 & .01 & 9.6 & 29 & -- & $<.01$ & $<.05$ & .04 & $<.1$ & $<.004$ & .011 & $<10$ & 13.0 \\
\hline WGW 290 & $11-08-99$ & .01 & 9.9 & 30 & -- & $<.01$ & $<.05$ & .03 & $<.1$ & $<.006$ & $<.01$ & 12.9 & 13.0 \\
\hline WGW 292 & $2-20-97$ & -- & 27 & -- & -- & -- & .08 & -- & -- & -- & -- & -- & -- \\
\hline WGW 292 & 5-03-99 & .02 & 30 & 81 & -- & $<.01$ & .06 & .05 & $<.1$ & .005 & .018 & 509 & 108 \\
\hline WGW 292 & 11-08-99 & .02 & 31 & 71 & -- & $<.01$ & .07 & $<.02$ & $<.1$ & $<.006$ & $<.01$ & 38.7 & 69.6 \\
\hline WGW 293 & 2-15-97 & -- & 11 & -- & -- & -- & .29 & -- & -- & -- & -- & -- & -- \\
\hline WGW 293 & 5-03-99 & .03 & 8.4 & 42 & -- & $<.01$ & .29 & .04 & $<.1$ & $<.004$ & .015 & 10.3 & $<3$. \\
\hline WGW 293 & 11-08-99 & .02 & 11 & 33 & -- & $<.01$ & .32 & $<.02$ & $<.1$ & $<.006$ & $<.01$ & 27.8 & $<3$. \\
\hline WGW 295 & $5-05-99$ & $<.01$ & 19 & 64 & -- & $<.01$ & 1.19 & .06 & $<.1$ & .012 & .023 & 298 & 15.4 \\
\hline WGW 295 & 11-09-99 & .02 & 21 & 52 & -- & $<.01$ & .64 & .03 & $<.1$ & $<.006$ & $<.01$ & 446 & 19.5 \\
\hline WGW 296 & 3-02-97 & -- & 13 & -- & -- & -- & .05 & -- & -- & -- & -- & -- & -- \\
\hline WGW 297 & $3-07-97$ & -- & 36 & -- & -- & -- & .04 & -- & -- & -- & -- & -- & -- \\
\hline WGW 299 & $3-01-97$ & -- & 6.3 & -- & -- & -- & .48 & -- & -- & -- & -- & -- & -- \\
\hline WGW 300 & $5-05-99$ & .01 & 10 & 112 & -- & $<.01$ & $<.05$ & .05 & $<.1$ & $<.004$ & .015 & 31.7 & 17.7 \\
\hline WGW 300 & 11-09-99 & $<.01$ & 10 & 102 & -- & $<.01$ & $<.05$ & $<.02$ & $<.1$ & $<.006$ & $<.01$ & 15.5 & 11.2 \\
\hline WGW 301 & 2-16-97 & -- & 14 & -- & -- & -- & .97 & -- & -- & -- & -- & -- & -- \\
\hline WGW 301 & $5-05-99$ & .02 & 15 & 47 & -- & $<.01$ & .71 & .04 & $<.1$ & .008 & .014 & $<10$ & 16.2 \\
\hline WGW 301 & 11-09-99 & .02 & 16 & 50 & -- & $<.01$ & .71 & $<.02$ & $<.1$ & $<.006$ & $<.01$ & 60.5 & 13.0 \\
\hline WGW 302 & $5-05-99$ & .03 & 11 & 103 & -- & $<.01$ & .09 & .04 & $<.1$ & $<.004$ & .02 & 15.5 & $<3$. \\
\hline WGW 302 & 11-08-99 & .02 & 12 & 102 & -- & $<.01$ & .10 & $<.02$ & $<.1$ & .007 & $<.01$ & 10.6 & $<3$. \\
\hline WGW 303 & 5-03-99 & .03 & 12 & 136 & -- & $<.01$ & .13 & .05 & $<.1$ & $<.004$ & .02 & $<10$. & 71.8 \\
\hline
\end{tabular}


Table 12. Chemical analyses and physical properties of ground water in the Big-Mishnock stream-aquifer system, central Rhode Island, 1997-99-Continued

\begin{tabular}{|c|c|c|c|c|c|c|c|c|c|c|c|c|c|}
\hline $\begin{array}{l}\text { Local } \\
\text { Well No. }\end{array}$ & Date & $\begin{array}{c}\text { Bromide, } \\
\text { dis- } \\
\text { solved } \\
\text { (mg/L) }\end{array}$ & $\begin{array}{l}\text { Silica, } \\
\text { dis- } \\
\text { solved } \\
\text { (mg/L) }\end{array}$ & $\begin{array}{l}\text { Solids, } \\
\text { residue at } \\
180^{\circ} \mathrm{C}, \\
\text { dissolved } \\
\text { (mg/L) }\end{array}$ & $\begin{array}{c}\text { Nitrogen, } \\
\text { nitrate, } \\
\text { calculated } \\
\text { (mg/L as } \mathrm{N} \text { ) }\end{array}$ & $\begin{array}{l}\text { Nitrogen, } \\
\text { nitrite, } \\
\text { dissolved } \\
\text { (mg/L as N) }\end{array}$ & $\begin{array}{c}\text { Nitrogen } \\
\text { nitrite + } \\
\text { nitrate } \\
\text { dissolved } \\
\text { (mg/L as N) }\end{array}$ & $\begin{array}{l}\text { Nitrogen, } \\
\text { ammonia, } \\
\text { dissolved } \\
\text { (mg/L as N) }\end{array}$ & $\begin{array}{c}\text { Nitrogen, } \\
\text { ammonia + } \\
\text { organic, } \\
\text { dissolved } \\
(\mathrm{mg} / \mathrm{L} \text { as } \mathrm{N})\end{array}$ & $\begin{array}{c}\text { Phos- } \\
\text { phorus, } \\
\text { dis- } \\
\text { solved } \\
\text { (mg/L } \\
\text { as P) }\end{array}$ & $\begin{array}{c}\text { Phos- } \\
\text { phorus, } \\
\text { ortho, } \\
\text { dissolved } \\
\text { (mg/L as } \mathrm{P})\end{array}$ & $\begin{array}{l}\text { Iron, } \\
\text { dis- } \\
\text { solved } \\
\text { (mg/L) }\end{array}$ & $\begin{array}{c}\text { Manga- } \\
\text { nese, } \\
\text { dis- } \\
\text { solved } \\
(\mu \mathrm{g} / \mathrm{L})\end{array}$ \\
\hline WGW 303 & 11-09-99 & 0.02 & 12 & 129 & -- & $<0.01$ & 0.21 & $<0.02$ & $<0.1$ & $<0.004$ & $<0.01$ & 120 & 50.2 \\
\hline WGW 305 & $2-28-97$ & -- & 11 & -- & -- & -- & .03 & -- & -- & -- & -- & -- & -- \\
\hline WGW 306 & $12-05-96$ & -- & -- & -- & 0.7 & $<.02$ & -- & -- & -- & -- & -- & 130 & 30 \\
\hline WGW 307 & $12-05-96$ & -- & -- & -- & 1.1 & $<.02$ & -- & -- & -- & -- & -- & 80 & $<20$ \\
\hline WGW 308 & $12-09-96$ & -- & -- & -- & .6 & $<.02$ & -- & -- & -- & -- & -- & 360 & 40 \\
\hline WGW 312 & $12-19-96$ & -- & -- & -- & .4 & $<.02$ & -- & -- & -- & -- & -- & 70 & $<20$ \\
\hline WGW 313 & $12-31-96$ & -- & -- & -- & .4 & $<.02$ & -- & -- & -- & -- & -- & 50 & $<20$ \\
\hline WGW 351 & $5-05-99$ & .02 & 13 & 44 & -- & $<.01$ & .56 & .05 & $<.1$ & $<.004$ & .014 & $<10$ & $<3$. \\
\hline WGW 351 & $11-09-99$ & .02 & 14 & 37 & -- & $<.01$ & .60 & $<.02$ & $<.1$ & $<.006$ & $<.01$ & 14.3 & $<3$. \\
\hline WGW 354 & $2-04-98$ & -- & -- & -- & .4 & $<.02$ & -- & -- & -- & -- & -- & $<20$ & $<20$ \\
\hline WGW 355 & 2-04-98 & -- & -- & -- & 1.1 & $<.02$ & -- & -- & -- & -- & -- & $<20$ & $<20$ \\
\hline WGW 356 & 2-04-98 & -- & -- & -- & .4 & $<.02$ & -- & -- & -- & -- & -- & $<20$ & $<20$ \\
\hline WGW 358 & 2-04-98 & -- & -- & -- & $<.05$ & $<.02$ & -- & -- & -- & -- & -- & 30 & $<20$ \\
\hline WGW 360 & 2-04-98 & -- & -- & -- & $<.05$ & $<.02$ & -- & -- & -- & -- & -- & $<20$ & $<20$ \\
\hline WGW 371 & 2-04-98 & -- & -- & -- & $<.05$ & $<.02$ & -- & -- & -- & -- & -- & $<20$ & $<20$ \\
\hline WGW 374 & $2-04-98$ & -- & -- & -- & .9 & $<.02$ & -- & -- & -- & -- & -- & $<20$ & $<20$ \\
\hline WGW 410 & 2-04-98 & -- & -- & -- & 5.8 & $<.02$ & -- & -- & -- & -- & -- & $<20$ & $<20$ \\
\hline WGW 411 & 2-04-98 & -- & -- & -- & $<.05$ & $<.02$ & -- & -- & -- & -- & -- & $<20$ & $<20$ \\
\hline
\end{tabular}


Table 13. Water levels in selected ponds and reservoirs in the Big-Mishnock stream-aquifer system, central Rhode Island, 1997-98

[Site locations shown (A) correspond to plate 1 . Water levels are gage height readings in feet above the gage datum or * a measurement below a measuring point (MP) of known altitude; SG, staff gage; SLG, slope gage; WWG, wire weight gage;--, no data available]

\begin{tabular}{|c|c|c|c|c|c|c|c|c|c|}
\hline Date & $\begin{array}{l}\text { Water } \\
\text { level } \\
\text { (feet) }\end{array}$ & Date & $\begin{array}{l}\text { Water } \\
\text { level } \\
\text { (feet) }\end{array}$ & Date & $\begin{array}{l}\text { Water } \\
\text { level } \\
\text { (feet) }\end{array}$ & Date & $\begin{array}{l}\text { Water } \\
\text { level } \\
\text { (feet) }\end{array}$ & Date & $\begin{array}{l}\text { Water } \\
\text { level } \\
\text { (feet) }\end{array}$ \\
\hline
\end{tabular}

(A) Beaver Dam Pond at New London Turnpike SG Altitude: 256.76 feet

\begin{tabular}{|c|c|c|c|c|c|c|c|c|c|}
\hline APR 15, 1997 & 7.25 & AUG 28, 1997 & 7.67 & DEC 09, 1997 & 8.09 & APR 13, 1998 & 7.76 & AUG 24, 1998 & 5.98 \\
\hline MAY 21 & 7.07 & SEP 17 & 7.91 & JAN 14, 1998 & 8.06 & MAY 19 & 7.74 & SEP 29 & 7.53 \\
\hline JUN 18 & 6.84 & OCT 16 & 8.22 & FEB 17 & 8.03 & JUN 25 & 7.48 & OCT 27 & 7.80 \\
\hline JUL 15 & 7.68 & NOV 13 & 7.76 & MAR 24 & 7.93 & JUL 15 & 7.17 & & \\
\hline
\end{tabular}

(B) Capwell Mill Pond at Burnt Sawmill Road SG Altitude: 246.28 feet

\begin{tabular}{|c|c|c|c|c|c|c|c|c|c|}
\hline APR 14, 1997 & 10.09 & AUG 27, 1997 & 9.66 & DEC 09, 1997 & 9.74 & APR 13, 1998 & 9.98 & AUG 24, 1998 & 9.76 \\
\hline MAY 20 & 9.89 & SEP 17 & 9.60 & JAN 15, 1998 & 9.91 & MAY 19 & 9.98 & SEP 28 & 9.72 \\
\hline JUN 17 & 9.69 & OCT 16 & 9.57 & FEB 17 & 9.93 & JUN 25 & 10.02 & OCT 27 & 9.72 \\
\hline JUL 15 & 9.56 & NOV 12 & 9.77 & MAR 25 & 10.06 & JUL 16 & 9.83 & & \\
\hline
\end{tabular}

(C) Carr Pond at Carr Pond Outfall SG Altitude: 313.43 feet

$\begin{array}{llllllllll}\text { APR 15, 1997 } & 17.90 & \text { AUG 27, 1997 } & 17.28 & \text { DEC 09, 1997 } & 17.6 & \text { APR 13, 1998 } & 17.87 & \text { AUG 26, 1998 } & 17.71 \\ \text { MAY 20 } & 17.73 & \text { SEP 17 } & 17.38 & \text { JAN 14, 1998 } & 17.90 & \text { MAY 19 } & 17.97 & \text { SEP } & -- \\ \text { JUN 18 } & 17.55 & \text { OCT 16 } & 17.14 & \text { FEB 17 } & 17.90 & \text { JUN 25 } & 18.22 & \text { OCT 27 } & 17.56 \\ \text { JUL 16 } & 17.28 & \text { NOV 13 } & 17.58 & \text { MAR 24 } & 18.06 & \text { JUL } & -- & & \end{array}$

(D) Flat River Reservoir at Hill Farm Road WWG Altitude: 238.82 feet

$\begin{array}{llllllllll}\text { APR 14, 1997 } & 9.63 & \text { AUG 28, 1997 } & 8.41 & \text { DEC 09, 1997 } & 5.08 & \text { APR 13, 1998 } & 9.30 & \text { AUG 26, 1998 } & 9.01 \\ \text { MAY 29 } & 9.28 & \text { SEP 18 } & 9.00 & \text { JAN 15, 1998 } & 8.33 & \text { MAY 19 } & 9.45 & \text { SEP } & -- \\ \text { JUN 18 } & 8.95 & \text { OCT 15 } & 8.42 & \text { FEB 17 } & 7.10 & \text { JUN 25 } & 9.60 & \text { OCT 27 } & 8.10 \\ \text { JUL 16 } & 8.02 & \text { NOV 12 } & 7.55 & \text { MAR 25 } & 9.25 & \text { JUL 16 } & 9.35 & \end{array}$

(E) Mishnock Lake at Mohawk Trail SG Altitude: 231.25 feet

$\begin{array}{llllllllll}\text { APR 15, 1997 } & 18.98 & \text { AUG 27, 1997 } & 18.63 & \text { DEC 09, 1997 } & 18.91 & \text { APR 13, 1998 } & 18.89 & \text { AUG 25, 1998 } & 18.80 \\ \text { MAY 21 } & 18.92 & \text { SEP 18 } & 18.61 & \text { JAN 15, 1998 } & 18.87 & \text { MAY 19 } & 18.94 & \text { SEP 29 } & 19.00 \\ \text { JUN 18 } & 18.78 & \text { OCT 15 } & 18.66 & \text { FEB 17 } & 19.17 & \text { JUN 26 } & 18.92 & \text { OCT 27 } & 19.08 \\ \text { JUL 16 } & 18.67 & \text { NOV 12 } & 18.86 & \text { MAR 25 } & 18.92 & \text { JUL 16 } & 18.86 & \end{array}$

(F) Quarry Pond at Division and Hopkins Hill Roads SLG Altitude: 254.53 feet

$\begin{array}{llllllllll}\text { APR 15, 1997 } & 17.50 & \text { AUG 28, 1997 } & 13.64 & \text { DEC 09, 1997 } & 13.98 & \text { APR 14, 1998 } & 18.78 & \text { AUG 26, 1998 } & 15.95 \\ \text { MAY 21 } & 16.90 & \text { SEP 17 } & 14.55 & \text { JAN 14, 1998 } & 15.00 & \text { MAY 19 } & 18.90 & \text { SEP 29 } & 14.90 \\ \text { JUN 17 } & 15.80 & \text { OCT 16 } & 13.18 & \text { FEB 17 } & 16.85 & \text { JUN 25 } & 19.00 & \text { OCT 27 } & 14.45 \\ \text { JUL 16 } & 14.37 & \text { NOV 12 } & 13.80 & \text { MAR 25 } & 19.00 & \text { JUL 15 } & 18.30 & \end{array}$

(G) *Sweet Pond at Sweet Sawmill Road MP Altitude: 284.56 feet (chiseled square)

\begin{tabular}{|c|c|c|c|c|c|c|c|c|c|}
\hline APR 15, 1997 & 3.37 & AUG 27, 1997 & 5.11 & DEC 09, 1997 & 3.85 & APR 13, 1998 & 3.69 & AUG 26, 1998 & 4.73 \\
\hline MAY 20 & 3.36 & SEP 17 & 5.10 & JAN 14, 1998 & 3.75 & MAY 20 & 3.73 & SEP 29 & 5.05 \\
\hline JUN 18 & 3.55 & OCT & -- & FEB 17 & 3.88 & JUN 25 & 4.27 & OCT 27 & 4.93 \\
\hline JUL 15 & 5.00 & NOV 12 & 3.79 & MAR 24 & 3.49 & JUL 15 & 4.64 & & \\
\hline \multicolumn{10}{|c|}{ (H) Tarbox Pond at Hopkins Hill Road SG Altitude: 280.65 feet } \\
\hline APR 15, 1997 & 10.12 & AUG 27, 1997 & 9.11 & DEC 09, 1997 & 9.16 & APR 13, 1998 & 9.37 & AUG 26, 1998 & 9.17 \\
\hline MAY 21 & 9.60 & SEP 17 & 9.14 & JAN 14, 1998 & 9.36 & MAY 19 & 9.44 & SEP 29 & 9.36 \\
\hline JUN 18 & 9.52 & OCT 16 & 9.53 & FEB 17 & 9.36 & JUN 25 & 9.44 & OCT 27 & 9.56 \\
\hline JUL 15 & 9.09 & NOV 13 & 9.14 & MAR 24 & 9.51 & JUL 15 & 9.22 & & \\
\hline
\end{tabular}


Table 14. Discharge measurements and specific conductance at partial-record streamflow sites in the Big-Mishnock stream-aquifer system, central Rhode Island, '1996-98

[ $\mathrm{ft}^{3} / \mathrm{s}$, cubic feet per second; mi, mile; $\mathrm{mi}^{2}$, square mile; $\mu \mathrm{S} / \mathrm{cm}$, microsiemens per centimeter; --, no data available]

\begin{tabular}{|c|c|c|c|c|c|c|c|c|c|c|c|}
\hline Date & $\begin{array}{c}\text { Discharge } \\
\left(\mathrm{ft}^{3} / \mathrm{s}\right)\end{array}$ & $\begin{array}{c}\text { Specific } \\
\text { conduc- } \\
\text { tance } \\
(\mu S / \mathrm{cm})\end{array}$ & Date & $\begin{array}{c}\text { Discharge } \\
\left(\mathrm{ft}^{3} / \mathrm{s}\right)\end{array}$ & $\begin{array}{c}\text { Specific } \\
\text { conduc- } \\
\text { tance } \\
(\mu \mathrm{S} / \mathrm{cm})\end{array}$ & Date & $\begin{array}{c}\text { Discharge } \\
\left(\mathrm{ft}^{3} / \mathrm{s}\right)\end{array}$ & $\begin{array}{c}\text { Specific } \\
\text { conduc- } \\
\text { tance } \\
(\mu \mathrm{S} / \mathrm{cm})\end{array}$ & Date & $\begin{array}{c}\text { Discharge } \\
\left(\mathrm{ft}^{3} / \mathrm{s}\right)\end{array}$ & $\begin{array}{c}\text { Specific } \\
\text { conduc- } \\
\text { tance } \\
(\mu \mathrm{S} / \mathrm{cm})\end{array}$ \\
\hline
\end{tabular}

01115630. Nooseneck River tributary to Big River. Latitude 41 37’36”, longitude 71³7’59”, Kent County, at State Highway 3 , at Nooseneck, and 5.5 mi southwest of

Washington, RI. Drainage area: $8.23 \mathrm{mi}^{2}$. Water years previously measured 1961-63, 1964-81, and 1992-94.

\begin{tabular}{|c|c|c|c|c|c|c|c|c|c|c|c|}
\hline JUL 18,1996 & 9.75 & -- & FEB 20, 1997 & 22.8 & 119 & SEP 17, 1997 & 3.96 & 169 & APR 13,1998 & 27.2 & 98 \\
\hline AUG 15 & 3.24 & 227 & MAR 17 & 21.7 & 125 & OCT 16 & 1.96 & 234 & MAY 19 & 28.4 & 90 \\
\hline SEP 26 & 6.36 & 156 & APR 14 & 42.8 & 110 & NOV 12 & 11.5 & 119 & JUN 25 & 32.6 & -- \\
\hline OCT 16 & 7.00 & 167 & MAY 20 & 17.8 & 129 & DEC 08 & 8.65 & 142 & JUL 15 & 12.0 & -- \\
\hline NOV 21 & 11.0 & -- & JUN 17 & 5.62 & 171 & JAN 15, 1998 & 19.7 & 122 & AUG24 & 4.02 & 141 \\
\hline DEC 30 & 33.1 & -- & JUL 15 & 2.21 & 226 & FEB 17 & 24.0 & -- & SEP 28 & 4.65 & -- \\
\hline JAN 23, 1997 & 29.5 & 124 & AUG 27 & 5.42 & 140 & MAR 24 & 44.6 & 98 & OCT 27 & 5.01 & 121 \\
\hline
\end{tabular}

01115670. Congdon River tributary to Big River. Latitude $41^{\circ} 36^{\prime} 44^{\prime \prime}$, longitude $71^{\circ} 37^{\prime} 24^{\prime \prime}$, Kent County, at Congdon Mill Road, 1.3 mi southeast of Nooseneck, RI.

Drainage area: $4.46 \mathrm{mi}^{2}$. Water years $1961-63$ previously measured.

\begin{tabular}{|c|c|c|c|c|c|c|c|c|c|c|c|}
\hline JUL 18, 1996 & 4.49 & -- & FEB 20, 1997 & 11.5 & 84 & SEP 17,1997 & 2.47 & 96 & APR 13, 1998 & 13.6 & 73 \\
\hline AUG 15 & 3.21 & -- & MAR 17 & 11.4 & 88 & OCT 16 & 1.18 & 102 & MAY 19 & 13.6 & 68 \\
\hline SEP 26 & 3.74 & 105 & APR 14 & 21.8 & 83 & NOV 12 & 5.17 & 95 & JUN 25 & 18.9 & - \\
\hline OCT 16 & 4.29 & 109 & MAY 20 & 10.4 & 87 & DEC 08 & 4.84 & 94 & JUL 15 & 6.52 & - \\
\hline NOV 21 & 6.43 & -- & JUN 17 & 3.58 & 99 & JAN 15,1998 & 10.5 & 89 & AUG 24 & 3.15 & 71 \\
\hline DEC 30 & 15.4 & -- & JUL 15 & .72 & 84 & FEB 17 & 11.1 & 86 & SEP 28 & 3.12 & 74 \\
\hline JAN 23, 1997 & 13.4 & 92.0 & AUG 27 & 1.87 & 101 & MAR 24 & 20.4 & 72 & OCT 27 & 2.40 & 81 \\
\hline
\end{tabular}

01115700. Unnamed tributary to Congdon River. Latitude $41^{\circ} 36^{\prime} 46^{\prime \prime}$, longitude $71^{\circ} 37^{\prime} 06 ”$, Kent County, at Sweet Sawmill Road, 1.3 mi southeast of Nooseneck, RI.

Drainage area: $0.48 \mathrm{mi}^{2}$.

\begin{tabular}{|c|c|c|c|c|c|c|c|c|c|c|c|}
\hline JUL 18, 1996 & 0.62 & -- & FEB 20, 1997 & 1.48 & 50 & SEP 17,1997 & 0.37 & 46 & APR 13,1998 & 1.96 & 46 \\
\hline AUG 15 & .40 & 44 & MAR 17 & 1.28 & 50 & OCT 16 & .33 & 46 & MAY 19 & 1.92 & 45 \\
\hline SEP 26 & .30 & 45 & APR 14 & 2.35 & 47 & NOV 12 & .54 & 50 & JUN 25 & 2.21 & -- \\
\hline OCT 16 & .41 & 47 & MAY 20 & 1.31 & 47 & DEC 08 & .58 & 49 & JUL 15 & 1.44 & -- \\
\hline NOV 21 & .72 & -- & JUN 17 & .70 & 45 & JAN 15, 1998 & .87 & 60 & AUG 24 & .81 & 42 \\
\hline DEC 30 & 1.79 & -- & JUL 15 & .46 & 45 & FEB 17 & 1.39 & 56 & SEP 28 & .66 & 42 \\
\hline JAN 23, 1997 & 1.57 & 52 & AUG 27 & .43 & 46 & MAR 24 & 2.63 & 50 & OCT 27 & .42 & 45 \\
\hline
\end{tabular}


Table 14. Discharge measurements and specific conductance at partial-record streamflow sites in the Big-Mishnock stream-aquifer system, central Rhode Island, 1996-98-Continued

\begin{tabular}{|c|c|c|c|c|c|c|c|c|c|c|c|}
\hline Date & $\begin{array}{c}\text { Discharge } \\
\left(\mathrm{ft}^{3} / \mathbf{s}\right)\end{array}$ & $\begin{array}{c}\text { Specific } \\
\text { conduc- } \\
\text { tance } \\
(\mu \mathrm{S} / \mathrm{cm})\end{array}$ & Date & $\begin{array}{c}\text { Discharge } \\
\left(\mathrm{ft}^{3} / \mathrm{s}\right)\end{array}$ & $\begin{array}{c}\text { Specific } \\
\text { conduc- } \\
\text { tance } \\
(\mu \mathrm{S} / \mathrm{cm})\end{array}$ & Date & $\begin{array}{c}\text { Discharge } \\
\left(\mathrm{ft}^{3} / \mathbf{s}\right)\end{array}$ & $\begin{array}{c}\text { Specific } \\
\text { conduc- } \\
\text { tance } \\
(\mu \mathrm{S} / \mathrm{cm})\end{array}$ & Date & $\begin{array}{c}\text { Discharge } \\
\left(\mathrm{ft}^{3} / \mathrm{s}\right)\end{array}$ & $\begin{array}{c}\text { Specific } \\
\text { conduc- } \\
\text { tance } \\
(\mu \mathrm{S} / \mathrm{cm})\end{array}$ \\
\hline
\end{tabular}

01115730. Carr River tributary to Capwell Mill Pond. Latitude $41^{\circ} 38^{\prime} 01^{\prime}$, longitude $71^{\circ} 34^{\prime} 52^{\prime}$, Kent County, at New London Turnpike, 4 mi southwest of Washington, RI.

Drainage area: $2.88 \mathrm{mi}^{2}$.

\begin{tabular}{|c|c|c|c|c|c|c|c|c|c|c|c|}
\hline JUL, 1996 & -- & -- & FEB 21, 1997 & 8.79 & 47 & SEP 17, 1997 & 0.78 & 52 & APR 13, 1998 & 12.4 & 46 \\
\hline AUG & -- & -- & MAR 18 & 6.72 & 49 & OCT & -- & -- & MAY 20 & 13.6 & 43 \\
\hline SEP & -- & -- & APR 14 & 16.5 & -- & NOV 12 & 2.83 & 41 & JUN 25 & 13.2 & -- \\
\hline OCT & -- & -- & MAY 20 & 8.20 & 47 & DEC 09 & 2.64 & 50 & JUL 16 & 5.42 & 50 \\
\hline NOV & -- & -- & JUN 17 & 2.23 & 48 & JAN 15, 1998 & 7.74 & 44 & AUG 24 & 2.92 & 62 \\
\hline DEC & -- & -- & JUL 15 & .24 & 49.7 & FEB 17 & 10.8 & 43.5 & SEP 29 & 1.06 & 53.1 \\
\hline JAN 24, 1997 & 8.37 & 50.2 & AUG 27 & .49 & 52.9 & MAR 24 & 21.7 & 42.2 & OCT 27 & 1.12 & 58.9 \\
\hline
\end{tabular}

01115770. Carr River tributary to Big River. Latitude 41 $38^{\prime} 35^{\prime \prime}$, longitude $71^{\circ} 36^{\prime} 30^{\prime \prime}$, Kent County, at Burnt Sawmill Road, 1.5 mi northeast of Nooseneck, RI and 4 mi southwest of Washington, RI. Drainage area: $7.33 \mathrm{mi}^{2}$. Water years $1964-80$ and 1995-96 previously measured.

\begin{tabular}{|c|c|c|c|c|c|c|c|c|c|c|c|}
\hline JUL 18, 1996 & 8.62 & -- & FEB 20, 1997 & 16.0 & 51 & SEP 17, 1997 & 1.80 & 48 & APR 13, 1998 & 20.6 & 48 \\
\hline AUG 15 & 5.52 & 41 & MAR 18 & 14.7 & 46 & OCT 16 & 1.00 & 49 & MAY 19 & 21.1 & 45 \\
\hline SEP 26 & 4.66 & 44 & APR 14 & 29.6 & 42 & NOV 12 & 7.32 & 57 & JUN 25 & 22.9 & - \\
\hline OCT 16 & 4.47 & 47 & MAY 20 & 13.3 & 41 & DEC 08 & 5.97 & 55 & JUL 15 & 9.87 & - \\
\hline NOV 21 & 8.09 & -- & JUN 17 & .41 & 47 & JAN 15, 1998 & 13.9 & 49 & AUG 24 & 3.43 & 47 \\
\hline DEC 30 & 20.4 & -- & JUL 15 & .94 & 43 & FEB 17 & 17.1 & 52 & SEP 28 & 2.68 & 44 \\
\hline JAN 23, 1997 & 19.4 & -- & AUG 27 & 3.19 & 45 & MAR 24 & 28.9 & 49 & OCT 27 & 2.62 & 51 \\
\hline
\end{tabular}

01115800. Big River tributary to Pawtuxet River. Latitude 41 $38^{\prime} 41^{\prime \prime}$, longitude $71^{\circ} 36^{\prime} 48^{\prime \prime}$, Kent County, at State Highway $3,0.6$ mi east of Kitts Corner, RI.

Drainage area: $23.1 \mathrm{mi}^{2}$. Water years $1992-96$ previously measured.

\begin{tabular}{|c|c|c|c|c|c|c|c|c|c|c|c|}
\hline JUL 18, 1996 & 24.9 & -- & FEB 20, 1997 & 59.0 & 113 & SEP 18,1997 & 9.45 & 117.0 & APR 14, 1998 & 68.1 & 81 \\
\hline AUG 15 & 16.4 & 110 & MAR 17 & 59.0 & 97 & OCT 17 & 5.83 & 128 & MAY 19 & 71.9 & 74 \\
\hline SEP 27 & 14.4 & 108 & APR 15 & 102 & 80 & NOV 12 & 31.4 & 96 & JUN 26 & 80.9 & - \\
\hline OCT 16 & 17.9 & 117 & MAY 21 & 43.8 & 96 & DEC 08 & 26.3 & 107 & JUL 15 & 32.7 & - \\
\hline NOV 21 & 30.9 & -- & JUN 18 & 15.4 & 110 & JAN 15, 1998 & 51.9 & 98 & AUG 25 & 12.6 & 86 \\
\hline DEC 30 & 79.6 & -- & JUL 16 & 7.82 & 119 & FEB 17 & 62.7 & 94 & SEP 29 & 11.8 & 90 \\
\hline JAN 23, 1997 & 71.5 & 101 & AUG 28 & 10.6 & 106 & MAR 25 & 121 & 82 & OCT 27 & 8.11 & 96 \\
\hline
\end{tabular}


Table 14. Discharge measurements and specific conductance at partial-record streamflow sites in the Big-Mishnock stream-aquifer system, central Rhode Island, 1996-98-Continued

\begin{tabular}{|c|c|c|c|c|c|c|c|c|c|c|c|}
\hline Date & $\begin{array}{c}\text { Discharge } \\
\left(\mathrm{ft}^{3} / \mathrm{s}\right)\end{array}$ & $\begin{array}{c}\text { Specific } \\
\text { conduc- } \\
\text { tance } \\
(\mu \mathrm{S} / \mathrm{cm})\end{array}$ & Date & $\begin{array}{c}\text { Discharge } \\
\left(\mathrm{ft}^{3} / \mathrm{s}\right)\end{array}$ & $\begin{array}{c}\text { Specific } \\
\text { conduc- } \\
\text { tance } \\
(\mu \mathrm{S} / \mathrm{cm})\end{array}$ & Date & $\begin{array}{c}\text { Discharge } \\
\left(\mathrm{ft}^{3} / \mathrm{s}\right)\end{array}$ & $\begin{array}{c}\text { Specific } \\
\text { conduc- } \\
\text { tance } \\
(\mu \mathrm{S} / \mathrm{cm})\end{array}$ & Date & $\begin{array}{c}\text { Discharge } \\
\left(\mathrm{ft}^{3} / \mathrm{s}\right)\end{array}$ & $\begin{array}{c}\text { Specific } \\
\text { conduc- } \\
\text { tance } \\
(\mu \mathrm{S} / \mathrm{cm})\end{array}$ \\
\hline
\end{tabular}

01115830. Bear Brook tributary to Pawtuxet River. Latitude 4139’37”, longitude 71³7'42”, Kent County, at Fish Hill Road, 3 mi southeast of Coventry, RI.

Drainage area: $3.98 \mathrm{mi}^{2}$. Water years $1961-63$ previously measured.

\begin{tabular}{|c|c|c|c|c|c|c|c|c|c|c|c|}
\hline JUL 18, 1996 & 2.04 & -- & FEB 21, 1997 & 9.46 & 89 & SEP 18, 1997 & 1.05 & 97 & APR 14, 1998 & 10.7 & 73 \\
\hline AUG 16 & 1.38 & 95 & MAR 18 & 8.93 & 87 & OCT 17 & .56 & 119 & MAY 20 & 9.96 & 73 \\
\hline SEP 27 & 1.57 & 96 & APR 15 & 13.6 & 80 & NOV 13 & 4.52 & 80 & JUN 26 & 11.0 & -- \\
\hline OCT 17 & 1.65 & 101 & MAY 21 & 7.60 & 82 & DEC 09 & 4.68 & 92 & JUL 16 & 3.54 & 69 \\
\hline NOV 22 & 5.12 & -- & JUN 18 & 1.67 & 100 & JAN 15, 1998 & 10.5 & 86 & AUG 25 & 1.06 & 80 \\
\hline DEC 31 & 13.1 & -- & JUL 16 & 1.29 & 117 & FEB 17 & 11.7 & 85 & SEP 29 & .45 & 74 \\
\hline JAN 24, 1997 & 10.1 & 92 & AUG 27 & .62 & 101 & MAR 25 & 17.7 & 73 & OCT 28 & 1.06 & 81 \\
\hline
\end{tabular}

01115963. Old Hickory Brook tributary to Pawtuxet River. Latitude 4139’23”, longitude $71^{\circ} 36^{\prime} 00^{\prime}$, Kent County, at Mishnock Road, 1.5 mi northeast of Kitts Corner, RI.

Drainage area: $0.33 \mathrm{mi}^{2}$

\begin{tabular}{|c|c|c|c|c|c|c|c|c|c|c|c|}
\hline JUL 18, 1996 & 0.08 & -- & FEB 21, 1997 & 0.42 & 487 & SEP 18, 1997 & 0.05 & 329 & APR 14, 1998 & 0.50 & 375 \\
\hline AUG 16 & .08 & 410 & MAR18 & .30 & 566 & OCT 17 & .02 & 333 & MAY 20 & .54 & 348 \\
\hline SEP 27 & .11 & 403 & APR 15 & .51 & 538 & NOV 13 & .19 & 350 & JUN 26 & .57 & -- \\
\hline OCT 17 & .09 & 393 & MAY 21 & .27 & 377 & DEC 09 & .13 & 374 & JUL 16 & .16 & 228 \\
\hline NOV 22 & .25 & -- & JUN 18 & .06 & 303 & JAN 15, 1998 & .35 & 610 & AUG 25 & .03 & 183 \\
\hline DEC 31 & .46 & -- & JUL 16 & .05 & 297 & FEB 17 & .52 & 545 & SEP 29 & .02 & 218 \\
\hline JAN 24, 1997 & .33 & 449 & AUG 27 & .03 & 293 & MAR 25 & .76 & 459 & OCT 28 & .03 & 260 \\
\hline
\end{tabular}

01115965. Outflow of Lake Mishnock tributary to Pawtuxet River. Latitude 41³9’20”, longitude 71³5'28”, Kent County, at Mishnock Road, 1.9 mi northeast of Kitts Corner, RI.

Drainage area: $0.29 \mathrm{mi}^{2}$.

\begin{tabular}{|c|c|c|c|c|c|c|c|c|c|c|c|}
\hline JUL 18, 1996 & 3.76 & -- & FEB 21, 1997 & 3.78 & 219 & SEP 18,1997 & 2.73 & 282 & APR 14, 1998 & 4.77 & 278 \\
\hline AUG 16 & 2.99 & 266 & MAR 18 & 3.78 & 282 & OCT 17 & 2.28 & 290 & MAY 20 & 4.89 & 276 \\
\hline SEP 27 & 2.92 & 269 & APR 15 & 4.64 & 209 & NOV 13 & 3.33 & 212 & JUN 26 & 4.98 & 244 \\
\hline OCT 17 & 2.62 & 266 & MAY 21 & 3.95 & 279 & DEC 09 & 3.55 & 300 & JUL 16 & 4.49 & 280 \\
\hline NOV 22 & 3.36 & -- & JUN 18 & 3.36 & 285 & JAN 15, 1998 & 3.15 & 295 & AUG 25 & 3.30 & 301 \\
\hline DEC 31 & 3.70 & -- & JUL 16 & 3.16 & 290 & FEB 17 & 8.33 & 285 & SEP 29 & 2.70 & 312 \\
\hline JAN 24, 1997 & 4.81 & 276 & AUG 27 & 3.06 & 286 & MAR 25 & 5.79 & 270 & OCT 28 & 3.01 & 312 \\
\hline
\end{tabular}


Table 14. Discharge measurements and specific conductance at partial-record streamflow sites in the Big-Mishnock stream-aquifer system, central Rhode Island, 1996-98-Continued

\begin{tabular}{|c|c|c|c|c|c|c|c|c|c|c|c|}
\hline Date & $\begin{array}{c}\text { Discharge } \\
\left(\mathrm{ft}^{3} / \mathbf{s}\right)\end{array}$ & $\begin{array}{c}\text { Specific } \\
\text { conduc- } \\
\text { tance } \\
(\mu \mathrm{S} / \mathrm{cm})\end{array}$ & Date & $\begin{array}{c}\text { Discharge } \\
\left(\mathrm{ft}^{3} / \mathbf{s}\right)\end{array}$ & $\begin{array}{c}\text { Specific } \\
\text { conduc- } \\
\text { tance } \\
(\mu \mathrm{S} / \mathrm{cm})\end{array}$ & Date & $\begin{array}{c}\text { Discharge } \\
\left(\mathrm{ft}^{3} / \mathbf{s}\right)\end{array}$ & $\begin{array}{c}\text { Specific } \\
\text { conduc- } \\
\text { tance } \\
(\mu \mathrm{S} / \mathrm{cm})\end{array}$ & Date & $\begin{array}{l}\text { Discharge } \\
\left(\mathrm{ft}^{3} / \mathbf{s}\right)\end{array}$ & $\begin{array}{c}\text { Specific } \\
\text { conduc- } \\
\text { tance } \\
(\mu \mathrm{S} / \mathrm{cm})\end{array}$ \\
\hline
\end{tabular}

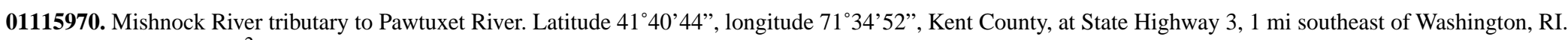

Drainage area: $3.32 \mathrm{mi}^{2}$. Water years $1961-63$ previously measured.

\begin{tabular}{|c|c|c|c|c|c|c|c|c|c|c|c|}
\hline JUL 18, 1996 & 5.86 & -- & FEB 21, 1997 & 8.85 & 189 & SEP 18,1997 & 3.15 & 243 & APR 14, 1998 & 9.60 & 187 \\
\hline AUG 16 & 3.69 & 232 & MAR 18 & 8.95 & 189 & OCT 17 & 2.43 & 262 & MAY 20 & 8.28 & 187 \\
\hline SEP 27 & 4.58 & 205 & APR 15 & 12.9 & 177 & NOV 13 & 6.43 & 183 & JUN 26 & 9.28 & 162 \\
\hline OCT 17 & 4.27 & 197 & MAY 21 & 7.57 & 164 & DEC 09 & 4.42 & 204 & JUL 16 & 4.98 & 247 \\
\hline NOV 22 & 5.33 & -- & JUN 18 & 3.48 & 266 & JAN 15, 1998 & 7.40 & 182 & AUG 25 & 2.93 & 288 \\
\hline DEC 31 & 9.49 & -- & JUL 16 & 3.15 & -- & FEB 17 & 9.68 & 212 & SEP 29 & 3.28 & 258 \\
\hline JAN 24, 1997 & 9.59 & 181 & AUG 28 & 3.28 & 255 & MAR 25 & 12.8 & 178 & OCT 28 & 3.54 & 248 \\
\hline
\end{tabular}


Table 15. Specific conductance and temperature at selected surface-water sites in the Big-Mishnock stream-aquifer system, central Rhode Island, 1997-98

[Site locations are shown on plate 1. No., number; $\mu \mathrm{S} / \mathrm{cm}$, microsiemens per centimeter at $25^{\circ} \mathrm{C} ;{ }^{\circ} \mathrm{C}$, degrees Celsius; --, no data available]

\begin{tabular}{|c|c|c|c|c|c|c|c|c|c|}
\hline \multirow[b]{2}{*}{$\begin{array}{l}\text { Site } \\
\text { No. }\end{array}$} & \multirow[b]{2}{*}{ Location of selected surface-water sites } & \multicolumn{2}{|c|}{ April 16, 1997} & \multicolumn{2}{|c|}{ October 21, 1997} & \multicolumn{2}{|c|}{ April 22, 1998} & \multicolumn{2}{|c|}{ October 23, 1998} \\
\hline & & $\begin{array}{c}\text { Specific } \\
\text { conduc- } \\
\text { tance } \\
(\mu \mathrm{S} / \mathrm{cm})\end{array}$ & $\begin{array}{c}\text { Tempe- } \\
\text { rature } \\
\left({ }^{\circ} \mathrm{C}\right)\end{array}$ & $\begin{array}{c}\text { Specific } \\
\text { conduc- } \\
\text { tance } \\
(\mu \mathrm{S} / \mathrm{cm})\end{array}$ & $\begin{array}{c}\text { Tempe- } \\
\text { rature } \\
\left({ }^{\circ} \mathrm{C}\right)\end{array}$ & $\begin{array}{c}\text { Specific } \\
\text { conduc- } \\
\text { tance } \\
(\mu \mathrm{S} / \mathrm{cm})\end{array}$ & $\begin{array}{c}\text { Tempe- } \\
\text { rature } \\
\left({ }^{\circ} \mathrm{C}\right)\end{array}$ & $\begin{array}{c}\text { Specific } \\
\text { conduc- } \\
\text { tance } \\
(\mu \mathrm{S} / \mathrm{cm})\end{array}$ & $\begin{array}{c}\text { Tempe- } \\
\text { rature } \\
\left({ }^{\circ} \mathrm{C}\right)\end{array}$ \\
\hline 1 & Nooseneck River at Sharp Street & 43 & 11.3 & 56 & 13.7 & 40 & 14.6 & 54 & 9.3 \\
\hline 2 & Nooseneck River at Fry School Road & 47 & 12.7 & 60 & 16.2 & 48 & 14.5 & 55 & 9.3 \\
\hline 3 & Unnamed tributary to Nooseneck River at unnamed road & 47 & 10.5 & 48 & 9.9 & 40 & 12.4 & 44 & 7.4 \\
\hline 4 & Raccoon Brook at Robin Hollow Road & 295 & 10.5 & 340 & 9.7 & 235 & 12.6 & 251 & 7.8 \\
\hline 5 & Unnamed tributary \#1 to Nooseneck River at Yard Pond outlet & 35 & 13.9 & 39 & 9.2 & 33 & 17.6 & -- & -- \\
\hline 6 & Nooseneck River at State Highway Route 3 & 113 & 13.2 & 251 & 9.3 & 94 & 10.6 & 173 & 6.7 \\
\hline 7 & $\begin{array}{l}\text { Unnamed tributary \#2 to Nooseneck River at unnamed pond } \\
\text { outlet, West of Nooseneck Hill Road }\end{array}$ & 228 & 11.2 & -- & -- & 179 & 11.2 & -- & -- \\
\hline 8 & $\begin{array}{l}\text { Unnamed tributary \#2 to Nooseneck River, West of Nooseneck } \\
\text { Hill Road, between sites } 7 \text { and } 9\end{array}$ & 265 & -- & -- & -- & -- & -- & 272 & 8.1 \\
\hline 9 & $\begin{array}{l}\text { Unnamed tributary \#2 to Nooseneck River as State Highway } \\
\text { Route } 3\end{array}$ & 270 & 11.0 & 455 & 10.4 & 20 & 10.3 & 274 & 8.4 \\
\hline 10 & Congdon River at Pine Hill Road & 38 & 7.9 & 436 & 8.4 & 34 & 10.9 & 44 & 6.6 \\
\hline 11 & Unnamed tributary \#1 to Congdon River at Pine Hill Road & 100 & 10.1 & -- & -- & 35 & 14.8 & 86 & 7.2 \\
\hline 12 & Unnamed tributary \#2 to Congdon River at New London Turnpike & 83 & 11.3 & 99 & 4.9 & 67 & 15.7 & 81 & 10.1 \\
\hline 13 & Congdon River at Congdon Mill Road & 84 & 9.1 & 101 & 8.8 & 66 & 13.1 & 80 & 7.7 \\
\hline 14 & Unnamed tributary \#3 to Congdon River at New London Turnpike & 54 & 10.4 & -- & -- & 45 & 17.3 & 53 & 8.6 \\
\hline 15 & Unnamed tributary \#3 to Congdon River at Sweet Sawmill Road & 48 & 7.6 & 47 & 9.2 & 43 & 12.1 & 45 & 7.9 \\
\hline 16 & Carr River at Carr Pond outlet & 33 & 10.5 & 37 & 13.9 & 32 & 13.4 & 32 & 14.6 \\
\hline 17 & Unnamed tributary \#1 to Carr River at New London Turnpike & 86 & 8.7 & -- & -- & 83 & 10.8 & 108 & 7.5 \\
\hline 18 & Carr River at Hopkins Hill Road, at outlet of Tarbox Pond & 44 & 11.4 & 60 & 11.8 & 43 & 14.1 & 66 & 10.9 \\
\hline 19 & Carr River at New London Turnpike & 44 & 10.6 & 51 & 12.6 & 42 & 13.2 & 59 & 9.8 \\
\hline 20 & Unnamed tributary \#2 to Carr River at Hopkins Hill Road & 46 & 9.5 & -- & -- & 43 & 8.5 & 49 & 6.9 \\
\hline 21 & Unnamed tributary \#3 to Carr River at Hopkins Hill Road & 41 & 14.0 & 95 & 11.6 & 323 & 11.2 & 660 & 9.7 \\
\hline 22 & Unnamed tributary \#3 to Carr River at Division Road & 408 & 13.0 & 918 & 9.7 & 336 & 10.1 & 648 & 7.0 \\
\hline 23 & Quarry Pond at old gravel pit, off Division Road & 229 & 12.4 & 216 & 14.7 & 173 & 15.7 & 267 & 11.4 \\
\hline 24 & Unnamed tributary \#3 to Carr River at unnamed dirt road & 346 & 10.5 & -- & -- & 252 & 13.8 & -- & -- \\
\hline 25 & Mud Bottom Brook at Sweet Sawmill Road & 36 & 7.5 & -- & -- & 35 & 14.2 & 40 & 7.1 \\
\hline
\end{tabular}


Table 15. Specific conductance and temperature at selected surface-water sites in the Big-Mishnock stream-aquifer system, central Rhode Island, 1997-98 -Continued

\begin{tabular}{|c|c|c|c|c|c|c|c|c|c|}
\hline \multirow[b]{2}{*}{$\begin{array}{l}\text { Site } \\
\text { No. }\end{array}$} & \multirow[b]{2}{*}{ Location of selected surface-water sites } & \multicolumn{2}{|c|}{ April 16, 1997} & \multicolumn{2}{|c|}{ October 21, 1997} & \multicolumn{2}{|c|}{ April 22, 1998} & \multicolumn{2}{|c|}{ October 23, 1998} \\
\hline & & $\begin{array}{c}\text { Specific } \\
\text { conduc- } \\
\text { tance } \\
(\mu \mathrm{S} / \mathrm{cm})\end{array}$ & $\begin{array}{c}\text { Tempe- } \\
\text { rature } \\
\left({ }^{\circ} \mathrm{C}\right)\end{array}$ & $\begin{array}{c}\text { Specific } \\
\text { conduc- } \\
\text { tance } \\
(\mu \mathrm{S} / \mathrm{cm})\end{array}$ & $\begin{array}{l}\text { Tempe- } \\
\text { rature } \\
\left.\text { ( }{ }^{\circ} \mathrm{C}\right)\end{array}$ & $\begin{array}{c}\text { Specific } \\
\text { conduc- } \\
\text { tance } \\
(\mu \mathrm{S} / \mathrm{cm})\end{array}$ & $\begin{array}{c}\text { Tempe- } \\
\text { rature } \\
\left({ }^{\circ} \mathrm{C}\right)\end{array}$ & $\begin{array}{c}\text { Specific } \\
\text { conduc- } \\
\text { tance } \\
(\mu \mathrm{S} / \mathrm{cm})\end{array}$ & $\begin{array}{c}\text { Tempe- } \\
\text { rature } \\
\left({ }^{\circ} \mathrm{C}\right)\end{array}$ \\
\hline 26 & Unnamed tributary \#4 to Carr River at Sweet Sawmill Road & 47 & 6.8 & 39.1 & 6.6 & 42 & 12.2 & 44 & 7.4 \\
\hline 27 & Carr River at Burnt Sawmill Road & 47 & 11.5 & 48 & 10.1 & 47 & 14.1 & 53 & 10.0 \\
\hline 28 & Big River as State Highway Route 3 & 94 & 12.0 & 132 & 9.3 & 80 & 12.2 & 100 & 8.6 \\
\hline 29 & Unnamed tributary \#1 to Big River at Rice Trail & 55 & 13.0 & -- & -- & 49 & 14.1 & 73 & 8.6 \\
\hline 30 & Unnamed tributary \#1 to Bear Brook at Harkney Hill Road & 168 & 9.5 & -- & -- & 127 & 12.4 & -- & -- \\
\hline 31 & Unnamed tributary \#1 to Bear Brook at Rice Trail & 141 & 9.5 & -- & -- & 113 & 12.6 & -- & -- \\
\hline 32 & Unnamed tributary \#2 to Bear Brook at Harkney Hill Road & 224 & 7.5 & -- & -- & 148 & 10.3 & -- & -- \\
\hline 33 & Unnamed tributary \#2 to Bear Brook at Rice Trail & 273 & 11.0 & 264 & 10.3 & 185 & 13.2 & 130 & 8.5 \\
\hline 34 & Unnamed tributary \#3 to Bear Brook at Fish Hill Road & 50 & 7.5 & 54 & 10.5 & 46 & 10.4 & 47 & 6.8 \\
\hline 35 & Unnamed tributary \#3 to Bear Brook at Rice Trail & 41 & 11.5 & 41 & 7.7 & 37 & 14 & 39 & 7.6 \\
\hline 36 & Unnamed tributary \#4 to Bear Brook at Harkney Hill Road & 50 & 7.5 & 267 & 10.2 & 44 & 11.1 & 44 & 5.7 \\
\hline 37 & Bear Brook at Fish Hill Road & 85 & 8.5 & 109 & 7.0 & 67 & 11.0 & 83 & 6.3 \\
\hline 38 & Big River at Harkney Hill Road & 129 & 12.5 & 131 & 10.7 & 78 & 12.7 & 96 & 10.2 \\
\hline 39 & Old Hickory Brook at Mishnock Road & 530 & 11.5 & 335 & 10.3 & 336 & 11.9 & 278 & 7.6 \\
\hline 40 & Mishnock River at Mishnock Road, at Lake Mishnock outlet & 270 & 14.0 & 293 & 15.3 & 255 & 15.5 & 327 & 13.4 \\
\hline 41 & Mishnock River as State Highway Route 3 & 188 & 10.0 & 268 & 9.6 & 156 & 11.8 & 257 & 8.8 \\
\hline
\end{tabular}


Table 16. Lithologic logs of selected wells and test holes in the Big-Mishnock stream-aquifer system, central Rhode Island

[Depth in feet below land surface. COW, Coventry well; WGW, West Greenwich well. Description of the sediment: Wentworth grade scale was used for logs described by geologist; SS, split spoon; ft, foot]

\begin{tabular}{|c|c|}
\hline \multicolumn{2}{|c|}{ Wentworth Grade Scale } \\
\hline $\begin{array}{l}\text { Grain size in } \\
\text { millimeters }\end{array}$ & Sediment term \\
\hline & Boulder \\
\hline \multirow[t]{2}{*}{256} & $-\ldots-\ldots$ \\
\hline & Cobble \\
\hline \multirow[t]{2}{*}{64} & $-\ldots-\ldots$ \\
\hline & Pebble \\
\hline \multirow[t]{2}{*}{4} & - - - - - - - \\
\hline & Granule \\
\hline \multirow[t]{2}{*}{2} & - - - - - - - \\
\hline & Very coarse sand \\
\hline \multirow[t]{2}{*}{1} & $-\ldots-\ldots$ \\
\hline & Coarse sand \\
\hline \multirow[t]{2}{*}{0.5} & $-\ldots$ \\
\hline & Medium sand \\
\hline \multirow[t]{2}{*}{0.25} & 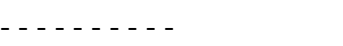 \\
\hline & Fine sand \\
\hline \multirow[t]{2}{*}{0.125} & $-\ldots$ \\
\hline & Very fine sand \\
\hline \multirow[t]{2}{*}{0.062} & $-\ldots$ \\
\hline & Silt \\
\hline \multirow[t]{2}{*}{0.004} & $-\ldots-\ldots$ \\
\hline & Clay \\
\hline
\end{tabular}

The following terms were used to approximate the percentage of grain sizes in a sample described by geologist.

\begin{tabular}{lr}
\hline \multicolumn{1}{c}{ Term } & Percent \\
\hline trace & $0-10$ \\
little & $10-20$ \\
some & $20-35$ \\
with & $35-49$ \\
and & 50 \\
\hline
\end{tabular}


Table 16. Lithologic logs of selected wells and test holes in the Big-Mishnock stream-aquifer system, central Rhode Island -Continued

\begin{tabular}{ll}
\hline \multirow{2}{*}{ Description } & \multicolumn{2}{c}{ Depth (ft) } \\
\cline { 2 - 2 } & From $\quad$ To \\
\hline
\end{tabular}

\section{COW 479}

Sand, very fine to very coarse; interbedded; some silt; little granule gravel, light brown......

Silt and very fine sand; light brownish gray......... Silt; some very fine sand; light brownish gray..... Silt and very fine sand; light brownish gray......... Sand, very fine and silt; light brownish gray........ Sand, very fine; some silt; light brownish gray.... Refusal

$\begin{array}{cl}0 & 21 \\ 21 & 28 \\ 28 & 35 \\ 35 & 42.5 \\ 42.5 & 49.5 \\ 49.5 & 63 \\ & 63\end{array}$

\section{WGW 285}

Sand, fine to medium; trace coarse; dark brown

Sand, fine to medium; medium brown

Sand, fine to coarse; granule gravel; medium brown .

Sand, fine; trace silt; light brown; damp

Sand, fine; trace silt; light brown; wet

Sand, fine; trace silt; light to medium brown; wet

Sand, fine; trace silt; light to medium brown .......

No returns

Refusal, probable bedrock

\section{WGW 286}

Sand, fine to medium; medium brown

Sand, fine to medium; light brown

Sand, fine to coarse; some gravel; light brown ....

Sand, medium; some gravel; little fine sand;

light brown

Sand, medium; light brown

Sand, fine to medium; light brown.

Sand, very fine; light brown

No returns

Refusal, possibly till or bedrock

\section{WGW 287}

Sand, medium; medium brown

Sand, medium to coarse; medium brown.

Sand, medium to coarse; little gravel; medium brown

Sand, medium to coarse; medium brown.

Sand, medium to coarse; some gravel; medium brown

Sand, medium to coarse; medium brown.............

Sand, medium to coarse; some gravel; medium brown

Refusal, possibly boulder or bedrock...

\begin{tabular}{ll}
\hline \multirow{2}{*}{ Description } & \multicolumn{2}{c}{ Depth $(\mathrm{ft})$} \\
\cline { 2 - 2 } & From $\quad$ To \\
\hline
\end{tabular}

\section{WGW 288}

Sand, fine to very fine; trace silt; medium brown .....

$0 \quad 1.5$

Sand, medium to coarse; some gravel

$1.5 \quad 12$

Sand, medium to coarse; little gravel

$12 \quad 23$

Refusal, probable boulder

\section{WGW 289}

Sand, fine to medium; trace granule to pebble gravel; light brown

Sand, medium; trace granule and pebble gravel; light brown

Sand, medium to coarse; some very coarse sand to granule gravel; trace pebble gravel......

Sand, very fine, interbedded with coarse sand; some pebbles

Sand, medium to very coarse; some granule gravel.

Sand, fine to medium, interbedded with coarse to very coarse sand with granule gravel; light brown

Sand, medium to coarse; little very coarse; little granule gravel; trace fine

Sand, medium to coarse; trace very fine sand; trace very coarse sand; trace granule gravel.....

Sand, medium to coarse; trace very coarse sand; trace granule gravel

Refusal, probable bedrock.

\section{WGW 290}

Sand, fine to medium; trace granule to pebble gravel; light brown

Sand, medium; trace granule to pebble gravel; light brown

Sand, medium to coarse; some very coarse sand to granule gravel, trace pebble gravel......

Sand, interbedded, very fine to coarse; some pebble gravel

Sand, medium to very coarse; some granule gravel

Bottom of hole

\section{WGW 291}

Organics, dark brown to black; little fine sand .... Sand, very fine with silt; light brown; interbedded with silt with very fine sand light grey brown..

Silt, trace fine sand, light gray.

No returns.

Refusal, possible boulder or bedrock.

\section{$0 \quad 2$}

26

$6 \quad 57$

$30 \quad 50$ 
Table 16. Lithologic logs of selected wells and test holes in the Big-Mishnock stream-aquifer system, central Rhode Island -Continued

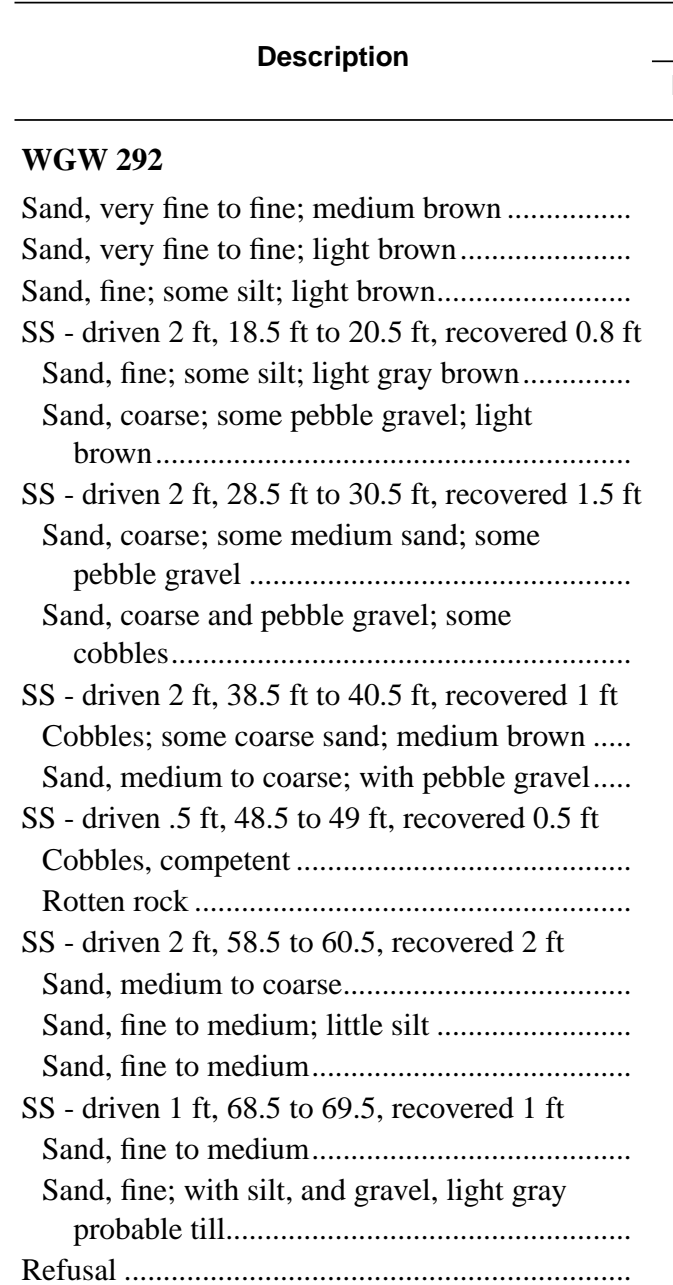

\section{WGW 293}

Sand, very fine to fine; medium brown ................

Sand, very fine to fine; light brown ......................

Sand, fine; some silt; light brown

Bottom of hole

\section{WGW 294}

Organic layer; dark brown to black.

Sand, fine; with silt; medium brown

Sand, medium to coarse; medium brown

Sand, fine to medium; with silt; medium brown

Silt; with fine sand; medium brown ....

Silt; with fine sand; some coarse sand; some

pebble gravel; medium brown.

Refusal, possible boulder

\begin{tabular}{ll}
\multicolumn{2}{c}{ Depth (ft) } \\
\hline From To \\
\hline
\end{tabular}

$0 \quad 1.5$

$1.5 \quad 15$

$15 \quad 18.5$

$18.5 \quad 18.6$

$18.6 \quad 19.3$

$28.5 \quad 29$

$38.5 \quad 39.1$

$39.1 \quad 39.5$

$48.5 \quad 48.8$

$48.8 \quad 49$

$58.5 \quad 58.7$

$58.7 \quad 59.1$

$59.1 \quad 60.5$

$68.5 \quad 68.7$

$68.7 \quad 69.5$

73

$\begin{array}{ll}0 & 1.5\end{array}$

$1.5 \quad 15$

$15 \quad 21$

Sand, very fine; with silt; topsoil; medium gray brown

Sand, very fine; with silt; medium gray brown...

Description

Depth (ft)

From To

$\begin{array}{lr}0 & 1 \\ 1 & 24 \\ & 24\end{array}$

$29 \quad 30$

Bottom of hole

\section{WGW 296}

Sand, fine; dark brown.

Sand, medium to coarse; little fine sand; some gravel.

Gravel, sub-rounded; with coarse sand..

Sand, fine; light brown...

No returns; probable gravel layer .

Sand, fine; light brown; damp..

No returns; probable gravel layer .

Sand, fine; trace gravel; light brown

Sand, coarse; with gravel

Easy drilling, no change in cuttings.

Possible boulder or bedrock ...

Refusal

\section{WGW 297}

Sand, fine; medium brown

Sand, fine to coarse; with gravel; light to medium brown

Sand, fine; light brown.

Sand, very fine; light gray brown...

Sand, very fine; with silt; light gray brow

Sand, very fine; with silt; trace gravel

Sand fine to medium; light gray brown ...........

Sand, fine to medium; light gray brown

Sand, medium; medium brown

Sand, medium; some fine sand; light gray brown.

Sand, very fine; with silt; light gray.

Bottom of hole

24

\section{WGW 298}

$0 \quad 1.5$

1.54

48

Sand, fine; little silt; medium to dark brown .......

Sand, very fine; some silt; light brown ................

Sand, very fine; with silt; light gray.

Sand, very fine to fine; some silt; light brown .....

Sand, very fine; with silt; light gray; damp..........

Sand, very fine; with silt; light gray; very damp.

Sand, very fine; with silt; light gray; wet.

Bottom of hole...

$\begin{array}{cc}0 & .5 \\ .5 & 1.5 \\ 1.5 & 7 \\ 7 & 12 \\ 12 & 16 \\ & \\ 16 & 20 \\ 20 & 34 \\ & 34\end{array}$


Table 16. Lithologic logs of selected wells and test holes in the Big-Mishnock stream-aquifer system, central Rhode Island -Continued

\begin{tabular}{ll}
\hline \multirow{2}{*}{ Description } & \multicolumn{2}{c}{ Depth (ft) } \\
\cline { 2 - 2 } & From To \\
\hline
\end{tabular}

WGW 299

Sand, fine to medium; some coarse; light brown

Sand, fine to medium; light brown

Sand, fine to medium; trace gravel; light brown

Sand, fine to medium; light brown........en.2.2...

Sand, fine to medium; trace gravel; light brown

Bottom of hole

\section{WGW 300}

Sand, fine to medium; trace silt; medium to dark brown

Sand, fine; with silt; trace gravel; medium brown

Sand, fine; some silt; medium brown.

Sand, very fine; with silt; light gray brown..........

Bottom of hole

\section{WGW 301}

Sand, fine to medium; trace silt; medium to dark brown

Sand, fine; with silt; trace gravel; medium brown

Sand, fine; some silt; medium brown.....

Sand, very fine; with silt; light gray brown

$\mathrm{SS}$ - driven $2 \mathrm{ft}, 8 \mathrm{ft}$ to $10 \mathrm{ft}$, recovered $2 \mathrm{ft}$

Sand, very fine; with silt; light gray brown .......

SS - driven $2 \mathrm{ft}, 18 \mathrm{ft}$ to $20 \mathrm{ft}$, recovered $1.5 \mathrm{ft}$

Sand, very fine; light gray brown ...

SS - driven $2 \mathrm{ft}, 28 \mathrm{ft}$ to $30 \mathrm{ft}$, recovered $2 \mathrm{ft}$

Sand, fine to very fine; little silt; light gray brown...

Sand, very fine; with silt; light gray brown ........

$\mathrm{SS}$ - driven $2 \mathrm{ft}, 38 \mathrm{ft}$ to $40 \mathrm{ft}$, recovered $1.5 \mathrm{ft}$

Sand, very fine; with silt; light gray brown .......

$\mathrm{SS}$ - driven $2 \mathrm{ft}, 48 \mathrm{ft}$ to $50 \mathrm{ft}$, recovered $1.5 \mathrm{ft}$

Sand; very fine to fine; some silt; light gray brown

Sand; medium to coarse; some silt .

Sand, fine; light gray brown

$\mathrm{SS}$ - driven $2 \mathrm{ft}, 58 \mathrm{ft}$ to $60 \mathrm{ft}$, recovered $1.5 \mathrm{ft}$

Sand, very fine; little silt; light gray brown.......

Cobble, overdriven in shoe of sampler...

$\mathrm{SS}$ - driven $2 \mathrm{ft}, 68 \mathrm{ft}$ to $70 \mathrm{ft}$, recovered $1.5 \mathrm{ft}$

Sand, medium to coarse; interbedded.

Sand, coarse; with pebbles

Sand, fine to medium

$1.5 \quad 5$

58

$8 \quad 23.5$

$1.5 \quad 5$

58

$8 \quad 49$

$8 \quad 10$

$68 \quad 68.4$

$68.4 \quad 68.7$

$68.7 \quad 69.5$

\begin{tabular}{ll}
\hline \multirow{2}{*}{ Description } & \multicolumn{2}{c}{ Depth (ft) } \\
\cline { 2 - 2 } & From $\quad$ To \\
\hline
\end{tabular}

\section{WGW 301-Continued}

SS - driven $2 \mathrm{ft}, 78 \mathrm{ft}$ to $80 \mathrm{ft}$, recovered $1.5 \mathrm{ft}$

Sand, medium to coarse ................................... 78

Sand, fine to medium ...................................... $\quad 78.2 \quad 78.7$

Sand, coarse to very coarse; granule gravel; small pebbles............................................... $\quad 78.7 \quad 79.1$

Sand, fine.................................................. $79.1 \quad 79.3$

Sand, medium to coarse .................................... $79.3 \quad 79.5$

$27 \quad 44.5 \quad \mathrm{SS}$ - driven $2 \mathrm{ft}, 95 \mathrm{ft}$ to $97 \mathrm{ft}$, recovered $1 \mathrm{ft}$

44.5 Sands, coarse to very coarse and fine to medium sand; interbedded

$95 \quad 96$

SS - driven $2 \mathrm{ft}, 98 \mathrm{ft}$ to $100 \mathrm{ft}$, recovered $1.3 \mathrm{ft}$

Gravel, granule

$98 \quad 98.4$

Sand, very fine to fine; fine to medium; and coarse sand, interbedded

$98.4 \quad 99.3$

SS - driven $2 \mathrm{ft}, 108 \mathrm{ft}$ to $110 \mathrm{ft}$, recovered $1 \mathrm{ft}$

Sand, medium and coarse to very coarse with granule gravel, interbedded................... 108

109

$\mathrm{SS}$ - driven $2 \mathrm{ft}, 118 \mathrm{ft}$ to $120 \mathrm{ft}$, recovered $1.2 \mathrm{ft}$

Sand, very coarse; granule gravel ......................

Sand, medium

$118 \quad 118.1$

Sand, coarse to very coarse; trace granule gravel.....

$118.1 \quad 118.5$

$0 \quad 1.5$

Silt, with fine sand

$118.5 \quad 118.7$

Sand, coarse to very coarse; granule gravel some pebbles

$118.7 \quad 118.9$

$\mathrm{SS}$ - driven $2 \mathrm{ft}, 128 \mathrm{ft}$ to $130 \mathrm{ft}$, recovered $0.5 \mathrm{ft}$

Gravel, granule

118.9

119.2

$\mathrm{SS}$ - driven $2 \mathrm{ft}, 138 \mathrm{ft}$ to $140 \mathrm{ft}$, recovered $1.5 \mathrm{ft}$

Sand, medium

128

128.5

Sand, coarse to very coarse; granule gravel; some pebbles.

138.1

Sand, medium to coarse; some pebbles

Sand, fine to medium

$138.1 \quad 138.3$

Silt, very fine sand; trace pebbles.

$138.3 \quad 138.5$

$138.5 \quad 138.7$

$138.7 \quad 139$

$139 \quad 139.5$

$\mathrm{SS}$ - driven $2 \mathrm{ft}, 148 \mathrm{ft}$ to $150 \mathrm{ft}$, no return

Bottom of hole

\section{WGW 302}

Sand, medium; trace coarse; dark brown.

Sand, coarse to very coarse, some granule gravel and pebbles; light brown....

Sand, fine; little coarse; some pebbles; light brown ...

rig chatter probable cobbles at $49 \mathrm{ft}$

Sand, fine to very fine; trace pebble gravel; trace coarse sand... 
Table 16. Lithologic logs of selected wells and test holes in the Big-Mishnock stream-aquifer system, central Rhode Island -Continued

\begin{tabular}{ll}
\hline \multirow{2}{*}{ Description } & \multicolumn{2}{c}{ Depth (ft) } \\
\cline { 2 - 2 } & From $\quad$ To \\
\hline
\end{tabular}

\section{WGW 303}

Sand, medium; dark brown Sand, medium; some gravel; light brown.............. Sand, fine; some silt; trace pebble gravel; wet..... Sand, very fine; with silt; little clay ...

Sand, very fine; with silt; light brown

Sand, fine; light brown .

Sand, fine; some silt; light brown..........................

Sand, fine; light brown ........................................

Sand, fine; some very fine...

Sand, fine; little medium; light brown .

Refusal, probable boulder or bedrock

\section{WGW 304}

Sand, fine; little coarse; red brown.

Gravel, sub-rounded to rounded; with fine sand; light brown.

Sand, fine to medium; trace coarse; light brown

Sand, fine to medium; little coarse; medium brown

Sand, coarse; with pebble gravel; sub-rounded

$0 \quad 2$

210

$10 \quad 16$

$16 \quad 20$

$20 \quad 21$

$21 \quad 30$

$30 \quad 31$

$31 \quad 41$

$41 \quad 69$

$74 \quad 80$

Sand, coarse to very coarse; some pebble gravel; trace fine sand.

Sand, coarse to very coarse; some medium; trace fine.

Sand, coarse to very coarse; trace medium and fine

Sand, coarse to very coarse; trace medium and fine; light brown

Refusal

\section{WGW 306}

No return

Sand, fine to medium; some coarse to very sand and granule gravel; trace silt; very fine sand and pebble gravel; brown.

Silt and very fine to fine sand; trace medium to very coarse sand and granule to pebble gravel; brownish gray

Sand, medium to very coarse and granule gravel; trace silt, fine sand and pebble gravel; brown...

Sand, very coarse and granule gravel; little pebble gravel; trace fine sand and cobble gravel; brown

Sand, medium to coarse; some very coarse sand; little granule gravel; trace fine sand and pebble gravel; brown

\begin{tabular}{ll}
\hline \multirow{2}{*}{ Description } & \multicolumn{2}{c}{ Depth (ft) } \\
\cline { 2 - 2 } & From $\quad$ To \\
\hline
\end{tabular}

\section{WGW 306-Continued}

Sand, medium to coarse; little very coarse sand and granule gravel; trace fine sand and pebble gravel; brown ..

Sand, fine to coarse; little silt and very fine sand; trace clay, very coarse sand and granule gravel; brown.

Sand, medium to very coarse; little granule gravel; trace fine sand; brown

Sand, coarse to very coarse and granule gravel; little medium sand; trace fine sand and pebble gravel; brown

Sand, medium to coarse; some very coarse sand and granule gravel; little fine sand; trace clay, silt and very fine sand; brown

Sand, fine to coarse; little silt and very fine sand; trace clay, very coarse sand and granule to pebble gravel; brown to grayish brown

Sand, fine to medium; some silt, very fine sand and coarse sand; grayish brown ...

Silt and very fine to fine sand; trace coarse to very coarse sand; gray

Sand, very fine to medium; some silt; trace

Sand, very fine to fine; some silt and medium very coarse sand; grayish brown sand;

trace clay; grayish brown

Silt and very fine to fine sand; trace clay, very coarse sand and granule gravel; gray

Sand, medium to granule gravel; brown

Sand, very coarse to granule gravel; little coarse sand; trace medium sand; brown.

Gravel, granule to pebble; little very coarse sand; trace coarse sand; brown

Refusal

\section{WGW 307}

Sand, coarse to very coarse and granule gravel to pebble gravel; brown

Sand, medium to coarse; little very coarse sand and granule gravel; trace pebble gravel; brown.

Sand, coarse to very coarse; trace granule gravel; brown.

Sand, coarse to very coarse and granule gravel; brown.

Sand, very coarse and granule gravel; little coarse sand and pebble gravel; brown

Sand, very coarse and granule gravel; little coarse sand; trace medium sand; brown 
Table 16. Lithologic logs of selected wells and test holes in the Big-Mishnock stream-aquifer system, central Rhode Island -Continued

\begin{tabular}{ll}
\hline \multirow{2}{*}{ Description } & \multicolumn{2}{c}{ Depth (ft) } \\
\cline { 2 - 2 } & From $\quad$ To \\
\hline
\end{tabular}

\section{WGW 307-Continued}

Sand, coarse to very coarse; some granule gravel; trace medium sand; brown

Sand, very coarse and granule gravel; some coarse sand; trace fine sand and pebble gravel; brown.....

Sand, coarse to very coarse; some granule gravel; trace fine to medium sand; brown

Sand, coarse to very coarse and granule gravel; trace fine to medium sand; brown

Sand, very coarse and granule gravel; some coarse sand; little granule gravel; brown

Sand, coarse to very coarse and granule gravel; little pebble gravel; trace medium sand brown

Sand, very coarse and granule gravel; little coarse sand and pebble gravel; brown

Gravel, granule to pebble; some very coarse sand; trace coarse sand; brown

Gravel, granule to cobble; trace coarse to very coarse sand; brown.

Sand, very coarse and granule gravel; little coarse sand; brown

Sand, very coarse and granule to pebble gravel; trace medium to coarse sand and cobble gravel; brown.

Sand, very coarse and granule to boulder gravel; brown; hard packed

Refusal

\section{WGW 308}

Sand, medium to coarse; trace fine sand, very coarse sand and granule to pebble gravel; light brown

Sand, medium to very coarse; little granule gravel; trace fine sand and pebble gravel; brown

Sand, medium to coarse; little fine sand; trace of very coarse sand and granule gravel; brown.

Sand, medium to very coarse; little granule gravel; trace clay, fine sand and pebble gravel; brown.

Sand, fine to medium; little very coarse sand and granule gravel; trace clay and pebble gravel; brown

Sand, very fine to fine; trace silt and granule gravel; grayish brown

Sand, very fine to fine; little silt; grayish brown

\begin{tabular}{ll}
\hline \multirow{2}{*}{ Description } & \multicolumn{2}{c}{ Depth (ft) } \\
\cline { 2 - 2 } & From $\quad$ To \\
\hline
\end{tabular}

\section{WGW 308-Continued}

Sand, very fine to fine; little silt; trace clay; grayish brown

Sand, very fine to fine; little silt; trace clay and cobble gravel; grayish brown

Sand, very fine to fine; trace clay, silt, very coarse sand and granule gravel; grayish brown

Sand, fine to medium; little very coarse sand; trace coarse sand and granule gravel; brown

Sand, medium to very coarse and granule to cobble gravel; trace fine sand; brown

Sand, very coarse and granule gravel; little coarse sand; trace medium sand; reddish brown.

Sand, very coarse and granule gravel; little coarse sand; trace medium sand and pebble to cobble gravel; reddish brown.

Refusal

\section{WGW 309}

Topsoil; dark blackish brown...

Silt to pebble gravel; brown (till)

Clay to pebble gravel; brown (till).

Clay to cobble gravel; brown (till).

Refusal (till)

WGW 310

No sample.

Clay to cobble gravel; reddish brown (till) ..........

Silt to cobble gravel; brown (till)

Silt to cobble gravel; whitish brown (till)

Refusal

\section{WGW 311}

Topsoil .....

Sand, fine to medium; trace silt, very coarse sand and granule to pebble gravel; brown .......

Sand, very fine to fine; trace very coarse sand to pebble gravel; brown .

Sand, very fine to fine; trace very coarse and pebble gravel; brown

Sand, very fine to fine; trace clay and very coarse sand; brown

$\begin{array}{rr}0 & 1 \\ 1 & 6 \\ 6 & 19 \\ 19 & 33 \\ & 33\end{array}$

Sand, very fine; trace clay, silt and fine sand; brown.

Silt and clay; grayish brown ....
Sand, very fine; trace fine sand and very coarse sand; grayish brown

$\begin{array}{rr}0 & 6 \\ 6 & 12 \\ 12 & 19 \\ 19 & 31 \\ & 31\end{array}$


Table 16. Lithologic logs of selected wells and test holes in the Big-Mishnock stream-aquifer system, central Rhode Island -Continued

\begin{tabular}{ll}
\hline \multirow{2}{*}{ Description } & \multicolumn{2}{c}{ Depth (ft) } \\
\cline { 2 - 2 } & From $\quad$ To \\
\hline
\end{tabular}

\section{WGW 311-Continued}

Sand, medium to coarse; little very coarse sand, trace granule to pebble gravel; reddish brown

Sand very fine to pebble gravel; brown...

Sand, fine to very coarse; trace silt and granule to pebble gravel; brown

Refusal

\section{WGW 312}

No sample

Sand, very fine to fine; trace very coarse sand to pebble gravel; grayish brown

Sand, very fine to fine; grayish brown

Sand, very fine to fine; trace very coarse sand and granule gravel; grayish brown

Sand, very fine to fine; trace clay, silt, and very coarse sand; grayish brown.....

Sand, very fine to medium; trace coarse sand to pebble gravel; brown

Sand, fine to medium; little coarse sand to pebble gravel; brown

Sand, fine to medium; little coarse sand to granule gravel; brown.

Sand, very fine to fine; trace very coarse sand and pebble gravel; brown
88

$90 \quad 97$

$97 \quad 104$

104

Sand, medium to very coarse and granule to pebble gravel; trace fine sand; reddish brown

Sand, very coarse and granule to pebble gravel; trace medium to coarse sand; reddish brown

Sand, coarse to granule gravel; trace medium sand; reddish brown

Sand, fine to medium; trace very coarse sand and granule gravel; reddish brown

Sand, coarse to granule gravel; trace fine to medium sand and pebble gravel; reddish brown

Sand, medium to very coarse; little granule gravel; trace fine sand and pebble gravel; brown

Sand, coarse to very coarse and granule gravel; trace fine sand and pebble gravel; brown

Sand, coarse to very coarse and granule gravel; trace very fine to fine sand and pebble gravel; grayish brown

\begin{tabular}{ll}
\hline \multirow{2}{*}{ Description } & \multicolumn{2}{c}{ Depth (ft) } \\
\cline { 2 - 2 } & From $\quad$ To \\
\hline
\end{tabular}

\section{WGW 312-Continued}

Sand, coarse to very coarse; little very fine to fine sand and granule gravel; grayish brown.

Sand, very fine to medium; trace coarse to very coarse sand and granule gravel; grayish brown

Sand very fine to medium, little coarse to very coarse sand; trace granule gravel; grayish brown

Sand, very coarse and granule gravel; trace fine to coarse sand; grayish brown.

Sand, very coarse and granule gravel; trace fine to coarse sand and pebble gravel; grayish brown

Refusal

\section{WGW 313}

No returns

Sand, fine to medium; trace coarse sand to pebble gravel; brown

Sand, very fine to fine; little silt; trace very coarse sand to pebble gravel; grayish brown

Sand, very fine to fine; little clay; trace silt and cobble gravel; grayish brown

Silt and clay; trace very fine sand; grayish brown....

Silt; little clay; trace granule gravel; gray

Sand, fine to medium and clay; trace silt and coarse to very coarse sand; grayish brown...

Sand, medium to coarse; little very coarse sand; trace clay, fine sand and granule gravel; reddish brown

Sand, medium to coarse; trace fine sand, very coarse sand and granule to pebble gravel; reddish brown

Sand, medium to coarse; little very coarse sand; trace granule to pebble gravel; brown ....

Sand, medium to granule gravel; trace pebble to cobble gravel; brown ..

Sand, fine to very coarse; little granule gravel; brown

Sand, medium to very coarse; little granule gravel; trace fine sand; brown .

Sand, medium to very coarse; trace fine sand and granule gravel; brown

Sand, medium to very coarse; trace fine sand; brown 
Table 16. Lithologic logs of selected wells and test holes in the Big-Mishnock stream-aquifer system, central Rhode Island -Continued

\begin{tabular}{ll}
\hline \multirow{2}{*}{ Description } & \multicolumn{2}{c}{ Depth (ft) } \\
\cline { 2 - 2 } & From $\quad$ To \\
\hline
\end{tabular}

\section{WGW 313-Continued}

Sand, medium to very coarse; trace fine sand and granule gravel; brown

Sand, fine to medium; trace coarse to very coarse sand; brown

Sand, fine to medium; little very coarse sand; trace very fine sand, coarse sand and granule gravel; brown.

Sand, fine to very coarse; trace very fine sand; brown

Refusal, probable bedrock

\section{WGW 314}

Topsoil..

Sand, fine to medium; reddish brown

Sand, medium to coarse; whitish brown

Sand, fine to coarse; trace very fine sand, very coarse sand and granule to pebble gravel; brown.

Sand, very fine to medium; trace very coarse sand and pebble gravel; grayish brown

Sand, very fine to fine; trace silt and clay; grayish brown

Sand, very fine; trace clay, silt, fine sand and pebble gravel; grayish brown

Sand, very fine; trace clay and silt; grayish brown

Sand, very fine and silt; little clay; grayish brown

Sand, very fine and silt; trace clay and very coarse sand; grayish brown

Sand, very fine to fine; trace clay; grayish brown

Sand, very fine to fine; trace medium to very coarse sand and clay; brown

Sand, very fine to medium; trace coarse to very coarse sand; brown

Sand, fine to medium; trace very fine sand and coarse to very coarse sand; brown.

Sand, fine to medium; little very coarse sand; trace clay and very fine sand; brown ......

Sand, fine to medium; little very coarse sand; trace coarse sand and granule gravel; brown

Sand, fine to medium; trace coarse to very coarse sand; brown

Sand, very fine to fine; little medium sand; trace clay and very coarse sand; brown.

Sand, very fine to medium; trace silt and coarse to very coarse sand; brown

\begin{tabular}{ll}
\hline \multirow{2}{*}{ Description } & \multicolumn{2}{c}{ Depth (ft) } \\
\cline { 2 - 2 } & From $\quad$ To \\
\hline
\end{tabular}

\section{WGW 314-Continued}

Sand, fine to medium; trace coarse to very coarse sand; brown

Sand, fine to coarse; little very coarse sand trace very fine sand and granule gravel; brown

Refusa

156

\section{WGW 336}

Sand, fine to coarse with silt; medium brown ...... 0

Sand, fine with silt; light gray ....

Sand, very fine and fine, interbedded; light gray; wet.

Sand, fine to coarse; medium brown

Sand, fine to coarse; some gravel; gray brown.....

Sand, fine to coarse, interbedded; trace gravel; medium brown

Sand, fine to coarse, interbedded; trace gravel; reddish brown

Sand, medium to very coarse; trace gravel; reddish brown

Sand, fine to very coarse; granule gravel; brown

$\mathrm{SS}$ - driven $2 \mathrm{ft}, 99 \mathrm{ft}$ to $101 \mathrm{ft}$, recovered $0.5 \mathrm{ft}$

Sand, fine to coarse; trace gravel; light gray ....

$\mathrm{SS}$ - driven $2 \mathrm{ft}, 104 \mathrm{ft}$ to $106 \mathrm{ft}$, recovered $1.5 \mathrm{ft}$

Sand, fine to very coarse; trace silt; trace granule to pebble gravel; light and dark brown

$\mathrm{SS}$ - driven $2 \mathrm{ft}, 109 \mathrm{ft}$ to $111 \mathrm{ft}$, recovered $1.5 \mathrm{ft}$

Sand, fine to very coarse; granule gravel, angular; trace to some silt; inter-bedded; light gray to medium brown

$\mathrm{SS}$ - driven $2 \mathrm{ft}, 119 \mathrm{ft}$ to $121 \mathrm{ft}$, recovered $1.8 \mathrm{ft}$

Sand, fine to very coarse; gravel, angular; trace silt, inter-bedded; medium brown ............

$\mathrm{SS}$ - driven $2 \mathrm{ft}, 129 \mathrm{ft}$ to $131 \mathrm{ft}$, recovered $2.0 \mathrm{ft}$

Sand, fine to very coarse; angular and granule gravel; medium brown.

$\mathrm{SS}$ - driven $2 \mathrm{ft}, 139 \mathrm{ft}$ to $141 \mathrm{ft}$, recovered $2 \mathrm{ft}$

Sand, fine to very coarse; gravel, angular; some silt; medium gray-brown

Bottom of hole

\section{WGW 337}

Sand, fine to coarse; with silt; trace gravel; medium brown ....

$\begin{array}{rr}0 & 4 \\ 4 & 60\end{array}$

Sand, very fine to fine; with silt; light gray..........

Sand, very fine to fine; with silt; trace gravel; light gray

$60-62$ 
Table 16. Lithologic logs of selected wells and test holes in the Big-Mishnock stream-aquifer system, central Rhode Island -Continued

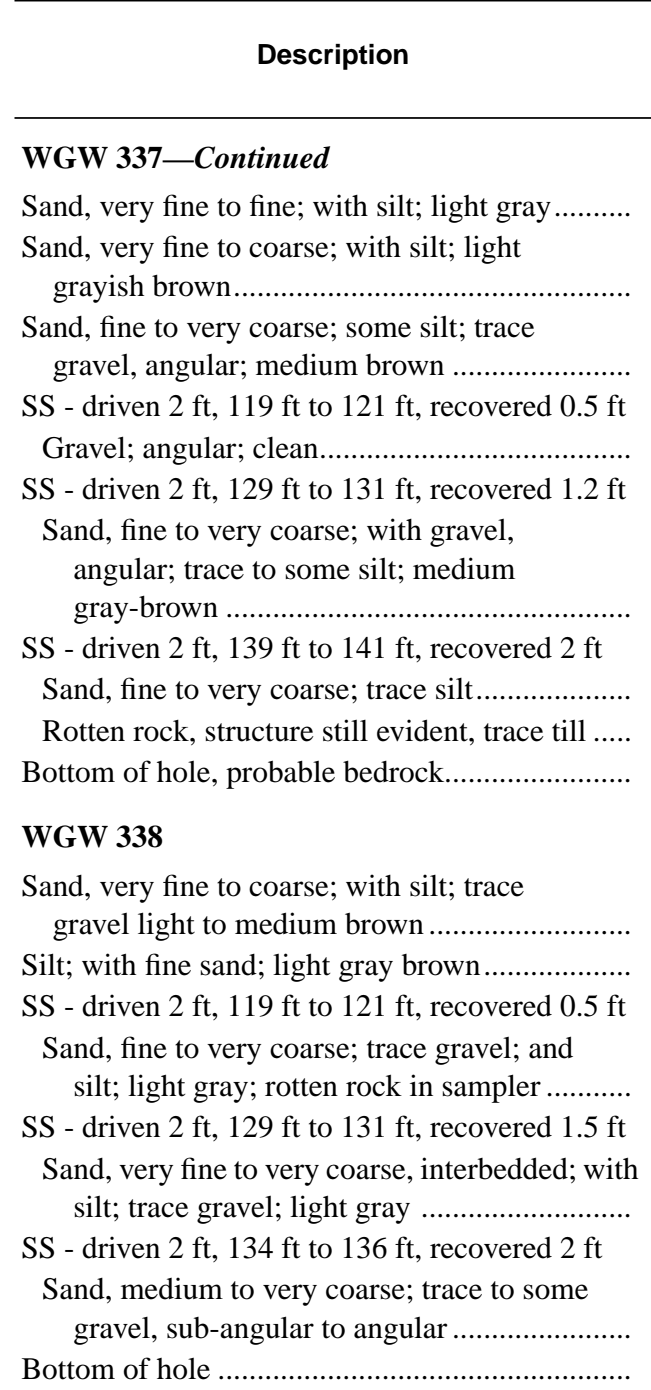

\section{WGW 339}

Sand, fine to very coarse; with gravel; some silt; medium brown

Sand, very fine to medium; with silt; light gray brown

SS - driven $2 \mathrm{ft}, 119 \mathrm{ft}$ to $121 \mathrm{ft}$, recovered $2 \mathrm{ft}$

Sand, fine to medium, trace to some silt; light gray brown

Gravel, sub-angular

Sand, fine to very coarse; trace silt; light gray brown

SS - driven $2 \mathrm{ft}, 129 \mathrm{ft}$ to $131 \mathrm{ft}$, recovered $1.8 \mathrm{ft}$

Sand, medium to very coarse; trace silt; light gray brown

$\mathrm{SS}$ - driven $2 \mathrm{ft}, 134 \mathrm{ft}$ to $136 \mathrm{ft}$, recovered $1.8 \mathrm{ft}$

Sand, fine to very coarse; with gravel; some silt; light brown

Bottom of hole

\begin{tabular}{ll} 
Depth (ft) \\
\hline From To \\
\hline
\end{tabular}

6290

$90 \quad 102$

$102 \quad 119$

$139 \quad 140$

$140 \quad 141$

142

$0 \quad 4$

$4 \quad 119$

119

119.5

136

138

$0 \quad 6$

6

119

$119 \quad 119.5$

$119.5 \quad 119.6$

$119.6 \quad 121$

134

135.8

140

\begin{tabular}{ll}
\hline \multirow{2}{*}{ Description } & \multicolumn{2}{c}{ Depth (ft) } \\
\cline { 2 - 2 } & From $\quad$ To \\
\hline
\end{tabular}

\section{WGW 340}

Sand, very fine to medium; with silt; light

Sand, very fine to medium; with silt; light gray brown gray

$\begin{array}{rr}4 & 134 \\ 129 & 131\end{array}$

$\mathrm{SS}$ - driven $2 \mathrm{ft}, 129 \mathrm{ft}$ to $131 \mathrm{ft}$, recovered $0 \mathrm{ft}$..

$\mathrm{SS}$ - driven $2 \mathrm{ft}, 134 \mathrm{ft}$ to $136 \mathrm{ft}$, recovered $2 \mathrm{ft}$

Sand, medium to coarse; trace to some silt; gravel layer; light brown

SS - driven $2 \mathrm{ft}, 139 \mathrm{ft}$ to $141 \mathrm{ft}$, recovered $2 \mathrm{ft}$

Sand, medium to very coarse; with gravel, angular; trace to some silt; light brown.

Sand, very coarse and gravel; light brown ........

$139 \quad 140.5$

$140.5 \quad 141$

Bottom of hole

145

\section{WGW 341}

Sand, fine to coarse; some gravel, subangular, sub-rounded; trace silt; light brown ...

Sand, very fine to fine; with silt; light gray

Sand, very fine to medium; with silt; light gray

Sand, very fine to medium; with silt; trace coarse sand; medium gray

$\mathrm{SS}$ - driven $2 \mathrm{ft}, 127 \mathrm{ft}$ to $129 \mathrm{ft}$, recovered $2 \mathrm{ft}$

Sand, medium to coarse; trace gravel; light gray

Sand, very fine to fine; with silt; light gray.......

$127 \quad 127.2$

127.2129

$\mathrm{SS}$ - driven $2 \mathrm{ft}, 132 \mathrm{ft}$ to $134 \mathrm{ft}$, recovered $2 \mathrm{ft}$

Sand, fine to medium; with silt; light gray brown .

$132 \quad 132.4$

Sand, fine to medium; with silt; light gray........

SS - driven $2 \mathrm{ft}, 137 \mathrm{ft}$ to $139 \mathrm{ft}$, recovered $1.3 \mathrm{ft}$

Sand, very fine to fine; with silt; light gray.......

Sand, fine to coarse; trace silt; trace gravel; light brown ...

$\begin{array}{ll}0 & 7\end{array}$

$7 \quad 40$

$40 \quad 120$

$120 \quad 127$

Sand, coarse to very coarse; trace gravel; light brown ..

$132.4 \quad 134$

$137 \quad 137.1$

$137.1 \quad 138.1$

$138.1 \quad 138.3$

Refusal, probable bedrock

149

\section{WGW 342}

Sand, fine to coarse; with cobbles (fill)

Sand, fine to coarse; trace gravel; medium brown

Sand, fine to coarse; trace silt; trace organics; dark gray.....

Sand, fine to coarse; trace to some gravel; medium brown .....

Sand, fine to coarse; some silt; light gray

14.519

No returns

1929 
Table 16. Lithologic logs of selected wells and test holes in the Big-Mishnock stream-aquifer system, central Rhode Island -Continued

\begin{tabular}{|c|}
\hline Description \\
\hline WGW 342-Continued \\
\hline 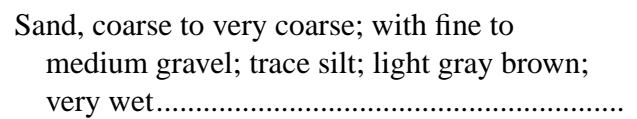 \\
\hline $\begin{array}{l}\text { Sand, fine to medium; some coarse sand; trace } \\
\text { silt; light gray brown }\end{array}$ \\
\hline 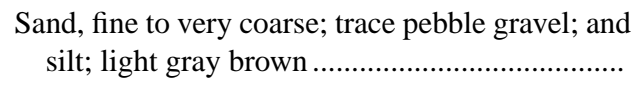 \\
\hline Sand, fine to very coarse; trace silt; and gravel.... \\
\hline \multirow{3}{*}{ 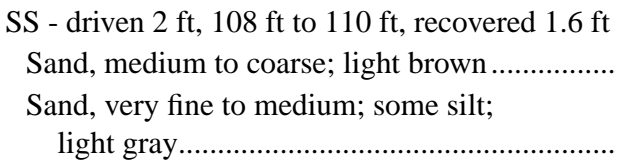 } \\
\hline \\
\hline \\
\hline \multirow{2}{*}{$\begin{array}{l}\text { SS - driven } 2 \mathrm{ft}, 118 \mathrm{ft} \text { to } 120 \mathrm{ft} \text {, recovered } 1.6 \mathrm{ft} \\
\text { Sand, fine to very coarse; with occasional } \\
\text { thin laminates of fine to very fine sand } \\
\text { with silt; trace gravel; light brown.................... }\end{array}$} \\
\hline \\
\hline 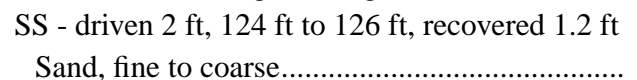 \\
\hline 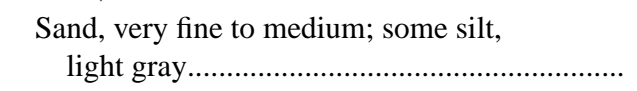 \\
\hline Bottom of hole. \\
\hline
\end{tabular}

\section{WGW 343}

Sand, fine to coarse; trace pebble gravel; trace silt; light brown

Sand, medium to very coarse; some fine sand; trace silt; light brown

Sand, medium to very coarse; some fine; trace silt; light brown ....

SS - driven $2 \mathrm{ft}, 107 \mathrm{ft}$ to $109 \mathrm{ft}$, recovered $1.6 \mathrm{ft}$

Sand, fine to medium...

Sand, very fine to fine; with silt; light gray .......

$\mathrm{SS}$ - driven $2 \mathrm{ft}, 119 \mathrm{ft}$ to $121 \mathrm{ft}$, recovered $1.8 \mathrm{ft}$

Sand, fine to medium; trace silt; light brown ....

Sand, very fine; some silt; light gray ..................

$\mathrm{SS}$ - driven $2 \mathrm{ft}, 124 \mathrm{ft}, 126 \mathrm{ft}$, recovered $2 \mathrm{ft}$

Sand, fine to medium; some silt; light gray.......

Sand, medium; trace silt; light brown.

Sand, very fine to medium; some silt; some staining....

Sand, very coarse; trace silt; medium brown.....

Sand, very fine; silt; light gray .....

Sand, very coarse; trace silt

Sand, very fine; with silt; light gray .....

SS - driven $2 \mathrm{ft}, 129 \mathrm{ft}$ to $131 \mathrm{ft}$, recovered $0.2 \mathrm{ft}$

Overdriven a cobble, very angular, shards of rock in spoon.

Bottom of hole

\begin{tabular}{ll}
\multicolumn{2}{c}{ Depth (ft) } \\
\hline From To \\
\hline
\end{tabular}

29

44

44

$44 \quad 57$

$57 \quad 81$

$81 \quad 108$

$108 \quad 109.2$

$109.2 \quad 109.6$

118

119.6

$124 \quad 124.2$

$124.2 \quad 125.2$

130

$0 \quad 27$

$27 \quad 72$

$73 \quad 107$

$107 \quad 107.2$

$107.2 \quad 108.6$

$119 \quad 119.4$

$119.4 \quad 120.8$

$124 \quad 124.5$

$124.5 \quad 124.6$

$124.6 \quad 125$

$125 \quad 125.3$

$125.3 \quad 125.6$

$125.6 \quad 125.8$

$125.8 \quad 126$

129 129.2

131

\begin{tabular}{ll}
\hline \multirow{2}{*}{ Description } & \multicolumn{2}{c}{ Depth (ft) } \\
\cline { 2 - 2 } & From $\quad$ To \\
\hline
\end{tabular}

\section{WGW 344}

Sand, fine to medium; some coarse to very coarse; trace gravel; reddish brown................................

Sand, fine to medium; light brown .......................

Sand, fine to coarse; light brown

$\begin{array}{lll}0 & 3.5\end{array}$

Sand, fine to very coarse; trace pea gravel; light gray brown.

$3.5 \quad 30$

$30 \quad 42$

Sand, fine to very coarse; trace silt; light brown ..

$42 \quad 82$

Sand, fine to coarse; trace pea gravel; trace silt; light brown.

102

90

Gravel, layered (based on rig chatter and drill rates.....

$113 \quad 117$

$\mathrm{SS}$ - driven $2 \mathrm{ft}, 119 \mathrm{ft}$ to $121 \mathrm{ft}$, recovered $2 \mathrm{ft}$

Sand, fine to coarse; light brown.

$119 \quad 119.6$

Sand, fine to medium; some silt; light brown ...

Sand, medium to very coarse; some gravel; trace fine sand and silt...

$119.6 \quad 119.8$

Sand, fine to very coarse; some gravel; trace to little silt

119.8

120.3

SS - driven $2 \mathrm{ft}, 129 \mathrm{ft}$ to $131 \mathrm{ft}$, no $\log$ of sample

Bottom of hole

$120.3 \quad 121$

$129 \quad 131$

\section{WGW 345}

Sand, fine to medium; trace silt; dark brown.......

Sand, fine to coarse; some gravel; trace silt light brown; cobble at $18 \mathrm{ft}$.

Sand, fine to medium; trace silt; light orange brown...

Sand, fine to medium; trace silt; light brown.......

Sand, fine to coarse; trace silt; light brown.

Sand, fine to very coarse; trace silt; trace gravel; light brown...

Sand, fine to coarse; trace to little silt; light brown.

$\mathrm{SS}$ - driven $2 \mathrm{ft}$, recovered $1.6 \mathrm{ft}$

Sand, very fine to medium; some silt; light brown ....

SS - driven $2 \mathrm{ft}, 119 \mathrm{ft}$ to $121 \mathrm{ft}$, recovered $2 \mathrm{ft}$

Sand, very fine to fine; trace silt; light gray ......

$\mathrm{SS}$ - driven $2 \mathrm{ft}, 129 \mathrm{ft}$ to $131 \mathrm{ft}$, recovered $2 \mathrm{ft}$

Sand, very fine to fine; some silt; light gray .....

$\mathrm{SS}$ - driven $2 \mathrm{ft}, 134 \mathrm{ft}$ to $136 \mathrm{ft}$, recovered $2 \mathrm{ft}$

Sand, very fine to fine; trace silt; light gray ......

Sand, medium to very coarse; some fine sand; trace silt; light gray..... 
Table 16. Lithologic logs of selected wells and test holes in the Big-Mishnock stream-aquifer system, central Rhode Island -Continued

\begin{tabular}{|c|c|c|c|c|c|}
\hline \multirow{2}{*}{ Description } & \multicolumn{2}{|c|}{ Depth (ft) } & \multirow{2}{*}{ Description } & \multicolumn{2}{|c|}{ Depth (ft) } \\
\hline & From & To & & From & To \\
\hline WGW 346 & & & WGW 348 & & \\
\hline $\begin{array}{l}\text { Topsoil; sand, fine to medium; reddish brown ..... } \\
\text { Sand, medium to coarse; trace clay and }\end{array}$ & 0 & 2 & 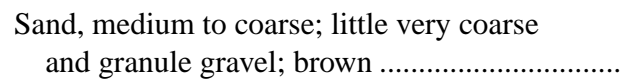 & 0 & 7 \\
\hline 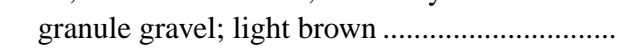 & 2 & 7 & Sand, medium to coarse; little granule gravel; & & \\
\hline Sand, fine to medium; trace granule gravel; & & & brown & 7 & 12 \\
\hline light brown ..... & 7 & 12 & Sand, fine; brown .. & 12 & 22 \\
\hline $\begin{array}{l}\text { Sand, fine to medium; trace coarse sand; light } \\
\text { brown }\end{array}$ & 12 & 17 & $\begin{array}{l}\text { Sand, very fine to fine; brown .................................. } \\
\text { Sand, medium to coarse; little fine sand; }\end{array}$ & 22 & 27 \\
\hline Sand, very fine to fine; trace medium sand; brown & 17 & 22 & brown & 27 & 32 \\
\hline 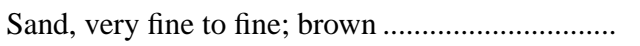 & 22 & 27 & Sand, very fine to fine; grayish brown .................... & 32 & 37 \\
\hline 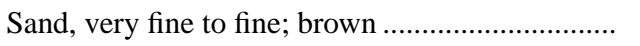 & 27 & 42 & Silt; trace clay; gray..... & 37 & 52 \\
\hline Sand, very fine to fine; trace silt; medium & & & 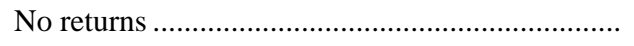 & 52 & 57 \\
\hline 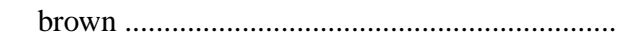 & 42 & 47 & Minimal returns, trace pebble gravel.... & 57 & 62 \\
\hline Sand, very fine to fine; some silt; medium & & & Silt; gray ...................... & 62 & 65 \\
\hline brown & 47 & 55 & No returns .. & 65 & 77 \\
\hline 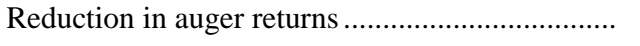 & 59 & 67 & 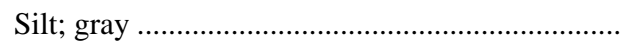 & 77 & 80 \\
\hline $\begin{array}{l}\text { Sand, very fine to fine; some silt; medium } \\
\text { brown }\end{array}$ & 67 & 80 & $\begin{array}{l}\mathrm{SS} \text { - driven } 2 \mathrm{ft}, 80 \mathrm{ft} \text { to } 82 \mathrm{ft} \text {, recovered } 0.7 \mathrm{ft} \\
\text { Sand, coarse to very coarse; little granule }\end{array}$ & & \\
\hline $\mathrm{SS}$ - driven $1.5 \mathrm{ft}, 81 \mathrm{ft}$ to $82.5 \mathrm{ft}$, recovered $0.5 \mathrm{ft}$ & & & 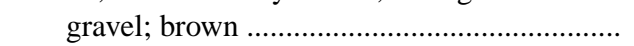 & 80 & 80.7 \\
\hline 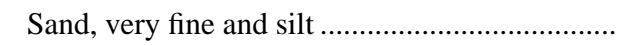 & 81 & 81.1 & $\mathrm{SS}$ - driven $2 \mathrm{ft}, 90 \mathrm{ft}$ to $92 \mathrm{ft}$, recovered $1 \mathrm{ft}$ & & \\
\hline $\begin{array}{l}\text { Sand, medium to coarse; little very coarse; } \\
\text { brown }\end{array}$ & 81.1 & 81.5 & 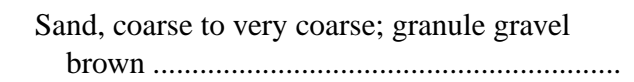 & 90 & 90.3 \\
\hline $\begin{array}{l}\mathrm{SS} \text { - driven } 1.5 \mathrm{ft}, 90 \mathrm{ft} \text { to } 91.5 \mathrm{ft} \text {, recovered } 1 \mathrm{ft} \\
\text { Interbedded lavers of very fine to fine sand }\end{array}$ & & & Sand, medium to coarse; little fine sand; & 903 & 908 \\
\hline 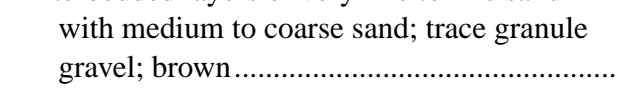 & 90 & 91.0 & 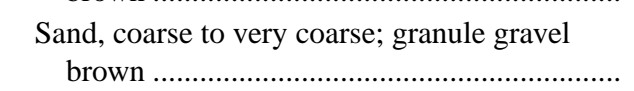 & 90.8 & 91 \\
\hline $\begin{array}{l}\mathrm{SS} \text { - driven } 1.5 \mathrm{ft}, 100 \mathrm{ft} \text { to } 101.5 \mathrm{ft} \text {, recovered } \\
1.5 \mathrm{ft}\end{array}$ & & & $\begin{array}{l}\mathrm{SS} \text { - driven } 2 \mathrm{ft}, 99 \mathrm{ft} \text { to } 101 \mathrm{ft} \text {, recovered } 0.7 \mathrm{ft} \\
\text { Sand fine to very coarse and pebble gravel }\end{array}$ & 99 & 99.7 \\
\hline Sand, medium to coarse; little fine; brown ......... & 100 & 101.5 & $\mathrm{SS}$ - driven $2 \mathrm{ft}, 113 \mathrm{ft}$ to $115 \mathrm{ft}$, recovered $1.2 \mathrm{ft}$ & & \\
\hline $\mathrm{SS}$ - driven $1.5 \mathrm{ft}, 110 \mathrm{ft}$ to $111.5 \mathrm{ft}$, recovered $1 \mathrm{ft}$ & & & Sand, fine to very coarse; granule to pebble & & \\
\hline $\begin{array}{l}\text { Sand, medium to coarse; little fine; brown .......... } \\
\text { Bottom of hole }\end{array}$ & 110 & $\begin{array}{l}111 \\
113\end{array}$ & $\begin{array}{l}\text { gravel; brown; tightly packed, possibly till... } \\
\mathrm{SS} \text { - driven } 2 \mathrm{ft}, 118 \mathrm{ft} \text { to } 120 \mathrm{ft} \text {, recovered } 2 \mathrm{ft}\end{array}$ & 113 & 114.2 \\
\hline WGW 347 & & & $\begin{array}{l}\text { Sand, fine to very coarse; granule to pebble } \\
\text { gravel; trace silt; very fine sand, and }\end{array}$ & & \\
\hline Sand, fine to medium; granule gravel; brown ....... & 0 & 7 & cobbles; brown; tightly packed, possibly & & \\
\hline Sand, very fine to fine; light brown ......................... & 7 & 32 & 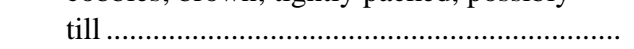 & 118 & 120 \\
\hline Sand, fine to medium; trace coarse sand .................. & 32 & 37 & Bottom of hole .... & & 120 \\
\hline 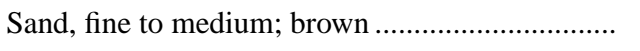 & 37 & 47 & & & \\
\hline Sand, very fine to fine; trace silt; trace granule & & & WGW 349 & & \\
\hline 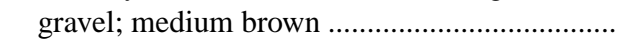 & 47 & 62 & Topsoil; dark brown ............................................. & 0 & 2 \\
\hline Sand, very fine to fine; little silt; brown ................... & 62 & 80 & Sand, fine to medium; trace very coarse sand; & & \\
\hline $\mathrm{SS}$ - driven $1.5 \mathrm{ft}, 80 \mathrm{ft}$ to $81.5 \mathrm{ft}$, recovered $1 \mathrm{ft}$ & & & 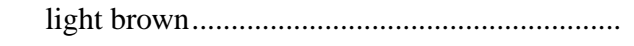 & 2 & 7 \\
\hline $\begin{array}{l}\text { Thin laminates of sand, very fine to silt; with } \\
\text { fine sand and fine to medium sand; trace }\end{array}$ & & & $\begin{array}{l}\text { Sand, fine to medium; trace coarse sand; light } \\
\text { brown }\end{array}$ & 7 & 12 \\
\hline 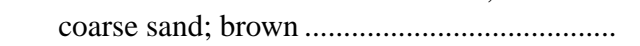 & 80 & 81 & 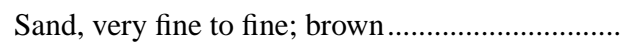 & 12 & 32 \\
\hline $\mathrm{SS}$ - driven $1.5 \mathrm{ft}, 90 \mathrm{ft}$ to $91.5 \mathrm{ft}$, recovered $0.8 \mathrm{ft}$ & & & 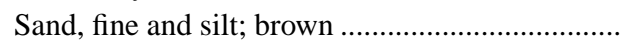 & 32 & 47 \\
\hline Sand, medium to coarse; trace fine and & & & No returns & 47 & 52 \\
\hline very coarse sand & 90 & 90.8 & Silt and clay; soupy; grayish brown........................ & 52 & 83 \\
\hline Bottom of hole, augers sand locked ........................ & & 95 & & & \\
\hline
\end{tabular}


Table 16. Lithologic logs of selected wells and test holes in the Big-Mishnock stream-aquifer system, central Rhode Island -Continued

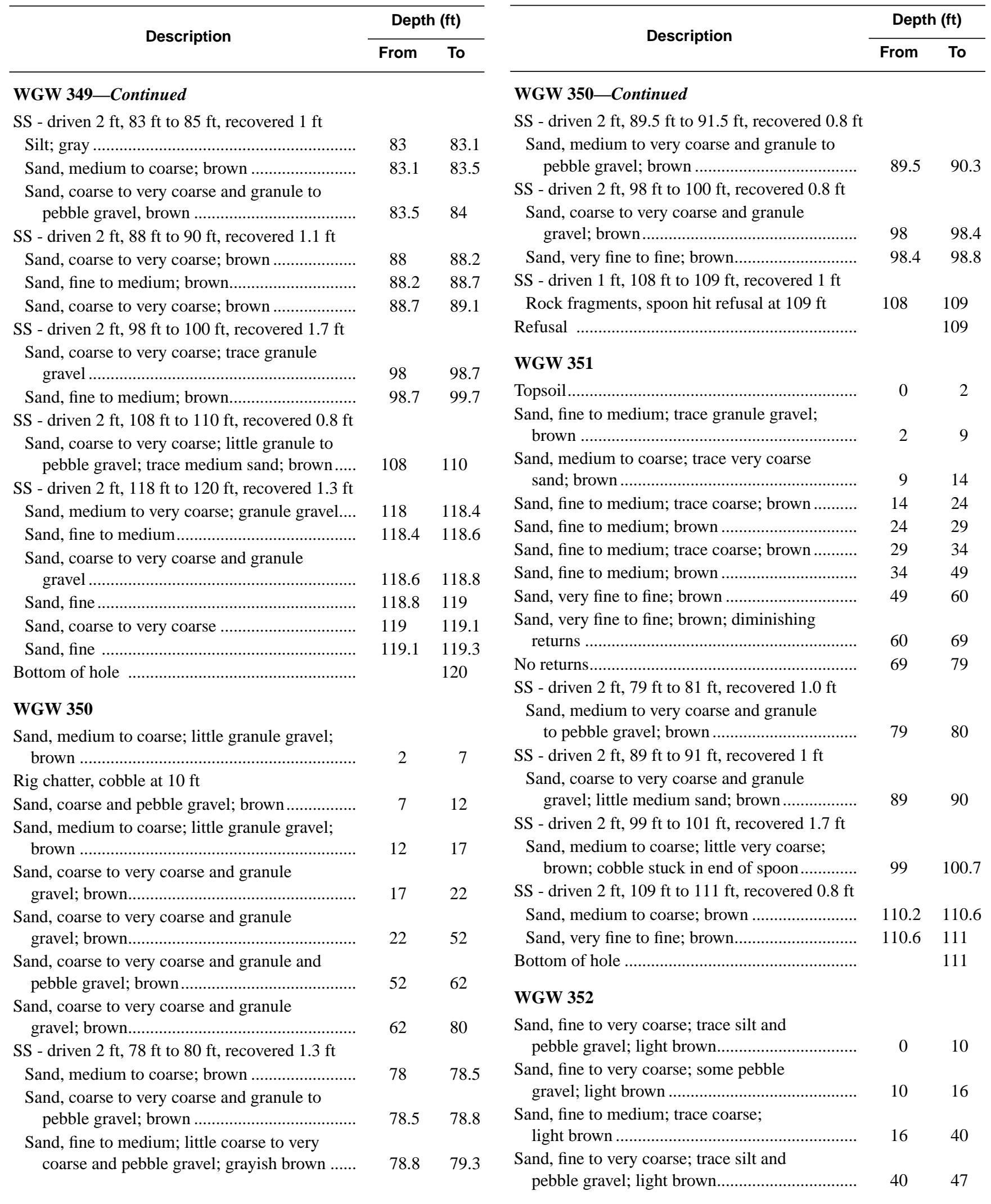


Table 16. Lithologic logs of selected wells and test holes in the Big-Mishnock stream-aquifer system, central Rhode Island -Continued

\begin{tabular}{ll}
\hline \multirow{2}{*}{ Description } & \multicolumn{2}{c}{ Depth (ft) } \\
\cline { 2 - 2 } & From $\quad$ To \\
\hline
\end{tabular}

\section{WGW 352-Continued}

Sand, very fine to medium; some coarse sand; trace silt and gravel

49

Sand, fine to coarse, trace silt and gravel light brown

SS - driven $2 \mathrm{ft}, 79 \mathrm{ft}$ to $81 \mathrm{ft}$, recovered $2 \mathrm{ft}$

Sand, fine to coarse; trace silt and gravel;

light brown

SS - driven $2 \mathrm{ft}, 99 \mathrm{ft}$ to $101 \mathrm{ft}$, recovered $2 \mathrm{ft}$

Sand, fine to medium; trace coarse sand

Sand, fine to medium

SS - driven $2 \mathrm{ft}, 109 \mathrm{ft}$ to $111 \mathrm{ft}$, recovered $1.7 \mathrm{ft}$

Sand, very fine to medium

Sand, very fine to fine.

Bottom of hole, augers sand locking...

\section{WGW 353}

Sand, very fine and silt; light gray brown ....

Sand, very fine; some silt and gravel ....

Sand, coarse to very coarse and gravel; some medium sand; trace silt

Sand, medium to very coarse; some gravel; medium brown

Sand, very fine to medium; trace silt.

Sand, very fine to medium; some silt

$\mathrm{SS}$ - driven $2 \mathrm{ft}, 80 \mathrm{ft}$ to $82 \mathrm{ft}$, recovered $2 \mathrm{ft}$

Sand, fine to medium; trace coarse to very coarse sand and gravel; light brown ...

SS - driven $2 \mathrm{ft}, 86 \mathrm{ft}$ to $88 \mathrm{ft}$, recovered $1.5 \mathrm{ft}$

Sand, fine to coarse; trace gravel

Sand, fine to medium; trace coarse sand ...........

Bottom of hole, augers sand locking

\section{WGW 354}

Sand, fine to coarse and gravel

Sand, very fine and silt; grayish brown.

Sand, fine to very coarse and granule gravel; trace cobble gravel; brown

Sand, coarse to very coarse and granule gravel; little fine to medium sand; brown

Sand, fine to medium; little very coarse sand; brown

Sand, fine to medium; trace coarse to very coarse sand; brown

Sand, very coarse and granule gravel; some fine to medium sand; trace pebble to cobble gravel; brown

Sand, medium to very coarse; little fine sand and granule gravel; brown.

\begin{tabular}{ll}
\hline \multirow{2}{*}{ Description } & \multicolumn{2}{c}{ Depth (ft) } \\
\cline { 2 - 2 } & From $\quad$ To \\
\hline
\end{tabular}

\section{WGW 354-Continued}

Sand, medium to coarse and granule gravel; little fine sand; trace pebble gravel; brown ......

Sand, medium to very coarse; trace granule to pebble gravel; brown .

Sand, medium to coarse; trace pebble gravel; brown ......

$106 \quad 111$

Sand, medium to granule gravel; brown

$111 \quad 116$

Sand, fine to very coarse; trace granule gravel; brown

$116 \quad 119$

Sand, very fine to fine; brown.

119

125

Sand, fine to medium and very coarse sand; trace very fine sand and pebble gravel; brown .

Sand, medium to coarse; trace fine sand; brown

Sand, medium to very coarse; trace fine sand and granule gravel; brown

Sand, coarse to very coarse; some granule gravel; trace fine sand; brown.

Sand, medium to coarse; little fine sand and very coarse sand; trace pebble gravel; grayish brown

Bottom of hole

\section{WGW 355}

Sand, very fine to fine; grayish brown

Sand, very fine to medium; little coarse sand; grayish brown

Sand, very coarse; with fine to coarse sand; grayish brown

Sand, very coarse and granule gravel; grayish brown

Sand, fine to coarse; some very coarse sand and granule gravel; brown

Sand, coarse to very coarse; little medium sand and granulmedium browne gravel; trace fine sand; light.

Sand, medium to coarse; some very coarse sand; little fine sand; trace cobble gravel; brown ......

Sand, medium to coarse; some very coarse sand; little to some fine sand; trace cobble and pebble gravel; light brown .

Sand, coarse to very coarse; some granular gravel and fine to medium sand; trace pea to cobble gravel; light brown .

Sand, coarse to very coarse; with granule gravel; some pea gravel; little medium 
Table 16. Lithologic logs of selected wells and test holes in the Big-Mishnock stream-aquifer system, central Rhode Island -Continued

\begin{tabular}{ll}
\hline \multirow{2}{*}{ Description } & \multicolumn{2}{c}{ Depth (ft) } \\
\cline { 2 - 2 } & From $\quad$ To \\
\hline
\end{tabular}

\section{WGW 355-Continued}

Sand, coarse to very coarse; some granule gravel; little cobble gravel and medium to fine sand; light medium brown

Sand, medium to very coarse; some fine sand and granule gravel; light brown

Sand, very coarse and granule gravel; some pea and cobble gravel; trace silt; light gray brown

Sand, coarse to very coarse and granule gravel; some medium sand; little fine sand and pea gravel; trace silt; light brown

Sand, coarse to very coarse and granule gravel; some medium to fine sand; little pea and cobble gravel, light brown

Sand, coarse to very coarse and granule gravel; little pea and cobble gravel; trace fine sand and silt; light brown

Sand, coarse to very coarse; some granule, pea, cobble gravel; some fine to medium sand; trace silt; light brown

Sand, coarse to very coarse; some granule, pea, pebble, and cobble gravel; trace fine to medium sand and silt; light brown...

Sand, medium to very coarse and granule gravel; some pea and cobble gravel; little fine sand; trace silt; light brown

Sand, very coarse and granule gravel; some pea and cobble gravel; little fine to medium sand; trace silt; light gray brown

Sand, very coarse; with granule gravel and coarse sand; some pea and cobble gravel; trace fine to medium sand. light brown....

Gravel, granule and very coarse sand; some pebble gravel; little medium sand; trace fine sand; light brown

Refusa

\section{WGW 356}

Gravel, pebble; medium brown

Sand, fine to very coarse; trace granule gravel; medium brown ...

Sand, fine to medium; light brown.

Sand, very fine to fine; light grayish brown

Sand, very fine to fine; brown

Sand, very fine to fine; trace clay; grayish brown

Silt and clay; trace very coarse sand and pebble gravel; gray

Sand, very fine to coarse and silt; little pebble gravel; gray brown.

\begin{tabular}{ll}
\hline \multirow{2}{*}{ Description } & \multicolumn{2}{c}{ Depth (ft) } \\
\cline { 2 - 2 } & From $\quad$ To \\
\hline
\end{tabular}

\section{WGW 356-Continued}

Sand, fine to very coarse; some granule and pebble gravel; medium brown

Sand, fine to coarse; little silt; trace granule gravel; medium brown

Sand, fine to very coarse; some granule, pebble, and cobble gravel....

No returns

Sand, medium to very coarse and granule gravel; some pea and cobble gravel: medium brown .... 78

Sand, fine to coarse; light brown .......................... $78 \quad 80$

Sand, fine to medium; some coarse to very coarse sand; light brown

Sand, fine to coarse; some very coarse sand to granule gravel; trace pea and cobble gravel; medium brown ...

Sand, medium to very coarse; light brown .......... $\quad 96 \quad 100$

Sand, medium to very coarse; little fine sand; light brown.

Bottom of hole

\section{WGW 357}

Sand, very fine and silt; trace very coarse sand, pebble gravel, and clay; grayish brown.

Silt and clay; gray

$21 \quad 28$

Sand, very coarse and granule gravel; some very fine sand and silt; gray

Sand, coarse to very coarse and granule gravel; trace silt and very fine sand; brown

Sand, medium to coarse; little fine sand; trace very coarse sand and granule gravel; brown ...

Sand, fine to medium; little very coarse sand and granule gravel; brown

Refusal

\section{WGW 358}

Sand, medium to very coarse; little granule gravel; trace pebble gravel and fine sand; brown.

Sand, very coarse and granule gravel; little fine to medium sand; trace pebble gravel; brown

Gravel; trace fine to very coarse sand; brown......

Sand, coarse to very coarse and granule gravel; little fine to medium sand; trace pebble gravel; brown gray 
Table 16. Lithologic logs of selected wells and test holes in the Big-Mishnock stream-aquifer system, central Rhode Island -Continued

\begin{tabular}{ll}
\hline \multirow{2}{*}{ Description } & \multicolumn{2}{c}{ Depth (ft) } \\
\cline { 2 - 2 } & From $\quad$ To \\
\hline
\end{tabular}

\section{WGW 358-Continued}

Sand, very coarse and granule gravel; trace fine sand; brown

Sand, coarse to very coarse; little granule gravel and fine sand; brown .....

$49 \quad 56$

Gravel, granule and very coarse sand; trace fine sand, coarse sand, and pebble gravel; brown

Gravel; little fine to coarse sand; brown

Bottom of hole, pushing cobble

63

\section{WGW 359}

Sand, very fine to very coarse and granule gravel; reddish brown

Sand, very fine to fine and very coarse sand to granule gravel; little cobble gravel; subangular to sub-rounded; brown ...

Gravel, granule to cobble; little very fine to fine sand and very coarse sand; brown..

Sand, fine to medium; trace silt and very coarse sand; grayish brown

Sand, very fine to very coarse; brown ...................

Refusal, probable bedrock

\section{WGW 360}

Sand, fine to medium; some coarse sand; light brown ..

Sand, fine; some medium sand, trace coarse sand light brown

Sand, medium to coarse; little fine and very coarse sand; light brown.

Sand, medium to very coarse; little granular gravel; trace fine sand; light brown .

Sand, fine to coarse; some very coarse sand; little very fine sand; light brown

Sand, medium to very coarse, some granular gravel; little fine sand; light brown ....

Sand, medium to very coarse and granule gravel; trace fine sand; light brown .

Refusal, probable bedrock

\section{WGW 361}

Sand, very fine to very coarse and silt; little granule gravel; light brown .

Sand, very fine to coarse and silt; some granule gravel; light brown

Refusal, probable boulders.

\begin{tabular}{ll}
\hline \multirow{2}{*}{ Description } & \multicolumn{2}{c}{ Depth (ft) } \\
\cline { 2 - 2 } & From $\quad$ To \\
\hline
\end{tabular}

\section{WGW 362}

Sand, very fine to coarse; some granule gravel and silt; light brown .

0 18

Sand, very fine to coarse and silt; light gray........

18

Refusal, probable till.

\section{WGW 363}

Sand, fine to coarse; some silt; trace granule gravel; light gray....

Sand, very fine to fine; some silt; light gray ........

Sand, very fine; trace silt; light gray....

Silt and very fine sand; light gray.....

Silt and very fine sand; trace clay; light gray ......

Sand, very fine and silt; light gray

Sand, medium to very coarse; some granule gravel; little fine sand; trace silt; brown.

Sand, medium to very coarse; little granule gravel; trace fine sand and silt; brown .

Sand, fine to medium; some coarse sand; little very coarse sand; trace granule to ebble gravel and very fine sand; brown

Sand, fine to coarse; trace very fine sand, very coarse sand, and granule gravel; brown.

Sand, medium to very coarse; trace fine sand and granule gravel; brown

Bottom of hole

Sand, very fine to very coarse; some silt; trace gravel; light gray...

Sand, very fine and silt; light gray.....

Sand, very fine; little to trace silt; light gray ...

Sand, very fine to fine; little silt, trace medium to coarse sand; light gray

Sand, fine to very coarse; some very fine sand; trace silt; light gray...

Sand, fine to very coarse; some granule gravel; trace very fine sand; light gray brown

Sand, medium to very coarse; some fine sand, trace granule gravel; light gray brown .

Bottom of hole

WGW 365

Sand, very fine to fine; trace silt; light brown gray

Sand, very fine to medium; some coarse to very coarse sand; trace silt; light brown
14

21

28

35

56

63

70

77

92

21

57

1928


Table 16. Lithologic logs of selected wells and test holes in the Big-Mishnock stream-aquifer system, central Rhode Island -Continued

\begin{tabular}{ll}
\hline \multirow{2}{*}{ Description } & \multicolumn{2}{c}{ Depth (ft) } \\
\cline { 2 - 2 } & From $\quad$ To \\
\hline
\end{tabular}

\section{WGW 365-Continued}

Sand, very fine to medium; some coarse to very coarse sand; trace granule gravel and silt; light brown

Sand, fine to coarse; some very fine and very coarse sand; trace granule gravel; light brown

Sand, fine to very coarse; some granule gravel; little very fine sand; light brown

Refusal

\section{WGW 366}

Sand, medium to coarse and very fine to very coarse sand; trace silt and granular gravel; light brown

Sand, very fine to fine and medium sand; little coarse to very coarse sand, trace silt and granule gravel; light gray.

Sand, fine to medium; some coarse to very coarse; trace very fine sand; light brown

Sand, fine to medium; little coarse to very coarse; trace granule gravel and very fine sand; light brown

Sand, very fine to fine; trace medium to very coarse sand and granule gravel; light brown....

Silt and very fine sand; dark gray.

Sand, very fine and silt; gray

Silt; dark gray

No returns

Sand, very fine and silt; little very coarse sand to angular granule gravel; dark gray ........

Silt and clay; dark gray

Sand, very fine; some silt; light brown

Sand, medium to coarse; trace fine sand and silt; light brown

Sand, medium to very coarse; little fine sand; trace granular gravel; light brown

Sand, medium to very coarse; trace to little fine sand; trace granule gravel; light brown

Refusal, probable bedrock

\section{WGW 367}

Sand, fine to very coarse; trace silt and very fine sand; light brown

Sand, very fine to medium; trace silt; light brown

Sand, very fine and silt; light gray

Silt; some very fine sand; light gray.....

\begin{tabular}{|c|c|c|}
\hline \multirow{2}{*}{ Description } & \multicolumn{2}{|c|}{ Depth (ft) } \\
\hline & From & To \\
\hline \multicolumn{3}{|l|}{ WGW 367-Continued } \\
\hline Sand, very fine; some silt; light gray........................ & 42.5 & 50 \\
\hline Sand, very fine to fine; trace silt; light brown ....... & 50 & 57 \\
\hline $\begin{array}{l}\text { Sand, medium to very coarse; some fine } \\
\text { sand; light brown }\end{array}$ & 57 & 64 \\
\hline $\begin{array}{l}\text { Sand, medium to very coarse; little fine sand; } \\
\text { trace very fine sand and silt; light brown .......... }\end{array}$ & 64 & 70 \\
\hline 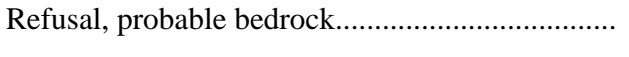 & & 70 \\
\hline \multicolumn{3}{|l|}{ WGW 368} \\
\hline $\begin{array}{l}\text { Sand, fine to coarse; some very coarse and } \\
\text { very fine sand and silt; light gray }\end{array}$ & 0 & 21 \\
\hline Sand, very fine; trace silt; light gray ........................ & 21 & 28 \\
\hline Sand, very fine; little silt; light gray.......................... & 28 & 35 \\
\hline 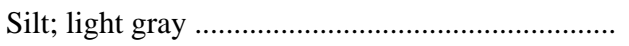 & 35 & 42 \\
\hline 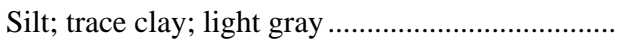 & 42 & 49 \\
\hline 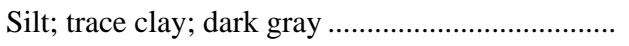 & 49 & 56 \\
\hline 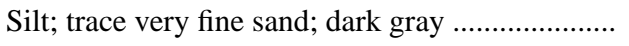 & 56 & 63.5 \\
\hline 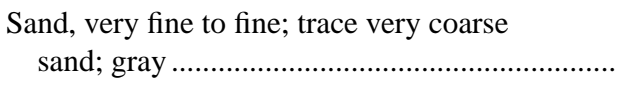 & 63.5 & 70.5 \\
\hline 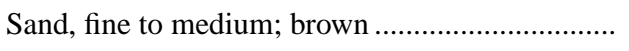 & 70.5 & 76 \\
\hline Refusal & & 76 \\
\hline
\end{tabular}

\section{WGW 369}

Sand, fine to very coarse; little silt and granule to cobble gravel; trace clay; grayish brown

Silt and very fine sand; trace very coarse sand and granule gravel and clay; grayish brown

Silt and clay; gray

Silt and very fine sand; grayish brown

Sand, very fine to fine; little silt; trace very coarse sand and granule gravel; grayish brown

Sand, coarse to very coarse; little granule gravel; trace fine sand; reddish brown

Refusal

\section{WGW 370}

Sand, coarse to very coarse and granule to pebble gravel; trace fine sand and silt; brown

Sand, very coarse and granule gravel; little pebble gravel; trace fine sand and silt; brown

Refusal, probable boulder 
Table 16. Lithologic logs of selected wells and test holes in the Big-Mishnock stream-aquifer system, central Rhode Island -Continued

\begin{tabular}{l} 
Description \\
\hline WGW 371 \\
Sand, fine to coarse; trace silt; light brown .......... \\
Sand, fine to very coarse; some granule \\
gravel; trace very fine sand; light brown .......... \\
Sand, medium to very coarse; some fine sand \\
and granule gravel; light brown ..................... \\
Sand, fine to very coarse and granule gravel; light \\
brown ...................................................... \\
Sand, medium to very coarse; some granule \\
gravel; light brown .................................... \\
Sand, medium to very coarse; some granule \\
gravel; little fine sand; light brown ................. \\
Sand, fine to very coarse; some granule \\
gravel; light brown ........................................... \\
Bottom of hole ..................................................... \\
WGW 372
\end{tabular}

\section{WGW 373}

Gravel, granule and very coarse sand; medium brown

Silt and very fine sand; light gray ....

Sand, very fine to medium and silt; trace to little granule gravel; medium gray.....

Sand, very fine and silt; trace to little granule gravel; medium gray .

Sand, coarse to very coarse; trace granular gravel.

Sand, very fine to medium; some silt and very coarse sand; trace granule gravel; medium gray.

Sand, very fine to fine; some silt; medium to dark gray.....

Sand, very fine and silt; light gray

Sand, very fine to very coarse; trace granular gravel; light brown

Refusal

\section{WGW 374}

Sand, fine to medium and silt; trace pebble gravel; light grayish brown

Depth (ft)
From To

\begin{tabular}{ll}
\hline \multirow{2}{*}{ Description } & \multicolumn{2}{c}{ Depth (ft) } \\
\cline { 2 - 2 } & From $\quad$ To \\
\hline
\end{tabular}

\section{WGW 374-Continued}

Sand, fine to medium; trace very fine sand; light gray brown

Sand, medium to very coarse; trace fine sand and granule gravel; brown

Sand very fine to fine; trace medium to coarse sand; brown gray ...

Sand, fine to medium; light brown ...

Sand, coarse to very coarse; some granule and pebble gravel; little fine to medium sand; trace very fine sand; medium brown ......

Sand, fine to very coarse; trace very fine sand and granule gravel; medium brown ......... $\quad 35 \quad 40$

Sand, very fine to very coarse; some silt; trace granule gravel; medium brown ..

Sand, fine to medium; trace very fine and coarse sand; medium brown

$20 \quad 28$

Sand, very fine to fine; some medium sand; trace silt; medium brown

Sand, very fine to fine; trace medium sand; and silt; medium brown .

Sand, medium to very coarse; some granule gravel; trace fine sand; brown

Sand, medium to very coarse; some granule gravel; trace pebble gravel; brown..

Sand, fine to very coarse; some granule gravel; trace pebble gravel; medium brown.

Sand, medium to very coarse; little granule gravel; medium brown

Sand, coarse to very coarse and granule gravel; some pebble gravel; trace fine to medium sand; medium brown

Sand, very fine to fine; some medium sand; trace coarse to very coarse sand; medium brown.

Sand, very fine to fine; light gray brown ............ 105

Sand, very fine to fine; trace silt; light gray brown ...

Sand, very fine to fine; some silt; light gray brown

Sand, medium to very coarse; some granule gravel, trace fine sand and pebble gravel; medium brown .

Gravel, pebble; some granular gravel

Gravel, granule; some pea gravel; trace medium to coarse sand; medium brown

Gravel, pebble and cobble; some granule gravel; trace medium to very coarse sand; medium brown 
Table 16. Lithologic logs of selected wells and test holes in the Big-Mishnock stream-aquifer system, central Rhode Island -Continued

\begin{tabular}{ll}
\hline \multirow{2}{*}{ Description } & \multicolumn{2}{c}{ Depth (ft) } \\
\cline { 2 - 2 } & From $\quad$ To \\
\hline
\end{tabular}

\section{WGW 374-Continued}

Gravel, granule and pebble; some very coarse sand; trace medium to coarse sand; medium brown

Sand, very coarse and granule gravel; some very coarse sand; trace medium to coarse sand; medium brown

Rock shards; angular; light gray, drilled

Refusal, probable bedrock

\section{WGW 375}

Sand, fine to coarse; reddish brown

Sand, very fine to fine; light brown

Sand, very fine to medium; trace coarse sand; light gray brown.

Sand, fine to medium; little coarse; trace very fine; light brown

Sand, very fine to medium; little coarse sand; trace silt; light brown

Sand, fine to medium; trace very fine and coarse sand and silt; gray brown

Sand, very fine to fine; some medium sand; trace coarse sand; gray brown

Sand, very fine to fine; trace medium sand; light gray brown

Sand, fine to very coarse; trace very fine sand and granule gravel; medium dark brown.

Sand, fine; little very fine sand; trace silt; medium gray brown

Sand, very fine; trace silt and fine sand; light gray

Sand, fine; trace very fine sand; light gray

Sand, very fine to fine; trace medium sand; light gray brown

Sand, very fine to fine; trace coarse sand and granule gravel; light gray brown

Sand, very fine to coarse; trace very coarse sand and granule gravel; light gray brown .......

Sand, fine to very coarse and granule gravel; some very fine sand and silt; medium brown

Sand, very coarse and granule gravel; some medium to coarse sand; little very fine to fine sand; trace silt; medium brown

Sand, very coarse and granule gravel; some medium to coarse sand; trace fine sand; medium brown

Sand, very coarse and granule gravel; some medium to coarse sand; medium brown

\begin{tabular}{ll}
\hline \multirow{2}{*}{ Description } & \multicolumn{2}{c}{ Depth (ft) } \\
\cline { 2 - 2 } & From $\quad$ To \\
\hline
\end{tabular}

\section{WGW 375-Continued}

Sand, very coarse and granule gravel; some medium to coarse sand and pebble gravel; trace fine sand; medium brown

Gravel, granule; with very coarse sand; some pebble gravel; trace medium to coarse sand; medium brown.

Bottom of hole

\section{WGW 376}

Sand, very fine to coarse, little very coarse sand and granule gravel; light gray...

Sand, very fine to medium; some coarse sand; trace very coarse sand and granule gravel; light gray.

Sand, very fine to medium; some silt; trace coarse to very coarse sand; light gray

Sand, very fine to very coarse; little silt and granule gravel; light gray brown...

Sand, fine to very coarse; some granule gravel; trace very fine sand; light brown

Sand, coarse to very coarse; some medium sand; little fine sand; medium brown

Sand, fine to medium; little very fine sand; trace granule gravel; light gray brown.

Sand, fine to medium; little very coarse sand; trace very fine sand; light brown...

Sand, very fine to fine; trace medium sand; light brown....

Sand, very fine; little granule and pebble gravel; light brown.

Sand, very fine to very coarse; little granule gravel; medium brown

Sand, very fine; trace silt; medium brown

Boulder, solid rock, drilled through it

Sand, medium to very coarse and granule gravel; some fine sand; trace very fine sand; medium brown

Sand, coarse to very coarse and granule gravel; some fine to medium sand; trace very fine sand; medium brown

Gravel, granule; with coarse to very coarse sand; medium sand; light brown...

Gravel, granule; with medium to very coarse sand; medium to light brown .....

Boulder, solid rock, drilled through it

No returns

$185.7 \quad 187.7$

Bottom of hole

187.7 
Table 16. Lithologic logs of selected wells and test holes in the Big-Mishnock stream-aquifer system, central Rhode Island -Continued

\begin{tabular}{ll}
\hline \multirow{2}{*}{ Description } & \multicolumn{2}{c}{ Depth (ft) } \\
\cline { 2 - 2 } & From $\quad$ To \\
\hline
\end{tabular}

\section{WGW 377}

Sand, fine to medium; some coarse to very coarse sand; little very fine sand; trace silt; light brown

Sand, very fine to fine; some pea gravel; little coarse to very coarse sand; trace medium sand and silt; light brown

Sand, very fine to very coarse; little granule gravel; light brown

Sand, very fine to fine; light gray brown; interbedded with medium to very coarse sand; and granule and pea gravel; light brown

Sand, very fine to fine; light gray

Sand, very fine to medium; little silt; trace coarse to very coarse sand; medium gray brown

Sand, very fine to medium; light gray.....

Sand, very fine to medium; trace coarse to very coarse sand; light gray brown ..

Sand, very fine to medium; little coarse to very coarse sand; trace silt; light gray brown

Sand, medium to very coarse; little fine sand; trace very fine sand; light brown

Sand, very fine to fine; trace silt; light brown .....

Sand, fine to medium; trace pebble gravel; light brown

Sand, very fine to fine; light brown

Sand, very fine to fine; trace silt; light brown .....

Sand, very fine; some silt; light brown...

Sand, very fine to very coarse and granule gravel; medium brown

Sand, very coarse and granule gravel; little medium to coarse sand; medium brown.

Sand, medium to very coarse and granule gravel; little fine to medium sand; medium brown

Sand, medium to very coarse; trace granule gravel; medium brown

Sand, coarse to very coarse; some granule gravel; trace fine to medium sand; medium brown

Boulder, drilled through it

Sand, coarse to very coarse and granular gravel; trace fine to medium sand

Boulde, drilled through it

Bottom of hole

$178 \quad 179.5$

$179.5 \quad 180.5$

180.5187

\begin{tabular}{ll}
\hline \multirow{2}{*}{ Description } & \multicolumn{2}{c}{ Depth (ft) } \\
\cline { 2 - 2 } & From $\quad$ To \\
\hline
\end{tabular}

\section{WGW 410}

Sand, very fine to fine; little granule gravel; brown

Sand, fine to medium; little granule to pebble gravel; brown

Sand, medium to very coarse and granule gravel to pebble gravel; brown .......................... 10

Gravel, pebble; some granule gravel; little medium to coarse sand; brown.....

Sand, medium to coarse; little very coarse sand and granule gravel; brown

Sand, medium to coarse; little very coarse sand and granule gravel; trace pebble gravel; brown.

Sand, fine to medium; some very coarse sand and granule gravel; little very fine sand and silt; brown

Sand, fine to medium; some very coarse sand and granule to pebble gravel; brown........

Sand, medium to very coarse and granule gravel; brown.

Sand, medium to coarse; little very coarse and pebble gravel; trace fine sand; brown

Sand, very coarse and granule gravel; little medium to coarse sand and pebble gravel; brown

Gravel, granule to pebble; some very coarse sand trace fine to medium sand; brown

Sand, very coarse and granule to pebble gravel; some medium to coarse sand; trace fine sand; brown

Sand, coarse to very coarse and granule to cobble gravel; some medium sand; little fine sand; brown

Sand, very coarse; with pebble gravel; some medium to coarse sand; little cobble gravel; trace fine sand; brown

Sand, medium to very coarse; with pebble gravel; rock fragments from drilling; dark brown

Bottom of hole

\section{WGW 411}

Sand, very fine to fine and silt; brown.

Sand, very fine and silt; grayish brown....

Sand, very fine to fine and silt; trace granule gravel; brown.

$0 \quad 5$

$5 \quad 15$

Sand, medium to coarse; little very coarse sand and granule gravel; trace pebble gravel; brown. 
Table 16. Lithologic logs of selected wells and test holes in the Big-Mishnock stream-aquifer system, central Rhode Island -Continued

\begin{tabular}{ll}
\hline \multirow{2}{*}{ Description } & \multicolumn{2}{c}{ Depth (ft) } \\
\cline { 2 - 2 } & From $\quad$ To \\
\hline
\end{tabular}

\section{WGW 411-Continued}

Sand, very coarse and granule gravel; little coarse sand and pebble gravel; trace medium sand; brown

Sand, medium to coarse; some very coarse sand; little granule gravel; trace pebble gravel; brown.

Sand, medium to very coarse and granule gravel; brown.

Sand, medium to coarse; some fine sand; little granule gravel; trace pebble gravel; brown

Sand, coarse to very coarse and granule gravel; little pebble gravel; trace medium sand brown

Sand, coarse to very coarse and granule gravel.

Sand, fine to medium; little coarse sand; trace granule gravel; brown

Sand, fine to medium; some pebble gravel; little very coarse sand and granule gravel; brown

Sand, fine to pebble gravel; brown

Sand, coarse to very coarse and granule to pebble gravel; trace medium sand and cobble gravel; grayish brown

Refusal, probable boulder

\section{WGW 412}

Sand, very fine to fine; trace very coarse sand; reddish brown

Sand, fine to medium; little coarse sand; brown

Sand, very fine to fine; grayish brown

Sand, very fine and silt; grayish brown

Silt; gray

Sand, very fine to fine; little silt; grayish brown

Sand, fine to medium; brown

Sand, very fine to fine; brown

Sand, fine to medium; brown

Sand, medium to coarse; little fine sand; trace very coarse sand; brown

Sand, medium to coarse; some very coarse sand; trace fine sand; brown

Sand, medium to very coarse; little granule gravel, trace fine sand; brown

Sand, coarse to granule gravel; little medium sand and pebble gravel; brown

Bottom of hole

\begin{tabular}{ll}
\hline \multirow{2}{*}{ Description } & \multicolumn{2}{c}{ Depth (ft) } \\
\cline { 2 - 2 } & From $\quad$ To \\
\hline
\end{tabular}

\section{WGW 413}

Sand, fine to medium; trace granule gravel; brown..... $0 \quad 5$

Sand, medium to coarse; little very coarse sand; brown

Silt; grayish brown

Sand, very fine and silt; grayish brown................ $20 \quad 25$

Sand, fine to medium; some coarse sand; brown

Sand, medium to coarse; some very coarse sand; little granule gravel; trace pebble gravel; brown

Sand, fine to coarse; brown

$30 \quad 35$

Sand, medium to coarse; some fine sand; trace very coarse sand; brown.

$35 \quad 40$

Sand, fine to medium; little very coarse sand; trace granule gravel; brown

Sand, very fine to fine; little medium sand; trace granule gravel; brown

Sand, very fine to fine; some very coarse sand and granule gravel; brown ....

Sand, very fine to fine; little medium sand; brown.

Sand, very fine to fine; some very coarse sand to granule gravel; brown.

Sand, very coarse and granule gravel; brown ......

Bottom of hole

\section{WGW 414}

Sand, fine to medium; little coarse sand; reddish brown

Sand, fine to coarse; little granule gravel; brown

Sand, coarse to very coarse and granule gravel; trace pebble gravel; brown

Sand, medium to very coarse and granule gravel; trace fine sand and pebble gravel; brown

Sand, very coarse to granule gravel; brown..........

Gravel, granule to pebble; little very coarse sand; trace cobble gravel; brown ...

Gravel, granule to pebble; little medium to coarse sand; brown

Sand, coarse to very coarse and granule gravel; little pebble gravel; trace cobble gravel; brown.

Sand, medium to coarse; little very coarse sand; trace granule to pebble gravel; brown 
Table 16. Lithologic logs of selected wells and test holes in the Big-Mishnock stream-aquifer system, central Rhode Island -Continued

\begin{tabular}{ll}
\hline \multirow{2}{*}{ Description } & \multicolumn{2}{c}{ Depth (ft) } \\
\cline { 2 - 2 } & From $\quad$ To \\
\hline
\end{tabular}

\section{WGW 414-Continued}

Sand, medium to coarse; trace very coarse sand; brown

Sand, fine to coarse; trace very coarse sand and granule to pebble gravel; brown

Sand, fine to medium; trace granule gravel; brown

Sand, very fine to medium; some granule to pebble gravel; trace cobble gravel; brown

Sand, fine to medium and granule to pebble gravel; some cobble gravel; brown .

Bottom of hole

\section{WGW 415}

Sand, very fine to medium; reddish brown to brown

Sand, medium to coarse; trace granule to pebble gravel; brown

Sand, fine to medium; trace granule gravel; brown

Sand, coarse to very coarse and granule gravel; little medium sand; trace pebble gravel; brown.

Sand, coarse to very coarse; trace granule gravel; brown.

Sand, very coarse and granule gravel; little coarse sand and pebble gravel; brown..

Sand, medium to very coarse and granule gravel; trace fine sand and pebble gravel; brown

Gravel, granule; some very coarse sand; little fine to medium sand; trace pebble gravel; brown

Sand, fine to coarse; trace pebble gravel; brown

Sand, fine to medium; trace granule gravel; brown

Sand, very fine to fine and silt; little medium sand; brown

Sand, fine to medium; brown

Sand, medium; some fine sand; trace granule gravel; brown

Sand, fine to medium; trace granule gravel; brown

Sand, fine to very coarse and granule gravel; trace pebble gravel; brown

Gravel, granule to pebble; little very coarse sand; brown .

Gravel, granule; some very coarse sand and pebble gravel; trace coarse sand; brown

\begin{tabular}{ll}
\hline \multirow{2}{*}{ Description } & \multicolumn{2}{c}{ Depth (ft) } \\
\cline { 2 - 2 } & From To \\
\hline
\end{tabular}

\section{WGW 415-Continued}

Rock, angular fragments from drilling..

Refusal, probable bedrock

86

86

\section{WGW 416}

Sand, fine; some medium sand; trace very fine sand; reddish brown

Sand, fine to coarse; trace granule gravel; light brown

Sand, fine to coarse; trace granule gravel; light brown .

Sand, fine to medium; trace coarse sand and granule gravel; light brown

Sand, medium to very coarse; trace fine sand and granule gravel; light gray brown

Sand, very fine to fine; light gray brown

Sand, fine to coarse; trace very coarse sand and granule gravel; light gray brown .

Sand, very fine to fine; medium gray brown ....

Sand, very fine to fine; trace silt; light brown

Sand, very fine to medium; trace coarse to very coarse sand and silt; light brown

Sand, very fine; trace silt; light brown .

Sand, very fine to medium; trace coarse; medium brown

Sand, very fine to medium; little granule gravel; medium brown

Rock chips from drilling

Refusal, probable bedrock

\section{WGW 417}

Sand, very fine to fine; trace granule gravel; reddish brown

Sand, very coarse and granule gravel; little coarse sand; reddish brown ..

Gravel, pebble to cobble; some granule gravel; trace medium sand; brown .....

Sand, coarse to very coarse; trace granule to pebble gravel; brown

Sand, coarse to very coarse; brown...

Gravel, granule to pebble; little cobble gravel and coarse to very coarse sand; trace fine sand; brown ...

Gravel, granule; some pebble gravel; little very coarse sand; trace coarse sand; brown .....

Gravel, granule to pebble; some very coarse sand; little coarse sand; brown

Gravel, pebble; some very coarse sand and granule gravel; little coarse sand; trace medium sand; brown

\section{0}


Table 16. Lithologic logs of selected wells and test holes in the Big-Mishnock stream-aquifer system, central Rhode Island -Continued

\begin{tabular}{ll}
\hline \multirow{2}{*}{ Description } & \multicolumn{2}{c}{ Depth (ft) } \\
\cline { 2 - 2 } & From $\quad$ To \\
\hline
\end{tabular}

\section{WGW 417-Continued}

Gravel, granule to pebble; some very coarse sand; trace fine to medium sand; brown

Sand, coarse to very coarse; little medium sand and granule gravel; reddish brown

Sand, coarse; some medium and very coarse sand; reddish brown

Sand, very fine to medium; little coarse sand; trace very coarse sand; reddish brown

Sand, coarse to very coarse; little medium sand and granule gravel; trace fine sand; reddish brown

Refusal, probable boulder

\section{WGW418}

Sand, fine to medium; brown ...

Sand, medium to coarse; little fine sand; trace very coarse sand and granule gravel; brown

Sand, fine to medium; trace coarse sand and granule gravel; grayish brown

Sand, medium to very coarse and granule gravel; little pebble gravel; brown.

Sand, fine to coarse; trace very coarse sand and granule gravel; brown.

Sand, fine to medium; little coarse sand; trace very coarse sand and granule gravel; brown

Sand, medium to coarse; trace very coarse sand and granule gravel; brown

Sand, coarse to very coarse, and granule gravel; little medium sand; trace pebble gravel; brown

Sand, medium to very coarse; some granule gravel; trace pebble gravel; brown

Sand, very coarse to granule gravel; little fine sand and pebble gravel; brown.

Gravel, granule and very coarse sand; little pebble gravel; trace fine sand; brown

Gravel, granule to pebble; some very coarse sand; trace medium sand; brown

Sand, medium to very coarse; trace fine sand, granule gravel, and rock fragments; brown......

Gravel, granule to pebble and coarse to very coarse sand; brown.

Gravel, granule to pebble and very coarse sand; trace medium to coarse sand and cobble gravel; brown

Refusal, probable bedrock

\begin{tabular}{ll}
\hline \multirow{2}{*}{ Description } & \multicolumn{2}{c}{ Depth (ft) } \\
\cline { 2 - 2 } & From $\quad$ To \\
\hline
\end{tabular}

\section{WGW 419}

Sand, very fine to medium; trace granule and pebble gravel; dark brown

Sand, fine to medium; little very fine sand; trace granule and pebble gravel; brown ....

Sand, coarse to very coarse and granule gravel; little pebble gravel; trace medium sand; 10 brown

Sand, medium to coarse; little pebble gravel; trace fine sand and granule gravel; brown

Sand, fine to medium; trace coarse sand and granule gravel; brown.

Sand, very coarse and granule gravel; little pebble gravel; trace fine sand; brown

Gravel, granule to pebble; some very coarse sand; brown

Sand, very coarse and granule gravel; little pebble gravel; trace coarse sand; brown

Gravel, pebble; some granule gravel; little very coarse sand; trace cobble gravel; brown

Gravel, pebble; some granule gravel; little medium sand; trace fine sand and cobble gravel; brown.

Sand, coarse to very coarse and granule to pebble gravel; trace medium sand; brown........

Sand, medium to coarse and granule to pebble gravel; brown

Sand, coarse to very coarse and granule gravel; little pebble gravel; trace fine sand; brown

Sand, very coarse and granule gravel; little coarse sand; trace pebble gravel; brown...

Casing would not advance, drilled out end ...........

Bottom of hole, probable not bedrock

$75 \quad 84$

\section{WGW 420}

Sand, fine to medium; trace granule gravel; dark brown

Sand, medium to coarse; little granule gravel; red.

Sand, coarse to very coarse and granule gravel; little pebble gravel

Sand, medium to very coarse and granule gravel; trace fine sand and pebble gravel; brown

Sand, fine to medium; little coarse sand; trace granule gravel; brown.

Sand, fine to medium; trace granule gravel; brown

5
10
15
20
25
30

0 
Table 16. Lithologic logs of selected wells and test holes in the Big-Mishnock stream-aquifer system, central Rhode Island -Continued

\begin{tabular}{ll}
\hline \multirow{2}{*}{ Description } & \multicolumn{2}{c}{ Depth (ft) } \\
\cline { 2 - 2 } & From $\quad$ To \\
\hline
\end{tabular}

\section{WGW 420-Continued}

Gravel, granule; some very coarse sand and pebble gravel; little fine sand; brown

Gravel, granule to pebble; little medium sand; trace fine sand; brown.....

30

35

Gravel, granule to pebble; some very coarse sand; little medium sand; trace fine sand; brown

Gravel, granule to pebble; some very coarse sand; trace coarse sand; brown

Gravel, granule to pebble; some medium to coarse sand; trace fine sand; brown

Sand, medium to coarse and granule gravel; little pebble gravel; trace fine sand; brown ......

Gravel, granule to pebble; trace fine to medium sand; brown

Sand, coarse to very coarse and granule to pebble gravel; trace medium sand; brown........

Sand, coarse to very coarse; little medium sand and granule gravel; trace pebble gravel; brown...

Sand, coarse to very coarse and granule to pebble gravel; trace medium sand; brown........

Sand, medium to coarse and granule to pebble gravel; little fine sand; trace very coarse sand; brown

Refusal, probable bedrock

\section{WGW 421}

Silt; gray......

Sand, medium to coarse; little silt; trace very coarse sand; grayish brown ..

Sand, coarse to very coarse; some granule gravel; trace medium sand; light brown

Sand, very coarse and granule gravel; little fine to medium sand; trace coarse sand and pebble gravel; brown

Sand. fine to medium; little fine sand; trace silt; brown

Sand, fine to medium; trace pebble gravel; brown

Gravel, granule to pebble; some very coarse sand; trace fine to medium sand; brown..

Gravel, granule to pebble; little fine to medium sand; trace cobble gravel; brown........

Gravel, granule to pebble; some very coarse sand; trace fine sand; brown

\begin{tabular}{ll}
\hline \multirow{2}{*}{ Description } & \multicolumn{2}{c}{ Depth (ft) } \\
\cline { 2 - 2 } & From $\quad$ To \\
\hline
\end{tabular}

\section{WGW 421-Continued}

Sand, medium to coarse; little granule gravel; trace fine sand and pebble gravel; brown

Gravel, granule to pebble; little very coarse sand; trace cobble gravel: brown.

Gravel, granule to pebble; little very coarse sand; trace medium sand; brown...............

Gravel, pebble; some granule gravel; little fine to medium sand; brown

Gravel, pebble to cobble; some fine to medium sand; trace granule gravel; brown ...... $65 \quad 70$

Sand, coarse to very coarse and granule gravel; little medium sand and pebble gravel; trace fine sand; brown

Gravel, granule to pebble; little medium to coarse sand; brown

Gravel, granule to pebble; little medium to coarse sand; reddish brown

Bottom of hole

\section{WGW 422}

Topsoil.

Sand and gravel

Refusal, probable till

\section{WGW 423}

Topsoil.

Sand and gravel.

Sand, very find and silt; trace clay

Sand, very coarse and gravel; angular

Refusal, probable till

\section{WGW 424}

Topsoil.

Sand and gravel

Sand, very fine and silt; trace clay

Refusal, probable till

\section{WGW 425}

Topsoil.

Sand and gravel

Sand, very fine and silt; trace clay

Sand, fine to very coarse; trace cobble gravel...... $\quad 20 \quad 27$

Sand, fine to very coarse; trace silt and granule gravel

Refusal, probable till
$27 \quad 36$

37.3 